\title{
Context matters in outcome and management of rheumatoid arthritis
}

Citation for published version (APA):

Hifinger, M. (2017). Context matters in outcome and management of rheumatoid arthritis: the role of sociocultural background and healthcare professionals' preferences. [Doctoral Thesis, Maastricht University]. Maastricht University. https://doi.org/10.26481/dis.20171215mh

Document status and date:

Published: 01/01/2017

DOI:

10.26481/dis.20171215mh

Document Version:

Publisher's PDF, also known as Version of record

\section{Please check the document version of this publication:}

- A submitted manuscript is the version of the article upon submission and before peer-review. There can be important differences between the submitted version and the official published version of record.

People interested in the research are advised to contact the author for the final version of the publication, or visit the DOI to the publisher's website.

- The final author version and the galley proof are versions of the publication after peer review.

- The final published version features the final layout of the paper including the volume, issue and page numbers.

Link to publication

\footnotetext{
General rights rights.

- You may freely distribute the URL identifying the publication in the public portal. please follow below link for the End User Agreement:

www.umlib.nl/taverne-license

Take down policy

If you believe that this document breaches copyright please contact us at:

repository@maastrichtuniversity.nl

providing details and we will investigate your claim.
}

Copyright and moral rights for the publications made accessible in the public portal are retained by the authors and/or other copyright owners and it is a condition of accessing publications that users recognise and abide by the legal requirements associated with these

- Users may download and print one copy of any publication from the public portal for the purpose of private study or research.

- You may not further distribute the material or use it for any profit-making activity or commercial gain

If the publication is distributed under the terms of Article $25 \mathrm{fa}$ of the Dutch Copyright Act, indicated by the "Taverne" license above, 
Context matters in outcome and management of rheumatoid arthritis: the role of socio-cultural background and healthcare professionals' preferences 
(C) Monika Hifinger, Maastricht 2017

No parts of this book may be reproduced or transmitted in any form or by any means, without prior permission in writing by the author, or when appropriate, by the publisher of the publications.

Layout: Tiny Wounters

Cover design Jean Scheijen

Printing: $\quad$ seismografics JK GmbH 


\title{
Context matters in outcome and management of rheumatoid arthritis: the role of socio-cultural background and healthcare professionals' preferences
}

\author{
DISSERTATION \\ to obtain the degree of doctor at Maastricht University \\ on the authority of the Rector Magnificus, Prof.dr. Rianne M. Letschert \\ in accordance with the decision of the Board of Deans, \\ to be defended in public \\ on Friday, December 15th 2017, at 11.30 hours
}

Monika Hifinger

born September 28th 1978

in Regensburg (Germany) 
Supervisor

Prof. dr. A. Boonen

\section{Co-supervisor}

Dr. M. Hiligsmann

Dr. S. Ramiro

\section{Assessment committee}

Prof.dr. M.A. Joore, (chair);

Dr. H.J. Bernelot Moens, Ziekenhuisgroep Twente (ZGT)

Prof.dr. T.W.J. Huizinga, Leids Universitair

Prof.dr. A.A.M. Masclee

Prof.dr. G. D.E.M. van der Weijden 


\section{Contents}

$\begin{array}{lll}\text { Chapter } 1 \text { General introduction } & 7\end{array}$

Part I The role of country and socio-cultural context in outcome 23 measurement in rheumatoid arthritis

Chapter 2 In rheumatoid arthritis, country of residence has an important

influence on fatigue: results from the multinational COMORA study

Chapter 3 In wealthier countries, patients perceive worse impact of the

disease although they have lower objectively assessed disease

activity: results from the cross-sectional COMORA study

Chapter 4 Equivalence of different versions of the health assessment

questionnaire (HAQ) across socio-demographic determinants:

analyses within QUEST-RA

Part II The healthcare professionals' preferences as contextual factor in the management of rheumatoid arthritis

Chapter 5 Patients' preferences and economic considerations play an

important role in treatment decisions: a discrete choice experiment among rheumatologists

Chapter 6 Economic considerations and patients' preferences affect treatment selection for rheumatoid arthritis patients: A discrete choice experiment among European rheumatologists

Chapter 7 Influence of disease activity on RA treatment choices in countries with restricted access to expensive, innovative drugs

Chapter 8 The eumusc.net standards of care for rheumatoid arthritis: importance and current implementation according to patients and healthcare providers in the Netherlands

Chapter 9 Summary and general discussion

Valorization

Acknowledgements

Curriculum vitae 



\section{Chapter 1}

General introduction 



\section{General introduction}

Rheumatoid arthritis (RA) is the most common autoimmune inflammatory rheumatic disease and affects approximately $0.5-1.0 \%$ of adults. ${ }^{1-3}$ The incidence of the disease is highest among persons between 50 and 70 years of age. RA occurs three times more frequently in women than in men, ${ }^{4}$ and both genetic and environmental factors contribute to the pathogenesis. ${ }^{1,2,5}$

The symptoms and signs of RA vary from joint complaints such as pain, stiffness, swelling and limited mobility to more constitutional symptoms such as fatigue and loss of overall health. RA limits persons in a variety of daily activities and restricts them in almost all social roles. ${ }^{6,7}$ To ensure researchers and clinicians account for the broad consequences of RA on functioning and health, frameworks for measurement of outcomes in RA have been proposed (e.g. by initiatives such as OMERACT ${ }^{8}$ (Outcome Measures in Rheumatology) or COMET $^{9}$ (Core Outcome Measures in Effectiveness Trials). These frameworks distinguish domains ('what' to measure) from instruments ('how' to measure). ${ }^{10}$ Outcome domains can be further grouped into domains reflecting the pathophysiology (e.g. inflammation, damage) and those reflecting the impact of the disease, including life impact on patients (e.g. pain, fatigue, physical function). ${ }^{11}$ Outcome instruments that measure domains should be validated to truthfully and reliably assess the domain. The subdomain 'inflammation' or 'disease activity' for example, can be measured by laboratory tests (e.g. erythrocyte sedimentation rate $(E S R)$ ), but also by the number of tender- or swollen joints (TJC, SJC). In addition, composite instruments that combine several of these tests with patients' self-rated level of disease activity such as the disease activity score including 28 joints (DAS28) are frequently used. Instruments assessing the impact on patients' lives are usually evaluated by patient-reported outcomes (PROs). PROs are questionnaires completed by patients that evaluate how patients function or feel in relation to (aspects of) a health condition, without interpretation by healthcare professionals (HCPs) or anyone else. ${ }^{12}$ In research and clinical care, PROs have been increasingly recognized as fundamentally important in understanding the natural course of the disease as well as the effects of treatments. ${ }^{12-15}$ The patients' voice has proven its value in research, as several studies have demonstrated discrepancies in outcome domains that matter for patients and physicians, and showed physicians do not accurately sense the impact of the disease on patients. $^{16,17}$

Treatment options for RA advanced significantly during the past decades. There are several general classes of drugs commonly used in the treatment of RA, including nonsteroidal anti-inflammatory drugs (NSAIDs), glucocorticoids and disease-modifying antirheumatic drugs (DMARDs). The management of RA primarily rests on attempts to 
control immune dysregulation, the actual root cause of the disease, by the long-term use of DMARDs. These agents are commonly characterized by their capacity to reduce inflammation and thereby reverse signs and symptoms, progression of joint damage, disability, and inability to work, and thus interfere with the entire disease process. Three major classes of DMARDs are distinguished: conventional synthetic chemical compounds (csDMARDs), biological agents (bDMARDs) and more recently targeted synthetic drugs (tsDMARDS) ${ }^{18,19}$ Importantly, bDMARDs as well as the newer tsDMARDs are much more costly than all previously available csDMARDs. In the light of substantially higher costs and some remaining concerns about the long-term safety, bDMARDs are currently recommended as second- or third-line agents, after the failure of treatment with CSDMARDs. ${ }^{18,20}$ However, affordability of bDMARDS remains a barrier for use and even with biosimilars entering the market, drug costs remain a concern. ${ }^{21,22}$

Most patients with RA are on chronic drug regimens and have persistent or intermittent active disease, ${ }^{23}$ interfering to a greater or lesser extent with their daily activities and participation in social roles. This implies that patients may also need long-term nonpharmacological care such as education about the disease and its management, as well as guidance and support, how to cope with the consequences of the disease. Recent recommendations for the management of RA therefore emphasize the use of nonpharmacological guidance in addition to the use of pharmacological agents. ${ }^{18,24}$

The advances in pharmacological and non-pharmacological treatment and its close monitoring through a broad range of outcome measures have greatly advanced quality of life of patients with RA. However, it also became clear that important variations in objective and experience-based outcomes could not be explained by biomedical factors alone, and better insight is needed to understand these variations. In search of nonbiological variables contributing to variation in functioning and health, the role of the personal or environmental context has been brought forward. Context might indeed influence the disease onset or severity (e.g. smoking), the type of treatment patients receive (e.g. type and quality of social security/health insurance system), or the experienced impact of the disease by the patient (e.g. coping, self-efficacy).

\section{Frameworks for health or health outcomes that include contextual factors}

The word 'context' frequently appears in literature. However, clear definitions are rare. An insightful description of the term 'context' provided by Noel Williams indicates on its ambiguity. 'Context is one of those words you will encounter again and again, without anyone offering anything like a useful definition. It is something of a catch-all word usually used to mean: all those things in the situation which are relevant to meaning in some sense, but which I haven't identified' ${ }^{25}$ In daily conversations, we are reminded of 
the importance to not take something out of its context and nothing can be fully understood isolated from it.

In the healthcare setting, context and contextual factors can be overall summarized as non-disease related factors that contribute to health and health outcomes. A few models have been developed in the past that incorporate and describe contextual (nondisease related) factors and their interplay with health and health outcomes. One of the first frameworks, implicitly addressing contextual factors, was proposed by Dahlgren and Whitehead (1991) and is often used to understand inequalities and inequities in healthcare. The framework (Figure 1.1) places the individual, characterised by constitutional (biological) factors but also a set of fixed social determinants of health (e.g. age, gender) in the centre, surrounded by several layers of determinants of health that can be modified and include individual lifestyle, social end community networks, the larger socio-economic, cultural and environmental context. ${ }^{26}$ The configuration of these different layers can have positive and protective influences, but they can also undermine health and wellbeing.

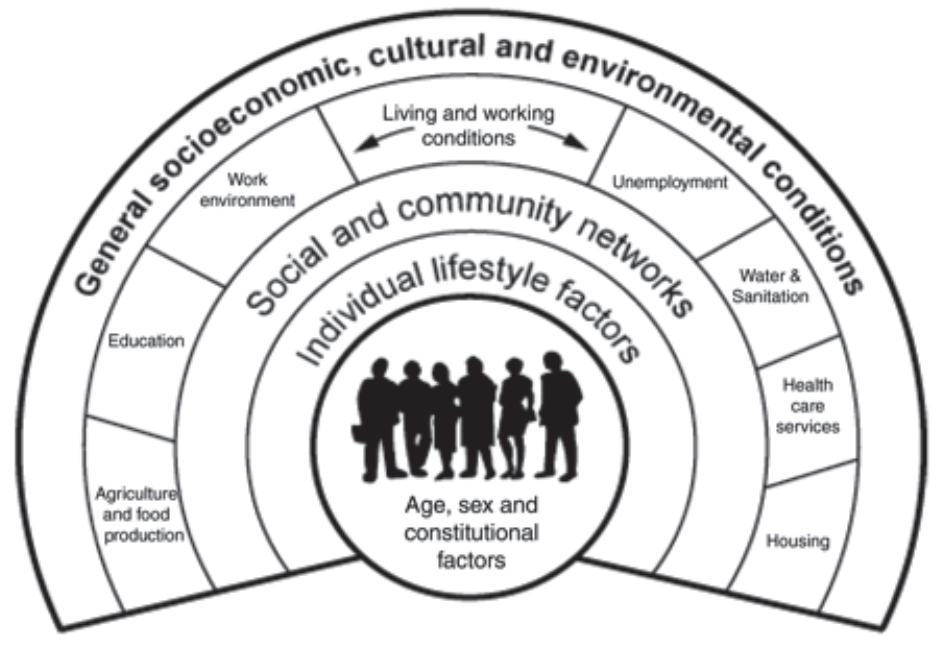

Figure 1.1 The main determinants of health. Source: Dahlgren and Whitehead $(1991)^{27}$

A second framework (Figure 1.2) that explicitly acknowledges the role of contextual factors, is the International Classification of Functioning, Disability and Health (ICF) framework endorsed by the World Health Organization (WHO) in $2001 .^{28}$ It represents a broad view of functioning and disability - across all domains of functioning in daily life (participation, activities, body functions and structures) - and explicitly accounts for 
environmental factors that influence functioning. The concept assumes that human functioning and disability can be viewed as the interactions between health impairments, activity limitations and participation restrictions on the one hand, and contextual factors on the other hand. In addition to recognizing the role of context in the framework of health, this concept classifies contextual factors into external environmental factors (e.g. social attitudes, architectural characteristics, legal and social structures, as well as climate or terrain) and internal personal factors including gender, age, coping styles, social background, education, profession, past and current experience, overall behaviour pattern, character and other factors that influence how disability is experienced by the individual (Figure 1.2). ${ }^{26}$

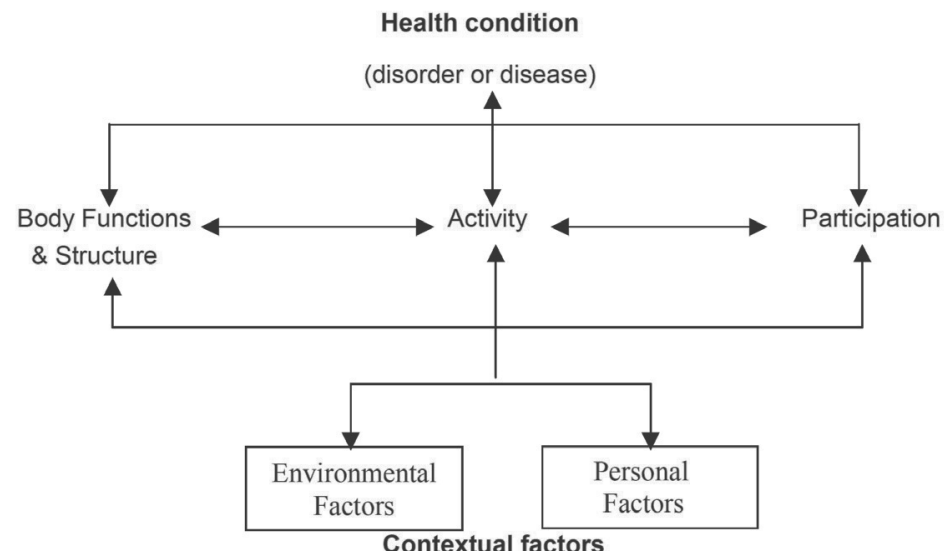

Figure 1.2 Contextual factors in the biopsychosocial framework of functioning and disability of the World Health Organization ${ }^{29}$

Further, in the recent framework of Outcome Measures in Rheumatology (OMERACT), which takes a more methodological view, the role of contextual factors in outcome assessment has been acknowledged and defined as variables that are not outcomes of studies, but need to be recognized (and measured) to understand the study results. This includes potential confounders and effect modifiers (Figure 1.3). ${ }^{9}$

Finally, a subset of contextual factors that receives attention in equity research is summarized in the PROGRESS-plus framework, proposing the following demographic and socio-economic determinants for health outcome research: Place of Residence, Race/Ethnicity, Occupation, Gender, Religion, Education, Socio-economic Status (SES), and Social Capital, with Plus representing additional categories such as age, disability, sexual orientation and literacy. ${ }^{30-34}$ The acronym PROGRESS-plus is not meant to encompass all possibly contributing (contextual) socio-economic factors relevant in 
health research, but rather serves as a reminder to consider the intersecting determinants of health for instance when designing or interpreting a research study.

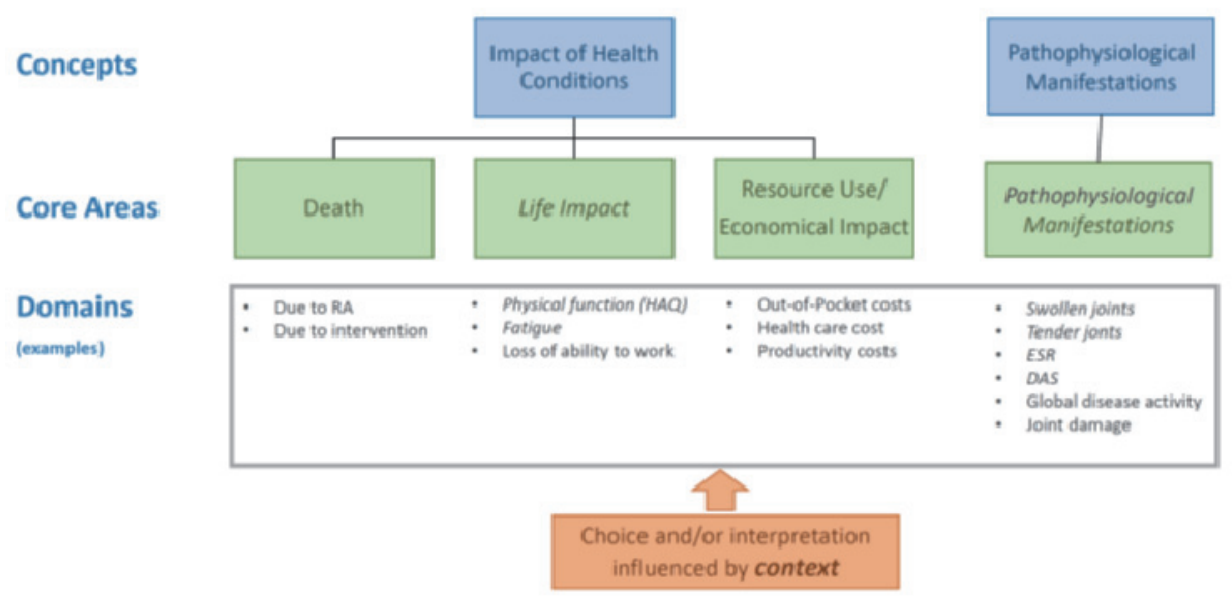

Figure 1.3 Conceptual framework of core areas for outcome measurement by OMERACT (Outcome Measures in Rheumatology) ${ }^{11}$

\section{The role of country as contextual factor in outcome measurement in rheumatoid arthritis}

While the role of contextual factors in assessing and interpreting outcomes, especially PROs, is recognized in clinical care, evidence of their influence is however limited in the literature. $^{35,36}$ Only a few contextual factors, namely gender, ${ }^{37}$ education, ${ }^{38-40}$ socioeconomic status, ${ }^{39}$ or coping and helplessness as personal factors, ${ }^{41}$ have been studied with regards to their influence on (a limited number of) outcomes. They have shown to contribute importantly to the outcomes studied. However, many potential contextual factors remain unexplored. An interesting contextual factors that so far received little attention is country of residence. Clinical studies are increasingly performed in a multinational design and treatment recommendations for clinical practice are often designed at an international level e.g. the European or North American level, without questioning transferability of results or recommendations to individual countries.

When investigating the role of country of residence on outcomes in RA, existing studies have so far mainly addressed translation and cultural validation of PROs. Such validation studies have been mostly performed across a limited number of countries with different languages, assuming that differences in language coincide with differences in 
cultures. ${ }^{42-47}$ Only very few studies addressed variations as separate phenomenon. For instance, a recent study investigating work presentism among RA patients revealed that the interpretation of the term 'performance', to describe the construct 'productivity while at work', was different for Romanian and Swedish participants who indicated that performance was rather related to competing (for example in sports) than to working. ${ }^{47}$ Another study addressed cultural differences when translating items of the health assessment questionnaire ( $\mathrm{HAQ}$ ) to assess patients' physical function. They found that e.g. opening a carton of milk or turn faucets to test light-fingeredness may not equally applicable across countries as it is not a routine daily activity for all patients. ${ }^{48}$ However, overall little is known about the influence of country on outcome measures beyond these aspects. Country of residence is a complex construct that may characterize the physical environment and living conditions, the economic prosperity or level of socioeconomic inequalities, the development status, the organisation, accessibility and quality of the healthcare system, and the existing cultural norms and beliefs. Currently, also insufficient evidence is available on the magnitude of influence of country, whether the influence of country is similar across different outcomes, and which country characteristics best explain the influence of country on outcome.

From a methodological point of view the challenge remains to understand, whether contextual factors have a 'true' influence on outcomes, or whether differences can be explained by measurement properties of outcome instruments. One approach that allows to quantify the role of bias trough specific items in a multi-item questionnaire, is differential item functioning within item response modelling. Differential item functioning is a statistical characteristic of an item that shows the extent to which the item might be measuring different abilities for members of different subgroups (e.g. by gender, education, or even country of residence). Only a limited number of studies investigated such response bias for outcome measures related to RA and other musculoskeletal diseases. Existing studies are mostly limited to measures assessing depression or quality of life, ${ }^{42-46,49-51}$ whereas studies on measures such as pain, fatigue or physical function are scarce. ${ }^{52,53}$ Also, there is little knowledge about which country characteristics actually exert such differences (e.g. environmental or personal factors). ${ }^{52,54-58}$

\section{The healthcare professional as contextual factor in the management of rheumatoid arthritis}

There is no doubt that a healthcare system itself is a key contextual factor contributing to health and health outcomes in RA. Increasingly, policy makers and healthcare planners set the scene (e.g. define drug reimbursement criteria) in which HCPs can reach individual treatment decisions. And although it may be self-evident that professionals 
themselves are influenced by their personal and environmental context (Figure 1.1), the influence of HCPs on health outcomes in RA remains poorly studied.

\section{Physicians' preferences for rheumatoid arthritis treatments}

For several decades, efficacy and safety of treatments were the most important considerations when making drug treatment choices. In the 21st century however, physicians are increasingly expected to also take into account patients' preferences and economic implications. Both, patient-centeredness and treatment efficiency, are relatively new to the physicians' decision making process. The concept of patientcenteredness including patient education or shared decision making was mainly brought forward by patients themselves and has proven some effectiveness. Notwithstanding, research still needs to fully reveal the benefits and the backside of the coin. ${ }^{59,60}$ And while extensive literature can be found on patients' preferences and their role in clinical decision making, ${ }^{59,61-63}$ the role of patients' preferences when physicians' make treatment choices remains unclear. Of note, understanding clinicians' preferences is also highly relevant when implementing standards in clinical practice as a clinician's disagreement may be an important barrier for implementation.

With introduction of expensive biologics in RA care, efficiency as an attribute gained significant importance in treatment choices and consequently the tension between physicians' obligations to meet the individual patients' needs and the obligations towards society to optimize healthcare costs has likely never been greater. In many countries, access to biologics has been restricted by policy makers through clearly defined reimbursement criteria or budget limitations on the level of practices or hospitals to optimize efficiency and manage costs. Notwithstanding, rheumatologists often remain largely autonomous to reach individual treatment decisions for their RA patients. An earlier report comparing drug usage across countries and regions in Europe found important variations in use of certain drugs. ${ }^{64}$ While findings could obviously be partly explained by differences in the countries' healthcare setting (e.g. reimbursement restrictions), the data also suggest that variations in physiciancs' preferences play additionally a major role. Earlier studies revealed indeed that in Western countries, clinicians are also willing to make economic trade-offs, ${ }^{65,66}$ however there is limited evidence on how rheumatologists finally balance economic implications with medical needs (efficacy and safety) or patients' preferences. Also, little is known about which possible economic implications matter most to rheumatologists, i.e. whether they primarily look at absolute costs or whether relative cost-effectiveness considerations play a role when choosing the treatment.

Finally, no data exist whether socio-demographic or cultural background of rheumatologists influence their choice of drugs, to what extent rheumatologists 
preferences towards patients' preferences and economic considerations differ across countries and whether the preferences for the different drug characteristics are influenced by the patient profile. i.e. the level if disease activity. Insights into the attitudes of rheumatologists are however important to fully understand the decision making process and possible consequences on patient outcomes.

\section{Priorities of healthcare professionals and patients in rheumatoid arthritis care}

As HCPs and patients have very different backgrounds and roles in the management of RA, they will likely also differ in the priorities in care. While patients are more concerned about pain, fatigue, quality of life and their independence and are in need for information on disease, drugs and personal lifestyle, physicians are more focused on timely treatment, efficacy and drug safety, and are increasingly forced to consider the societal impact (e.g. healthcare costs). Recently, the European standards of care (SOCs) for the management of RA have been developed. ${ }^{24}$ SOCs represent a set of recommendations for RA patients. They are based on existing clinical guidelines and describe management of the disease, care, access to patient information and support and knowledge that patients should receive. Although HCPs and patients contributed to its development, the implementation of uniform standards in daily clinical practice has never been audited. It remains unclear to what extent patients and HCPs agree on the priorities within these standards and how they fit their socio-cultural context. In efforts to implement SOCs, it is important to understand the current needs and whether priorities are shared by patients and HCPs.

On this line, further insights into whether the patients' socio-demographic background influences importance and implementation of standards and to what extent patients' and HCPs' perception towards care overlaps, is important. Disagreement in priorities among patients but also between patients and HCP are likely major barriers for their successful implementation. 


\section{Aim of the thesis}

In this thesis we aimed to explore the role of (1) country of residence (as possible surrogate for a shared socio-cultural environment) and (2) the HCPs preferences on outcome and management of RA care, respectively. Our specific study questions included:

Part I: Do contextual factors such as country of residence or socio-demographic background influence outcome measurements in RA?

a. Does country of residence influence different outcomes in RA?

b. Can the role of context in PROs be explained by item bias?

Part II: Which factors drive HCPs' treatment preferences for patients with RA?

a. Are drug treatment choices of physicians influenced by patients' preferences and economic considerations?

b. Does country of residence and/or the patient profile influence rheumatologists' preferences when choosing drug treatments?

c. Do HCPs and patients share priorities in RA care?

\section{Outline of the thesis}

In Part I of the thesis, we investigated the influence of socio-cultural context on different outcomes among patients with RA. Chapter 2 and 3 explored the extent to which RA outcomes vary across countries and whether the influence of country differed across outcomes. More specifically, in Chapter 2, we investigated whether country of residence contributed to variations in fatigue, an important outcome for patients with RA. In addition, we investigated whether the role of country can be explained by specific country characteristics such as language, climate, economic- and development status. In Chapter 3, we further explored whether the influence of country of residence differs between objective outcomes (related to pathophysiology), physician-reported outcomes and PROs in RA. For both studies we used the international COMORA (COMOrbidities in Rheumatoid Arthritis) study that included more than 4,000 RA patients from rheumatology practices in 17 different countries worldwide. ${ }^{67}$ COMORA has been designed as a cross-sectional study to investigate comorbidities among RA patients and thus contained an extensive set of socio-demographic data as well as patient- and 
physician-reported disease characteristics (disease activity, patient impact, comorbidities and treatment)). As one of the few existing international databases, COMORA provided the opportunity to analyse a broad variety of outcomes in RA across countries or world-regions. In chapter 4, we applied differential item functioning within the item response theory framework to investigate whether observed differences in PROs can be attributed to item bias in the outcome measure. More specifically, we investigated the presence of item bias across a series of patient level socio-demographic determinants applying item response theory frameworks to four different versions of the health assessment questionnaire (HAQ) reported in an international database QUEST-RA (The Quantitative Standard Monitoring of Rheumatoid Arthritis study). The $\mathrm{HAQ}$ is a multi-item patient questionnaire that has become the dominant instrument to assess physical function of RA patients in clinical practice and research worldwide. In one of the few international databases in RA - QUEST-RA -individual items of four different versions of the HAQ were collected in addition to a variety of socio-demographic data. As the database comprised a large and diverse sample size with patient data from more than 10,000 RA patients across 34 countries worldwide, it provided a unique opportunity to investigate the role of contextual factors on outcomes in RA.

In part I we explored the role of country of residence as contextual factors on outcome measures in RA. In Part II, we addressed the role of the HCP as a contextual factors in the management of RA. We aimed to understand how rheumatologists value different treatment characteristics when choosing drug treatments for their RA patients, including efficacy, safety, patient's preferences and economic consequences (Chapters 5 to 7). For this purpose, we developed a discrete choice experiment (DCE), a frequently used method to elicit preferences in healthcare. ${ }^{68}$

In Chapter 5, DCE data of 63 Dutch rheumatologists were analysed to understand the magnitude of effects for the attributes related to patients' preference and economic implications compared to the more classical attributes efficacy and safety. Further, we aimed to quantify variations in preferences based on age, gender and work environment.

In Chapter 6, we aimed to understand the additional influence of country of residence on the treatment choice of rheumatologists. For this study, data from 559 rheumatologists across 12 different European countries were analysed. The countries were selected to cover a broad range of healthcare settings, economic background but also geographical regions in Europe (North, South, West and East).

In Chapter 7, we further aimed to understand whether the patient's disease severity has an influence on how rheumatologists prioritise different characteristics of a treatment. The study was performed in three countries with comparatively strict reimbursement 
criteria for biologics (i.e. reimbursement limited to patients with high disease activity and failure of several csDMARDs), namely Hungary, Romania and United Kingdom.

In addition to investigating solely the rheumatologist's attitudes, we further aimed to understand possible areas and levels of (dis-)agreement between HCPs and their patients when providing non-pharmacological treatment. Chapter 8 therefore describes a study investigating whether priorities and care gaps identified by HCP align with priorities and care gaps of patients, when managing RA. In addition, the study aimed to gain insights into possible barriers towards implementation of optimal care in clinical practice. For this study, a survey was conducted among $91 \mathrm{HCPs}$ (rheumatologists and rheumatology nurses) and 389 patients with RA from the Netherlands. European standards of care were used as proxy for optimal care.

Chapter 1: General introduction and outline

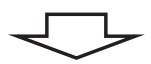

Part I: Influence of socio-cultural context on outcome measures in rheumatoid arthritis (RA)

Chapter 2: Influence of country on self-reported fatigue in RA

Chapter 3: Influence of country on objective versus patient-reported outcomes

Chapter 4: Measurement equivalence of the health assessment questionnaire across contextual factors

Part II: The healthcare professionals' preferences as contextual factor in the management of RA

Chapter 5: The role of patients' preferences and economic consequences on rheumatologists' drug treatment choices

Chapter 6: The influence of country on drug treatment choices in RA

Chapter 7: The influence of the patient profile on drug treatment choices in RA

Chapter 8: Do patients and healthcare professionals share priorities in care?

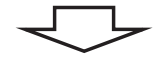

Chapter 9: General discussion

Figure 1.4 Outline of the thesis 


\section{References}

1 Silman AJ, Pearson JE. Epidemiology and genetics of rheumatoid arthritis. Arthritis Res 2002;4(Suppl 3):S265-72.

2 Harney S, Wordsworth BP. Genetic epidemiology of rheumatoid arthritis. Tissue Antigens 2002;60(6): 465-73.

3 Kirwan J, Heiberg T, Hewlett S, et al. Outcomes from the Patient Perspective Workshop at OMERACT 6. J Rheumatol 2003;30(4):868-72.

4 Global burden of musculoskeletal disease revealed in new WHO report. Bull World Health Organ 2003;81(11):853-4.

5 Svendsen AJ, Kyvik KO, Houen G, et al. On the origin of rheumatoid arthritis: the impact of environment and genes--a population based twin study. PLoS One 2013;8(2):e57304.

6 Geuskens GA, Burdorf A, Hazes JM. Consequences of rheumatoid arthritis for performance of social roles--a literature review. J Rheumatol 2007;34(6):1248-60.

7 Woolf AD, Pfleger B. Burden of major musculoskeletal conditions. Bulletin of the World Health Organization 2003;81:646-56.

8 Chua JR, Gibson KA, Pincus T. Pain and other self-report scores in patients with osteoarthritis indicate generally similar disease burden to patients with rheumatoid arthritis. Clin Exp Rheumatol 2017;35 Suppl 107(5):88-93.

9 Pollard LC, Choy EH, Gonzalez J, Khoshaba B, Scott DL. Fatigue in rheumatoid arthritis reflects pain, not disease activity. Rheumatology (Oxford) 2006;45(7):885-9.

10 van Riel PL, van Gestel AM. Clinical outcome measures in rheumatoid arthritis. Ann Rheum Dis 2000;59 Suppl 1:i28-31.

11 Boers M, Kirwan JR, Wells G, et al. Developing core outcome measurement sets for clinical trials: OMERACT filter 2.0. J Clin Epidemiol 2014;67(7):745-53.

12 Gossec L, Dougados M, Dixon W. Patient-reported outcomes as end points in clinical trials in rheumatoid arthritis. RMD Open 2015;1(1):e000019.

13 Kalyoncu U, Dougados M, Daures JP, Gossec L. Reporting of patient-reported outcomes in recent trials in rheumatoid arthritis: a systematic literature review. Ann Rheum Dis 2009;68(2):183-90.

14 Lohr KN, Zebrack BJ. Using patient-reported outcomes in clinical practice: challenges and opportunities. Qual Life Res 2009;18(1):99-107.

15 Orbai AM, Bingham CO, 3rd. Patient reported outcomes in rheumatoid arthritis clinical trials. Curr Rheumatol Rep 2015;17(4):28.

16 Smolen JS, Strand V, Koenig AS, Szumski A, Kotak S, Jones TV. Discordance between patient and physician assessments of global disease activity in rheumatoid arthritis and association with work productivity. Arthritis Res Ther 2016;18(1):114.

17 Barton JL, Imboden J, Graf J, Glidden D, Yelin EH, Schillinger D. Patient-physician discordance in assessments of global disease severity in rheumatoid arthritis. Arthritis Care Res (Hoboken) 2010;62(6): 857-64.

18 Smolen JS, Landewe R, Breedveld FC, et al. EULAR recommendations for the management of rheumatoid arthritis with synthetic and biological disease-modifying antirheumatic drugs: 2013 update. Ann Rheum Dis 2014;73(3):492-509.

19 Smolen JS, Breedveld FC, Burmester GR, et al. Treating rheumatoid arthritis to target: 2014 update of the recommendations of an international task force. Ann Rheum Dis 2016;75(1):3-15.

20 Singh JA, Saag KG, Bridges SL, Jr., et al. 2015 American College of Rheumatology Guideline for the Treatment of Rheumatoid Arthritis. Arthritis Rheumatol 2016;68(1):1-26.

21 Putrik P, Ramiro S, Kvien TK, et al. Inequities in access to biologic and synthetic DMARDs across 46 European countries. Ann Rheum Dis 2014;73(1):198-206.

22 Putrik $\mathrm{P}$, Ramiro S, Kvien TK, et al. Variations in criteria regulating treatment with reimbursed biologic DMARDs across European countries. Are differences related to country's wealth? Ann Rheum Dis 2014;73(11):2010-21.

23 Sesin CA, Bingham CO, 3rd. Remission in rheumatoid arthritis: wishful thinking or clinical reality? Semin Arthritis Rheum 2005;35(3):185-96. 
24 Stoffer MA, Smolen JS, Woolf A, et al. Development of patient-centred standards of care for rheumatoid arthritis in Europe: the eumusc.net project. Ann Rheum Dis 2014;73(5):902-5.

25 Bate PR, Glenn; Fulop, Naomi ; Øvretveit, John; Dixon-Woods, Mary Perspectives on context: A selection of essays considering the role of context in successful quality improvement. The Health Foundation: Inspiring Improvement 2014.

26 Exworthy M. Policy to tackle the social determinants of health: using conceptual models to understand the policy process. Health Policy Plan 2008;23(5):318-27.

27 Dahlgren Gr, Whitehead M. Policies and strategies to promote equity in health. Copenhagen: World Health Organization Regional Office for Europe; 1991.

28 International Classification of Functioning, Disability and Health. World Health Organisation Geneva, 2001.

29 World Health Organization (WHO): Towards a Common Language for Functioning, Disability and Health: ICF - The International Classification of Functioning, Disability and Health [Online]. Available from http://www.who.int/classifications/icf/training/icfbeginnersguide.pdf.

30 O'Neill J, Tabish $\mathrm{H}$, Welch $\mathrm{V}$, et al. Applying an equity lens to interventions: using PROGRESS ensures consideration of socially stratifying factors to illuminate inequities in health. J Clin Epidemiol 2014;67(1):56-64.

31 Evans T WM, Diderichsen F, Bhuiya A, Wirth M, eds. . Introduction. in: Challenging inequities in health: from ethics to action. Oxford University Press; 2001.

32 Evans $\mathrm{T}$, Brown $\mathrm{H}$. Road traffic crashes: operationalizing equity in the context of health sector reform. Inj Control Saf Promot 2003;10(1-2):11-2.

33 Whitehead M. The concepts and principles of equity and health. Health Promotion Int 1991;6(3):217-28.

34 Tugwell $\mathrm{P}$, Maxwell $\mathrm{L}$, Welch V, et al. Is health equity considered in systematic reviews of the Cochrane Musculoskeletal Group? Arthritis Rheum 2008;59(11):1603-10.

35 Finger ME, Boonen A, Woodworth TG, et al. An OMERACT Initiative Toward Consensus to Identify and Characterize Candidate Contextual Factors: Report from the Contextual Factors Working Group. The J Rheumatol 2017.

36 Verstappen SM. Outcomes of early rheumatoid arthritis--the WHO ICF framework. Best practice \& research. Clin Rheumatol 2013;27(4):555-70.

37 McHorney CA, Fleishman JA. Assessing and understanding measurement equivalence in health outcome measures. Issues for further quantitative and qualitative inquiry. Med Care 2006;44(11 Suppl 3):S205-10.

38 Brus HL, van de Laar MA, Taal E, Rasker JJ, Wiegman O. Effects of patient education on compliance with basic treatment regimens and health in recent onset active rheumatoid arthritis. Ann Rheum Dis 1998;57(3):146-51.

39 Putrik P, Sokka T, Ramiro S, Boonen A. Impact of socioeconomic gradients within and between countries on health of patients with rheumatoid arthritis (RA): lessons from QUEST RA. Best Pract Res Clin Rheumatol 2012;26(5):705-20.

40 Putrik P, Ramiro S, Lie E, et al. Less educated and older patients have reduced access to biologic DMARDs even in a country with highly developed social welfare (Norway): results from Norwegian cohort study NOR-DMARD. Rheumatology (Oxford) 2016;55(7):1217-24.

41 Stucki G, Cieza A, Geyh S, et al. ICF Core Sets for rheumatoid arthritis. J Rehabil Med 2004(44 Suppl):8793.

42 McKenna SP, Doward LC. The translation and cultural adaptation of patient-reported outcome measures. Value Health 2005;8(2):89-91.

43 Hahn EA, Bode RK, Du H, Cella D. Evaluating linguistic equivalence of patient-reported outcomes in a cancer clinical trial. Clin Trials 2006;3(3):280-90.

44 Bruce B, Fries JF. The Stanford Health Assessment Questionnaire: dimensions and practical applications. Health Qual Life Outcomes 2003;1:20.

45 van der Zee-Neuen A, Putrik P, Ramiro S, et al. Work outcome in persons with musculoskeletal diseases: comparison with other chronic diseases \& the role of musculoskeletal diseases in multimorbidity. BMC Musculoskelet Disord 2017;18(1):10.

46 Gossec L, Paternotte S, Aanerud GJ, et al. Finalisation and validation of the rheumatoid arthritis impact of disease score, a patient-derived composite measure of impact of rheumatoid arthritis: a EULAR initiative. Ann Rheum Dis 2011;70(6):935-42. 
47 Leggett S, van der Zee-Neuen A, Boonen A, et al. Content validity of global measures for at-work productivity in patients with rheumatic diseases: an international qualitative study. Rheumatology (Oxford) 2016;55(8):1364-73.

48 Islam N, Baron Basak T, OudeVoshaar MA, Ferdous N, Rasker JJ, Atiqul Haq S. Cross-cultural adaptation and validation of a Bengali Health Assessment Questionnaire for use in rheumatoid arthritis patients. Int J Rheum Dis 2013;16(4):413-7.

49 Symmons DP. Environmental factors and the outcome of rheumatoid arthritis. Best Pract Res Clin Rheumatol 2003;17(5):717-27.

50 Margaretten M, Barton J, Julian L, et al. Socioeconomic determinants of disability and depression in patients with rheumatoid arthritis. Arthritis Care Res (Hoboken) 2011;63(2):240-6.

51 Katz PP, Barton J, Trupin L, et al. Poverty, Depression, or Lost in Translation? Ethnic and Language Variation in Patient-Reported Outcomes in Rheumatoid Arthritis. Arthritis Care Res (Hoboken) 2016;68(5):621-8.

52 Oude Voshaar MA, Glas CA, ten Klooster PM, Taal E, Wolfe F, van de Laar MA. Crosscultural measurement equivalence of the Health Assessment Questionnaire II. Arthritis Care Res (Hoboken) 2013;65(6):1000-4.

53 Rose M, Bjorner JB, Becker J, Fries JF, Ware JE. Evaluation of a preliminary physical function item bank supported the expected advantages of the Patient-Reported Outcomes Measurement Information System (PROMIS). J Clin Epidemiol 2008;61(1):17-33.

54 Siemons L, Krishnan E. A short tutorial on item response theory in rheumatology. Clin Exp Rheumatol 2014;32(4):581-6.

55 Siemons L, Ten Klooster PM, Taal E, Glas CA, Van de Laar MA. Modern psychometrics applied in rheumatology--a systematic review. BMC Musculoskelet Disord 2012;13:216.

56 Teresi JA, Ocepek-Welikson K, Kleinman M, et al. Analysis of differential item functioning in the depression item bank from the Patient Reported Outcome Measurement Information System (PROMIS): An item response theory approach. Psychol Sci Q 2009;51(2):148-80.

57 Pollard B, Johnston M, Dixon D. Exploring differential item functioning in the SF-36 by demographic, clinical, psychological and social factors in an osteoarthritis population. BMC Musculoskelet Disord 2013;14:346.

58 Goetz C, Ecosse E, Rat AC, Pouchot J, Coste J, Guillemin F. Measurement properties of the osteoarthritis of knee and hip quality of life OAKHQOL questionnaire: an item response theory analysis. Rheumatology (Oxford) 2011;50(3):500-5.

59 Barry MJ, Edgman-Levitan S. Shared decision making--pinnacle of patient-centered care. N Engl J Med 2012;366(9):780-1.

60 de Haes $H$. Dilemmas in patient centeredness and shared decision making: a case for vulnerability. Patient Educ Couns 2006;62(3):291-8.

61 Oshima Lee E, Emanuel EJ. Shared decision making to improve care and reduce costs. N Engl J Med 2013;368(1):6-8.

62 Clayman ML, Bylund CL, Chewning B, Makoul G. The Impact of Patient Participation in Health Decisions Within Medical Encounters: A Systematic Review. Med Decis Making 2016;36(4):427-52.

63 Pollard S, Bansback N, Bryan S. Physician attitudes toward shared decision making: A systematic review. Patient Educ Couns 2015;98(9):1046-57.

64 Richards M. Extent and causes of international variations in drug usage - A report for the Secretary of State for Health 2010.

65 Shah NT. A role for physicians: an observation on cost containment. Am J Prev Med 2013;44(1 Suppl 1):S19-21.

66 Blumenthal D. Controlling health care expenditures. N Engl J Med 2001;344(10):766-9.

67 Dougados $M$, Soubrier M, Antunez A, et al. Prevalence of comorbidities in rheumatoid arthritis and evaluation of their monitoring: results of an international, cross-sectional study (COMORA). Ann Rheum Dis 2014;73(1):62-8.

68 de Bekker-Grob EW, Ryan M, Gerard K. Discrete choice experiments in health economics: a review of the literature. Health Econ 2012;21(2):145-72. 


\section{Part I}

The role of country and socio-cultural context in outcome measurement in rheumatoid arthritis 



\section{Chapter}

In rheumatoid arthritis, country of residence has an important influence on fatigue: results from the multinational COMORA study

Hifinger M, Putrik P, Ramiro S, Keszei AP, Hmamouchi I, Dougados M, Gossec L, Boonen A Rheumatology (Oxford) 2016;55(4): 735-744. 


\section{Abstract}

\section{Objectives}

To investigate the relationship between country of residence and fatigue in rheumatoid arthritis (RA), and to explore which country characteristics are related to fatigue.

\section{Methods}

Data from the multinational COMORA study were analysed. Contribution of country of residence to level of fatigue (0-10 on visual analogue scale (VAS)) and presence of severe fatigue (VAS $\geq 5$ ) was explored in multivariable linear or logistic regression models including first socio-demographic and objective disease outcomes $\left(M_{1}\right)$, and then also subjective outcomes $\left(M_{2}\right)$. Next, country of residence was replaced by country characteristics: gross domestic product (GDP), human development index (HDI), latitude (as indicator of climate), language and income inequality index (Gini-index). Model fit $\left(R^{2}\right)$ for linear models was compared.

\section{Results}

3920 patients from 17 countries were included, mean age 56 years (SD 13), 82\% females. Mean fatigue across countries ranged from 1.86 (SD 2.46) to 4.99 (SD 2.64) and proportion of severe fatigue from 14\% (Venezuela) to 65\% (Egypt). Objective disease outcomes did not explain much of the variation in fatigue $\left(R_{M 1}^{2}=0.12\right)$, while subjective outcomes had a strong negative impact and partly explained the variation in fatigue $\left(R^{2}{ }_{M 2}=0.27\right)$. Country of residence had a significant additional effect (increasing model fit to $R^{2}{ }_{M 1}=0.20$ and $R^{2}{ }_{M 2}=0.36$ respectively). Remarkably, higher GDP and better HDI were associated with higher fatigue, and explained a large part the country effect. Logistic regression confirmed limited contribution of objective outcomes and relevant contribution of country of residence.

\section{Conclusion}

Country of residence has an important influence on fatigue. Paradoxically, patients from wealthier countries had higher fatigue. 


\section{Introduction}

Fatigue is highly prevalent in rheumatoid arthritis (RA) and is experienced almost universally by patients with the disease. ${ }^{1,2}$ The experience of fatigue is not yet completely understood. It is described as a multicausal, multidimensional and complex phenomenon in which psychological and biological mechanisms play a role, possibly in interaction with genetic predisposition. ${ }^{3}$ Patients with RA experience chronic fatigue often as unpredictable, overwhelming and not relieved by sleep. ${ }^{1,2,4}$ Fatigue is consistently ranked among the top outcome priorities of patients, often as high as or higher than pain. ${ }^{2,4}$ Fatigue affects many areas of daily life. Among others, fatigue reduces work ability or forces patients to omit valued activities. ${ }^{2,4}$ Last but not least, patients experience difficulties in having their fatigue or increased need for rest and sleep acknowledged by their environment. ${ }^{4}$

RA-related fatigue has received increasing attention in outcome research. In 2006, OMERACT (Outcome Measures in Rheumatology) endorsed fatigue as part of the core set of outcome measures for all future studies, highlighting the importance of this symptom. ${ }^{5}$ One of the challenges when addressing fatigue in clinical care and outcome research is that fatigue is an invisible subjective symptom. As objective measures for assessing fatigue do not exist, assessment is done through patient-reported outcomes (PROs) which by definition are influenced by subjective appraisal of the patient. ${ }^{6}$ Although a large number of validated instruments exist today to reliably measure fatigue, $^{7}$ the interpretation of PROs remains complex; this is especially true because personal and environmental factors have a large impact on the way patients appraise fatigue. ${ }^{8}$ The role of various social and environmental factors (e.g. social stress, lack of social support) has already been revealed in a recent systematic review. ${ }^{3}$ Two studies showed that lack of social support contributed to higher levels of fatigue., ${ }^{9,10}$ While formal cross-cultural validation of instruments for assessing fatigue has never been done, one comparative study on fatigue between the UK and the US revealed significant cultural differences in how patients and their environment perceive RA-related fatigue. Patients from the UK largely felt they had to manage fatigue alone leading to comparatively negative attitudes toward fatigue, whereas US participants reported active coping strategies with stronger support of friends and family. ${ }^{2}$

More recently, the Quantitative Patient Questionnaires in Standard Monitoring of Patients with RA (QUEST-RA), a daily practice patient register that aims to explore inequalities in health outcomes of RA patients across countries, ${ }^{11,12}$ documented large variations in mean fatigue levels of participating countries. Further exploration did not find an association between fatigue and the country's socio-economic welfare in terms of gross domestic product (GDP). ${ }^{11}$ However, the analysis did not explore the variation in 
fatigue between individual countries. Also, the contribution of other country-related factors (such as income inequalities, development status or language) to the variation in fatigue across has not been investigated.

As multinational trial settings become increasingly prevalent in clinical research, it is important to understand how non-disease related factors, including country of residence, influence fatigue. This knowledge is not only relevant when interpreting (multinational) observational or intervention studies, but can also help to improve strategies for management of fatigue in clinical care.

COMOrbidities in RA (COMORA) was a large multinational study in 17 countries worldwide aiming to understand prevalence and monitoring practices of comorbidities. ${ }^{13}$ By providing additional data on demographic and disease characteristics, including fatigue, COMORA offered the opportunity for understanding the variation in level and severity of fatigue across countries and for exploring which surrogates that characterize the economic or cultural background of the countries could explain possible country differences.

\section{Patients and methods}

\section{Study design and data collection}

Data from COMORA, an international, cross-sectional, multicentre observational study, were collected in 2011 and 2012 and provided information about 3920 patients from 17 countries in Europe, North-and South America, North Africa, and Asia. The original COMORA study was reviewed and approved by all local institutional review boards or ethics committees (in each of the 17 participating countries). Patients were eligible to participate in the study if they were at least 18 years of age, fulfilled the 1987 American College of Rheumatology (ACR) classification criteria for RA, and were able to understand and complete the questionnaire. Written informed consent was obtained from all subjects before enrolment. ${ }^{13}$ This secondary analysis did not have ethical approval.

COMORA investigators collected data on socio-economic characteristics (age, gender, current paid employment status (yes or no), the highest level of education (completed primary, secondary or university education) and marital status (single, married, divorced or widower)), health-related risk factors including smoking status (past, current, never smoked), body weight $(\mathrm{kg})$ and body height $(\mathrm{cm})$ from which BMI was calculated. For analyses, patients were classified into four categories, namely underweight (BMI<18.5), normal weight $(18.5 \leq \mathrm{BMl}<25)$, overweight $(25<\mathrm{BMI} \leq 30)$, and obese $(\mathrm{BMI}>30)$ patients. $^{14,15}$ 
Further, various RA-related clinical characteristics were recorded, including patients' tender 28-joint count (TJC), swollen 28-joint count (SJC), erythrocyte sedimentation rate (ESR), presence of high rheumatoid factor or high positive anti-citrullinated protein antibody (ACPA) (yes or no), presence of erosive disease (yes or no), functional status (modified health assessment questionnaire $(\mathrm{mHAQ}))^{16,17}$ and patient and physician global assessment (PatGA, PhyGA) measured on a visual analogue scale (VAS 0-10). Disease activity was assessed using the 28-joint disease activity score (DAS28) calculated based on TJC, SJC, PhyGA and ESR. ${ }^{18}$

Information on RA medication intake comprised current and past use of synthetic and biologic disease modifying anti-rheumatic drugs (DMARDs), corticosteroids and nonsteroidal anti-inflammatory drugs (NSAIDs). Intake of corticosteroids was assessed using the mean daily prednisone intake in milligram during the last 3 months. Intake of NSAIDs was assessed calculating the mean intake of NSAID equivalents during the last 3 months. ${ }^{19}$ Data on past and current comorbidities were retrieved from the medical record, and used to compute the Rheumatic Disease Comorbidity Index (RDCl). ${ }^{20}$ The index includes respiratory diseases, myocardial infarction, hypertension, diabetes, depression, ulcers or other gastrointestinal infections, fractures and cancer. As information on fractures was not collected in the study, it was not included in the index.

\section{Outcome of interest}

Level of fatigue and presence of severe fatigue were the outcomes of interest. Patients were asked to rate their experienced level of fatigue during the past 48 hours on a 0-10 VAS (anchors $0=$ no fatigue, $10=$ exhausted). Presence of severe fatigue was defined as a score on the VAS of $\geq 5$. ${ }^{21}$

\section{Characteristics of countries that further explain a possible role of country of residence}

To further explore the possible role of country of residence in fatigue, countries were classified according to five country-specific characteristics namely socio-economic welfare status, human development status, income inequalities (within a country), climate and language characteristics.

GDP was used to assess the socio-economic welfare of each participating country. ${ }^{22}$ GDP was adjusted for purchasing power parity to ensure comparability between countries. For the analysis, countries were split into tertiles.

To investigate the influence of the country's human development status on the selfassessed level of fatigue, a standardized index, namely the Human Development Index (HDI) was applied. HDI is a composite statistic of life expectancy, education, and income (adjusted for purchasing power parity) reported by the United Nations Development Program (UNDP). ${ }^{23}$ Countries were allocated following UNDP classification to: very high 
human development, high human development, moderate human development and low human development.

The role of income inequalities in the assessment of fatigue was investigated using the Gini-index. The Gini-index represents the income distribution of a nation's residents and is an indicator for income inequalities within a country. ${ }^{24}$ Participating countries were split into tertiles.

The latitude of the country's capital was applied to allocate countries to geographical regions with comparable climate conditions (e.g. hours of daylight, average temperature, seasonal changes). The countries were grouped following the major climate zones, namely equatorial countries $\left(0^{\circ}-29^{\circ}\right)$, mid-latitude $\left(30^{\circ}-60^{\circ}\right)$ countries or countries from arctic zone $\left(>60^{\circ}\right) .^{25}$

Last, participating countries were classified by the main language spoken in the country (official language). Five language categories were defined, namely Romance, Germanic, Arabic, Asian and Uralic languages.

\section{Statistical analysis}

Linear and logistic regression models were computed with the level of fatigue and presence of severe fatigue as dependent variables, respectively. Socio-demographic and clinical covariates were retained in the multivariable models if they showed a statistically significant associations $(p<0.10)$ with fatigue in univariable regression, or were important confounders.

Two core models were developed. In Model $1\left(M_{1}\right)$, the role of demographics (age, gender), comorbidities (RDCI) and objective disease characteristics (SJC, TJC and ESR) were assessed. In Model $2\left(M_{2}\right)$, TJC, SJC and ESR were replaced by DAS28 (accounting also for the patient global assessment), and $\mathrm{mHAQ}$ was added.

In both models country of residence was added in the last step as a categorical variable (17 individual countries). The country with the lowest level of fatigue (Venezuela) was used as reference. In linear regression models, country of residence was consecutively replaced by country specific factors, including the country's socio-economic welfare (GDP), human development status (HDI), income inequality (Gini-index), climate (latitude) or linguistic determinants (language). Improvement in model fit $\left(R^{2}\right)$ of both linear regression models $\left(M_{1}, M_{2}\right)$ was compared when including either individual countries or country-specific variables. Interactions between country (individual or grouped by GDP and HDI) and (a) gender (both models), (b) TJC and SJC $\left(M_{1}\right)$, (c) MHAQ and DAS28 $\left(\mathrm{M}_{2}\right)$ were checked. Where interaction had a $\mathrm{p}$-value $<0.01$, stratified analyses were performed. Complete cases were included in the analysis (3717 patients $(5.2 \%$ missing data) in model 1, 3679 patients (6.1\% missing data) in model 2).

Statistical analysis was performed using STATA (version 12) software. $^{26}$ 


\section{Results}

\section{Baseline demographic and clinical characteristics}

In total, 3920 patients with RA from 17 countries (range 30-411) were included in the COMORA study. Mean age of patients was 56 years ranging from 18 to 89 years (standard deviation (SD) 13), 82\% of patients were females.

The mean fatigue was 4.13 (SD 2.77) and varied significantly across countries. The highest level of fatigue was found in the Netherlands (4.99, SD 2.64), the lowest in Venezuela (1.89, SD 2.46). Severe fatigue (VAS $\geq 5$ ) was observed in $47 \%$ of all patients with only $14 \%$ of patients in Venezuela but $65 \%$ of patient in Egypt. Mean DAS28 was 3.74 (SD 1.55), and mean mHAQ was 1.04 (SD 0.66). On average, patients reported one comorbidity, depression was the most frequently reported comorbidity (15\%) (Table 2.1).

Medication, BMI, level of education and employment status were not associated with fatigue and therefore not included in the models $\left(M_{1}\right.$ or $\left.M_{2}\right)$.

\section{Relationship between fatigue, socio-economic and clinical factors}

The model containing objective disease characteristics $\left(M_{1}\right)$ had a low model fit $\left(R^{2}\right)$ of only 0.12. A detailed overview of missing data in variables included in the regression analyses (per country, overall) can be found in Appendix 1, available as supplementary data at Rheumatology Online.

Females had a 0.60 points higher fatigue than males and every comorbidity increased fatigue by 0.30 points. For each additional tender or swollen joint fatigue increased by only 0.14 and 0.03 respectively. The influence of ESR on fatigue was negligible (Table 2.2). Adding subjective disease characteristics more than doubled the overall model fit $\left(R^{2}{ }_{M 2}=0.27\right)$. One point on a scale of DAS28 and $\mathrm{mHAQ}$ contributed to an increase of 0.37 and 1.50 points in fatigue, respectively (Table 2.2) and attenuated the influence of gender and comorbidities.

Similarly, the odds of being severely fatigued (VAS $\geq 5$ ) were primarily associated with female gender, higher number of comorbidities and worse subjective disease characteristics. Age and objective disease characteristics played a minor role (Table 2.2). 


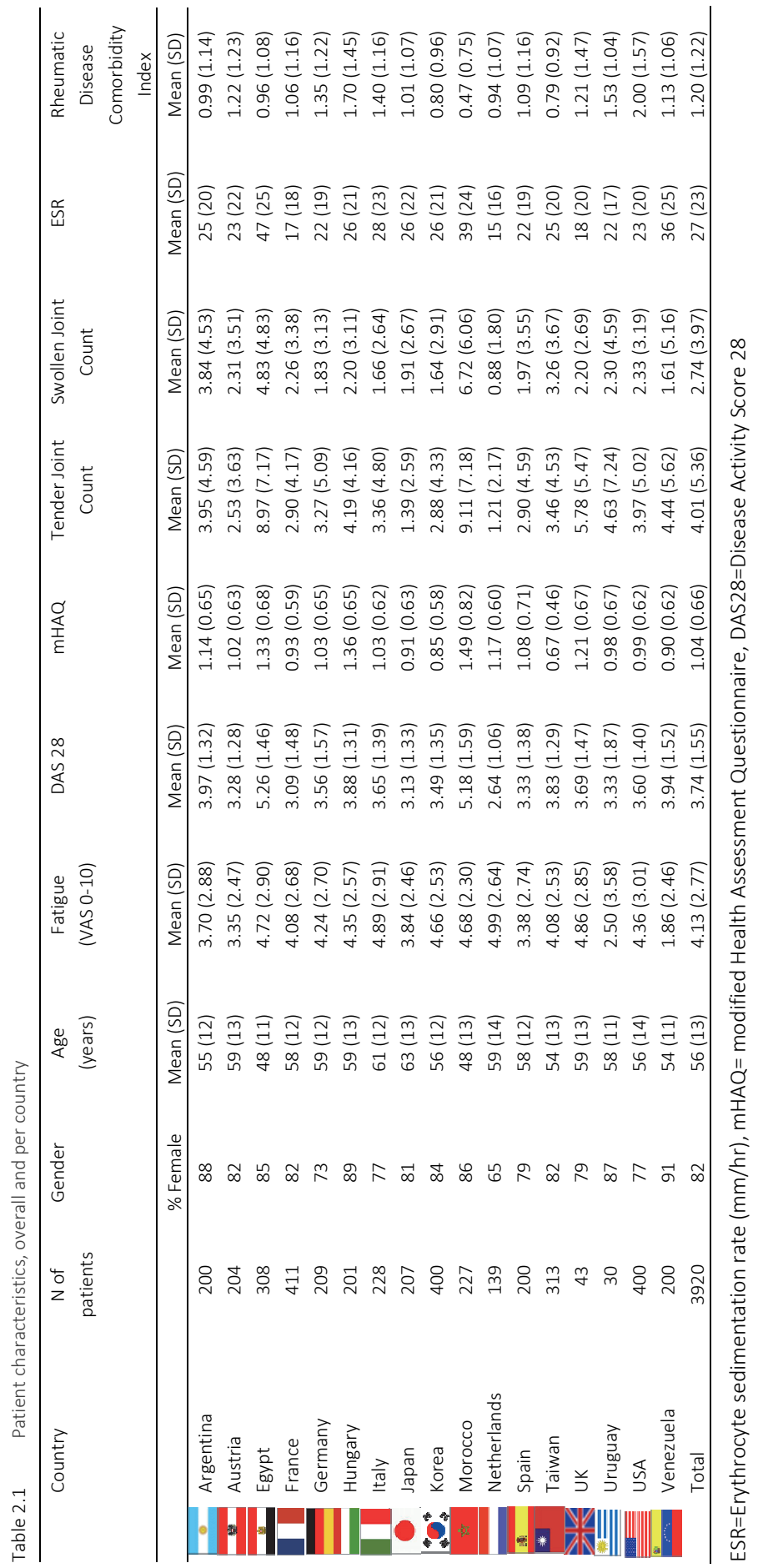


Table 2.2 Association of individual socio-demographic and clinical characteristics with fatigue

\begin{tabular}{|c|c|c|c|c|}
\hline & \multicolumn{2}{|c|}{$\begin{array}{c}\text { Model } 1 \\
\text { Objective } \\
\text { disease characteristics } \\
\mathrm{n}=3717 \\
\end{array}$} & \multicolumn{2}{|c|}{$\begin{array}{c}\text { Model } 2 \\
\text { Objective and patient-reported } \\
\text { disease characteristics } \\
\mathrm{n}=3679\end{array}$} \\
\hline & $\begin{array}{c}\text { Linear regression } \\
\beta[95 \% \mathrm{Cl}] \\
R^{2}=0.12\end{array}$ & $\begin{array}{l}\text { Logistic regression } \\
\text { OR }[95 \% \mathrm{Cl}]\end{array}$ & $\begin{array}{l}\text { Linear regression } \\
\qquad \begin{array}{c}\beta[95 \% \mathrm{Cl}] \\
\mathrm{R}^{2}=0.27\end{array}\end{array}$ & $\begin{array}{l}\text { Logistic regression } \\
\text { OR }[95 \% \mathrm{Cl}]\end{array}$ \\
\hline \multicolumn{5}{|l|}{ Independent variable } \\
\hline Age (years) & $-0.01[-0.02,0.01]$ & $0.99[0.98 ; 1.00]$ & $-0.02[-0.02 ;-0.01]$ & $0.99[0.98 ; 1.00]$ \\
\hline Female vs. male & $0.60[0.38 ; 0.82]$ & $1.60[1.31 ; 1.96]$ & $0.31[0.11 ; 0.51]$ & $1.39[1.12 ; 1.72]$ \\
\hline Rheumatic Disease & $0.30[0.23 ; 0.37]$ & $1.25[1.18 ; 1.33]$ & $0.18[0.11 ; 0.25]$ & $1.17[1.10 ; 1.25]$ \\
\hline \multicolumn{5}{|l|}{ Comorbidity Index (0-8) } \\
\hline Swollen Joint Count (0-28) & $0.03[0.00 ; 0.06]$ & $1.01[0.99 ; 1.04]$ & In DAS28 & In DAS28 \\
\hline Tender Joint Count (0-28) & $0.14[0.12 ; 0.16]$ & $1.09[1.07 ; 1.11]$ & In DAS28 & In DAS28 \\
\hline $\mathrm{ESR}(\mathrm{mm} / \mathrm{hr})$ & $0.00[0.00 ; 0.01]$ & $1.00[1.00 ; 1.01]$ & In DAS28 & In DAS28 \\
\hline DAS28 (0-10) & n.c. & n.c. & $0.37[0.31 ; 0,42]$ & $1.25[1.18 ; 1.33]$ \\
\hline mHAQ (0-3) & n.c. & n.c. & $1.50[1.36 ; 1,64]$ & $2.94[2.57 ; 3.35]$ \\
\hline
\end{tabular}

Results from multivariable linear (outcome: level of fatigue) and logistic (outcome: chance to be severely fatigued, VAS $\geq 5$ ) regression models. ESR=Erythrocyte Sedimentation Rate, $\mathrm{mHAQ}=$ modified Health Assessment Questionnaire, DAS28= Disease Activity Score $28, \mathrm{R}^{2}=$ Overall model fit, $\mathrm{OR}=$ odds ratio to be severely fatigued. n.c.=not considered, objective components of DAS28 considered individually, $\mathrm{mHAQ}$ allocated to subjective disease characteristics. *estimates with $p<0.05$ are in bold

\section{Contribution of country of residence to the variation in fatigue}

When level of fatigue was the outcome, adding country of residence improved the model fit from $R^{2}=0.12$ to $R^{2}=0.20(p<0.001)$ for model 1 (objective measures) and from $R^{2}=0.27$ to $R^{2}=0.36(p<0.001)$ for model 2 (objective and subjective outcomes) (Figure 2.2). Using Venezuela (the country with the lowest fatigue) as reference, the fully adjusted differences in fatigue $\left(\mathrm{M}_{2}\right)$ varied between +0.80 (Uruguay) to +3.54 (the Netherlands) (Table 2.3, Figure 2.1).

Similarly, the risk of being severely fatigued varied substantially across countries. Compared to Venezuela, the odds of patients from the Netherlands being severely fatigued were 31-fold higher (Table 2.3). Notably, coefficients of socio-demographic and clinical variables did not change substantially in any of the models when country of residence was added (Table 2.2 and 2.3 ).

\section{Contribution of country characteristics to the variation in fatigue}

In a last step, we replaced individual countries by country characteristics in the linear regressions. Comparison of overall model fit revealed that HDI (an index for human development) and GDP (an indicator for the country's socio-economic welfare) explained the largest part of the contribution of country of residence $\left(R_{M 2}^{2}=0.27, R_{M 2}^{2}\right.$ (countries) $\left.=0.36(p<0.001), R^{2}{ }_{M 2(H D I)}=0.33(p<0.001), R_{M 2(G D P)}^{2}=0.32(p<0.001)\right)$ (Figure 2.2). 
In the fully adjusted model $\left(\mathrm{M}_{2}\right)$, patients from countries with the lowest GDP had 1.30 points lower fatigue compared to those from the highest group and patients from countries with the lowest HDI had 1.32 points lower fatigue. Climate (latitude), income inequalities (Gini-index) and type of language did not contribute significantly and did not explain the influence of country of residence on variation in fatigue $\left(R^{2}{ }_{M 2}\right.$ (gini) $=0.28$ $(p<0.001), R^{2}$ M2 (language) $=0.30(p<0.001), R_{M 2}^{2}$ (latitude) $\left.=0.30 \quad(p<0.001)\right)$. None of the interactions was statistically significant.

Table 2.3 Association of country of residence with fatigue

\begin{tabular}{|c|c|c|c|c|}
\hline & \multicolumn{2}{|c|}{$\begin{array}{c}\text { Model } 1 \\
\text { Objective } \\
\text { disease characteristics } \\
\mathrm{n}=3717\end{array}$} & \multicolumn{2}{|c|}{$\begin{array}{c}\text { Model } 2 \\
\text { Objective and patient-reported } \\
\text { disease characteristics } \\
\text { n=3679 }\end{array}$} \\
\hline & $\begin{array}{l}\text { Linear regression } \\
\qquad \begin{array}{c}\beta[95 \% \mathrm{Cl}] \\
\mathrm{R}^{2}=0.20\end{array}\end{array}$ & $\begin{array}{l}\text { Logistic regression } \\
\text { OR }[95 \% \mathrm{Cl}]\end{array}$ & $\begin{array}{l}\text { Linear regression } \\
\qquad \begin{array}{c}\quad 95 \% \mathrm{Cl}] \\
\mathrm{R}^{2}=0.36\end{array}\end{array}$ & $\begin{array}{l}\text { Logistic regression } \\
\quad \text { OR }[95 \% \mathrm{Cl}]\end{array}$ \\
\hline Age (years) & $-0.02[-0.02,-0.01]$ & $0.99[0.98,0.99]$ & $-0.03[-0.03,-0.02]$ & $0.98[0.97,0.99]$ \\
\hline Female vs. male & $0.73[0.52 ; 0.94]$ & $1.84[1.49,2.26]$ & $0.41[0.22 ; 0.60]$ & $1.55[1.24,1.95]$ \\
\hline $\begin{array}{l}\text { Rheumatic Disease Comorbidity } \\
\text { Index (0-8) }\end{array}$ & $0.33[0.25 ; 0.40]$ & $1.27[1.19,1.36]$ & $0.20[0.13 ; 0.53]$ & $1.19[1.10,1.27]$ \\
\hline Swollen Joint Count (0-28) & $0.05[0.02 ; 0.07]$ & $1.03[1.00,1.05]$ & In DAS28 & In DAS28 \\
\hline Tender Joint Count (0-28) & $0.14[0.12 ; 0.16]$ & $1.10[1.08,1.12]$ & In DAS28 & In DAS28 \\
\hline $\mathrm{ESR}(\mathrm{mm} / \mathrm{hr})$ & $0.01[0.00 ; 0.01]$ & $1.01[1.00,1.01]$ & In DAS28 & In DAS28 \\
\hline DAS28 (0-10) & n.c. & n.c. & $0.47[0.41 ; 0.53]$ & $1.41[1.32 ; 1.50]$ \\
\hline mHAQ (0-3) & n.c. & n.c. & $1.55[1.42 ; 1,69]$ & $3.24[2.80 ; 3.75]$ \\
\hline Argentina vs. VZ & $1.88[1.37 ; 2.38]$ & $5.80[3.10,10.81]$ & $1.46[1.01 ; 1.91]$ & 5.40 [2.78; 10.47] \\
\hline Austria vs. VZ & $1.83[1.33 ; 2.33]$ & $3.93[2.06 ; 7.51]$ & $1.70[1.25 ; 2.15]$ & $4.21[2.10,8.43]$ \\
\hline Egypt vs.VZ & $1.92[1.46 ; 2.38]$ & $4.66[2.59 ; 8.39]$ & $1.44[1.03 ; 1.85]$ & $3.94[2.11 ; 7.33]$ \\
\hline France vs. VZ & $2.61[2.18 ; 3.05]$ & $8.41[4.70 ; 15.05]$ & $2.64[2.25 ; 3.03]$ & 11.73 [6.29; 21.85] \\
\hline Germany vs. VZ & $2.74[2.18 ; 3.29]$ & $7.04[3.64 ; 13.66]$ & $2.54[2.04 ; 3.04]$ & $7.94[3.90,16.16]$ \\
\hline Hungary vs VZ & $2.41[1.91 ; 2.90]$ & $7.07[3.83 ; 13.06]$ & $1.78[1.33 ; 2.23]$ & 5.76 [2.99; 11.07] \\
\hline Italy vs. VZ & $3.30[2.81,3.78]$ & $16.35[8.95 ; 29.88]$ & $3.12[2.69 ; 3.55]$ & 21.56 [11.33; 41.00] \\
\hline Japan vs. VZ & $2.63[2.13 ; 3.13]$ & $6.58[3.49 ; 12.40]$ & $2.59[2.14 ; 3.04]$ & 14.61 [7.90; 27.04] \\
\hline Korea vs. VZ & $3.21[2.77 ; 3.64]$ & $10.26[5.76 ; 18.28]$ & $3.19[2.80 ; 3.58]$ & $3.82[1.99,7.33]$ \\
\hline Morocco vs. VZ & $1.951 .45 ; 2.44]$ & $5.57[3.02 ; 10.26]$ & $1.25[0.80 ; 1.69]$ & $0.23[0.13,0.39]$ \\
\hline Netherlands vs VZ & $3.95[3.39 ; 4.51]$ & 27.14 [14.17; 52.09] & $3.54[3.02 ; 4.06]$ & $31.23[15.40 ; 63.30]$ \\
\hline Spain vs. VZ & $1.93[1.43,2.43]$ & $4.47[2.34 ; 8.53]$ & $1.64[1.18 ; 2.09]$ & $4.52[2.26,9.04]$ \\
\hline Taiwan vs. VZ & $2.46[2.01 ; 2.91]$ & $5.85[3.23 ; 10.60]$ & $2.69[2.28 ; 3.09]$ & $9.75[5.19,18.34]$ \\
\hline UK vs. VZ & $3.15[-1.75 ; 0.15]$ & $12.84[5.19 ; 31.74]$ & $2.85[2.02 ; 3.68]$ & $14.22[5.50,36.76]$ \\
\hline Uruguay vs. Venezuela & $0.56[-0.39 ; 1.53]$ & $3.53[1.22 ; 10.18]$ & $0.80[-0.06 ; 1.66]$ & $4.87[1.49,15.84]$ \\
\hline USA vs. VZ & $2.39[1.95 ; 2.84]$ & $8.08[4.51 ; 14.46]$ & 2.37 [1.97; 2.77] & $10.94[5.88,20.37]$ \\
\hline Venezuela (VZ) & & Referen & country & \\
\hline
\end{tabular}

Results from multivariable linear (outcome: level of fatigue) and logistic (outcome: chance to be severely fatigued, VAS $\geq 5$ ) regression models. ESR=Erythrocyte Sedimentation Rate, $\mathrm{mHAQ}=$ modified Health Assessment Questionnaire, DAS28= Disease Activity Score 28, $R^{2}=$ Overall model fit; $O R=$ odds ratio to be severely fatigued, n.c.=not considered, objective components of DAS28 considered individually, mHAQ allocated to subjective disease characteristics. *all models adjusted for individual sociodemographic and clinical disease characteristics; **estimates with $\mathrm{p}<0.05$ are in bold; ${ }^{* * *}$ Venezuela, selected as reference category, country with the lowest level of fatigue (mean, unadjusted) 

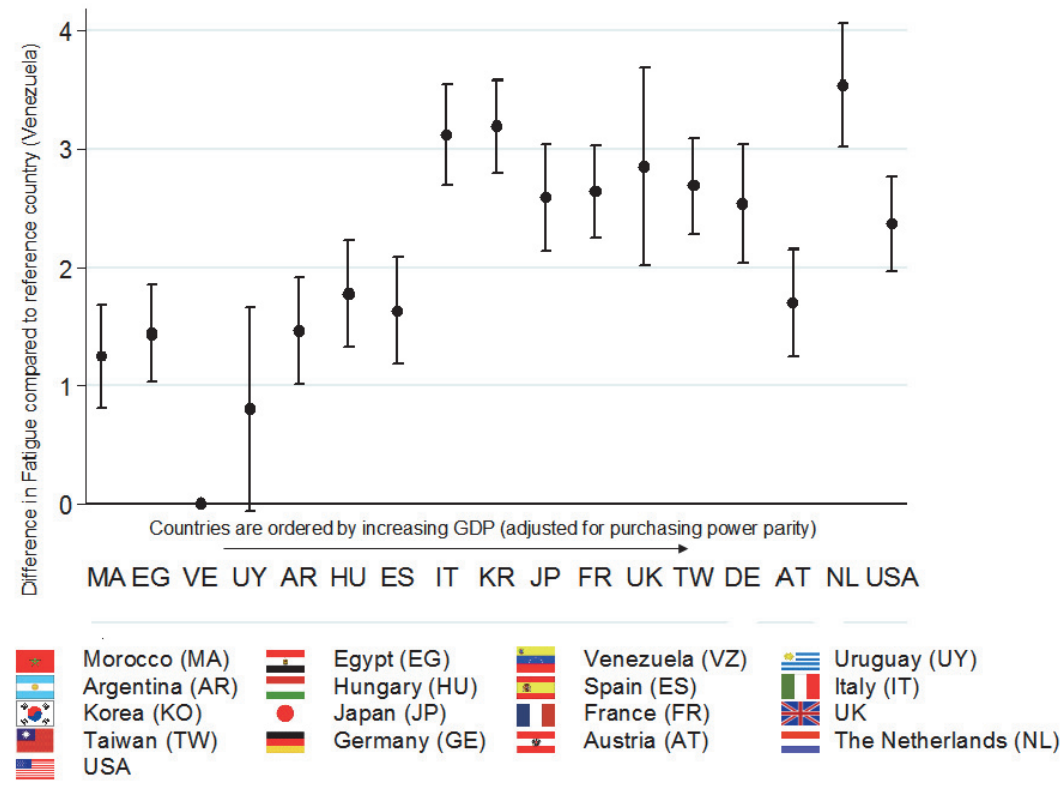

Figure 2.1 Differences in average level of fatigue between individual countries. GDP =Gross Domestic Product. Model adjusted for objective and patient reported disease characteristics

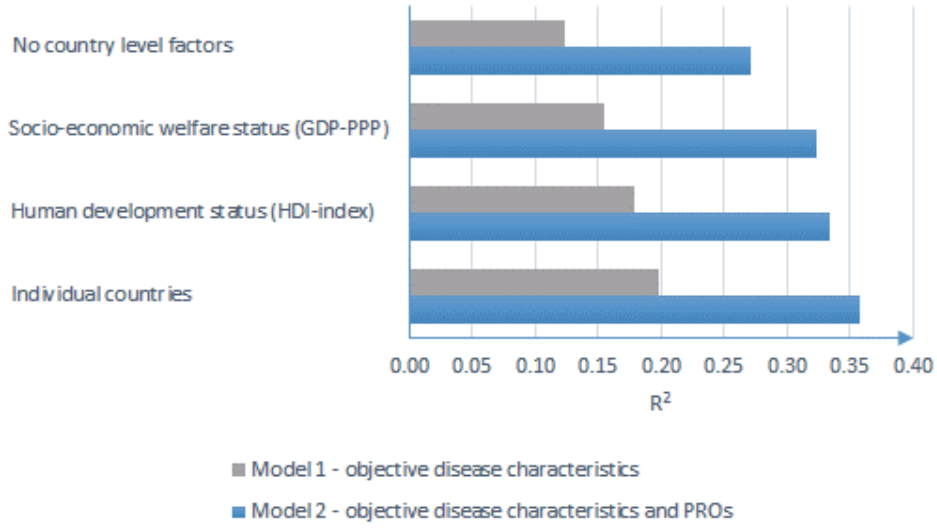

Figure 2.2 Contribution of individual countries and various country characteristics in explaining variation in fatigue. $R^{2}=$ overall model fit of linear regression models, the higher the values (maximum 1.0) the better is the explanation of fatigue. GDP (PPP) =Gross Domestic Product (Purchasing Power Parity), $\mathrm{HDI}=$ Human Development Index, $\mathrm{PRO}=$ patient-reported outcomes (subjective disease characteristics) 


\section{Discussion}

The current study reports that country of residence had an independent and important influence on fatigue in patients with RA. Interestingly, patients in high-income countries (based on GDP) or in countries with higher human development (based on the HDI) experienced higher fatigue compared to patients from countries with lower GDP or HDI. When exploring fatigue independent of country of residence, our results showed that objective RA-related disease characteristics such as TJC, SJC, ESR as well as physician reported comorbidities had a very limited contribution. Consistent with the literature female gender, worse PatGA and worse physical functioning were strongly associated with higher fatigue. ${ }^{3,21,27,28}$ It is not surprising that appraisal-based measures, such as PatGA and mHAQ highly correlate with fatigue, as each of them reflects implicitly also the patient's personal beliefs, values and expectations. Of interest and again consistent with findings of the literature, RA medication did not contribute to variation in fatigue across countries when adjusted for clinical confounders. ${ }^{29}$

As already mentioned, the influence of country was substantial. In the country with highest levels of fatigue, fatigue was 3.54 points higher and the odds to be severely fatigued were 31-fold higher compared to the country with the lowest level of fatigue. Although the minimal clinically important difference (MCID) has been developed to understand clinical relevant difference in fatigue for an individual patient, it can be helpful to realize that the MCID for fatigue (measured on a 0-10 VAS) between 0.9 and 1.5 is already considered clinically meaningful according to the literature. ${ }^{30,31}$ While it is of interest to understand whether, and at which level, country of residence influences fatigue, it is also important to explore possible mechanisms that may help to explain the observed phenomenon. While GDP and the multidimensional indicator for human development, $\mathrm{HDI}$, explained a large part of the influence of country of residence on fatigue, income inequalities within the country, climate-related factors and linguistic aspects had no or almost no influence on variation in fatigue. Interestingly, patients were more fatigued in countries ranking highest for human development (HDI) and socio-economic welfare (GDP). We previously showed that higher socio-economic status of a country was associated with better DAS28. ${ }^{32}$ Also literature suggests, that higher GDP is associated with better access to (RA-related) healthcare. ${ }^{33}$ Therefore the current finding that higher GDP and HDI are associated with worse fatigue seems a paradox. Possibly, the societal pressure in highly developed countries to engage in many social roles and the efforts needed to fulfil and maintain these roles, result in increased fatigue. Also, patients in highly developed countries may have higher expectations towards treatment outcomes and relief of all experienced problems, including 
fatigue. ${ }^{2,9,10}$ To fully understand findings the in RA, it would be insightful to also have population estimates of fatigue from the participating countries.

Our finding that fatigue is higher in countries with higher GDP is not consistent with a recently published analysis of the international database QUEST-RA. ${ }^{11}$ Although QUESTRA used different anchor descriptions and recall period for the assessment of fatigue (7 days versus 48 hours on 0-10 VAS), they did not find an influence of GDP on fatigue after adjusting for socio-demographic and clinical disease characteristics. A possible explanation for the observed differences is that several Eastern European low-GDP countries that participated in QUEST-RA but not in COMORA $^{27}$ showed significantly higher fatigue levels than the overall mean fatigue level in COMORA and therefore may have caused the difference in results with regard to GDP. When comparing mean fatigue levels from the countries participating in both studies, these were however largely comparable indicating consistency between both databases. Countries from Eastern Europe might share the very fast-paced, demanding lifestyle and high workload of many Western European countries.

Some limitations have to be taken into account for the interpretation of the results. International studies like COMORA cannot guarantee that the enrolled patients are fully representative of the RA patients in the participating countries. For the majority of countries, centres with a research interest in RA participated; as a consequence patients from each country were likely to represent the optimally treated group. Referral bias in less-developed countries is highly probable. Lower awareness of arthritis among patients and general practitioners and thus delayed diagnosis and treatment could partly explain worse DAS28 and physical functioning but cannot explain lower fatigue compared to more highly-developed countries. Also, the cross-sectional design implies certain limitations in the interpretation of the findings and no causal relationships can be established. Longitudinal studies could help to further understand whether differences between countries are static or whether changes in fatigue are also culturally determined. Further, data on potential other country characteristics that could explain cultural differences in fatigue, were not always available or not available from the years of study conduct. For example, although the Gini-index, reflecting income inequality, was available for all participating countries, the period of collection was 15 years (1998 to 2013) and for some countries the index therefore did not overlap with the recruitment period. To understand a possible impact of climate on fatigue, the latitude of the country's capital has been used. However, the climate is a complex construct and can refer to hours of sunshine, average temperature, level of seasonal variation etc. Latitude is likely a very rough surrogate; especially in large countries like e.g. US, Argentina, several different climate conditions may exist. Similarly, only limited linguistic aspects could be studied. Language did not show to influence reported levels of fatigue. 
However language type may not cover all linguistic aspects. Earlier studies reported that the interpretation of the visual analogue scale for fatigue and its anchor descriptions may vary across countries and regions. ${ }^{8,34,35}$ The word exhausted used in the anchor description of the present study has slightly different meanings in English and Romance languages like Spanish or French. Also, the word fatigue as inherent word in addition to tiredness does not exist in many European languages, indicating that linguistic aspects could influence assessment of fatigue. ${ }^{36}$ It should be emphasized that the VAS fatigue has been validated with regard to reliability and construct validity, but lacks formal cross-cultural validation. ${ }^{7,37}$ Also, reducing the assessment of fatigue into a VAS may be over simplistic. However, because of its simple use and confirmed validity, the VAS is one of the most frequently used tools to measure fatigue. Finally, information on personality traits, believes towards disease or fatigue, experience of stress and anxiety could not be explored within the current study, as such data were not collected. It would be of interest to explore in future studies, how personal (psycho-social) characteristics interact with cultural and economic country-characteristics in relation to not only fatigue but also other PROs.

The relevance of our findings cannot be ignored. First, as fatigue is an important outcome and clinical studies and trials are increasingly performed in a multinational setting, results of multinational studies should be interpreted cautiously. Our study contributes to the cross-cultural validation and indicates that data cannot simply be transferred between countries. Secondly, clinicians should realize that objective measures are less relevant for the management of fatigue and could even communicate to patients that cultural factors seem to play a role. The observed paradox suggests that reducing social pressure and expectations of patients might be an important treatment factor for RA related fatigue.

In conclusion, country of residence has an important influence on the experienced level of fatigue even after adjustment of relevant disease and socio-demographic characteristics of patients. Interestingly, patients from highly developed countries with high economic standards were more fatigued than patients from less developed countries. Non-RA-related factors seem to influence the experience of fatigue more than objective measures that evaluate disease activity. Extrapolation of results on fatigue for trials or observational studies should be done cautiously.

Supplementary tables are published online on https://academic.oup.com/rheumatology 


\section{References}

1 Kirwan JR, Hewlett S. Patient perspective: reasons and methods for measuring fatigue in rheumatoid arthritis. J Rheumatol 2007;34(5):1171-3.

2 Hewlett S, Cockshott Z, Byron M, et al. Patients' perceptions of fatigue in rheumatoid arthritis: overwhelming, uncontrollable, ignored. Arthritis Rheum 2005;53(5):697-702.

3 Nikolaus S, Bode C, Taal E, van de Laar MA. Fatigue and factors related to fatigue in rheumatoid arthritis: a systematic review. Arthritis Care Res (Hoboken) 2013;65(7):1128-46.

4 Feldthusen C, Bjork M, Forsblad-d'Elia H, Mannerkorpi K, University of Gothenburg Centre for PersonCentred C. Perception, consequences, communication, and strategies for handling fatigue in persons with rheumatoid arthritis of working age--a focus group study. Clin Rheumatol 2013;32(5):557-66.

5 Kirwan JR, Minnock, P., Adebajo A. et al. Patient perspective: fatigue as a recommended patient centered outcome measure in rheumatoid arthritis. J Rheumatol 2007;34(5):1174-7.

6 Schwartz CE, Rapkin BD. Reconsidering the psychometrics of quality of life assessment in light of response shift and appraisal. Health Qual Life Outcomes 2004;2:16.

7 Hewlett S, Hehir, M., Kirwan, J. R. Measuring Fatigue in Rheumatoid Arthritis: A Systematic Review of Scales in Use. Arthritis Rheum 2007;57(3):429-39.

8 Wild D, Grove A, Martin M, et al. Principles of Good Practice for the Translation and Cultural Adaptation Process for Patient-Reported Outcomes (PRO) Measures: report of the ISPOR Task Force for Translation and Cultural Adaptation. Value Health 2005;8(2):94-104.

9 Riemsma RP, Rasker JJ, Taal E, Griep EN, Wouters JM, Wiegman O. Fatigue in rheumatoid arthritis: the role of self-efficacy and problematic social support. Br J Rheumatol 1998;37(10):1042-6.

10 Huyser BA, Parker JC, Thoreson R, Smarr KL, Johnson JC, Hoffman R. Predictors of subjective fatigue among individuals with rheumatoid arthritis. Arthritis Rheum 1998;41(12):2230-7.

11 Gron KL, Ornbjerg LM, Hetland ML, et al. The association of fatigue, comorbidity burden, disease activity, disability and gross domestic product in patients with rheumatoid arthritis. Results from 34 countries participating in the Quest-RA program. Clin Exp Rheum 2014;32(6):869-77.

12 Sokka T, Kautiainen $\mathrm{H}$, Pincus $\mathrm{T}$, et al. Disparities in rheumatoid arthritis disease activity according to gross domestic product in 25 countries in the QUEST-RA database. Ann Rheum Dis 2009;68(11):1666-72.

13 Dougados $M$, Soubrier M, Antunez A, et al. Prevalence of comorbidities in rheumatoid arthritis and evaluation of their monitoring: results of an international, cross-sectional study (COMORA). Ann Rheum Dis 2014;73(1):62-8.

14 WHO Obesity: preventing and managing the global epidemic: Report of a WHO Consultation. WHO Technical Report Series 894.;Geneva 2000.

15 WHO. Physical status: the use and interpretation of anthropometry. Report of a WHO Expert Committee. WHO Technical Report Series 854; Geneva 1995.

16 Maska L, Anderson J, Michaud K. Measures of functional status and quality of life in rheumatoid arthritis: Health Assessment Questionnaire Disability Index (HAQ), Modified Health Assessment Questionnaire (MHAQ), Multidimensional Health Assessment Questionnaire (MDHAQ), Health Assessment Questionnaire II (HAQ-II), Improved Health Assessment Questionnaire (Improved HAQ), and Rheumatoid Arthritis Quality of Life (RAQoL). Arthritis Care Res (Hoboken) 2011;63 Suppl 11:S4-13.

17 Bruce B, Fries JF. The Stanford Health Assessment Questionnaire: dimensions and practical applications. Health Qual Life Outcomes 2003;1:20.

18 Prevoo ML, van 't Hof MA, Kuper HH, van Leeuwen MA, van de Putte LB, van Riel PL. Modified disease activity scores that include twenty-eight-joint counts. Development and validation in a prospective longitudinal study of patients with rheumatoid arthritis. Arthritis Rheum 1995;38(1):44-8.

19 Dougados M, Simon P, Braun J, et al. ASAS recommendations for collecting, analysing and reporting NSAID intake in clinical trials/epidemiological studies in axial spondyloarthritis. Ann Rheum Dis 2011;70(2):249-51.

20 Wolfe F, Michaud K, Li T, Katz RS. Chronic conditions and health problems in rheumatic diseases: comparisons with rheumatoid arthritis, noninflammatory rheumatic disorders, systemic lupus erythematosus, and fibromyalgia. J Rheumatol 2010;37(2):305-15.

21 Pollard LC, Choy EH, Gonzalez J, Khoshaba B, Scott DL. Fatigue in rheumatoid arthritis reflects pain, not disease activity. Rheumatology (Oxford) 2006;45(7):885-9. 
22 Europe in figures -Eurostat yearbook (http://ec.europa.eu/eurostat) [database on the Internet, cited July, 2015] 2015.

23 Human Development Report 2013 (http://hdr.undp.org/en/data) [database on the Internet cJ, 2014].

24 World Data Bank G-I-hdwodvrtasbg-i, [database on the Internet, cited June, 2014].

25 World Atlas - sort by capital city per country http://www.worldatlas.com/aatlas/findlatlong.htm dotl, cited June, 2014].

26 StataCorp. 2011. Stata Statistical Software: Release 12. College Station TSL.

27 Sokka T, Kautiainen H, Toloza S, et al. QUEST-RA: quantitative clinical assessment of patients with rheumatoid arthritis seen in standard rheumatology care in 15 countries. Ann Rheum Dis 2007;66(11):1491-6.

28 Minnok P., MCKee G., Bresnihan B., Fitzgerald O., D.J. V. How Much Is Fatigue Explained by Standard Clinical Characteristics of Disease Activity in Patients With Inflammatory Arthritis? A Longitudinal Study. Arthritis Care Res 2014;66(11):1597-603.

29 Campbell RC, Batley M, Hammond A, Ibrahim F, Kingsley G, Scott DL. The impact of disease activity, pain, disability and treatments on fatigue in established rheumatoid arthritis. Clin Rheumatol 2012; 31(4): 717-22.

30 Pouchot J, Kherani RB, Brant R, et al. Determination of the minimal clinically important difference for seven fatigue measures in rheumatoid arthritis. J Clin Epidemiol 2008;61(7):705-13.

31 Wells G, Li T, Maxwell L, MacLean R, Tugwell P. Determining the minimal clinically important differences in activity, fatigue, and sleep quality in patients with rheumatoid arthritis. J Rheumatol 2007;34(2):280-9.

32 Putrik P, Ramiro S, Keszei AP, et al. Lower education and living in countries with lower wealth are associated with higher disease activity in rheumatoid arthritis: results from the multinational COMORA study. Ann Rheum Dis 2015.

33 Putrik P, Ramiro S, Kvien TK, et al. Inequities in access to biologic and synthetic DMARDs across 46 European countries. Ann Rheum Dis 2014;73(1):198-206.

34 McKenna SP, Doward LC. The translation and cultural adaptation of patient-reported outcome measures. Value Health 2005;8(2):89-91.

35 Breugelmans R. Dangers in using translated medical questionnaires: the importance of conceptual equivalence across languages and cultures in patient-reported outcome measures. Chest 2009;136(4): 1175-7.

36 Radbruch L, Strasser F, Elsner F, et al. Fatigue in palliative care patients -- an EAPC approach. Palliat Med 2008;22(1):13-32.

37 Hewlett S, Dures E, Almeida C. Measures of fatigue: Bristol Rheumatoid Arthritis Fatigue MultiDimensional Questionnaire (BRAF MDQ), Bristol Rheumatoid Arthritis Fatigue Numerical Rating Scales (BRAF NRS) for severity, effect, and coping, Chalder Fatigue Questionnaire (CFQ), Checklist Individual Strength (CIS2OR and CIS8R), Fatigue Severity Scale (FSS), Functional Assessment Chronic Illness Therapy (Fatigue) (FACIT-F), Multi-Dimensional Assessment of Fatigue (MAF), Multi-Dimensional Fatigue Inventory $(\mathrm{MFI})$, Pediatric Quality Of Life (PedsQL) Multi-Dimensional Fatigue Scale, Profile of Fatigue (ProF), Short Form 36 Vitality Subscale (SF-36 VT), and Visual Analog Scales (VAS). Arthritis Care Res (Hoboken) 2011;63 Suppl 11:S263-86. 


\section{Chapter}

In wealthier countries, patients perceive worse impact of the disease although they have lower objectively assessed disease activity: results from the crosssectional COMORA study

P. Putrik, S. Ramiro, M. Hifinger, A.P. Keszei, I. Hmamouchi, M. Dougados, L. Gossec, A. Boonen Ann Rheum Dis. 2016;75(4):715-720 


\section{Abstract}

\section{Objectives}

To investigate patterns in patient-reported and physician-reported disease outcomes in patients with rheumatoid arthritis (RA) from countries with different level of socioeconomic development.

\section{Methods}

Data from a cross-sectional multinational study (COMOrbidities in RA) were used. Contribution of socio-economic welfare (gross domestic product (GDP); low vs. high) of country of residence to physician reported (tender joint count, swollen joint count (SJC), erythrocyte sedimentation rate, disease activity score based on 28 joints assessment (DAS28)-3v based on these three components and physician global assessment) and patient-reported (modified Health Assessment Questionnaire (mHAQ), patient global assessment and fatigue) disease outcomes was explored in linear regressions, adjusting for relevant confounders.

\section{Results}

In total, 3920 patients with RA from 17 countries (30 to 411 patients per country) were included, with mean age of 56 years (SD 13) and $82 \%$ women. Mean SJC varied between 6.7 (Morocco) and 0.9 (The Netherlands), mean mHAQ ranged between 0.7 (Taiwan) and 1.5 (The Netherlands). Venezuela had the lowest (1.7) and the Netherlands the highest score on fatigue (5.0). In fully adjusted models, lower GDP was associated with worse physician-reported outcomes (1.85 and 2.84 more swollen and tender joints, respectively, and 1.0 point higher DAS28-3v), but only slightly worse performance-based patient-reported outcome ( 0.15 higher $\mathrm{mHAQ}$ ), and with better evaluation-based patient-reported outcomes ( 0.43 and 0.97 points lower on patient global assessment and fatigue, respectively).

\section{Conclusions}

In patients with RA, important differences in physician-reported and patient-reported outcomes across countries were seen, with overall a paradox of worse physicianreported outcomes but better patient-reported outcomes in low-income countries, while results indicate that these outcomes in multinational studies should be interpreted with caution. Research on explanatory factors of this paradox should include nondisease driven cultural factors influencing health. 


\section{Background}

Inequalities in health of patients with rheumatoid arthritis (RA) between countries with high and low welfare have been reported; however, evidence remains scarce. ${ }^{1,2}$ The few studies that compared health-related outcomes in patients with RA across countries mainly addressed the disease activity. Sokka et al. ${ }^{1}$ showed in 6004 patients enrolled in the Quantitative Patient Questionnaires in Standard Monitoring of Patients with RA (QUEST-RA), an inverse relation between disease activity score based on 28 joints assessment (DAS28) and gross domestic product (GDP) per capita. Putrik et al. confirmed this in fully adjusted analyses in a different multinational study. ${ }^{2}$ Another study compared fatigue in patients in the UK and the US and revealed significant cultural differences in how patients and their environment perceive RA-related fatigue. ${ }^{3}$ For other core RA outcomes, including physician and patient global assessment, physical function, ${ }^{4,5}$ to our knowledge only data from (QUEST-RA) are available and analyses suggested that patients in less wealthy societies tended to score worse on all of these outcomes. Few studies outside RA have shown that reporting of pain depends on cultural background of patients. ${ }^{6-9}$

Commonly, disease outcomes are referred to as physician-reported (such as DAS28 and its components tender joint count (TJC), swollen joint count (SJC), erythrocyte sedimentation rate (ESR)) or patient-reported outcomes (e.g. fatigue). In studies on inequalities in outcomes in RA across countries, it has never been explored whether physician-reported and patient-reported outcomes in patients with RA follow the same patterns across (groups of) countries. This is relevant when interpreting results from multinational studies and also to gain insight into factors contributing to different types of outcomes.

The aim of this study was to investigate the patterns in physician-reported and patientreported health outcomes in patients with RA from countries with different level of socio-economic development.

\section{Methods}

\section{Study design and data collection}

Data from a cross-sectional multinational (17 countries) observational study, COMOrbidities in RA (COMORA), were used. ${ }^{10}$ Consecutive outpatients were invited to enrol in the study if they were aged $\geq 18$ years, fulfilled the 1987 American College of Rheumatology classification criteria for $\mathrm{RA}^{11}$ and were able to understand and complete the questionnaires that were administered. ${ }^{10}$ 
Data on demographic (age and gender), socio-economic (education: primary, secondary or university education), comorbidities, disease duration (in years) and currently prescribed medication (synthetic and biological disease-modifying anti-rheumatic drugs (sDMARD and bDMARDs), non-steroidal anti-inflammatory drugs (NSAIDs) and glucocorticoids) were collected. From information on comorbidities the Rheumatic Diseases Comorbidity Index (RDCl) was computed. ${ }^{2,12,13}$

Information on GDP per capita (adjusted for purchasing power parity, measured in international dollars) was extracted from the International Monetary Fund for $2011 .^{14}$ GDP was dichotomised in low-GDP and high-GDP countries, with a cut-off at 20000 international \$ per capita, which was the threshold that discriminated best between groups after visual data inspection.

\section{Outcome variables}

The following outcomes were investigated: physician-reported outcomes (TJC, SJC, ESR and DAS28 computed from these three assessments (DAS-3v) and physician global assessment) and patient-reported outcomes (modified Health Assessment Questionnaire (mHAQ; 0-3), ${ }^{15,16}$ patient global assessment (0-10) and fatigue (0-10)). Finally, the DAS28 including patient global (DAS28-4v) was considered as a mixed measure. ${ }^{17}$

\section{Statistical analysis}

Linear regression models were computed to explore the contribution of individual countries (reference was always the country with lowest mean on variable of interest) and GDP (low vs. high) to each of the outcomes. All models were adjusted for potentially relevant confounders, including age (years), gender (female vs. male), education (three categories) and comorbidities (continuous RDCl score) and repeated with and without adjustment for current RA medication (steroids (yes/no), NSAIDs and DMARDs (yes/no)) to evaluate potential impact of medication use on the outcome. When perception-based and evaluation-based measures were the outcomes, models were adjusted for TJC, SJC and ESR. Statistical software Stata V.12 was used. ${ }^{18}$

\section{Results}

In total, 3920 patients with RA from 17 countries (range 30-411) were included in COMORA (mean age 56 years (SD 13; 82\% women; Table 3.1). Mean SJC varied between 6.7 (Morocco) and 0.9 (The Netherlands), mean mHAQ ranged between 0.7 (Taiwan) 
and 1.5 (The Netherlands), Venezuela had the lowest and the Netherlands the highest average scores on fatigue (1.7 and 5.0, respectively; Table 3.1 and Figure 3.1). For details on missing data, see Supplementary Table S1, available online.

\section{Differences in outcomes across countries}

In models with country of residence as independent variable and adjusted for all confounders including medication, large variations in outcomes across countries were observed ( $p$ value $<0.001$ ). Adjusted for potential confounders and compared with the Netherlands, SJC varied from +0.9 (95\% Cl 0.1 to 1.7 ) in Germany to +5.8 (5.0 to 6.6) in Morocco. Adjusted differences in mHAQ reached 0.7 points, from 0.2 (0.1 to 0.3 ) in Korea to 0.9 (0.8 to 1.0) in Morocco (compared with Taiwan) and adjusted fatigue (compared with Venezuela) 1.8 (1.3 to 2.3) in Spain to 3.8 (3.2 to 4.4) in the Netherlands (Figure 3.1).

\section{Differences in outcomes according to GDP}

When replacing country by GDP in fully adjusted models, patients from low-GDP countries had on average 1.9 and 2.8 more swollen and tender joints, respectively, $11 \mathrm{~mm} / \mathrm{h}$ higher ESR and 1.0 point higher DAS28-3v (Table 3.2). Similarly, mHAQ was 0.15 higher in countries with low GDP. However, patients from low GDP societies had a 0.43 and 0.15 lower score on patient and physician global assessment, respectively, and 0.97 lower score on fatigue compared with high-GDP countries. For the mixed outcome DAS28-4v, low-GDP countries scored 0.94 points higher than the high-GDP countries. Change in coefficients after excluding medication from the models did not exceed $10 \%$ (Table 3.2). Because of many missing values in physician global assessment in the Netherlands, we have repeated the regression models with this outcome excluding all the patients from the Netherlands and observed no substantial changes in the models. Disease duration was not a confounder in relationship between the GDP and the outcomes (data not shown). Secondary analyses using a random effects model gave essentially the same results (data not shown). 


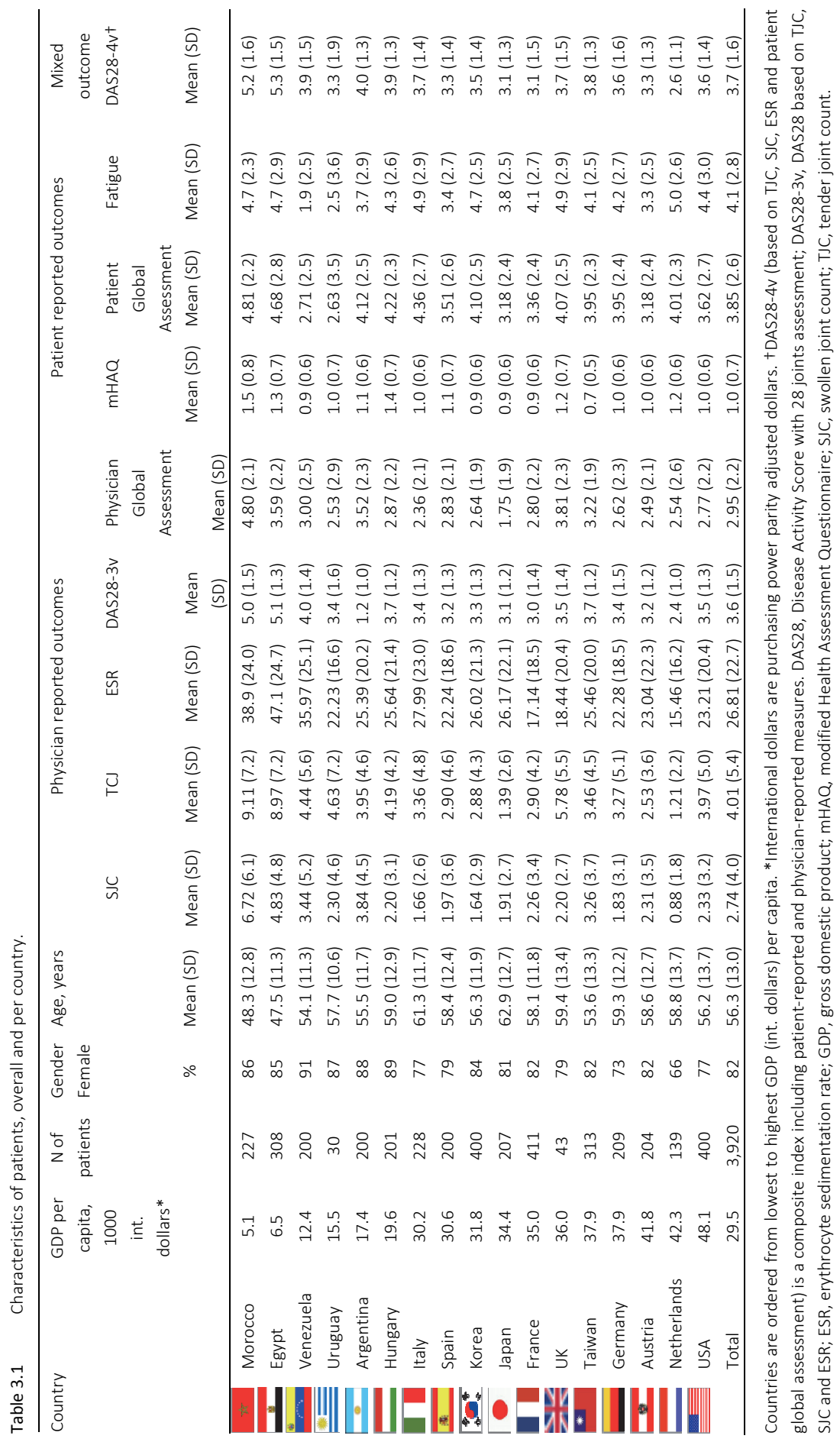


A

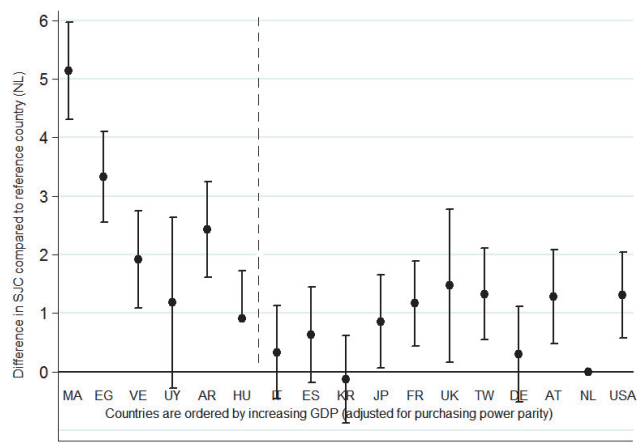

B
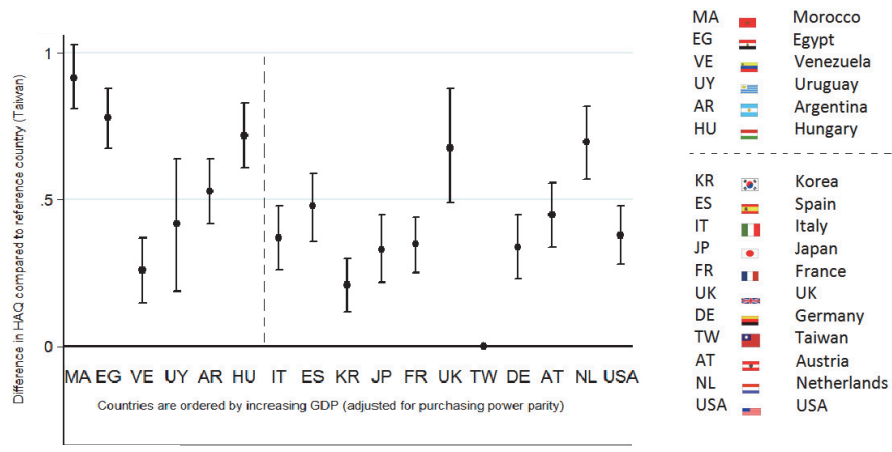

C

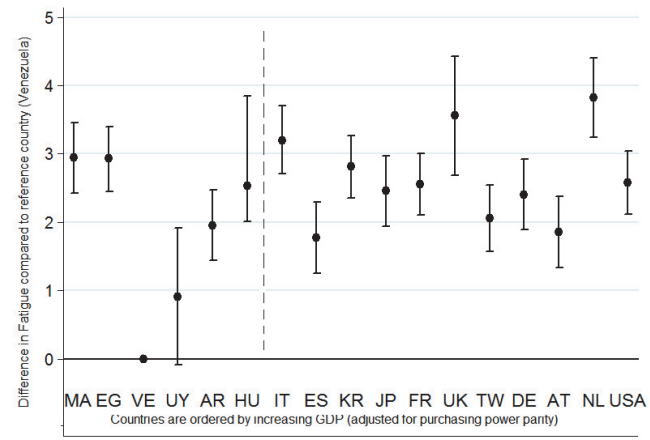

Figure 3.1 Differences in swollen joint count (SJC; A), physical function (modified Health Assessment Questionnaire (mHAQ); B) and fatigue (C) across countries. Estimates are derived from models adjusted for age, gender, education, comorbidities and medication. The $Y$ axis (or the deviation from the zero-line) presents the (adjusted) difference with the reference country (always the country with lowest mean on the variable of interest). Countries are ordered from lowest to highest gross domestic product (GDP) per capita (in international dollars), dashed line indicates border between high and low GDP group of countries. 
Table 3.2 Association between performance, perception and evaluation-based outcomes with GDP, results from multivariable model.

\begin{tabular}{|c|c|c|c|}
\hline \multirow[t]{2}{*}{$\begin{array}{l}\text { Type of the } \\
\text { outcome }\end{array}$} & \multirow[t]{2}{*}{ Variable } & \multicolumn{2}{|c|}{$\begin{array}{c}\text { GDP (low vs. high) } \\
\beta[95 \% \text { Confidence Interval] }\end{array}$} \\
\hline & & $\begin{array}{l}\text { Model including } \\
\text { medication* }\end{array}$ & $\begin{array}{l}\text { Model excluding } \\
\text { medicationt }\end{array}$ \\
\hline \multirow{5}{*}{$\begin{array}{l}\text { Physician } \\
\text { reported } \\
\text { outcomes }\end{array}$} & Tender Joint Count (0-28) & $2.84[2.47$ to 3.22$]$ & $2.94[2.57$ to 3.31$]$ \\
\hline & Swollen Joint Count (0-28) & 1.851 .57 to 2.13$]$ & 1.90 [1.62 to 2.18$]$ \\
\hline & $\mathrm{ESR}(\mathrm{mm} / \mathrm{hr})$ & 11.49 [9.89 to 13.09$]$ & 12.17 [10.57 to 13.77$]$ \\
\hline & DAS28 3v, without PatGA (0-10) & 0.98 [0.88 to 1.08$]$ & 1.02 [0.92 to 1.12$]$ \\
\hline & Physician Global Assessment (0-10) & $-0.15[-0.27$ to -0.03$]$ & $-0.20[-0.32$ to -0.08$]$ \\
\hline \multirow{3}{*}{$\begin{array}{l}\text { Patient reported } \\
\text { outcomes }\end{array}$} & mHAQ (0-3) & 0.15 [0.10 to 0.19$]$ & 0.13 [0.08 to 0.17$]$ \\
\hline & Patient Global Assessment (0-10) & $-0.43[-0.60$ to -0.26$]$ & $-0.46[-0.63$ to -0.29$]$ \\
\hline & Fatigue $(0-10)$ & $-0.97[-1.17$ to -0.77$]$ & $-1.02[-1.21$ to -0.82$]$ \\
\hline Mixed outcome & DAS28 4v $(0-10) \ddagger$ & 0.94 [0.84 to 1.05$]$ & 0.99 [0.88 to 1.09$]$ \\
\hline
\end{tabular}

All models are adjusted for age, gender, education and comorbidities. Models with performance and perception-based outcomes are additionally adjusted for SJC, TJC and ESR. *n from 3521 to 3790. in from 3521 to 3812 . ҒDAS28-4v includes SJC, TJC, ESR and patient global assessment. DAS28, disease activity score with 28 joints assessment; ESR, erythrocyte sedimentation rate; GDP, gross domestic product; $\mathrm{mHAQ}$, modified Health Assessment Questionnaire; PatGA, patient global assessment; SJC, swollen joint count; TJC, tender joint count.

\section{Discussion}

The present study showed that patients from countries with lower socio-economic welfare score worse on most of physician-reported measures for disease activity (SJC, TJC, ESR or DAS28 based on these three components) and on perceived difficulties in physical functioning ( $\mathrm{mHAQ}$ ). Differences in DAS28 seem to be highly relevant while magnitude of variation in $\mathrm{mHAQ}$ was less pronounced but not negligible. ${ }^{19,20}$ Paradoxically, patients in poorer societies evaluated their patient global assessment and fatigue similar to or better compared with wealthy countries, although the absolute differences were smaller.

Explaining the paradox is not straightforward. The higher disease activity in poorer countries was previously observed and attributed partly to availability of innovative biological DMARDs but also delay in diagnosis and access to rheumatological care may play a role. ${ }^{1,2}$ On this line, it is not unexpected that patients report more difficulties with daily tasks and activities (measured by $\mathrm{mHAQ}$ ) as disease activity has a strong influence on execution of tasks. However, it would be expected that these patients would evaluate 
their global disease activity as being worse and would experience more fatigue. ${ }^{21}$ Clearly, this is not the case. One might also think that DMARDs induced fatigue, but results persisted after adjusting for current pharmacological treatment (including sDMARDs and bDMARDs), excluding this possibility. Apparently, non-disease factors play a role. Lower income societies may set less pressure with regard to execution of multiple social roles. Withdrawal from social roles due to sickness and reliance on extended family for care may be more acceptable than in wealthier but more individualistic societies. Moreover, in low-income countries, patients may be less informed about treatment options, have lower expectations from the treatment and more likely accept the achieved outcomes, while patients in high-income countries may be overoptimistic about the potential of the new treatments to improve all the disease outcomes. ${ }^{21}$ Physician's attitude may also, although unconsciously, be more optimistic in lower income countries as they live in an environment where the overall standards of health is lower. This can make them to judge the global health of patients slightly better and also to trigger higher satisfaction among their patients.

Interestingly, the differences between high-GDP and low-GDP countries in patient global assessment are higher than differences in physician global assessment, which were negligibly small. Since the models with perceived and evaluated outcomes were adjusted for TJC, SJC and ESR, it appears that physicians mostly base their judgement on these objective parameters, while patient's assessment is likely more subjective and takes other contextual and cultural factors into account. ${ }^{22}$

This study has several limitations. First, studies like COMORA cannot guarantee a representative sample of the patients with RA in participating countries. Centres with research interest in RA are more likely to participate, which leads to an overrepresentation of the optimally treated group in each country. Second, GDP is an aggregated measure (at country level) and is only a remote proxy for the countries socioeconomic welfare. However, it is commonly used in international studies. Next, crosssectional design hinders conclusions about the direction of associations. Nonetheless, it is plausible to suggest that macro-economic indicators are relatively stable compared with health indicators and can be assumed to precede the outcomes in our study. It is important to note that differences between countries may go unnoticed for patients within the country, particularly if no large within country differences exist, and thus the value of international studies like COMORA should not be underestimated.

While differences in objective or performance-based measures across countries remain the greatest concern as they point at existing health inequities, variations in subjective evaluation-based outcomes are important and deserve further investigation. Future research should focus more on how non-disease-driven cultural and other contextual factors impact objectively measured and experienced heath. If confirmed, these results 
suggest to stratify international trial results for country or to examine the interaction between country and treatment effect.

Supplementary tables are published online on http://ard.bmj.com/ 


\section{References}

1. Sokka T, et al. Disparities in rheumatoid arthritis disease activity according to gross domestic product in 25 countries in the QUEST-RA database. Ann Rheum Dis 2009;68(11):1666-72.

2. Putrik $P$, et al. Lower education and living in countries with lower wealth are associated with higher disease activity in rheumatoid arthritis: results from the multinational COMORA study. Ann Rheum Dis 2016;75(3):540-6.

3. Hewlett $\mathrm{S}$, et al. Patients' perceptions of fatigue in rheumatoid arthritis: overwhelming, uncontrollable, ignored. Arthritis Rheum 2005;53(5):697-702.

4. Boers $\mathrm{M}$, et al. World Health Organization and International League of Associations for Rheumatology core endpoints for symptom modifying antirheumatic drugs in rheumatoid arthritis clinical trials. J Rheumatol Suppl 1994;41:86-9.

5. Kirwan JR, et al. Patient perspective: fatigue as a recommended patient centered outcome measure in rheumatoid arthritis. J Rheumatol 2007;34(5):1174-7.

6. Greenwald HP. Interethnic differences in pain perception. Pain 1991;44(2):157-63.

7. Breivik H, et al. Survey of chronic pain in Europe: prevalence, impact on daily life, and treatment. Eur J Pain 2006;10(4):287-333.

8. Juarez G, Ferrell B, Borneman T. Influence of culture on cancer pain management in Hispanic patients. Cancer Pract 1998;6(5):262-9.

9. Callister LC, et al. The pain of childbirth: perceptions of culturally diverse women. Pain Manag Nurs 2003;4(4):145-54.

10. Dougados $\mathrm{M}$, et al. Prevalence of comorbidities in rheumatoid arthritis and evaluation of their monitoring: results of an international, cross-sectional study (COMORA). Ann Rheum Dis 2014;73(1): 62-8.

11. Arnett FC, et al. The American Rheumatism Association 1987 revised criteria for the classification of rheumatoid arthritis. Arthritis Rheum 1988;31(3):315-24.

12. Wolfe $\mathrm{F}$, et al. Chronic conditions and health problems in rheumatic diseases: comparisons with rheumatoid arthritis, noninflammatory rheumatic disorders, systemic lupus erythematosus, and fibromyalgia. J Rheumatol 2010;37(2):305-15.

13. England BR, et al. Validation of the Rheumatic Disease Comorbidity Index. Arthritis Care Res 2015; 67(6):865-72.

14. IMF, World Economic Outlook Database (http://www.imf.org/external/pubs/ft/weo/2011/02/weodata/index.aspx). 2011.

15. Uhlig T, Haavardsholm EA, Kvien TK. Comparison of the Health Assessment Questionnaire (HAQ) and the modified HAQ (MHAQ) in patients with rheumatoid arthritis. Rheumatology (Oxford) 2006;45(4):454-8.

16. Pincus $T$, et al. Assessment of patient satisfaction in activities of daily living using a modified Stanford Health Assessment Questionnaire. Arthritis Rheum 1983;26(11):1346-53.

17. Prevoo ML, et al. Modified disease activity scores that include twenty-eight-joint counts. Development and validation in a prospective longitudinal study of patients with rheumatoid arthritis. Arthritis Rheum 1995;38(1):44-8.

18. StataCorp. 2011. Stata Statistical Software: Release 12. College Station, TX: StataCorp LP.

19. Wells GA, et al. Minimum important difference between patients with rheumatoid arthritis: the patient's perspective. J Rheumatol 1993;20(3):557-60.

20. van Gestel AM, et al. Development and validation of the European League Against Rheumatism response criteria for rheumatoid arthritis. Comparison with the preliminary American College of Rheumatology and the World Health Organization/International League Against Rheumatism Criteria. Arthritis Rheum 1996;39(1):34-40.

21. Campbell RC, et al. The impact of disease activity, pain, disability and treatments on fatigue in established rheumatoid arthritis. Clin Rheumatol 2012;31(4):717-22.

22. Khan NA, et al. Determinants of discordance in patients' and physicians' rating of rheumatoid arthritis disease activity. Arthritis Care Res (Hoboken) 2012;64(2):206-14. 


\section{Chapter 4}

Equivalence in the health assessment questionnaire (HAQ) across socio-demographic determinants: analyses within QUEST-RA

M. Hifinger, S. Norton, S. Ramiro, P. Putrik, T. Sokka-Isler, A. Boonen Semin Arthritis Rheum, 2017; doi: 10.1016/j.semarthrit.2017.08.003.

[Epub ahead of print] 


\section{Abstract}

\section{Objectives}

To investigate potential bias in scores of the Health Assessment Questionnaire (HAQ) related to socio-demographic (SD) background of patients with rheumatoid arthritis (RA).

\section{Methods}

Data from the Quantitative Standard Monitoring of Rheumatoid Arthritis study (QUESTRA), comprising 9,022 patients were analysed. Physical function was assessed through 30 items of four $\mathrm{HAQ}$ versions: the HAQ-Disability scale, $\mathrm{HAQ}-\mathrm{II}$, modified $\mathrm{HAQ}$ and multidimensional HAQ (MD-HAQ). Differential item functioning (DIF) was investigated using item response theory models implemented in a latent variable modelling framework. Models were equivalent to ordinal logistic regression models with $\mathrm{HAQ}$ score (item level) as outcome, the latent trait 'physical function' and individual SD factors (age, gender, education and employment status) as predictors. Next, scores of composite HAQs were adjusted for DIF. To assess the impact of DIF on associations between SD factors and HAQs, multilevel mixed-effect linear regression models with individuals nested in country were estimated with DIF-adjusted or unadjusted HAQ as outcome.

\section{Results}

Relevant DIF (OR $\geq 1.1$ or $\leq 0.90$ ) was found in several HAQ items, primarily for age, gender and work-status. Adjustment of composite HAQs for DIF resulted in small increases $(\triangle 0.02-0.07), M D-H A Q$ best compensated for bias related to SD factors $(\triangle 0.02)$. In regressions, all SD factors remained significantly related to DIF-adjusted $H A Q s$, with differences in coefficients largest for gender $(\Delta 0.02-0.07)$ but overall negligible.

\section{Conclusions}

SD factors produce response bias in individual $\mathrm{HAQ}$ items but have little impact on composite HAQs. When interpreting HAQ across SD factors, MD-HAQ is preferred, but caution remains when comparing function across gender. 


\section{Introduction}

Rheumatoid arthritis (RA) is a chronic inflammatory disease associated with varying impairments in daily tasks and activities. ${ }^{1}$ In the traditional biomedical paradigm, severity and impact of rheumatic diseases have been mainly assessed using objective measures such as erythrocyte sedimentation rate (ESR), painful and swollen joint counts and radiographic damage. To better understand the impact of the disease on the life of patients, patient-reported outcomes (PRO) have been developed. The Health Assessment Questionnaire (HAQ) was among the first patient-reported disability measures validated for use in RA and has become the dominant instrument for assessment of physical function of RA patients in clinical practice and research worldwide. ${ }^{2-4} \mathrm{HAQ}$ is a predictor of several outcomes including work participation and mortality. ${ }^{5,6}$ Numerous studies provided evidence that variation in HAQ can be explained by (fluctuations in) disease activity as well as by (more permanent) radiographic damage. ${ }^{7,8}$

Today, a number of validated versions of the $\mathrm{HAQ}$ exist. For several decades the original (Stanford HAQ), often also referred to as HAQ Disability Index (HAQ-DI), 10, has been considered the gold standard to measure physical function in RA. However, with 8 domains and overall 41 items, the length of the questionnaire makes its use in clinical practice rather difficult, leading to the development of additional versions of the $H A Q$, intended to be easier to score with better or equal psychometric properties. The modified HAQ (MHAQ) ${ }^{11}$ is a $\mathrm{HAQ}$ version that has a substantially reduced number of items (8 compared to 41) and a simplified scoring system. Another simplified version of the $\mathrm{HAQ}$, called multi-dimensional (MD-HAQ) $)^{2}$ consisting of 10 items has been designed to better detect improvements in function at the lower end of the scale as compared to the MHAQ and incorporates additional items relating to psychological functioning. Addressing this floor effect has become particularly important with increasing efforts to achieve early diagnosis and the paradigm shift towards early treatment. Another version of the $\mathrm{HAQ}, \mathrm{HAQ} \|^{12}$ has also been implemented in an attempt to correct the floor effects seen with earlier modifications of the HAQ using a different methodological development approach compared to MD-HAQ. HAQ-II consists of 10 items and is now among the most frequently used $\mathrm{HAQ}$ versions. ${ }^{13}$

There is increasing awareness that socio-demographic (SD) factors can have an important impact on RA outcomes. ${ }^{14-19}$ The magnitude of health disparities related to SD background of patients has been the focus of public policy interest as some of them might be avoidable. ${ }^{20}$ With regard to $\mathrm{HAQ}$, a number of studies in RA found relevant differences in $\mathrm{HAQ}$ related to education ${ }^{16}$ or gender. ${ }^{14}$ However, little research has determined the extent to which these observed differences relate to true differences in 
physical function between SD groups, or are simply caused by biased item responses between SD groups leading to systematically biased interpretation of findings.

A common technique to investigate response bias across items is the analysis of differential item functioning (DIF). DIF occurs when an individual item included in a PRO performs differently for one subgroup (e.g. female) than it does for another (e.g. male) at the same level of the construct it is intended to measure (e.g. physical function). That is to say, the item may be confounded by gender since a person's response to the item may not solely depend on the underlying level of disability.

Despite the widespread use of the $\mathrm{HAQ}$, relatively few studies have investigated DIF for the HAQ items ${ }^{1,21-23}$ and no systematic attention has been given to DIF across different SD groups. Insight into the presence and magnitude of DIF is relevant when interpreting differences in HAQ outcomes between SD determinants and investigating inequalities or inequities in RA care. We hypothesize that bias will be present across several HAQ items. More specifically, we expect that for the same level of physical function, women, elderly, lower educated and employed persons may experience more difficulty with more strenuous activities affecting mainly the lower limbs. As the HAQ-DI contains the fewest number of items addressing strenuous (lower limb) activities, we expect the HAQ-DI to be least sensitive to the influence of DIF. However, we have no specific expectations about the magnitude of the effect for the total HAQ score, nor about the extent to which DIF can explain the influence of the patient's SD background on HAQ. In the present study we therefore aimed at investigating potential bias among RA patients in the assessment of physical function across four different versions of the HAQ using DIF. For the analysis, data from QUEST-RA were used to understand presence, magnitude and relevance of measurement equivalence across a number of SD determinants.

The Quantitative Standard Monitoring of Rheumatoid Arthritis study (QUEST-RA) ${ }^{24}$ is a multi-centre database that collected SD data as well as extensive data on physical function from more than 10,000 RA patients - a unique setting to undertake the present study.

\section{Materials and methods}

\section{Patients and assessments}

Baseline data from the international, multi-centre observational study QUEST-RA, were collected between the years 2005 and 2012. The dataset included information from 10150 RA patients from 34 countries worldwide. The protocol was approved by all local institutional review boards or ethics committees. Patients were eligible to participate in the study if they were at least 18 years of age and fulfilled the 1987 American College of 
Rheumatology (ACR) classification criteria for RA. Written informed consent was obtained from all subjects before enrolment.

Following preliminary analysis, data from 4 countries (Egypt, Morocco, Serbia and Russia) were excluded from the present analysis. DIF was observed on the country level to the extent that total scores from these countries were potentially non-comparable with other countries. Since DIF at the country level would interfere with results found for SD factors, they have been excluded. ${ }^{25}$

\section{Data collection}

Patients completed a self-reported questionnaire, comprising SD background and clinical disease characteristics (PROs), 0-10 visual analogue scales (VAS, 10 worst outcome) for patient global assessment of disease (PatGA), fatigue and pain. Furthermore, patients underwent a clinical examination to assess tender-and swollen joint count (TJC, SJC), and had a laboratory test assessing ESR, C-reactive protein (CRP) and rheumatoid factor (RF). Data on medication intake, disease duration and comorbidities were collected by attending physicians. ${ }^{24,26,27}$ From the available comorbidities, the Rheumatic Disease Comorbidity Index (RDCl) was calculated. ${ }^{3,28}$ The 28-joint count disease activity score (DAS28) based on 28-swollen and tender joint counts, ESR and PatGA ${ }^{29}$ was computed.

\section{Physical function assessment}

Four frequently applied and validated versions of the HAQ were used to develop the item pool for the patient survey - the original $\mathrm{HAQ}$-DI as well as three revised versions of the $\mathrm{HAQ}$ including the MHAQ, MD-HAQ and $\mathrm{HAQ}-\mathrm{II}$. For each individual $\mathrm{HAQ}$ item, the patient could select among four response categories $(0=$ without any difficulty to $3=$ unable to do). Overall, 30 individual HAQ items were tested in the survey (Table 4.2). Although aids and devices were assessed, these were excluded from the present analyses since they focused on potential bias in the difficulty ratings of the 30 activity items. On the same line, the four items relating to psychological functioning from the MD-HAQ were not used as they target a different dimension than physical functioning.

Of note, the HAQ-DI comprises 20 specific items of physical function and groups them into eight categories (dressing and grooming, arising, eating, walking, hygiene, reach and activities). The highest scores (scale 0-3) per category are used to compute the average $\mathrm{HAQ}$ score across the eight individual items. The revised versions of the HAQ (HAQ-II, $\mathrm{MHAQ}, \mathrm{MD}-\mathrm{HAQ}$ ) reduced the number of items to 10,8 and 10 items, respectively (Table 4.2). Compared to the HAQ-DI, some items were replaced by new items in HAQ-II, MHAQ, MD-HAQ. 
In QUEST-RA, the patient questionnaire (including the individual HAQ items) was translated into each different language by local rheumatologists and translated back into English by professional translators (exceptions: Danish, Finnish and Swedish translation, they were piloted in clinics). Existing official translations of official patient-reported outcomes were used whenever available. More details on the translation process can be found elsewhere. ${ }^{24}$

\section{Demographic and socio-economic factors explored for differential item functioning}

SD determinants of interest available in QUEST-RA included age (in years), gender, work status and level of education. ${ }^{27,30,31}$ Work status (working yes or no) was classified for further analyses into full- and part-time workers, students and homemakers as 'working', whereas patients that were retired or disabled were considered 'not working'. Educational level was assed using the number of years of formal school education.

\section{Statistical analysis}

Item response theory (IRT) models representing the association between an individuals' observed response to an item and the (unobservable) score on an underlying latent variable (e.g. their true level of disability) were estimated using Mplus 7.1. ${ }^{32}$ Specifically, since the HAQ has an ordinal response scale, the estimated models were full information maximum likelihood graded response models. ${ }^{33}$ In simple terms, the baseline model, prior to assessing DIF, involves simultaneously estimating an ordinal logistic regression model for each item regressed onto the latent variable. The model thresholds relate to the item difficulties and the slope the item discrimination. Preliminary analysis examining the fit of the baseline IRT model (not shown) confirmed that all $30 \mathrm{HAQ}$ items formed a unidimensional scale without the need for removing any items.

The overall analysis was conducted in three steps: 1) identifying DIF for individual items, 2) adjusting HAQ version scale scores to remove the confounding effects of DIF, and 3) examining the impact of DIF difference in interpretation for models regressing unadjusted versus DIF-adjusted HAQ scores on SD determinants.

In the first step, DIF by each factors was assessed using the multiple-indicator-multiplecause (MIMIC) model method. ${ }^{34}$ This extends the baseline model to regress item responses onto an additional variable (e.g. age, gender, education or work status) in addition to the latent disability variable. Since disability is controlled for, the odds ratio $(\mathrm{OR})$ relating to the SD factor reflects the direction and magnitude of DIF. For example, an OR of two for female gender indicates that women are twice as likely to report greater difficulty with the activity (e.g. driving) compared to males with the same 
disability level. To facilitate interpretation, ORs for age and education were expressed as standardized ORs. In total, 120 individual models were estimated - one for each HAQ item and SD factor pairing (i.e. 30 items times 4 SD variables). A Benjamini-Hochberg false discovery rate correction for multiple-testing was applied to determine statistically significant DIF. ${ }^{35}$ DIF was considered clinically important when ORs differed from 1 by $10 \%$ or more (OR $\geq 1.1$ or $\leq 0.90$ ), a cut-off frequently used in studies investigating DIF with ordinal logistic regression approaches. ${ }^{36,37}$

In the second step, scores for the four HAQ versions were calculated by estimating separate IRT models including only the subset of items included in each of the four HAQ versions considered. Using the MIMIC method, ${ }^{34}$ item responses were regressed on a latent disability variable and whichever SD factors demonstrated significant and clinically important DIF for the item in the first step. The HAQ-DI has a unique scoring system where, of the 20 items, only those with the highest ratings across eight domains are scored, with further weighting for devices and aids. Since DIF is modelled at the items rather than domain level it is not possible to apply the traditional scoring algorithm. Instead, all 20 items included in the HAQ-DI were used in the IRT MIMIC model. Resulting scores are not directly comparable (i.e. are lower) to those from the traditional HAQ-DI but remove systematic differences that would confound estimates in the following step. Moreover, the scoring of the revised versions of the HAQ avoids this issue, and thus the adjusted scores are more directly comparable when interpreting influence of DIF in our study.

In the final step of the analysis, regression models assessed the degree to which bias at the item level biased the estimates of the association between SD factors and the total scores for each version of the $\mathrm{HAQ}$. The purpose of this step is to demonstrate the impact of DIF using the HAQ in a common analysis and as such determining the degree of bias and demonstrate the validity of other analyses. Separate multilevel linear regression models were estimated for each of the HAQ versions with unadjusted (Model 1, $\mathrm{M}_{1}$ ) and DIF adjusted HAQ (Model 2, $M_{2}$ ) scores as outcome. A random effect was estimated to account for the clustering of patients within countries. The four SD factors assessed for DIF were included as predictors in addition to DAS28 and RDCl. Bias was assessed by comparing the difference in regression coefficients for the SD factors between $M_{1}$ and $M_{2}$. Further assessment of bias was provided by comparing goodnessof-fit using the variance explained by the fixed factors (marginal R-squared). ${ }^{38}$ Relative differences in parameter estimates of $\geq 10 \%$ were considered as indicating relevant bias. ${ }^{39}$ Regression analyses were estimated in Stata $12 .{ }^{40}$ 


\section{Results}

In total, 9,022 patients from 30 countries were included in the final analyses. Mean age of patients was 55.6 years (SD 13.6), 80.8\% were female. On average, patients attended school for 11.0 years (SD 4.1), 54.2\% of patients reported to be working (paid in full or part time or unpaid as student or homemaker). Mean composite HAQ scores (mean across items) were 0.7 (SD 0.7) for HAQ-DI, 0.6 (SD 0.6) for MHAQ, 0.8 (SD 0.6) for MD$\mathrm{HAQ}$ and 1.0 (SD 0.7) for HAQ-II. Further descriptive statistics (overall and per country) can be extracted from Table 4.1.

For each of the SD determinants, important and significant DIF (false discovery rate (FDR) $p<0.05$ and change of standardized $O R \geq 1.1$ or $\leq 0.90$ ) was seen in univariable analysis for several HAQ items (Table 4.2). Age was related to important and significant DIF for 14 of 30 items. Controlling for overall disability, older patients were less likely to indicate difficulty in performing tasks involving hand function (e.g. cut meat, lift cup, open jar, turn faucet) and transfers (e.g. get in/out of bed or on/off the toilet). However, controlling for overall disability, older patients were more likely to indicate difficulty for physically demanding activities, especially when lower limb function is involved (e.g. run or walk 2 miles, climb stairs, do sports or move/lift heavy objects). Of note, these activities were often part of the revised $\mathrm{HAQ}$ versions.

For employment status important and significant DIF was seen in 19 of 30 items. Controlling for overall disability, patients who were in paid or unpaid employment were more likely to report difficulties with tasks involving the hands (e.g. cut meat, open jar) but less likely to report difficulty with more strenuous activities involving lower limb function (e.g. running or walking 2 miles) in univariable analyses.

For gender, important and significant DIF was observed in 23 of 30 HAQ items. Compared to males with the same overall disability, females reported systematically less difficulties for items related to dressing and grooming as well arising, whereas they reported more difficulties for items that require hand strength or are physically more demanding. The highest gender-related DIF was found for driving a car with females experiencing more than twice the likelihood of reporting greater difficulty compared to males despite same overall disability level (OR=2.26).

For education, 10 of 30 items showed significant and important DIF but no clear trend could be observed.

To assess the impact of DIF on overall scores of $\mathrm{HAQ}$, DIF adjusted HAQ scores were estimated for each version. After adjusting, all mean HAQ scores increased $(\Delta+0.02$ to +0.07 , dependent on $\mathrm{HAQ}$ version). The smallest increase was observed for MD-HAQ $(+0.02)$, which best compensated for the item bias resulting from SD background (Table 4.3). 


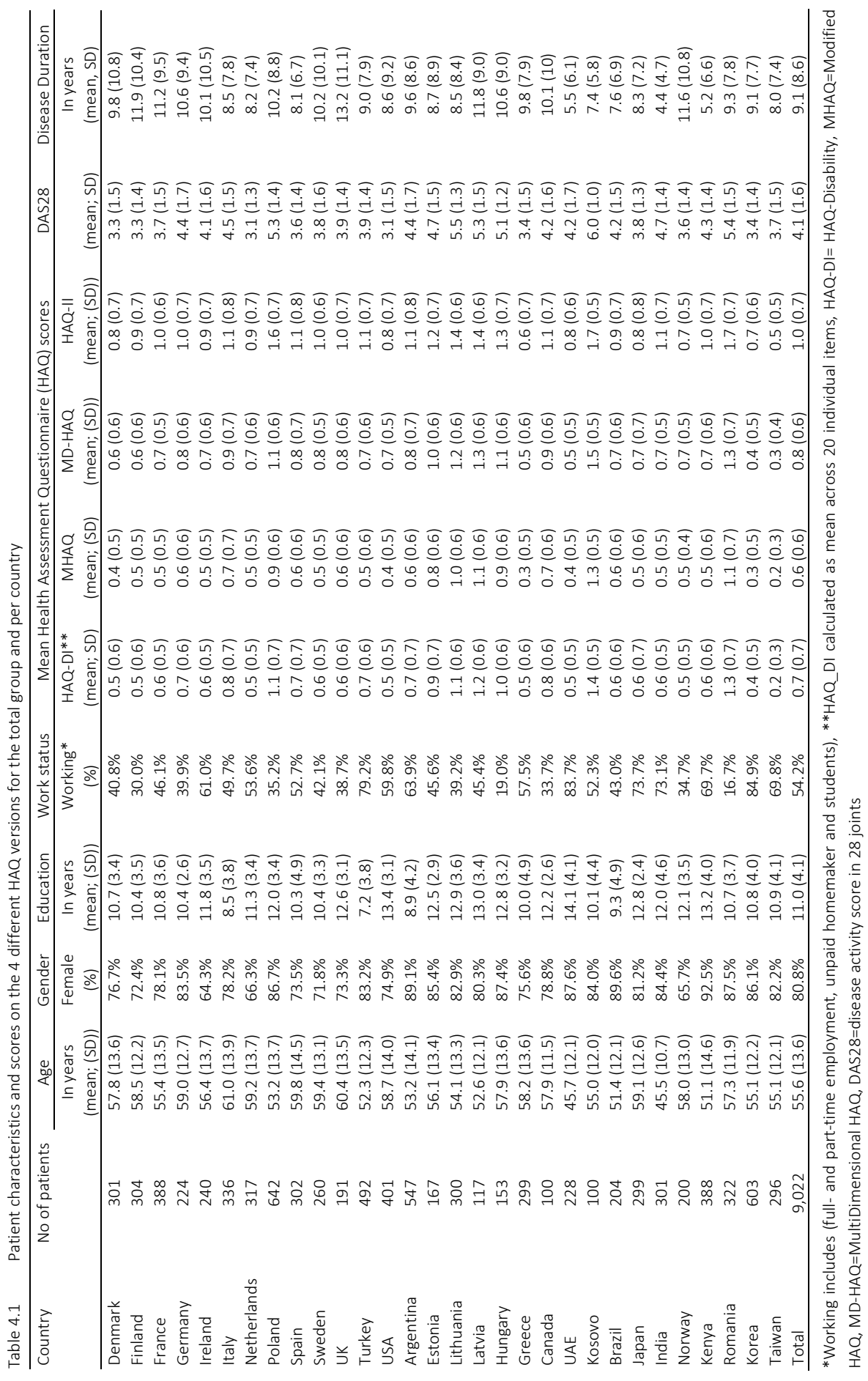




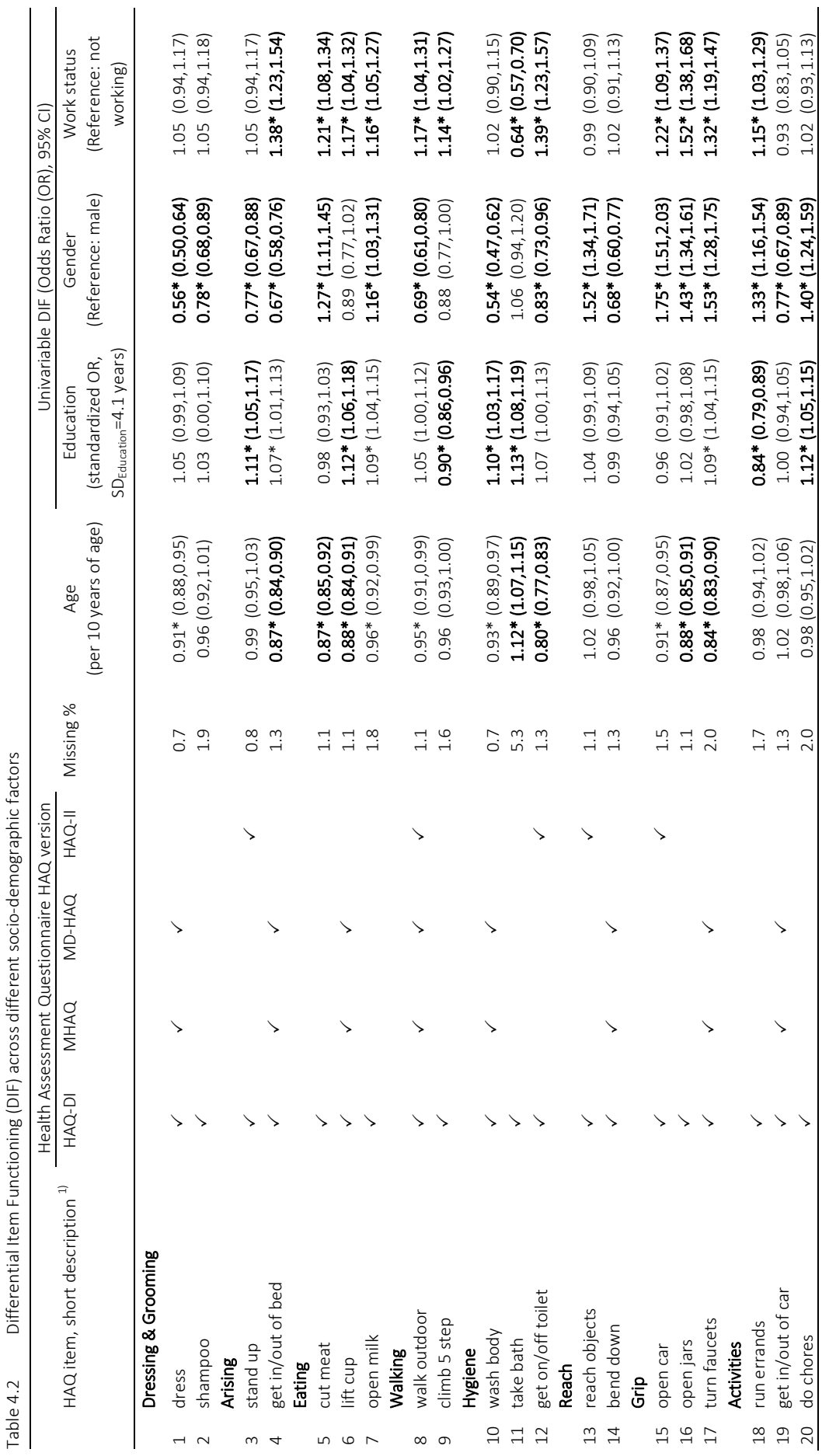




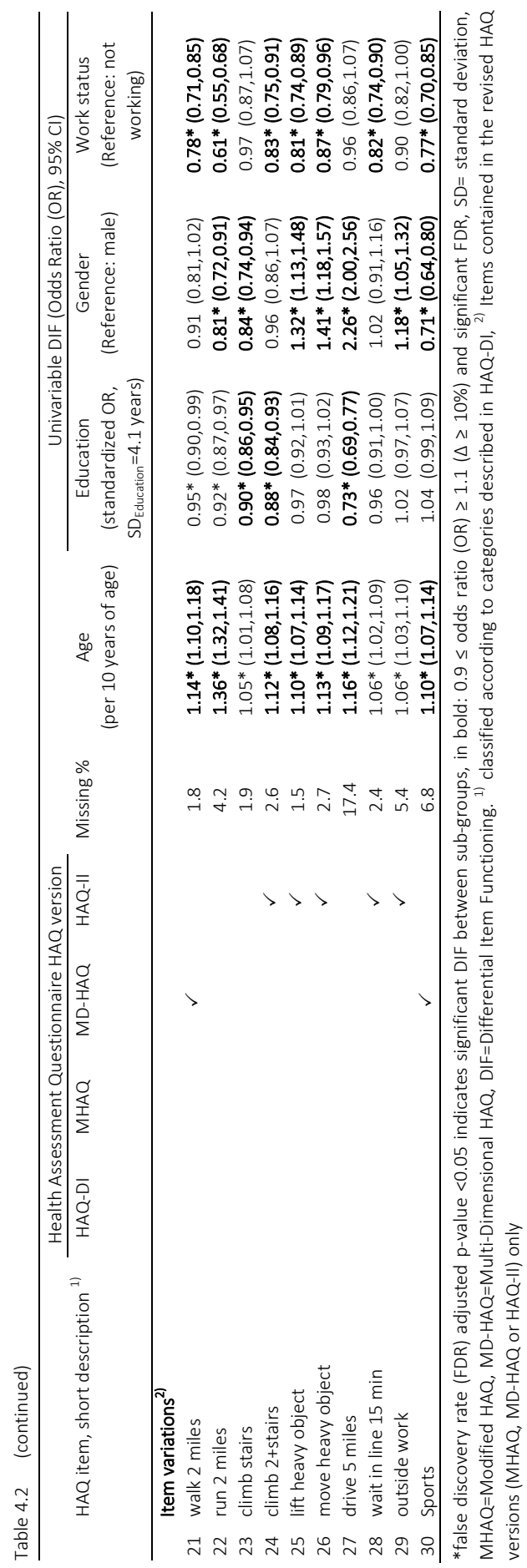




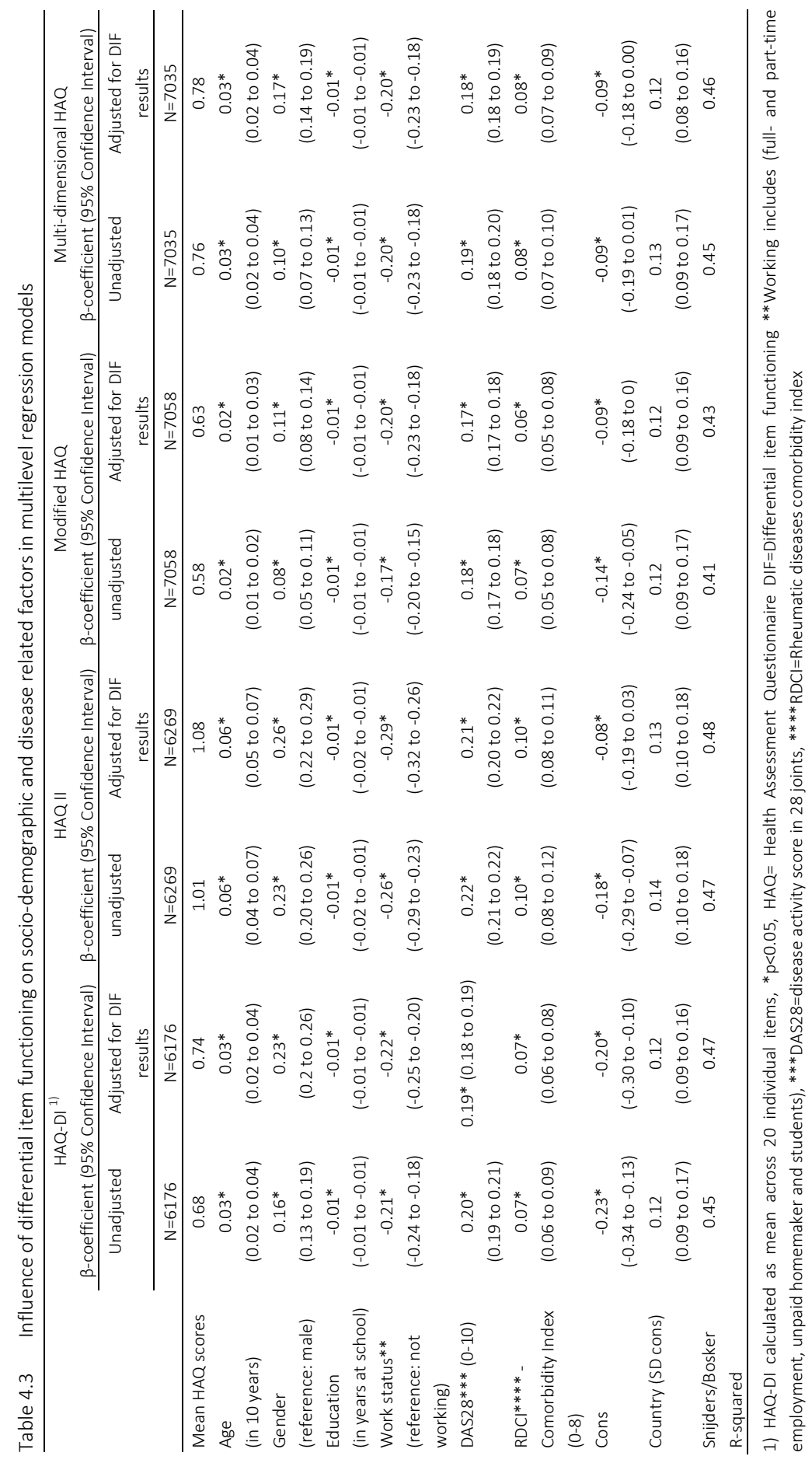


When comparing crude and DIF-adjusted HAQ scores in multilevel regression models, coefficients for gender increased for all $H A Q$ versions $(\triangle \beta:+0.02$ to +0.07 corresponding to relative increases +10 to $70 \%$ ). This increase indicates that effect of DIF between males and females is underestimated, in particular for HAQ-DI and MD-HAQ. Coefficients for education, age, DAS28, RDCl as well as country remained largely unchanged (Table 4.3). Overall model fit consistently increased by 2 to $5 \%$ in relative terms after adjustment of HAQ for DIF, indicating that some systematic measurement error was removed from the total scores (Table 4.3).

\section{Discussion}

The present study revealed that for RA patients, the SD background confounded selfreported difficulties in physical function of various individual $\mathrm{HAQ}$ items across a range of versions of the HAQ. After adjusting for DIF, all composite HAQ scores increased but overall showed good measurement accuracy across different SD groups. The smallest DIF-related changes were observed for MD-HAQ suggesting its use when investigating physical function across different SD groups. Regression analyses revealed that effect of DIF mean differences between males and females were generally underestimated and require some caution when comparing $\mathrm{HAQ}$ outcomes between these groups.

Gender DIF has been detected for a number of health outcomes (e.g. pain, fatigue) with women being more likely to report symptoms of distress and thus score worse on experience-based outcomes. ${ }^{41}$ Studies specifically investigating DIF related to physical function confirmed the present findings of gender DIF in various individual HAQ items. ${ }^{21,22}$ In line with the DIF patterns observed by Rose et al for several items of the HAQ-DI, men did worse with dressing or grooming, women with grip, reach or strength. ${ }^{22}$ However, when interpreting these findings, it cannot be ignored that the difference in physical constitution between women and men may also play a role in the experience of physical abilities. For example, men are usually taller than women, possibly contributing to the finding that men experience reaching objects less difficult irrespective of their disease-related functional limitations. Similarly, men are usually stronger possibly contributing to women experiencing more difficulty with lifting or moving heavy objects, cutting meat, opening jar or turning faucets.

When comparing results across age, we are the first to show that in RA higher age was overall associated with higher level of difficulties for many physical demanding activities e.g. walking, climbing stairs, sports, move/lift heavy objects. In an osteoarthritis index, ${ }^{42}$ DIF was reported for items measuring physical function, with older patients reporting more limitations in climbing stairs than they would have for an unbiased item. ${ }^{43}$ IRT 
models do not enable detection of the specific reason for differential item function, but physical factors (e.g. loss of body strength and fitness) may partly explain the variance. Interestingly, older patients tended to experience usual activities of daily living - dressing and grooming, arising, eating, walking, hygiene, reach, grip - as less strenuous.

Work status seemed to be a relevant source of DIF. However, DIF found between working and non-working patients should be interpreted cautiously. In QUEST-RA, patients that work were on average more than 10 years younger than patients that do not work. As such it was not surprising that the findings for work status overlap with findings for age with younger patients being more likely to respond similar to patients that work. While it cannot be excluded that age accounted for some of the observed DIF, it is useful to note the greater number of items exhibited DIF by work status than by age. Maybe time pressure and other stress factors that are likely found to a larger extent among working patients contributed to this effect. Unexpectedly, working patients were more likely to report difficulties for tasks involving the hands but less likely to report difficulties for activities involving lower limb function. Possibly, patients at working age rely to a larger extent on hand function for daily tasks (e.g. office employees, students) and thus have greater demands for hand function. The fact that working patients report less difficulties for strenuous activities may partly relate to a selection effect with working patients overall characterized by better overall health and body constitution ('healthy workers') that allows these patients to experience less difficulties for activities such as queuing, walking or running moderate distances .It is of note, that the groups 'not employed' is a mixture of persons that are retired due to age, work disabled or economically unemployed.

Interestingly, only small effects were observed for education as potential source of DIF. Item bias for education was found in several earlier studies. Perkins et al. ${ }^{44}$ investigated DIF on the Short Form-36 health survey among healthy individual and found that respondents with less education had less difficulty with vigorous activities at all values of the physical functioning scale. Likely, item bias on education is more important for cognitive tests rather than for tests on physical function. ${ }^{20}$

Although a number of individual HAQ items showed significant DIF across all SD factors, it seems that the magnitude of effects minimize in the total score of different versions of the HAQ. After adjusting total HAQ scores for DIF, the mean scores increased by $<0.1$ for all versions of the $\mathrm{HAQ}$. Of note, although the minimal clinically important difference (MCID) has been developed to understand a clinically relevant difference in physical function for an individual patient, it can be helpful to realize that the MCID for HAQ (measured on a 0-3 scale) is considered between 0.2 and 0.3. ${ }^{9,45-47}$

Regression analyses revealed that coefficients of clinical confounders and most SD factors remain largely unaffected by the adjustment of composite HAQs for DIF, 
indicating that observed DIF has very limited influence on the association between HAQ and clinical and SD confounders. However, some changes in coefficient were observed for gender indicating that some measurement equivalence cannot be ignored; the clinical relevance of effects however is expected to be small.

Some limitations have to be considered when interpreting study results. First, although a rigorous translation process was followed, linguistic or translational bias cannot be fully excluded potentially influencing the interpretation of HAQ items. However, across countries and languages, the study recruited patients of diverse SD background so that potential linguistic effects in some individual countries are not expected to influence overall results. Second, the database did not allow for analysis of further possible socioeconomic factors, e.g. the influence of race, religion or individual economic background due to lack of adequate variables. Following the PROGRESS framework, ${ }^{48}$ these factors may contribute to different perception towards health. Finally, the analysis investigated only uniform DIF relating to item difficulties. Non-uniform DIF, where differences in item discrimination is also assessed, was not assessed but could be examined in further analyses.

This study is among the first to investigate item bias when assessing physical function across multiple SD factors. QUEST-RA included data on four different versions of the $\mathrm{HAQ}$ and thus allowed comparison of different clinically relevant tools to assess physical function. The analysis included more than 9,000 patients from 30 countries and thus provides a unique opportunity to overcome limitations on generalizability of results.

\section{Conclusions}

Although important item bias between different SD groups could be found for individual $\mathrm{HAQ}$ items, composite $\mathrm{HAQ}$ scores overall measure accurately the level of physical function across different SD groups. Still, there is some need for caution when comparing physical function between males and females. 


\section{References}

1. Oude Voshaar MA, Glas CA, ten Klooster PM, Taal E, Wolfe F, van de Laar MA. Crosscultural measurement equivalence of the Health Assessment Questionnaire II. Arthritis Care Res (Hoboken) 2013;65(6):1000-4.

2. Pincus T, Swearingen C, Wolfe F. Toward a multidimensional Health Assessment Questionnaire (MDHAQ): assessment of advanced activities of daily living and psychological status in the patientfriendly health assessment questionnaire format. Arthritis Rheum 1999;42(10):2220-30.

3. Wolfe F, Michaud K, Li T, Katz RS. Chronic conditions and health problems in rheumatic diseases: comparisons with rheumatoid arthritis, noninflammatory rheumatic disorders, systemic lupus erythematosus, and fibromyalgia. J Rheumatol 2010;37(2):305-15.

4. Wolfe F, Pincus T. Listening to the patient: a practical guide to self-report questionnaires in clinical care. Arthritis Rheum 1999;42(9):1797-808.

5. de Croon EM, Sluiter JK, Nijssen TF, Dijkmans BA, Lankhorst GJ, Frings-Dresen MH. Predictive factors of work disability in rheumatoid arthritis: a systematic literature review. Ann Rheumc Dis 2004;63(11): 1362-7.

6. Callahan LF, Pincus T, Huston JW, 3rd, Brooks RH, Nance EP, Jr., Kaye JJ. Measures of activity and damage in rheumatoid arthritis: depiction of changes and prediction of mortality over five years. Arthritis Care Res 1997;10(6):381-94.

7. Welsing PM, van Gestel AM, Swinkels HL, Kiemeney LA, van Riel PL. The relationship between disease activity, joint destruction, and functional capacity over the course of rheumatoid arthritis. Arthritis Rheum 2001;44(9):2009-2017.

8. Kapetanovic MC, Lindqvist E, Nilsson JA, Geborek P, Saxne T, Eberhardt K. Development of functional impairment and disability in rheumatoid arthritis patients followed for 20 years: relation to disease activity, joint damage, and comorbidity. Arthritis Care Res (Hoboken) 2015;67(3):340-8.

9. Bruce B, Fries JF. The Stanford Health Assessment Questionnaire: dimensions and practical applications. Health Qual Life Outcomes 2003;1:20.

10. Fries JF, Spitz P, Kraines RG, Holman HR. Measurement of patient outcome in arthritis. Arthritis Rheum 1980;23(2):137-145.

11. Pincus T, Summey JA, Soraci SA, Jr., Wallston KA, Hummon NP. Assessment of patient satisfaction in activities of daily living using a modified Stanford Health Assessment Questionnaire. Arthritis Rheum 1983;26(11):1346-53.

12. Wolfe F, Michaud K, Pincus T. Development and validation of the health assessment questionnaire II: a revised version of the health assessment questionnaire. Arthritis Rheum 2004;50(10):3296-305.

13. Maska L, Anderson J, Michaud K. Measures of functional status and quality of life in rheumatoid arthritis: Health Assessment Questionnaire Disability Index (HAQ), Modified Health Assessment Questionnaire (MHAQ), Multidimensional Health Assessment Questionnaire (MDHAQ), Health Assessment Questionnaire II (HAQ-II), Improved Health Assessment Questionnaire (Improved HAQ), and Rheumatoid Arthritis Quality of Life (RAQoL). Arthritis Care Res (Hoboken) 2011;63 Suppl 11:S4-13.

14. Massardo L, Pons-Estel BA, Wojdyla D, Cardiel MH, Galarza-Maldonado CM, Sacnun MP, et al. Early rheumatoid arthritis in Latin America: low socioeconomic status related to high disease activity at baseline. Arthritis Care Res (Hoboken) 2012;64(8):1135-43.

15. Sokka T, Kautiainen H, Pincus T, Toloza S, da Rocha Castelar Pinheiro G, Lazovskis J, et al. Disparities in rheumatoid arthritis disease activity according to gross domestic product in 25 countries in the QUESTRA database. Ann Rheum Dis 2009;68(11):1666-72.

16. Pincus T, Callahan LF. Formal education as a marker for increased mortality and morbidity in rheumatoid arthritis. J Chronic Dis 1985;38(12):973-84.

17. Carmona L, Loza E. Despair on disparities. Ann Rheum Dis 2009;68(11):1657-8.

18. Putrik P, Ramiro S, Keszei AP, Hmamouchi I, Dougados M, Uhlig T, et al. Lower education and living in countries with lower wealth are associated with higher disease activity in rheumatoid arthritis: results from the multinational COMORA study. Ann Rheum Diseases 2016;75(3):540-6. 
19. Putrik P, Ramiro S, Hifinger M, Keszei AP, Hmamouchi I, Dougados M, et al. In wealthier countries, patients perceive worse impact of the disease although they have lower objectively assessed disease activity: results from the cross-sectional COMORA study. Ann Rheum Dis 2016;75(4):715-20.

20. Teresi JA, Fleishman JA. Differential item functioning and health assessment. Qual Life Res 2007;16 Suppl 1:33-42.

21. ten Klooster PM, Taal E, van de Laar MA. Rasch analysis of the Dutch Health Assessment Questionnaire disability index and the Health Assessment Questionnaire II in patients with rheumatoid arthritis. Arthritis Rheum 2008;59(12):1721-8.

22. Rose M, Bjorner JB, Becker J, Fries JF, Ware JE. Evaluation of a preliminary physical function item bank supported the expected advantages of the Patient-Reported Outcomes Measurement Information System (PROMIS). J Clin Epidemiol 2008;61(1):17-33.

23. Kucukdeveci AA, Sahin H, Ataman S, Griffiths B, Tennant A. Issues in cross-cultural validity: example from the adaptation, reliability, and validity testing of a Turkish version of the Stanford Health Assessment Questionnaire. Arthritis Rheum 2004;51(1):14-9.

24. Sokka T, Kautiainen H, Toloza S, Makinen H, Verstappen SM, Lund Hetland $M$, et al. QUEST-RA: quantitative clinical assessment of patients with rheumatoid arthritis seen in standard rheumatology care in 15 countries. Ann Rheum Dis 2007;66(11):1491-6.

25. Norton S, Hifinger M, Ramiro S, Putrik P, Sokka-Isler T, Boonen A. Comparability of the health assessment questionnaire between countries: Psychometric examination of cross-national measurement equivalence Ann Rheumc Dis 2016;75(2):165.

26. Gron KL, Ornbjerg LM, Hetland ML, Aslam F, Khan NA, Jacobs JW, et al. The association of fatigue, comorbidity burden, disease activity, disability and gross domestic product in patients with rheumatoid arthritis. Results from 34 countries participating in the Quest-RA program. Clin Exp Rheumatol 2014; 32(6):869-77.

27. Sokka T, Toloza S, Cutolo M, Kautiainen H, Makinen H, Gogus F, et al. Women, men, and rheumatoid arthritis: analyses of disease activity, disease characteristics, and treatments in the QUEST-RA study. Arthritis Res Ther 2009;11(1):R7.

28. England BR, Sayles H, Mikuls TR, Johnson DS, Michaud K. Validation of the rheumatic disease comorbidity index. Arthritis Care Res (Hoboken) 2015;67(6):865-72.

29. Prevoo ML, van 't Hof MA, Kuper HH, van Leeuwen MA, van de Putte LB, van Riel PL. Modified disease activity scores that include twenty-eight-joint counts. Development and validation in a prospective longitudinal study of patients with rheumatoid arthritis. Arthritis Rheum 1995;38(1):44-8.

30. Jawaheer D, Olsen J, Lahiff M, Forsberg S, Lahteenmaki J, da Silveira IG, et al. Gender, body mass index and rheumatoid arthritis disease activity: results from the QUEST-RA Study. Clin Exp Rheumatol 2010; 28(4):454-61.

31. Sokka T, Kautiainen H, Pincus T, Verstappen SM, Aggarwal A, Alten R, et al. Work disability remains a major problem in rheumatoid arthritis in the 2000s: data from 32 countries in the QUEST-RA study. Arthritis Res Ther 2010;12(2):R42.

32. Muthén, L.K. and Muthén, B.O. (1998-2015). Mplus User's Guide. Seventh Edition. Los Angeles, CA: Muthén \& Muthén 2015.

33. Samejima F. Estimation of latent ability using response pattern of graded scores 1 ETS Research Bulletin Series 1968;1968(1):i-169.

34. Yu YF, Yu AP, Ahn J. Investigating differential item functioning by chronic diseases in the SF-36 health survey: a latent trait analysis using MIMIC models. Med Care 2007;45(9):851-9.

35. Benjamini Y, Hochberg Y. Controlling the False Discovery Rate: A Practical and Powerful Approach to Multiple Testing. Journal of the Royal Statistical Society Series B (Methodological) 1995;57(1):289-300.

36. Pollard B, Johnston M, Dixon D. Exploring differential item functioning in the SF-36 by demographic, clinical, psychological and social factors in an osteoarthritis population. BMC Musculoskelet Disord 2013; 14:346.

37. Crane PK, Gibbons LE, Jolley L, van Belle G, Selleri R, Dalmonte E, et al. Differential item functioning related to education and age in the Italian version of the Mini-mental State Examination. Int Psychogeriatr 2006;18(3):505-15.

38. Snijders TAB, Bosker RJ. Multilevel analysis : an introduction to basic and advanced multilevel modeling. London: SAGE 1999. 
39. Cohen J. A power primer. Psychol Bull 1992;112(1):155-9.

40. StataCorp. 2011. Stata Statistical Software: Release 12. College Station, TX: StataCorp LP.

41. McHorney CA, Fleishman JA. Assessing and understanding measurement equivalence in health outcome measures. Issues for further quantitative and qualitative inquiry. Med Care 2006;44(11 Suppl 3):S205-10.

42. Bellamy N, Buchanan WW, Goldsmith CH, Campbell J, Stitt LW. Validation study of WOMAC: a health status instrument for measuring clinically important patient relevant outcomes to antirheumatic drug therapy in patients with osteoarthritis of the hip or knee. J Rheumatol 1988;15(12):1833-40.

43. Pollard B, Johnston M, Dixon D. Exploring differential item functioning in the Western Ontario and McMaster Universities Osteoarthritis Index (WOMAC). BMC Musculoskelet Disord 2012;13:265.

44. Fleishman JA, Lawrence WF. Demographic variation in SF-12 scores: true differences or differential item functioning? Med Care 2003;41(7 Suppl):III75-86.

45. Wells G, Li T, Maxwell L, MacLean R, Tugwell P. Determining the minimal clinically important differences in activity, fatigue, and sleep quality in patients with rheumatoid arthritis. J Rheumatol 2007;34(2):280-9.

46. Wells GA, Tugwell P, Kraag GR, Baker PR, Groh J, Redelmeier DA. Minimum important difference between patients with rheumatoid arthritis: the patient's perspective. J Rheumatol 1993;20(3):557-60.

47. Wolfe F, Michaud K, Strand V. Expanding the definition of clinical differences: from minimally clinically important differences to really important differences. Analyses in 8931 patients with rheumatoid arthritis. J Rheumatol 2005;32(4):583-9.

48. O'Neill J, Tabish H, Welch V, Petticrew M, Pottie K, Clarke M, et al. Applying an equity lens to interventions: using PROGRESS ensures consideration of socially stratifying factors to illuminate inequities in health. J Clin Epidemiol 2014;67(1):56-64. 


\section{Part II}

The healthcare professionals' preferences as contextual factor in the management of rheumatoid arthritis 



\section{Chapter}

Patients' preferences and economic considerations play an important role in treatment decisions:

a discrete choice experiment among rheumatologists

Hifinger M, Hiligsmann M, Ramiro S, Severens JL, Fautrel B, Watson V, Boonen A Rheumatology (Oxford) 2017;56(1):68-76 


\section{Abstract}

\section{Objective}

To evaluate to what extent rheumatologists consider economic aspects and patients' preferences when choosing drug treatment in patients with active rheumatoid arthritis (RA).

\section{Methods}

In a discrete choice experiment, rheumatologists were asked to choose between two unlabelled drug treatment options for a hypothetical RA patient with moderate disease activity who failed two synthetic DMARDs. Attributes and levels of drug treatments were selected based on existing literature, rheumatologists' opinion and expert consensus. This resulted in five attributes each described by three levels: efficacy (level of improvement and achieved state on Disease Activity Score 28 (DAS28)), safety (probability of a serious adverse event), patients' preference (level of agreement), annual medication costs and cost-effectiveness (incremental cost-effectiveness ratio). An efficient experimental design generated 14 treatment choices and a random parameter logit model estimated the relative importance of attributes.

\section{Results}

Sixty-three rheumatologists from the Netherlands contributed to the analysis; $44 \%$ were female and mean age was 49 (SD 8) years. Drug-efficacy had the strongest relative contribution to the drug choice (44\%) followed by medication costs (24\%), patients' preferences (17\%) and cost-effectiveness (14\%). Patients' preferences were most relevant when patients disliked a proposed treatment. The risk of serious but uncommon or rare side effects only played a minor role in the treatment choice (1\%).

\section{Conclusion}

In addition to drug efficacy, rheumatologists account for economic aspects and for patients' preferences when deciding on drugs. Decisions are more influenced by absolute costs than relative cost-effectiveness and by patients' disliking opposed to favouring the treatment. 


\section{Introduction}

During the past decades, the management paradigm of patients with rheumatoid arthritis (RA) has changed. The introduction of the concept of early aggressive treatment and later of biologic disease modifying anti-rheumatic drugs (bDMARDs) fundamentally improved disease outcomes for the majority of patients. ${ }^{1,2}$ However, these innovations and especially the bDMARDs increased treatment costs dramatically. ${ }^{3}$ The impact of biologics on national healthcare budgets has been huge and most societies regulate access by restricting their use. ${ }^{4,5}$ While rheumatologists argue that treatment innovations should be available to all patients, they also realized that healthcare resources are not infinite. Over the past decade, cost-effectiveness considerations became part of international treatment guidelines. ${ }^{6}$ In clinical practice however, tradeoffs based on cost-effectiveness at the group level may conflict with the physicians' desire to prescribe the best available treatment to their patients irrespective of economic consequences.

At the same time, societies increasingly expect that physicians actively involve patients in the management of their disease. Preference-based medicine is expected to increase patient trust, satisfaction with care, adherence to treatment plans and thus improve health outcomes. Recent studies revealed that informed patients use less healthcare and thus reduce healthcare costs. ${ }^{7-9}$ For the European League Against Rheumatism (EULAR), patient preference is one of three overarching principles for the management of RA emphasizing its importance. ${ }^{10}$ Although the term patient-centred care is omnipresent in RA care, implementation to clinical reality remains a challenge

The addition of the economic and patient perspective has increased the complexity of treatment decisions substantially. It is not fully understood whether rheumatologists are prepared to manage this new level of complexity. In the majority of developed countries, rheumatologists remain largely autonomous in reaching individual treatment decisions for their RA patients. In this role as key players in their healthcare systems, rheumatologists still have influence on the efficient use of healthcare resources.

To continuously improve high quality healthcare, ${ }^{11}$ insight is needed into how rheumatologists value the changing dimensions of RA treatment. There is limited knowledge about how rheumatologists make treatment choices and whether they are willing to trade-off benefits and costs in clinical practice. In addition, the extent to which rheumatologists are willing to consider patients' preferences in daily clinical practice and comply, despite potential challenges, with existing theoretical frameworks is still unknown.

The aim of the study was therefore to investigate to what extent rheumatologists consider costs, cost-effectiveness and patients' preferences in addition to safety and 
efficacy in RA treatment decisions and to gain insights into contextual factors (e.g. age, gender or work environment) that potentially contribute to the relative importance of these treatment characteristics.

\section{Methods}

In this cross-sectional study, a discrete choice experiment (DCE) was designed to investigate relative preferences of rheumatologists when choosing drug treatments in RA. DCEs have been increasingly used to elicit preferences in healthcare. ${ }^{12}$ In a DCE, interventions are described by characteristics (attributes) and accompanying levels. Respondents are asked to repeatedly choose their preferred treatment in a series of choice sets between two alternative (hypothetical) treatment options that vary in the attributes of interest. The survey included Dutch clinical personnel (rheumatologists) only. Ethical approval was not required for this type of study.

\section{Selection of attributes and levels}

When developing a DCE, the selection of attributes and levels is fundamentally important to obtain valid results to a specific research question. ${ }^{13,14}$ In this study, a step wise approach was followed, that emphasized that patients' preferences and the economic dimension of treatment had to be included to meet the study objectives. First,

potentially important attributes and levels were identified from the literature. ${ }^{2,13,15-24}$ Second, an initial list of attributes was agreed with an expert group $(n=6)$ consisting of rheumatologists and methodologists in the field of economic evaluations, DCE and decision making. Third, the proposed candidates attributes, attribute definitions and levels were further discussed with other clinical rheumatologists $(n=8)$.

Five attributes and attribute definitions - efficacy (status and improvement of disease activity based on Disease Activity Score 28 (DAS28)), safety (risk of a serious adverse event $(A E)$ ); patient's preference (level of agreement with treatment choice), annual drug costs and a cost-effectiveness ratio (compared to usual care) - and three levels per attribute were finally agreed and approved by the expert group. Details for all attributes and levels can be seen in Table 5.1. 
Table 5.1 Attributes and levels for RA drug treatment

\begin{tabular}{|c|c|c|}
\hline $\begin{array}{l}\text { ATTRIBUTES AND ATTRIBUTE } \\
\text { DEFINITIONS }\end{array}$ & ATTRIBUTE LEVELS & LEVEL DESCRIPTIONS \\
\hline \multirow[t]{3}{*}{$\begin{array}{l}\text { Efficacy } \\
\text { *Improvement and status of } \\
\text { disease activity based on DAS28 }\end{array}$} & $\begin{array}{l}\text { Good DAS28 response - } \\
\text { remission achieved }\end{array}$ & $\begin{array}{l}\text { DAS28 improvement by } 3.0 \text { points } \\
\text { Achievement of remission } \\
\text { (DAS } 28<2.6)\end{array}$ \\
\hline & $\begin{array}{l}\text { 2. Good DAS } 28 \text { response - low } \\
\text { disease activity achieved }\end{array}$ & $\begin{array}{l}\text { DAS28 improvement by } 2.0 \text { points } \\
\text { Achievement of low disease activity } \\
(2.6<\text { DAS } 28 \leq 3.2)\end{array}$ \\
\hline & 3. Moderate DAS28 response & $\begin{array}{l}\text { DAS28 improvement by } 1.0 \text { point } \\
\text { Low disease activity or remission } \\
\text { cannot be achieved (DAS28 remains } \\
>3.2 \text { ) }\end{array}$ \\
\hline $\begin{array}{l}\text { Safety } \\
\text { Probability of a serious adverse } \\
\text { event }\end{array}$ & $\begin{array}{l}\text { 1. Very rare } \\
\text { 2. Rare } \\
\text { 3. Uncommon }\end{array}$ & $\begin{array}{l}5 \text { out of } 100,000 \text { patients } \\
5 \text { out of } 10,000 \text { patients } \\
5 \text { out of } 1,000 \text { patients }\end{array}$ \\
\hline $\begin{array}{l}\text { Patient's Preference } \\
\text { Patient expressed level of } \\
\text { agreement with treatment } \\
\text { choice }\end{array}$ & $\begin{array}{l}\text { 1. } \quad \text { Treatment favoured } \\
\text { 2. Neutral } \\
\text { 3. } \\
\text { Treatment disfavoured }\end{array}$ & \\
\hline $\begin{array}{l}\text { Cost-effectiveness } \\
{ }^{* *} I C E R \text {, in costs per QALY gained }\end{array}$ & $\begin{array}{ll}\text { 1. } & \text { Favourable } \\
\text { 2. } & \text { Moderate } \\
\text { 3. Unfavourable }\end{array}$ & $\begin{array}{l}15,000 € / \text { QLY } \\
30,000 € / Q A L Y \\
75,000 € / Q A L Y\end{array}$ \\
\hline $\begin{array}{l}\text { Overall medication costs } \\
\text { Per year, in local currency }\end{array}$ & $\begin{array}{l}\text { 1. Low } \\
\text { 2. Medium } \\
\text { 3. High }\end{array}$ & $\begin{array}{r}800 € / \text { year } \\
8,000 € / \text { year } \\
14,000 € / \text { year }\end{array}$ \\
\hline
\end{tabular}

DAS28=Disease Activity Score 28; ICER =incremental cost effectiveness ratio, QALY=quality-adjusted life year. *In the choice sets, also changes of the individual DAS28 components (tender joint count (TJC), swollen joint count (SJC), erythrocyte sedimentation rate (ESR), patient global assessment of disease activity (PGA)) were presented $\rightarrow$ see Table 5.2; ** ICER is expressed in costs (Euro,€) per QALY gained for the selected treatment compared to usual care

\section{Experimental design}

To limit the number of choice sets in the $\mathrm{DCE}^{25}$ and thus increase response rate and/or improve response reliability, ${ }^{26}$ a Bayesian efficient experimental design including 14 choice sets was computed (using Ngene software ${ }^{27}$ ). A Bayesian design maximizes precision of estimated parameters for a given number of choice questions, ${ }^{28}$ by incorporating a priori information about the sign and value of parameters. The a priori information needed to generate the choice sets was obtained from a pilot DCE with 10 rheumatologists. Further, to avoid implausible treatment options, the experimental design was restricted to realistic combinations between efficacy, costs and costeffectiveness. Finally, to ensure reliability, a dominance test (choice set with one treatment option clearly dominating the other to ensure that treatment options were carefully reviewed by respondents) and two re-test choice sets (repetition of a choice set 
to assess test-retest reliability) were integrated in the final design. A total of 17 choice sets, each presenting 2 unlabelled treatment options (A and B), were included in the survey. An example of a choice set is shown in Table 5.2.

Table 5.2. Example choice set-repeated 17 times with varying attribute levels

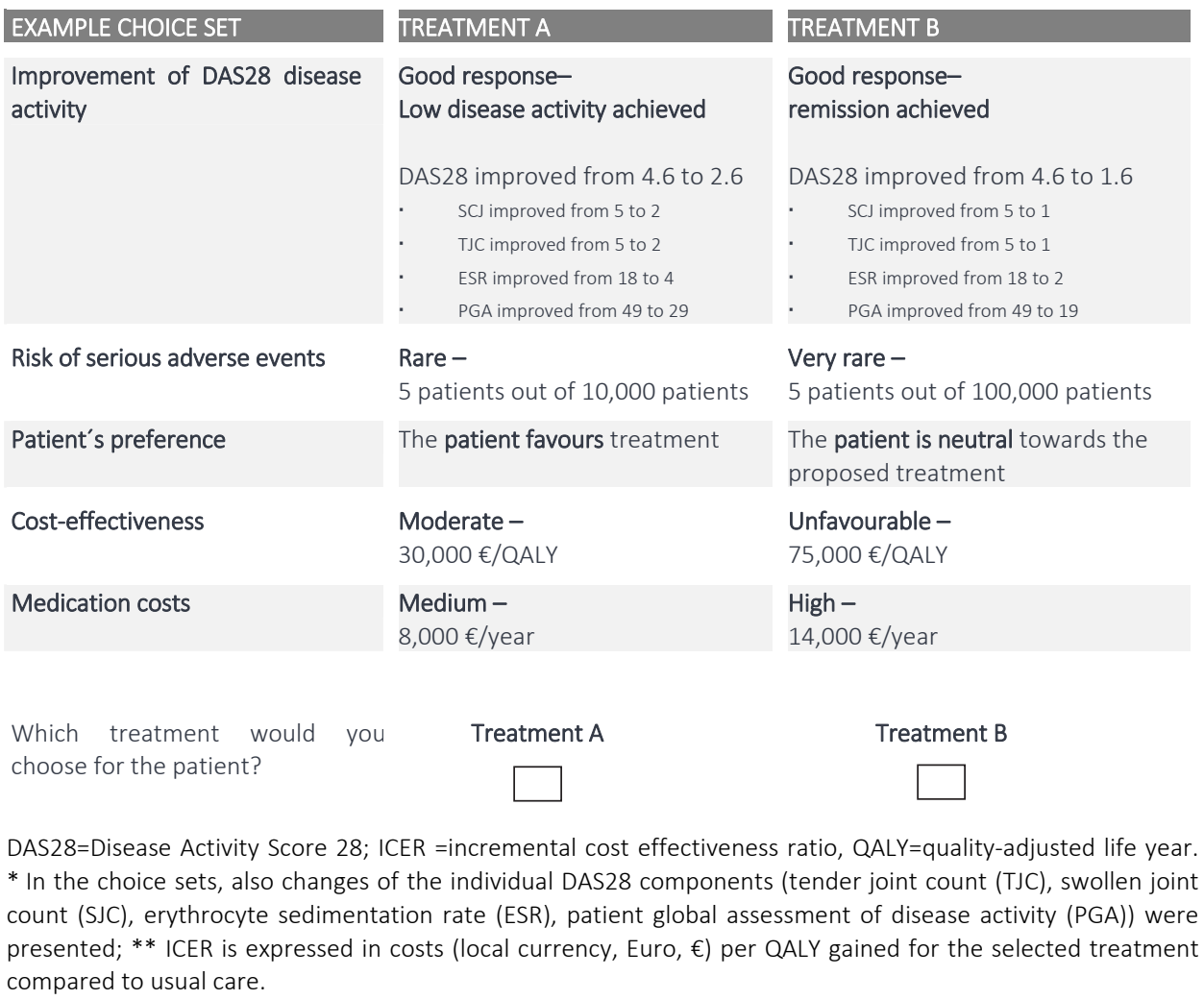

\section{Development of patient profiles}

When making choices in the DCE, it is important that all respondents are considering the same patient. We selected a profile that addresses a clear need for change in the treatment regimen and a decisional problem in terms of balancing efficacy, safety, patient's preference and the economic consequences (absolute costs and costeffectiveness ratio). The patient profile was developed by the expert group and reviewed by rheumatologists $(n=8)$ and resulted in a profile of a patient with anti-citrullinated positive RA and moderate disease activity despite two synthetic DMARDs (Table 5.3). 
The survey was piloted among rheumatologists $(n=14)$ who did not contribute to previous development steps to ensure that choice sets, attributes and levels were relevant, clear and comprehensive.

\section{Statistical analysis}

Responses were considered for data analysis when at least $50 \%$ of choice sets were completed and participants successfully passed the dominance test. The DCE provides the respondent's preferred treatment choice amongst two presented alternatives. A panel random parameters logit (RPL) model was used to analyse data using Nlogit, version $5{ }^{29}$ This analysis provided the observable relative preference (utility $U$ ) of rheumatologist (i) for a treatment choice (j) which can be defined as a sum of preference scores for attributes/levels.

$U_{i j}=\beta 0+\left(\beta_{1}+\eta_{1 i}\right)$ Good response $+\left(\beta_{2}+\eta_{2 i}\right)$ Remission $+\left(\beta_{3}+\eta_{3 i}\right)$ Rare AE $+\left(\beta_{4}+\eta_{4 i}\right)$ Uncommon $A E+\left(\beta_{5}+\eta_{5 i}\right)$ Favoured preference $+\left(\beta_{6}+\eta_{6 i}\right)$ Disfavoured preference + $\left(\beta_{7}+\eta_{7_{i}}\right)$ Cost-effectiveness $+\left(\beta_{8}+\eta_{8 i}\right)$ Costs

$\beta_{0}$ is the constant, $\beta_{1-8}$ are the mean attribute utility weights (physicians' preferences) for the respective attribute and $\eta_{i}$ represents the standard deviation (SD) of the random parameter for rheumatologist i. Dummy coding was used (for ease of interpretation of the results) to describe variables $\beta_{1-6}$. Reference categories for efficacy, safety and patient's preference were moderate response, very rare and neutral patient attitude, respectively. The signs of the $\beta$ coefficients indicate whether the attribute has a negative or positive effect on the rheumatologists' preference. The coefficients $\beta_{1-6}$ represent the change in preference compared to the reference category, the coefficient for costeffectiveness $\left(\beta_{7}\right)$ describes the change of preference per increments of $€ 10,000$ /qualityadjusted life year (QALY) and the coefficient for overall medication costs $\left(\beta_{7}\right)$ the change in preference for each $€ 1,000$ increase in annual treatment costs. A RPL model allows model parameters to vary between respondent, which is reflected in the random parameter (called standard deviation, SD, $\beta_{S D}, \eta_{S D}$ ). If this random parameter is significantly different from zero, this is interpreted as evidence of significant preference variation for the attribute within the population. ${ }^{30}$ In our study, all parameters were included as random parameters and assumed to be normally distributed. Overall model fit was estimated using McFadden Pseudo R-squared $\left(R^{2}\right)$.

To assess whether the attitude of rheumatologists towards patient's preferences was independent of the attitude towards safety and efficacy, interactions between patients' preferences and efficacy as well as patients' preferences and side effects were tested. To estimate the relative importance of the attributes, relative importance weights were calculated using the method described by Malhotra and Birks. ${ }^{31}$ The relative importance 
weights were derived by dividing the range of the level coefficients for one attribute by the sum of ranges of all attributes. This method assumes that the relative importance of an attribute is based on the range of attributes levels. Changing attribute levels could have led to different conclusions. Attributes levels were however based on plausible range of options. Flynn et al. suggest to use comparable scales to assess relative attribute impacts, e.g. calculate marginal rates of substitution instead. ${ }^{32}$ The MRS represent the extra (or saved) annual drug costs that rheumatologists consider acceptable for additional (or foregone) benefits when compared to the reference level. MRS were estimated for the non-monetary attributes that contributed significantly to the rheumatologists' choice.

Subgroup analyses were conducted to better understand patterns that contribute to the variation in observed preferences. Different sub-groups analyses were performed according to age (1=younger or equal the median age and $2=$ older than median age), gender, work environment (1=academic and $2=$ non-academic setting) and self-assessed knowledge on cost-effectiveness analyses (1=lower or equal median and $2=$ higher than median). A likelihood ratio (LR) test was used to assess differences between the subgroups of interest. When LR-test showed significant differences between sub-groups $(p<0.05)$, a heteroskedastic conditional logit model was used to estimate interaction between each attribute and sub-groups. Heteroscedastic model also take into account heterogeneity in error variances across sub-groups. Significant interaction term means significant difference in coefficient across sub-groups.

\section{Results}

\section{Respondents' characteristics}

Overall 235 rheumatologists were invited to participate, 63 responses were finally included in the analysis. Mean age of participating rheumatologists was 48.9 years, and $44.4 \%$ were females. Rheumatologists assessed their knowledge on cost-effectiveness as on average 6.4 (SD 2.0) and their level of agreement with reimbursement criteria was 8.0 (SD 1.9) with $22.2 \%$ of respondents ranking the highest score (10). Further details on the respondents' characteristics can be found in Table 5.4.

Rheumatologists found the DCE-task moderately difficult (mean 5.8, SD 1.9). In line with existing literature, $85.7 \%$ (re-test 1 ) and $82.5 \%$ (re-test 2) of respondents, chose the same alternative in the test-retest exercises. ${ }^{30}$ 
Table 5.4 Rheumatologists' characteristics

\begin{tabular}{lc}
\hline Rheumatologists' characteristics (N=63) & \\
\hline Number of invited rheumatologists & 250 \\
Number of participating rheumatologists & 47 \\
Excluded responses & 3 \\
Incomplete (less than 50\%) & 1 \\
Failed dominance test & 63 \\
Number of responses included in the analysis & 48.9 (SD 7.6) \\
Mean age (years) & $44.4 \%$ \\
Gender (\% female) & $33.3 \%$ \\
Work environment & $65.1 \%$ \\
\% academic hospital & \\
\% non-academic hospital & $17.5 \%$ \\
Work experience & $23.8 \%$ \\
Less than 5 years & $39.7 \%$ \\
Five to 10 years & $19.0 \%$ \\
11 to 20 years & $6.4(S D 2.0)$ \\
More than 20 years & 6.5 (SD 1.8) \\
Self-assessed knowledge about cost-effectiveness analyses (mean)* & \\
Perceived importance of relative cost-effectiveness in national reimbursement & $6.6(S D 1.7)$ \\
decisions (mean)** & 8.0 (SD 1.9) \\
Perceived importance of absolute costs in clinical practice (mean)** &
\end{tabular}

$\mathrm{SD}=$ Standard Deviation. *0-10 Numeric rating scale (NRS), anchors: I do not (0)/I fully (10) understand costeffectiveness analyses; ** 0-10 NRS, anchors: not important (0), very important (10); *** 0-10 NRS scale, anchors: I do not agree (0), I fully agree (10)

\section{The panel random parameters logit model}

The main results of the RPL model are presented in Table 5.5. Compared to a moderate DAS28 response, rheumatologists preferred on average good response without remission $(\beta=2.40)$ and even more a good response with remission $(\beta=4.40)$, both $p<0.001$. No significant differences were observed in the relative importance of safety when risk of a serious $A E$ increased from $0.005 \%$ (i.e. 5: 100,000 ) to $0.05 \%$ (i.e. $5: 10,000)$ or $0.5 \%(5: 1,000)$, respectively. Compared to a neutral attitude of the patient towards a drug, patient's favoring a treatment $(\beta=0.29)$ increased preference $(p<0.1)$, and the patient's dislike of a treatment significantly reduced the rheumatologist's preference $(\beta=-1.45, p<0.001)$. The negative signs of costs and cost-effectiveness indicate that rheumatologists prefer a treatment with low cost and low ICER. As revealed by the significance of the SD, variation among respondents was observed for several attributes (levels). For some attributes the magnitude of the SD exceeded the mean estimate. Therefore, while uncommon severe side effects on average did not contribute to preference, some rheumatologists considered infrequent but serious $A E$ important whereas others did not. Rheumatologists considered the ICER to some extent, however the large and significant SD indicates some rheumatologists did not take into ICER 
account when making their treatment decisions. Overall model fit $\left(R^{2}\right)$ was 0.46 . No interaction between patients' preferences and efficacy or safety was found.

Table 5.5 Results from the Random Parameters Logit Model

\begin{tabular}{|c|c|c|}
\hline Attributes and Levels & $\begin{array}{c}\text { Estimate } \\
\text { (95\% confidence interval) }\end{array}$ & Standard Deviation \\
\hline \multicolumn{3}{|l|}{ Efficacy } \\
\hline Moderate response & Reference level & \\
\hline Good response & $2.395^{* * *}(1.809$ to 2.981$)$ & $0.493^{*}$ \\
\hline Remission & $4.400 * * *$ (3.431 to 5.369$)$ & $0.990 * * *$ \\
\hline \multicolumn{3}{|l|}{ Safety } \\
\hline Very rare & Reference level & \\
\hline Rare & 0.141 (-0.227 to 0.509$)$ & 0.044 \\
\hline Uncommon & $0.051(-0.423$ to 0.527$)$ & $1.008 * * *$ \\
\hline \multicolumn{3}{|l|}{ Patient's preference } \\
\hline Patient favours treatment & $0.290 *(-0.046$ to 0.626$)$ & 0.016 \\
\hline Patient is neutral & Reference level & \\
\hline Patient disfavours treatment & $-1.453^{* * *}(-2.009$ to -0.897$)$ & $0.838 * * *$ \\
\hline $\begin{array}{l}\text { Cost-effectiveness } \\
(10,000 € / \text { QALY })\end{array}$ & $-0.228 * * *(-0.326$ to -0.130$)$ & $0.205^{* * *}$ \\
\hline $\begin{array}{l}\text { Overall medication costs } \\
(1,000 € / \text { year })\end{array}$ & $-0.177^{* * *}(-0.227$ to -0.126$)$ & $0.087 * * *$ \\
\hline Constant & $-0.262 * *(-0.517$ to 0.007$)$ & \\
\hline
\end{tabular}

$* * *$ significant at $1 \%$; ${ }^{* *}$ significant at $5 \%$; ${ }^{*}$ significant at $10 \%$; Pseudo $\mathrm{R}^{2}=0.46$, log-likelihood $=-328$

\section{Relative importance weight of treatment attributes}

The relative importance of treatment attributes is shown in Figure 5.1. Treatment efficacy contributed most $(43.8 \%)$ to the overall treatment preference. Economic aspects also played an important role, with absolute costs for medication being more relevant than relative cost-effectiveness considerations $(23.7 \%$ versus $13.7 \%$ contribution). Also patients' preferences were relevant for the treatment decision (17.3\%) while the overall contribution of safety was limited (1.4\%). 
Relative contribution of treatment attributes to overall decision
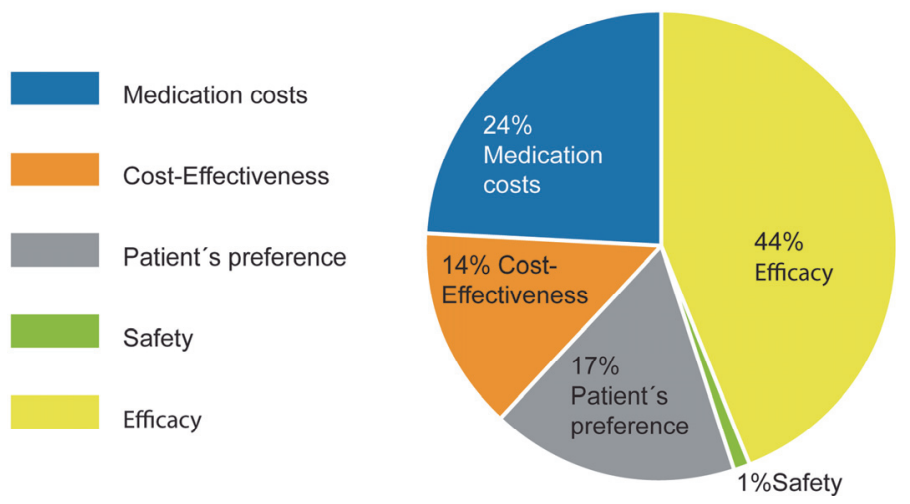

Figure 5.1 Relative contribution of treatment attributes to overall decision

\section{Marginal substitution rates}

About $€ 16,000$ and $€ 29,000$ additional medication costs per patient per year were considered acceptable by rheumatologist to achieve good response with or without remission, respectively, compared to moderate response. Further, rheumatologists accepted up to $€ 2,000$ additional costs per year to align the treatment according to patients' preferences but the treatment should be at least $€ 9,000$ per year less costly to accept a treatment that patients dislike. All marginal substitution rates can be found in Appendix 2, available as supplementary data at Rheumatology Online.

\section{Sub-group analyses}

A likelihood ratio test revealed significant $(p<0.05)$ differences between all sub-groups (age, gender, work-environment and knowledge on cost-effectiveness). Relative importance weights of sub-groups also revealed some differences. However, when applying heteroscedastic interaction models to adjust for heterogeneity in error variances across sub-groups, results revealed no significant $(p<0.1)$ differences between subgroup and attributes. A summary of the results can be found in Appendix 3, available as supplementary data at Rheumatology Online. 


\section{Discussion}

While efficacy is the most important driver for RA treatment decisions, this study revealed that rheumatologists also consider patients' preferences and economic aspects when selecting drug treatments for their patients. Among economic aspects, absolute medication costs, and only to a lesser extent cost-effectiveness, contributed to treatment decisions. Furthermore, rheumatologists take patients' preferences into account especially when patients' express to dislike a proposed treatment.

In line with present recommendations, clinicians primarily target for remission. ${ }^{6}$ The frequency of serious AEs played a limited role in the choice of a drug treatment in patients with persistently active disease and previous treatment failures. This needs to be interpreted with caution as it naturally does not diminish the overall importance of safety in drug treatment choices for rheumatologists. Findings indicate that in patients with active disease and bad prognostic factors, infrequent but serious AEs are less important compared to other treatment attributes. While during the design of the study there was no doubt on the importance of safety as an attribute, it should be noted that also during the preparation of the DCE, there were important discussions on how to define 'safety' in the experiment. The majority of rheumatologists indicated manageable and reversible AEs would be irrelevant when treatment decisions involved a change after treatment failures. However, differences in opinion existed about whether the type or the frequency of serious AEs would matter most, finally the latter received more support to serve as definition for 'safety'. In line with these discussions, results revealed that the additional role of serious AEs varied importantly among respondents, especially when the likelihood of occurrence was above $0.05 \%$ and beyond. It is likely that in clinical practice also more common but less severe AEs are considered when choosing a drug treatment. Possibly, personal experiences of the clinician with serious AEs or the patient's individual attitude towards a particular risk influences individual decision, however clear conclusions cannot be made from the present survey.

The study findings further revealed that rheumatologists trade-off economic aspects of a treatment. Apparently, rheumatologists are concerned about optimal use of (limited) healthcare resources. Interestingly, medication costs were more important than relative cost-effectiveness. No significant difference was observed between clinicians who assessed their own knowledge of cost-effectiveness as high compared to clinicians who assessed their knowledge as moderate or low. This was surprising as an ICER provides more rational information on how to optimally spend resources (i.e. where to gain most QALYs for the same amount of money); likely in clinical practice rheumatologists are driven by the short-term budget considerations in their direct work environment even if decisions are made at the expense fewer QALYs gained at societal level. Although 
knowledge about cost-effectiveness did not affect treatment choices, rheumatologists may still find an ICER difficult to interpret, and most likely, difficult to incorporate into clinical practice. Cost-effectiveness data, for example, do not provide an indication of how much money is spent on an annual basis (a frequently used tool to manage healthcare budgets on hospital level) and do not explain how much it costs (annually) to treat one patient successfully.

The results on the importance of patients' preferences in treatment decisions indicate that rheumatologists are moving towards patient-centeredness and shared decision making. Although often viewed as important, there can be various and legitimate reasons to not actively involve patients in the treatment decision process. ${ }^{33,34}$ of interest, rheumatologists acknowledged patients' preferences, especially when patients expressed disagreement with treatment choices. Apparently, healthcare providers recognize such negative feelings might result in lack of adherence and decisional conflicts within patients. Ongoing initiatives that develop tools that support patients to fully understand their disease, treatment options and the associated benefits and risks may help them to communicate with the physician. ${ }^{35}$

Sub-group analyses for age, gender work environment and knowledge on costeffectiveness suggest that there are no significant differences in attitudes between subgroups. Possibly, strong personal believes and experiences (independent of the tested group-characteristics) play an important role in treatment decisions.

The study has four limitations. First, the response rate was comparatively low and we cannot exclude selection bias. Participants represented the entire spectrum of age, work-environment and experience, which suggest that the samples are representative. Second, although the Dutch healthcare setting is comparable to other countries, especially other wealthy Western European countries in many aspects (e.g. reimbursement criteria or local clinical guidelines for treatments), it is possible that attitudes towards economic aspects and patients' preferences differ across countries. Third, in the present study, a number of assumptions had to be made that may not be fully transferrable to clinical realities. Rheumatologists were forced to make a choice between two hypothetical treatments that varied in a limited number of independent attributes and levels that were narrowed in clear definitions. In reality however, the decision about drug treatment may be a complex interplay of multiple factors, partly even dependent on each other (e.g. a patient's concern about AEs may result in a change of the physician's attitude towards the attributes safety or patients' preferences can be influenced by multiple aspects e.g. affordability, convenience or safety). Also the study was specifically designed to evaluate the importance of economic evidence and patients' preferences, attributes describing these dimensions had to be included. However, during development of the survey, rheumatologists clearly confirmed the 
presented attributes as most relevant for treatment decisions in clinical practice. Finally, this study provides only insight into stated preferences. Real practice observations (or revealed preferences) would be additionally informative, however the design and execution of such a study is difficult. According to earlier studies, support for shared decision making did not consistently reflect practical use. Specifically, although physicians tended to report a preference for shared decision making (as also found in the present study), decisions were typically made more frequently by the physician alone. $^{9}$

This is the first study to investigate relative preferences in drug treatment choices among rheumatologists. Results of this experiment are descriptive, and cannot be considered normative. In an era where management of patients with chronic disease becomes increasingly complex, data of the current study are relevant to starting a discussion and initiating further research on physicians' behavior and how to make trade-offs in clinical practice between classic drug characteristics (mainly efficacy and safety), and economic aspects and/or patients' preferences.

\section{Conclusion}

This study suggests that there is overall acceptance among rheumatologists to trade-off efficacy and safety against economic aspects and patients' preferences when selecting a drug treatment for RA patients. However, variability is observed on the extent to which rheumatologists state they are accounting for these aspects of drug-management. As the emphasis on healthcare expenditures and patient empowerment in clinical care is likely to increase, more research and better guidance on how to include these dimensions in increasingly complex clinical decisions is needed.

Supplementary tables are published online on https://academic.oup.com/rheumatology 


\section{References}

1 Aoki A, Suda A, Nagaoka S, et al. Preferences of Japanese rheumatoid arthritis patients in treatment decision-making. Mod Rheumatol 2013;23(5):891-6.

2 van der Velde $G$, Pham B, Machado $M$, et al. Cost-effectiveness of biologic response modifiers compared to disease-modifying antirheumatic drugs for rheumatoid arthritis: a systematic review. Arthritis Care Res (Hoboken) 2011;63(1):65-78.

3 Franke LC, Ament AJ, van de Laar MA, Boonen A, Severens JL. Cost-of-illness of rheumatoid arthritis and ankylosing spondylitis. Clin Exp Rheumatol 2009;27(4 Suppl 55):S118-23.

4 Putrik $\mathrm{P}$, Ramiro S, Kvien TK, et al. Variations in criteria regulating treatment with reimbursed biologic DMARDs across European countries. Are differences related to country's wealth? Ann Rheum Dis 2014;73(11):2010-21.

5 Putrik P, Ramiro S, Kvien TK, et al. Inequities in access to biologic and synthetic DMARDs across 46 European countries. Ann Rheum Dis 2014;73(1):198-206.

6 Smolen JS, Landewe R, Breedveld FC, et al. EULAR recommendations for the management of rheumatoid arthritis with synthetic and biological disease-modifying antirheumatic drugs: 2013 update. Ann Rheum Dis 2014;73(3):492-509.

7 Barry MJ, Edgman-Levitan S. Shared decision making--pinnacle of patient-centered care. N Engl J Med 2012;366(9):780-1.

8 Oshima Lee E, Emanuel EJ. Shared decision making to improve care and reduce costs. N Engl J Med 2013;368(1):6-8.

9 Mulley AG, Trimble C, Elwyn G. Stop the silent misdiagnosis: patients' preferences matter. BMJ 2012;345:e6572.

10 Smolen JS, Breedveld FC, Burmester GR, et al. Treating rheumatoid arthritis to target: 2014 update of the recommendations of an international task force. Ann Rheum Dis 2015.

11 Crossing the Quality Chasm: A New Health System for the 21st Century. Washington (DC); 2001.

12 Clark MD, Determann D, Petrou S, Moro D, de Bekker-Grob EW. Discrete choice experiments in health economics: a review of the literature. Pharmacoeconomics 2014;32(9):883-902.

13 Coast J, Al-Janabi H, Sutton EJ, et al. Using qualitative methods for attribute development for discrete choice experiments: issues and recommendations. Health Econ 2012;21(6):730-41.

14 Ryan M. Discrete choice experiments in health care. BMJ 2004;328(7436):360-1.

15 Augustovski F, Beratarrechea A, Irazola V, et al. Patient preferences for biologic agents in rheumatoid arthritis: a discrete-choice experiment. Value Health 2013;16(2):385-93.

16 Muhlbacher AC, Nubling M. Analysis of physicians' perspectives versus patients' preferences: direct assessment and discrete choice experiments in the therapy of multiple myeloma. Eur J Health Econ 2011;12(3):193-203.

17 Muhlbacher AC, Lincke HJ, Nubling M. Evaluating patients' preferences for multiple myeloma therapy, a Discrete-Choice-Experiment. Psychosoc Med 2008;5:Doc10.

18 Barton JL. Patient preferences and satisfaction in the treatment of rheumatoid arthritis with biologic therapy. Patient Prefer Adherence 2009;3:335-44.

19 Tang B, Rahman M, Waters HC, Callegari P. Treatment persistence with adalimumab, etanercept, or infliximab in combination with methotrexate and the effects on health care costs in patients with rheumatoid arthritis. Clin Ther 2008;30(7):1375-84.

20 Kievit W, Adang EM, Fransen J, et al. The effectiveness and medication costs of three anti-tumour necrosis factor alpha agents in the treatment of rheumatoid arthritis from prospective clinical practice data. Ann Rheum Dis 2008;67(9):1229-34.

21 Kievit W, van Hulst L, van Riel P, Fraenkel L. Factors that influence rheumatologists' decisions to escalate care in rheumatoid arthritis: results from a choice-based conjoint analysis. Arthritis Care Res (Hoboken) 2010;62(6):842-7.

22 Malottki K, Barton P, Tsourapas A, et al. Adalimumab, etanercept, infliximab, rituximab and abatacept for the treatment of rheumatoid arthritis after the failure of a tumour necrosis factor inhibitor: a systematic review and economic evaluation. Health Technol Assess 2011;15(14):1-278. 
23 Schoels M, Wong J, Scott DL, et al. Economic aspects of treatment options in rheumatoid arthritis: a systematic literature review informing the EULAR recommendations for the management of rheumatoid arthritis. Ann Rrheum Dis 2010;69(6):995-1003.

24 Aletaha $D$, Landewe R, Karonitsch $T$, et al. Reporting disease activity in clinical trials of patients with rheumatoid arthritis: EULAR/ACR collaborative recommendations. Arthritis Rheum 2008;59(10): 1371-7.

25 de Bekker-Grob EW, Ryan M, Gerard K. Discrete choice experiments in health economics: a review of the literature. Health Econ 2012;21(2):145-72.

26 Hall J, Fiebig DG, King MT, Hossain I, Louviere JJ. What influences participation in genetic carrier testing? Results from a discrete choice experiment. J Health Econ 2006;25(3):520-37.

27 Writing Group for the ARG, Bonds DE, Harrington M, et al. Effect of long-chain omega-3 fatty acids and lutein + zeaxanthin supplements on cardiovascular outcomes: results of the Age-Related Eye Disease Study 2 (AREDS2) randomized clinical trial. JAMA Intern Med 2014;174(5):763-71.

28 Reed Johnson F, Lancsar E, Marshall D, et al. Constructing experimental designs for discrete-choice experiments: report of the ISPOR Conjoint Analysis Experimental Design Good Research Practices Task Force. Value Health 2013;16(1):3-13.

29 Medley JA. Cost-effectiveness of a WOC advanced practice nurse in the acute care and outpatient setting. J Wound Ostomy Continence Nurs 2014;41(4):307-10.

30 Hiligsmann M, Dellaert BG, Dirksen CD, et al. Patients' preferences for osteoporosis drug treatment: a discrete-choice experiment. Arthritis Res Ther 2014;16(1):R36.

31 NK Malhotra DB. Marketing research: An applied approach. Pearson Education 2007.

32 Lancsar E, Louviere J, Flynn T. Several methods to investigate relative attribute impact in stated preference experiments. Soc Sci Med 2007;64(8):1738-53.

33 de Haes $\mathrm{H}$. Dilemmas in patient centeredness and shared decision making: a case for vulnerability. Patient Educ Couns 2006;62(3):291-8.

34 Bertakis KD, Azari R. Determinants and outcomes of patient-centered care. Patient Educ Couns 2011; 85(1):46-52.

35 Stoffer MA, Smolen JS, Woolf A, et al. Development of patient-centred standards of care for rheumatoid arthritis in Europe: the eumusc.net project. Ann Rheum Dis 2014;73(5):902-5. 



\section{Chapter}

Economic considerations and patients' preferences affect treatment selection for rheumatoid arthritis patients: a discrete choice experiment among European

rheumatologists

Hifinger M, Hiligsmann M, Ramiro S, Watson V, Severens JL, Fautrel B, Uhlig T, van Vollenhoven $R$, Jacques $P$, Detert J, Canas da Silva J, Scirè CA, Berghea F, Carmona L, Péntek M, Keat A, Boonen A Ann Rheum Dis. 2017;76(1):126-132 


\section{Abstract}

\section{Objective}

To compare the value that rheumatologists across Europe attach to patients' preferences and economic aspects when choosing treatments for patients with rheumatoid arthritis (RA)

\section{Methods}

In a discrete choice experiment, European rheumatologists chose between two hypothetical drug treatments for a patient with moderate disease activity. Treatments differed in five attributes: efficacy (improvement and achieved state on disease activity), safety (probability of serious adverse events), patient's preference (level of agreement), medication costs and cost-effectiveness (incremental cost-effectiveness ratio (ICER)). A Bayesian efficient design defined fourteen choice sets and a random parameter logit model was used to estimate relative preferences for rheumatologists across countries. Cluster analyses and latent class models were applied to understand preference patterns across countries and among individual rheumatologists.

\section{Results}

Responses of 559 rheumatologists from 12 European countries were included in the analysis (49\% females, mean age 48 years). In all countries, efficacy dominated treatment decisions followed by economic considerations and patient's preferences. Across countries, rheumatologists avoided selecting a treatment that patients disliked. Latent class models revealed four respondent profiles: one traded off all attributes except safety, and the remaining three classes disregarded ICER. Among individual rheumatologists, 57\% disregarded ICER and these were more likely from Italy, Romania, Portugal or France whereas $43 \%$ disregarded uncommon/rare side effects and were more likely from Belgium, Germany, Hungary, the Netherlands, Norway, Spain, Sweden or United Kingdom

\section{Conclusion}

Overall, European rheumatologists are willing to trade between treatment efficacy, patients' treatment preferences and economic considerations. However, the degree of trade-off differs between countries and among individuals. 


\section{Background}

Traditionally, drug treatment decisions for patients with rheumatoid arthritis (RA) were primarily based on benefits and risks associated with a drug. Patient's preferences and treatment costs usually received little attention, only. ${ }^{1}$ The introduction of biologics has increased treatment opportunities substantially. The new treatments are between 20 and 60 times more costly, and therefore raise concerns about affordability of RA care, ${ }^{2,3}$ Today, in most European countries, access to biologics is highly regulated. ${ }^{4}$ In addition to the economic dimension becoming increasingly important, physicians across Europe are encouraged to actively involve their patients in treatment decisions. Patient-centered care is expected to improve adherence to agreed treatment plans and thus positively influence health outcomes. ${ }^{5}$ However, it can be a challenge to include patient's preferences in decisions that are influenced by multiple other aspects.

Although costs and cost-effectiveness (CE) have been given consideration in recent European League Against Rheumatism (EULAR) developed treatment recommendations $s^{6,7}$, recommendations rely mainly on evidence for effectiveness and safety. Optimal patient care across Europe will depend on how recommendations are implemented in the context of differences in the economic situations of countries and differences in the attitudes of physicians and patients. A recent article revealed a strong association between access to (expensive) biologics and the country's wealth. ${ }^{8}$ Interestingly however, another review found that drug coverage for innovative and expensive drugs does not necessarily translate into its use; there were differences in use between countries with comparable reimbursement criteria, and also between regions within a country. ${ }^{9}$ Differences in attitudes among clinicians likely contribute to differences in treatment choices. ${ }^{10}$

To our knowledge, limited data exists about the differences in values that rheumatologists attach to various treatment characteristics beyond efficacy and safety. Little is known about how rheumatologists assess economic consequences of a treatment choice - do they take into account relative CE considerations or primarily use absolute costs to make economic trade-offs? Moreover, there is limited research on how rheumatologists consider patient's preferences.

In this study, we aim to assess if rheumatologists across Europe are willing to trade-off treatment efficacy and safety for economic considerations and patient's preferences. Further, the study aims to determine different preference profiles of rheumatologists and whether preference profiles are associated with the country rheumatologists are located in. 


\section{Methods}

A discrete choice experiment (DCE) was designed to investigate relative preferences of rheumatologists when choosing drug treatments in RA. In the DCE, rheumatologists were presented with a series of choices and asked in each to select the preferred drug treatment among two hypothetical treatment options ( $\mathrm{A}$ or B). The treatment options were described by a set of attributes, further specified by attribute levels.

\section{Selection of attributes and levels and patient profile}

Selection of attributes and levels is fundamental in the design of a reliable DCE study. ${ }^{11}$ ${ }^{12}$ We followed a stepwise approach. First, potentially important attributes, attribute definitions and levels were identified from literature. ${ }^{11,13-23}$ Second, an expert group $(n=6)$ consisting of rheumatologists and experts in the field of economic evaluations, DCE and decision-making agreed on an initial list of attributes, attribute definitions and levels. Third, the proposed candidate attributes, attribute definitions and levels were discussed with 8 rheumatologists from three countries to ensure they reflected clinical realities.

Five attributes were selected for the DCE: efficacy (status and improvement of disease activity score of 28 joints (DAS28), safety (risk of a serious adverse event (AE)), patient' s preference (level of agreement with treatment choice), annual drug costs and CE (Incremental Cost-effectiveness Ratio (ICER) compared to usual care expressed as incremental cost of one quality adjusted life year (QALY) gain)). For each attribute, three levels were agreed (Figure 6.1).

The patient profile (possibly influencing treatment choices) was selected to imply a clear need for change in the treatment and a decisional problem in terms of balancing previously agreed attributes. The patient profile allowed for a switch to expensive (biological) medications in the majority of countries to ensure respondents do not feel intuitively restricted in their decision by local healthcare regulations. The agreed profile described a patient with anti-citrulline antibody positive RA and moderate disease activity despite two conventional synthetic disease modifying anti-rheumatic drugs (csDMARDs). The full patient profile (Supplementary Table S6.1) has been approved by experts and rheumatologists

\section{Experimental design}

Based on the attributes and levels there are $243\left(3^{5}\right)$ possible treatment combinations too many to ask each rheumatologist to evaluate. ${ }^{24}$ We reduce the number of choice sets using a Bayesian efficient experimental design (Ngene software ${ }^{25}$ ). A Bayesian 
design aims to maximize precision of estimated parameters for a given number of choice questions ${ }^{26}$ by incorporating a priori information about sign and value of parameters. The a priori information was gained from a preliminary DCE with 10 rheumatologists. Implausible or unrealistic treatment options were excluded from the design (e.g. efficacy is low, costs are high, but the CE is best). In addition, three choice sets were included to test if respondents made sensible choices. 1. a dominance test - a choice set with one treatment option that is clearly better than the other; and 2. two repeated choices choice sets that repeat earlier choices to assess the stability of respondents' choices. A total of 17 choice sets were included in the questionnaire. An example of a choice set is shown in Figure 6.1.

\section{(a) Attributes and levels describing drug treatment options in the DCE experiment}

\begin{tabular}{|c|c|c|}
\hline $\begin{array}{l}\text { ATTRIBUTES AND ATTRIBUTE } \\
\text { DEFINITIONS }\end{array}$ & ATTRIBUTE LEVELS & LEVEL DESCRIPTIONS \\
\hline \multirow[t]{3}{*}{$\begin{array}{l}\text { Efficacy } \\
\text { *Improvement and status of } \\
\text { disease activity based on DAS28 }\end{array}$} & $\begin{array}{l}\text { 1. Good DAS28 response - } \\
\text { remission achieved }\end{array}$ & $\begin{array}{l}\text { DAS28 improvement by } 3.0 \text { points } \\
\text { Achievement of remission } \\
(\text { DAS } 28<2.6)\end{array}$ \\
\hline & $\begin{array}{l}\text { 2. Good DAS } 28 \text { response - low } \\
\text { disease activity achieved }\end{array}$ & $\begin{array}{l}\text { DAS28 improvement by } 2.0 \text { points } \\
\text { Achievement of low disease activity } \\
(2.6<\text { DAS } 28 \leq 3.2)\end{array}$ \\
\hline & 3. Moderate DAS28 response & $\begin{array}{l}\text { DAS28 improvement by } 1.0 \text { point } \\
\text { Low disease activity or remission } \\
\text { cannot be achieved (DAS } 28 \text { remains } \\
>3.2 \text { ) }\end{array}$ \\
\hline $\begin{array}{l}\text { Safety } \\
\text { Probability of a serious adverse } \\
\text { event }\end{array}$ & $\begin{array}{l}\text { 1. Very rare } \\
\text { 2. Rare } \\
\text { 3. Uncommon }\end{array}$ & $\begin{array}{l}5 \text { out of } 100,000 \text { patients } \\
5 \text { out of } 10,000 \text { patients } \\
5 \text { out of } 1,000 \text { patients }\end{array}$ \\
\hline $\begin{array}{l}\text { Patient's Preference } \\
\text { patient expressed level of } \\
\text { agreement with treatment choice }\end{array}$ & $\begin{array}{l}\text { 1. } \text { Treatment favoured } \\
\text { 2. Neutral } \\
\text { 3. Treatment disfavoured }\end{array}$ & \\
\hline $\begin{array}{l}\text { Cost-effectiveness } \\
{ }^{* *} \text { ICER, in costs per QALY gained }\end{array}$ & $\begin{array}{l}\text { 1. Favourable } \\
\text { 2. Moderate } \\
\text { 3. Unfavourable }\end{array}$ & $\begin{array}{l}15,000 € / Q A L Y \\
30,000 € / Q A L Y \\
75,000 € / Q A L Y\end{array}$ \\
\hline $\begin{array}{l}\text { Overall medication costs } \\
\text { Per year, in local currency }\end{array}$ & $\begin{array}{l}\text { 1. Low } \\
\text { 2. Medium } \\
\text { 3. High }\end{array}$ & $\begin{array}{r}800 € / \text { year } \\
8,000 € / \text { year } \\
14,000 € / \text { year }\end{array}$ \\
\hline
\end{tabular}


(b) Example choice set - repeated 17 times with varying attribute levels

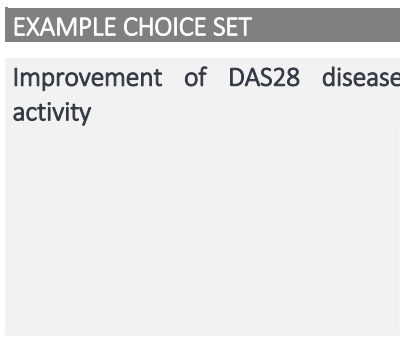

Risk of serious adverse events

Patient's preference

Cost-effectiveness

Medication costs

\section{TREATMENT A}

Good response-

Low disease activity achieved

DAS28 improved from 4.6 to 2.6

SCJ improved from 5 to 2

TJC improved from 5 to 2

ESR improved from 18 to 4

PGA improved from 49 to 29

Rare -

5 patients out of 10,000 patients

The patient disfavours treatment

Unfavourable -

75,000 €/QALY

High -

$14,000 € /$ year

\section{TREATMENT B}

Good response-

remission achieved

DAS28 improved from 4.6 to 1.6

- $\quad$ SCJ improved from 5 to 1

- TJC improved from 5 to 1

- $\quad$ ESR improved from 18 to 2

- $\quad$ PGA improved from 49 to 19

Uncommon -

5 patients out of 1,000 patients

The patient favours treatment

Moderate -

30,000 €/QALY

High -

$14,000 € /$ year

Which treatment would you

choose for the patient?

Treatment A

Treatment B

$X$

In the example choice set the respondent preferred treatment B over treatment A when choosing a drug treatment for a patient with moderate disease activity

Figure 6.1 Attributes and levels and example choice set of DCE experiment.

$\mathrm{DCE}=$ discrete choice experiment, DAS28=Disease Activity Score 28; ICER =incremental cost effectiveness ratio, QALY=quality-adjusted life year. ${ }^{*}$ In the choice sets, also changes of the individual DAS28 components (tender joint count (TJC), swollen joint count (SJC), erythrocyte sedimentation rate (ESR), patient global assessment of disease activity (PGA)) were presented $\rightarrow$ see Figure 6.1b; ** ICER is expressed in costs (local currency, e.g. Euro (€)) per QALY gained for the selected treatment compared to usual care.

\section{The questionnaire}

The questionnaire consisted of two parts - 1. the DCE task and 2. questions collecting socio-demographic data (e.g. age, gender, work environment) to facilitate interpretation of the results. The full questionnaire was piloted among rheumatologists $(n=14)$ from two different countries to ensure that choice sets, attributes and levels were relevant, clear and plausible across countries. Economic attributes were presented in local currencies. ${ }^{27}$ An online survey was distributed by email through a national principle investigator (PI) per country. 


\section{Country selection}

As attitudes of rheumatologists may be influenced by external factors like the country's culture, wealth or healthcare environment, countries from all geographic regions in Europe were invited: Belgium (BE), France (FR); Germany (GE), Hungary (HU), Italy (IT), Netherlands (NL) Norway (NO), Portugal (PT), Romania (RO), Spain (SP), Sweden (SE) and United Kingdom (UK).

\section{Statistical analysis}

Rheumatologists responses were considered for data analyses when at least $50 \%$ of choice sets were completed and they successfully passed the dominance test. A threestep approach was used to analyse data.

First, a mixed logit (ML) model was used to assess the relative importance of attributes, using Nlogit, version $5 .^{28}$ The following utility model was estimated:

$\mathrm{U}_{\mathrm{ij}}=\beta 0+\left(\beta_{1}+\eta_{1 \mathrm{i}}\right)$ Good response $+\left(\beta_{2}+\eta_{2 \mathrm{i}}\right)$ Remission $+\left(\beta_{3}+\eta_{3 \mathrm{i}}\right)$ Rare $A E+\left(\beta_{4}+\eta_{4 i}\right)$ Uncommon $A E+\left(\beta_{5}+\eta_{5 i}\right)$ Favoured preference $+\left(\beta_{6}+\eta_{6 i}\right)$ Disfavoured preference + $\left(\beta_{7}+\eta_{7 i}\right)$ Cost-effectiveness $+\left(\beta_{8}+\eta_{8 i}\right)$ Costs

$U$ represents the observable relative preference of rheumatologist (i) for a treatment choice (j) which can be defined as a sum of preference scores for attributes/levels. $\beta_{0}$ is the constant, $\beta_{1-8}$ are the mean attribute utility weights (physician's preferences) for the respective attribute and $\eta_{i}$ represents the random parameter for rheumatologist $i$. Dummy coding was used to describe variables $\beta_{1-6}$. Reference categories for efficacy, safety and patient's preference were moderate response, very rare adverse events and neutral patient attitude, respectively. The signs of the $\beta$ coefficients indicate whether the attribute has a negative or positive effect on the rheumatologists' preference. $\mathrm{A} \mathrm{ML}$ model allows model parameters to vary between respondents, which is reflected in the random parameter. If the standard deviation (SD) of this random parameter is significantly different from zero, this is interpreted as evidence of significant preference variation for the attribute within the population. ${ }^{29}$ Results were considered significant for $\mathrm{p}<0.05$.

The relative importance of attributes was calculated based on the range of the level coefficients per attribute using the method described by Malhotra and Birks. ${ }^{30}$ More specifically, the relative importance weights were derived by dividing the range of the level coefficients for one attribute by the sum of ranges of coefficients of all attributes.

Second, to assess potential similarities, countries were grouped on the basis of their similarity in mean relative importance weights across the five attributes. Hierarchical Ward's linkage with a squared Euclidean distance measure was used (using STATA 
version $12^{31}$ ). To determine the optimal cluster number, a second clustering method (k-means) was applied and results were compared to hierarchical Ward's linkage to verify if cluster structures were reproducible. Introduction of additional clusters was stopped where both clustering methods provided different results. Further we based the

decision on numbers of clusters on the rule of thumb suggesting $k \sqrt{\frac{\pi}{2}}$, with $\mathrm{k}$ describing the number of suggested clusters and the number of observations.

Third, a latent class model (LCM, using Nlogit) was used to determine preference profiles of all individual rheumatologists. LCM can be used to identify the existence of and the number of classes in the population based on their treatment preferences. The LCM can also be used to explore if covariates (such as clusters of countries) influence the probability to belong to a particular class. Class membership is latent in that each respondent belongs to each class up to a modelled probability. ${ }^{32}$ In order to determine the number of classes, we selected the model with the best fit based on the Akaike information criterion. To further understand the role of country, previously developed country clusters were added as covariate to the latent class model in an additional step. Statistically significant parameter estimates $(p<0.05)$ indicate that the covariate (i.e. the dummy of country-cluster) contributes to the explanation of latent classes. For example, if the parameter estimate for the covariate country cluster is positive and significant for a certain class, it indicates that rheumatologists from the countries that belong to the country cluster are more likely to belong to that particular class.

\section{Results}

\section{Respondent's socio-demographic characteristics}

Overall, 559 rheumatologists from 12 European countries were included in the analysis. Mean age was 48.0 years and $49 \%$ of rheumatologists were females (Table 6.1). Testretest reliability was in line with existing literature ${ }^{29}$ with $82.3 \%$ (re-test 1 ) and $80.8 \%$ (retest 2) of respondents having chosen the same alternative in the test-retests. Five respondents failed in the dominance test and were therefore excluded from the analysis.

\section{Attribute preferences when selecting a new treatment, overall and at a country-level}

The main results of the MLmodel are summarized in Table 6.2a (coefficients) and 6.2b (relative importance) for all countries and each country separately. The detailed results 
overall and per country from ML models can be extracted from Supplementary Table S6.2.

Table 6.1 Characteristics of rheumatologists for the total group and each country separately

\begin{tabular}{llccc}
\hline & & Gender & Age & Work environment \\
\cline { 3 - 4 } & & $n_{\text {female }} / \mathrm{n}_{\text {overall }}$ & years \pm SD & $n_{\text {academic }} / \mathrm{n}_{\text {overall }}$ \\
& & $(\%$ female $)$ & $(\%)$ academic setting \\
\hline Belgium & $(\mathrm{n}=33)$ & $16 / 32(53 \%)$ & $41.4 \pm 8.0$ & $16 / 32(53 \%)$ \\
France & $(\mathrm{n}=40)$ & $21 / 38(55 \%)$ & $51.7 \pm 10.6$ & $2 / 38(5 \%)$ \\
Germany & $(\mathrm{n}=44)$ & $16 / 43(37 \%)$ & $49.3 \pm 8.9$ & $8 / 43(19 \%)$ \\
Hungary & $(n=71)$ & $48 / 70(69 \%)$ & $50.6 \pm 11.1$ & $34 / 70(49 \%)$ \\
Italy & $(n=59)$ & $20 / 57(35 \%)$ & $44.0 \pm 11.4$ & $31 / 57(54 \%)$ \\
Netherlands & $(n=63)$ & $28 / 63(44 \%)$ & $48.9 \pm 7.6$ & $21 / 63(33 \%)$ \\
Norway & $(n=41)$ & $22 / 39(56 \%)$ & $47.6 \pm 10.2$ & $17 / 39(44 \%)$ \\
Portugal & $(n=39)$ & $19 / 36(53 \%)$ & $46.7 \pm 12.8$ & $11 / 36(31 \%)$ \\
Romania & $(n=42)$ & $25 / 42(59 \%)$ & $43.3 \pm 9.2$ & $20 / 42(48 \%)$ \\
Sweden & $(n=24)$ & $16 / 24(67 \%)$ & $50.5 \pm 9.7$ & $18 / 24(75 \%)$ \\
Spain & $(n=63)$ & $31 / 62(50 \%)$ & $48.1 \pm 8.3$ & $54 / 62(87 \%)$ \\
United Kingdom & $(n=40)$ & $9 / 40(23 \%)$ & $53.5 \pm 8.1$ & $34 / 40(85 \%)$ \\
All countries & $(n=559)$ & $267 / 546(49 \%)$ & $48.0 \pm 10.1$ & $266 / 546(49 \%)$ \\
\hline
\end{tabular}

$\mathrm{N}=$ number of responses, $\mathrm{SD}=$ standard deviation

Coefficients (Table 6.2a) revealed, that in all countries good response and especially remission were significantly more desirable than moderate response $\left(\beta_{\text {remission }}>\beta_{\text {good }}\right.$ response). When coefficients were significant, probability of a serious adverse event decreased preference for that given treatment option $\left(\beta_{\text {uncommon }}<\beta_{\text {rare }}\right)$. The patient's agreement with the treatment was universally associated with an increased preference and a stronger, negative impact on preference was seen when patients dislike treatments $\left(\left|\beta_{\text {disagreement }}\right|>\left|\beta_{\text {agreement }}\right|\right)$. The contribution of patient's disagreement with a treatment choice was significant in all countries. The economic aspect also played an important role. Higher economic burden was consistently associated with decreased preference. CE was not significant in three countries (FR, IT, RO), medication costs however were significant in all countries. When comparing contribution of different attributes across countries (Table 6.2b), results revealed that efficacy dominated the treatment choice in all countries with comparatively low variations between countries (range 39-52\%). High variability was observed for the relative contribution of safety (range 1-20\%), whereas patient's preference played role in all countries (range 7-21\%). 
Similarly, absolute costs played a role in all countries (range 10-24\%), whereas contribution of CE varied importantly with several countries largely disregarding CE (range 4-21\%). In the majority of countries absolute costs were more important than relative $\mathrm{CE}$ considerations.

\section{Cluster of countries according to the preference profile}

Two clusters were identified (Table 6.2). In cluster 1 (BE, GE, HU, NL, NO, SE, SP, UK) all attributes, except safety, had a relevant contribution to treatments choice. In cluster 2 including (FR, IT, PT, RO), there was a higher emphasis on safety (range 18-20\%) and lower emphasis on relative CE considerations (range 3-8\%).

\section{Classes of individual rheumatologists according to the preference profile}

Four classes of rheumatologists have been identified according to their preference profile (Table 6.3).In all classes, efficacy (both levels) and patient's disagreement with a treatment were significant determinants of treatment choice. In class 1, rheumatologists accounted for both economic attributes (absolute costs and relative CE) but largely disregarded safety. Overall, $43 \%$ of rheumatologists were estimated to belong to class 1 . Rheumatologists belonging to one of the remaining classes 2-4 disregarded ICER.

Respondents of class 3 balanced safety and total medication costs, while those in class 2 and 4 accounted only for either safety (class 2 ) or total medication costs (class 4 ). The probabilities to belong to classes 2, 3 and 4 were estimated with $22.6 \%, 31.1 \%$ and $11.1 \%$ respectively. Rheumatologists from country cluster 2 (FR, IT, PT, RO) were significantly more likely to be located in classes 2, 3 and 4, with CE playing a minor role. 


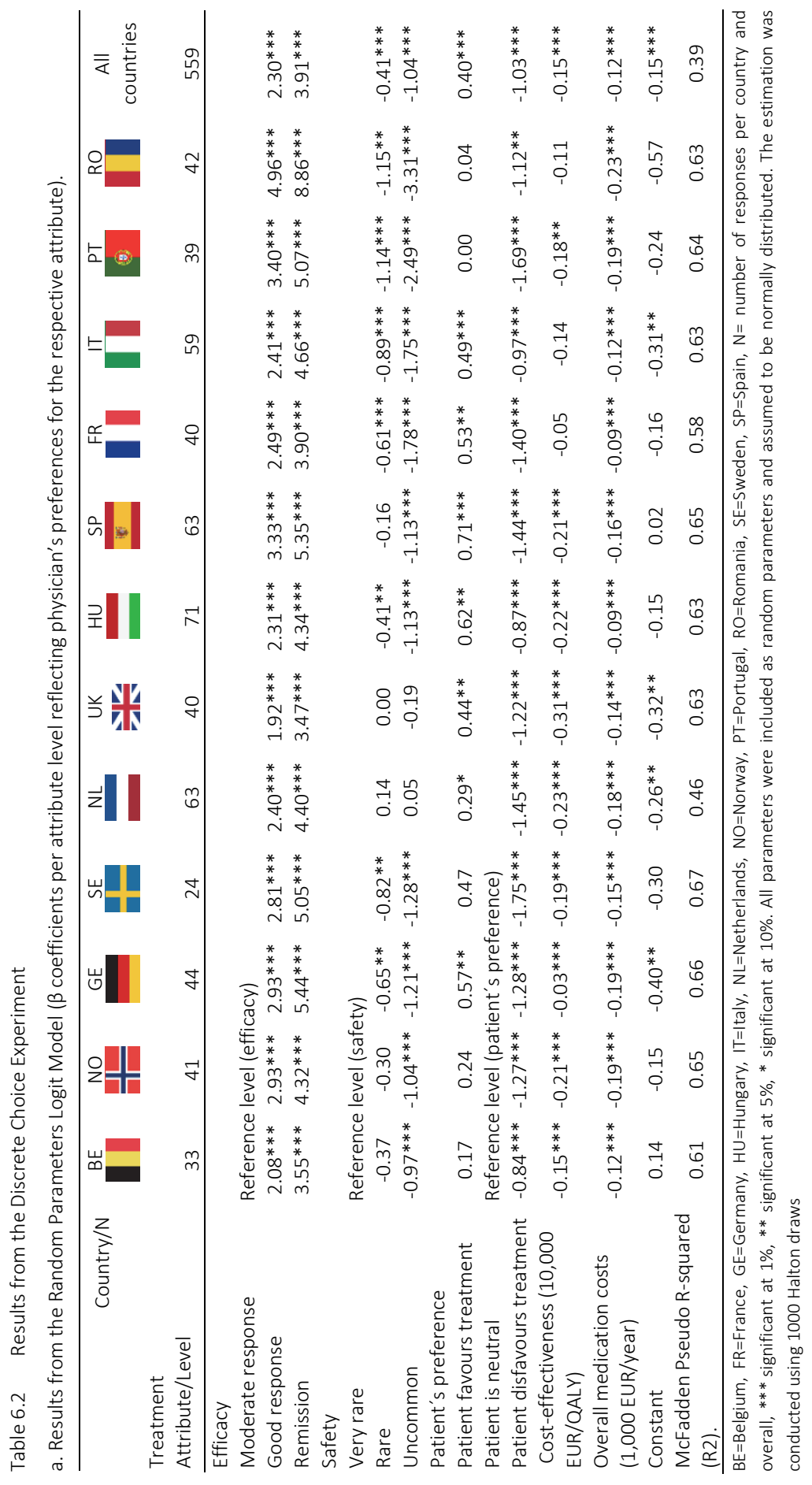




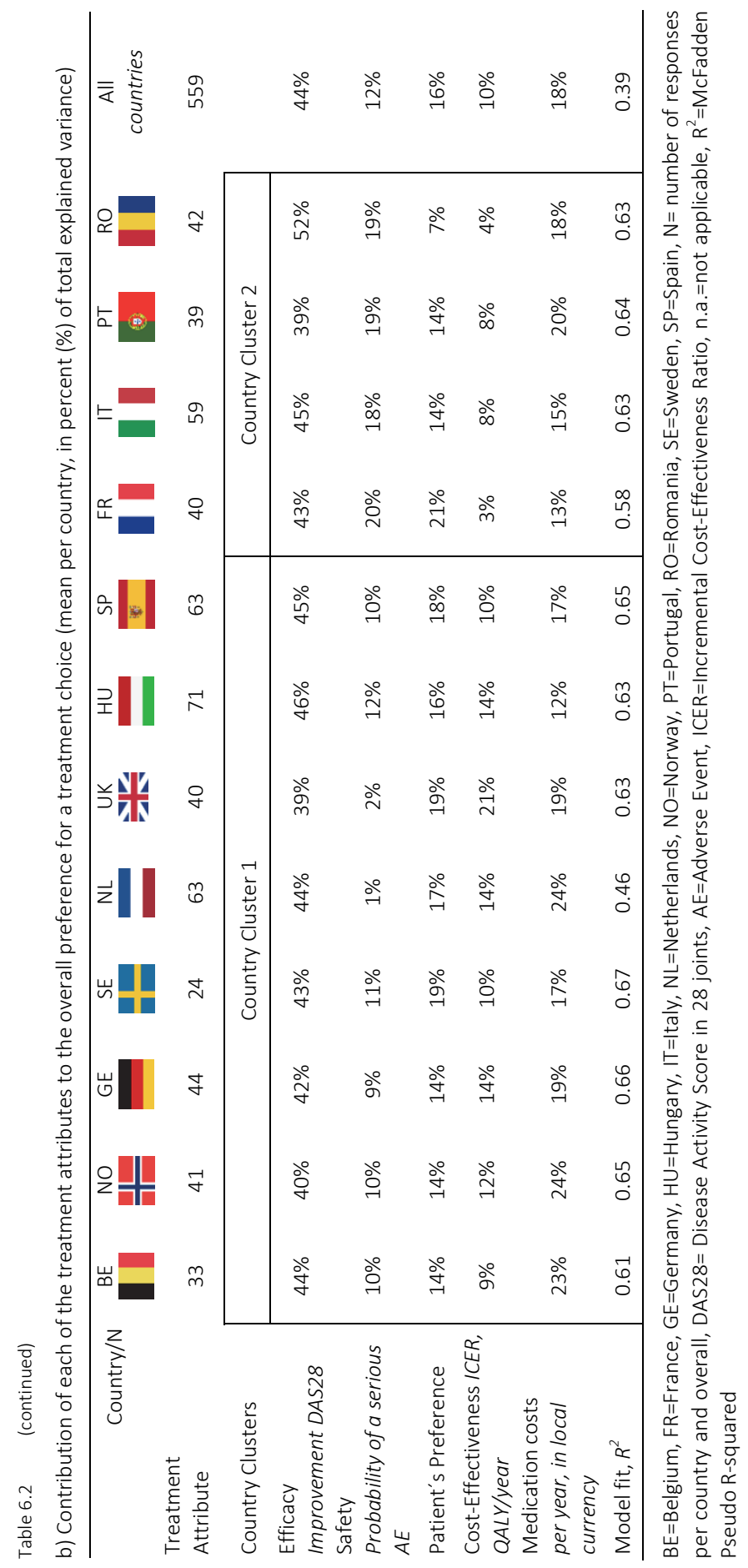


Table 6.3 Results latent class model distinguished 4 classes of respondents.

\begin{tabular}{|c|c|c|c|c|}
\hline $\begin{array}{l}\text { Latent class model } \\
\text { (Responder type) }\end{array}$ & $\begin{array}{c}\text { Latent class } 1 \\
\text { All attributes } \\
\text { (except safety) } \\
\text { balanced }\end{array}$ & $\begin{array}{c}\text { Latent class } 2 \\
\text { Emphasis on efficacy, } \\
\text { safety and patient's } \\
\text { preference, economic } \\
\text { aspects less relevant }\end{array}$ & $\begin{array}{l}\text { Latent class } 3 \\
\text { All attributes } \\
\text { except cost- } \\
\text { effectiveness } \\
\text { balanced }\end{array}$ & $\begin{array}{c}\text { Latent class } 4 \\
\text { Emphasize on } \\
\text { efficacy, patient } \\
\text { dislike and costs }\end{array}$ \\
\hline $\begin{array}{l}\text { Average class } \\
\text { probability }^{11}\end{array}$ & $43.2 \%$ & $22.6 \%$ & $23.1 \%$ & $11.1 \%$ \\
\hline \multicolumn{5}{|l|}{ Efficacy } \\
\hline $\begin{array}{l}\text { Moderate response } \\
\text { Good response }\end{array}$ & $\begin{array}{c}\text { Reference level } \\
1.98^{* * *}\end{array}$ & $\begin{array}{c}\text { Reference level } \\
3.65^{* * *}\end{array}$ & $\begin{array}{c}\text { Reference level } \\
2.32^{* * *}\end{array}$ & $\begin{array}{c}\text { Reference level } \\
1.74 * * *\end{array}$ \\
\hline Remission & $3.08 * * *$ & $6.39 * * *$ & $3.38 * * *$ & $3.85 * * *$ \\
\hline \multicolumn{5}{|l|}{ Safety } \\
\hline Very rare & Reference level & Reference level & Reference level & Reference level \\
\hline Rare & 0.09 & $-1.38 *$ & $-0.96 * * *$ & -0.44 \\
\hline Uncommon & -0.07 & $-2.71 * * *$ & $-2.45 * * *$ & $-0.58 *$ \\
\hline \multicolumn{5}{|l|}{ Patient's preference } \\
\hline Favours treatment & $0.33^{* * *}$ & $2.35^{* * *}$ & $-0.37 * *$ & 0.53 \\
\hline $\begin{array}{l}\text { neutral } \\
\text { Disfavours treatment }\end{array}$ & $\begin{array}{l}\text { Reference level } \\
-0.84^{* * *}\end{array}$ & $\begin{array}{c}\text { Reference level } \\
1.53^{* * *}\end{array}$ & $\begin{array}{l}\text { Reference level } \\
-1.34^{* * *}\end{array}$ & $\begin{array}{c}\text { Reference level } \\
-3.17^{* * *}\end{array}$ \\
\hline $\begin{array}{l}\text { Cost-effectiveness } \\
(10,000 \text { EUR/QALY) }\end{array}$ & $-0.29 * * *$ & $-0.28^{*}$ & -0.03 & -0.07 \\
\hline $\begin{array}{l}\text { Overall medication costs } \\
\text { (1000 EUR/year) }\end{array}$ & $-0.13^{* *}$ & -0.02 & $-0.11 * * *$ & $-0.09 * * *$ \\
\hline Constant & 0.02 & $-1.64 * * *$ & $-0.22 * *$ & -0.34 \\
\hline $\begin{array}{l}\text { Class probability model - } \\
\text { cluster } 2^{2)}\end{array}$ & ـ & $1.41 * * *$ & $2.09 * * *$ & $1.16^{*}$ \\
\hline
\end{tabular}

$* * *$ significant at $1 \%, * *$ significant at $5 \%, *$ significant at $10 \%$. 1) Average class probability = Probability that individual respondent chooses drug treatments according to respective responder types (all 559 responses from 12 countries included in the analysis). 2) Parameter estimates indicate that rheumatologists belonging to country cluster 2 (consisting of Romania, France, Portugal and Italy, see table 6.2) compared to country cluster 1 (reference) are significantly more likely to be in classes 2, 3 or 4 .

\section{Discussion}

The study revealed that across countries rheumatologists are willing to trade-off efficacy against patient's preferences and/or economic aspects in treatment choices. Fourtythree per cent of rheumatologists balanced all attributes, including CE when choosing a therapy, while for all other rheumatologists, CE did not play a substantial role. Medication costs however remained relevant for $77 \%$ of clinicians. Two groups of countries could be distinguished. One group, which represented the majority of countries, was more likely to balance all treatment attributes including $C E$, while the other group placed little emphasis on CE.

In all countries, rheumatologists considered economic, indicating that rheumatologists support efficient use of limited healthcare resources. However, latent class analyses showed that about half of individual rheumatologists are estimated to largely disregard 
the CE. This can be explained by clinicians having limited access to CE data of relevant drugs or methodological complexities and weaknesses in existing data. ${ }^{33,}{ }^{34}$ Given the importance of ICER, we need to ensure that trustful and comparable good quality data are provided to clinicians to support its use in clinical decision making. In addition, the direct healthcare environment often rather supports economic trade-offs based on absolute costs ${ }^{35}$ even though CE data provide more valuable information on efficient treatment choices for society. The present findings confirmed that in UK CE and more specifically ICER plays a more decisive role in reimbursement decisions compared to many other European countries. ${ }^{36}$ Of note, CE studies are frequently limited to selected countries although transferability of data across countries is not always possible, further limiting its use. ${ }^{33}$

Patient's preferences were taken into account by all rheumatologists, despite variations observed among individuals and between countries. Cultural differences in the physician-patient relationship or the physician's attitude may partly explain the differences. A recent review e.g. found that clinicians are more likely to support shareddecision making when their direct work environment supports the concept. ${ }^{1}$ Interestingly however, rheumatologists from all countries considered in particular patient's disagreement, possibly to avoid poor drug adherence. Although perception towards shared decision making can vary, this study for the first time revealed consensus among individuals and across countries on the importance of a patient's disagreement, and is the first to address patient's preferences in the context of other treatment attributes.

Some limitations have to be considered for interpretation of results. First, the sample size was lower in some countries and differences in socio-demographics across countries were observed, thus selection bias and limitations in generalizability of results cannot be excluded. Sub-group analyses of the results from NL (results not reported), revealed no significant differences in preferences for different sub-groups. Further an efficient experimental design was developed to optimize response efficiency. Second, pharmaceutical industry ${ }^{37}$ or local healthcare regulations (in particular the reimbursement criteria) may influence the preferences. However, most participating countries do not restrict access to expensive drugs for patients described in the DCE, therefore this type of effect is likely limited to countries with very strict criteria (UK, HU and RO). Third, although the presented attributes were confirmed as most relevant for treatment decisions in RA and a strong methodology was used to select and defined attributes, it cannot be excluded that further attributes play a role in some countries. Further research could contribute to a better understanding on other relevant factors across European countries. Fourth, presenting two economic attributes - costs and CE in the DCE has it's limitation as also absolute costs together with efficacy and safety 
provide insights into CE of a drug. However, only including both economic attributes allowed to raise awareness on the fact that clinicians are still predominantly focused on costs.

Finally, this study provides only insight into stated preferences. It remains unknown whether rheumatologists reach decisions in the same way in clinical practice as they state in the theoretical framework of the DCE. Also, in clinical reality decisional problems may exceed the complexity reflected in the study design. Revealed preferences would be additionally informative, however design and execution of such a study would be very difficult.

Despite limitations, this study reveals that values rheumatologists attach to treatment characteristics vary importantly between countries and among individual rheumatologists. The complexity of today's treatment decisions justifies more research on behavior of prescribers, as the clinicians' attitude is one important factor contributing to quality and equality in healthcare. We hope the current study will raise awareness on the importance of physicians' behaviors and open discussion on how clinicians are expected to trade-off various aspects of a treatment decision.

\section{Conclusion}

Overall, rheumatologists take efforts to balance multiple aspects of a treatment choice including the patient's potential disagreement and the economic consequences. However important differences in the assessment of economic aspects were observed between and within countries. In most countries clinicians still focus on absolute costs while CE would provide more valuable information on the societal consequences of a decision. 


\section{References}

1 Pollard S, Bansback N, Bryan S. Physician attitudes toward shared decision making: A systematic review. Patient education and counseling 2015;98(9):1046-57.

2 Chen YF, Jobanputra $P$, Barton $P$, et al. A systematic review of the effectiveness of adalimumab, etanercept and infliximab for the treatment of rheumatoid arthritis in adults and an economic evaluation of their cost-effectiveness. Health Technol Assess 2006;10(42):iii-iv, xi-xiii, 1-229.

3 Jonsson B, Kobelt G, Smolen J. The burden of rheumatoid arthritis and access to treatment: uptake of new therapies. Eur J Health Econ 2008;8 Suppl 2:S61-86.

4 Putrik $\mathrm{P}$, Ramiro S, Kvien TK, et al. Variations in criteria regulating treatment with reimbursed biologic DMARDs across European countries. Are differences related to country's wealth? Annals of the rheumatic diseases 2014;73(11):2010-21.

5 Stewart M, Brown JB, Donner A, et al. The impact of patient-centered care on outcomes. J Fam Pract 2000;49(9):796-804.

6 Smolen JS, Landewe R, Breedveld FC, et al. EULAR recommendations for the management of rheumatoid arthritis with synthetic and biological disease-modifying antirheumatic drugs: 2013 update. Annals of the rheumatic diseases 2014;73(3):492-509.

7 Smolen JS, Landewe R, Breedveld FC, et al. EULAR recommendations for the management of rheumatoid arthritis with synthetic and biological disease-modifying antirheumatic drugs. Annals of the rheumatic diseases 2010;69(6):964-75.

8 Putrik P, Ramiro S, Kvien TK, et al. Inequities in access to biologic and synthetic DMARDs across 46 European countries. Annals of the rheumatic diseases 2014;73(1):198-206.

9 Jönssona B. RS, Wilking N. Cost effectiveness in practice and its effect on clinical outcomes. Journal of Cancer Policy 2014;2(1):10.

10 Richards M. Extent and causes of international variations in drug usage - A report for the Secretary of State for Health 2010.

11 Coast J, Al-Janabi H, Sutton EJ, et al. Using qualitative methods for attribute development for discrete choice experiments: issues and recommendations. Health Econ 2012;21(6):730-41.

12 Ryan M. Discrete choice experiments in health care. Bmj 2004;328(7436):360-1.

13 van der Velde G, Pham B, Machado M, et al. Cost-effectiveness of biologic response modifiers compared to disease-modifying antirheumatic drugs for rheumatoid arthritis: a systematic review. Arthritis Care Res (Hoboken) 2011;63(1):65-78.

14 Augustovski F, Beratarrechea A, Irazola V, et al. Patient preferences for biologic agents in rheumatoid arthritis: a discrete-choice experiment. Value in health : the journal of the International Society for Pharmacoeconomics and Outcomes Research 2013;16(2):385-93.

15 Muhlbacher AC, Nubling M. Analysis of physicians' perspectives versus patients' preferences: direct assessment and discrete choice experiments in the therapy of multiple myeloma. Eur J Health Econ 2011;12(3):193-203.

16 Muhlbacher AC, Lincke HJ, Nubling M. Evaluating patients' preferences for multiple myeloma therapy, a Discrete-Choice-Experiment. Psychosoc Med 2008;5:Doc10.

17 Barton JL. Patient preferences and satisfaction in the treatment of rheumatoid arthritis with biologic therapy. Patient Prefer Adherence 2009;3:335-44.

18 Tang B, Rahman M, Waters HC, Callegari P. Treatment persistence with adalimumab, etanercept, or infliximab in combination with methotrexate and the effects on health care costs in patients with rheumatoid arthritis. Clin Ther 2008;30(7):1375-84.

19 Kievit W, Adang EM, Fransen J, et al. The effectiveness and medication costs of three anti-tumour necrosis factor alpha agents in the treatment of rheumatoid arthritis from prospective clinical practice data. Annals of the rheumatic diseases 2008;67(9):1229-34.

20 Kievit W, van Hulst L, van Riel P, Fraenkel L. Factors that influence rheumatologists' decisions to escalate care in rheumatoid arthritis: results from a choice-based conjoint analysis. Arthritis Care Res (Hoboken) 2010;62(6):842-7. 
21 Malottki K, Barton P, Tsourapas A, et al. Adalimumab, etanercept, infliximab, rituximab and abatacept for the treatment of rheumatoid arthritis after the failure of a tumour necrosis factor inhibitor: a systematic review and economic evaluation. Health Technol Assess 2011;15(14):1-278.

22 Schoels M, Wong J, Scott DL, et al. Economic aspects of treatment options in rheumatoid arthritis: a systematic literature review informing the EULAR recommendations for the management of rheumatoid arthritis. Annals of the rheumatic diseases 2010;69(6):995-1003.

23 Aletaha $D$, Landewe $R$, Karonitsch $T$, et al. Reporting disease activity in clinical trials of patients with rheumatoid arthritis: EULAR/ACR collaborative recommendations. Arthritis and rheumatism 2008;59(10):1371-7.

24 de Bekker-Grob EW, Ryan M, Gerard K. Discrete choice experiments in health economics: a review of the literature. Health Econ 2012;21(2):145-72.

25 Ngene. http://www.choice-metrics.com/.

26 Reed Johnson F, Lancsar E, Marshall D, et al. Constructing experimental designs for discrete-choice experiments: report of the ISPOR Conjoint Analysis Experimental Design Good Research Practices Task Force. Value in health : the journal of the International Society for Pharmacoeconomics and Outcomes Research 2013;16(1):3-13.

27 Currency converter. http://www.xe.com/currencyconverter/.

28 Nlogit, https://www.limdep.com.

29 Hiligsmann M, Dellaert BG, Dirksen CD, et al. Patients' preferences for osteoporosis drug treatment: a discrete-choice experiment. Arthritis research \& therapy 2014;16(1):R36.

30 NK Malhotra DB. Marketing research: An applied approach. Pearson Education 2007.

31 StataCorp. 2011. Stata Statistical Software: Release 12. College Station TSL.

32 de Bekker-Grob EW, Rose JM, Donkers B, Essink-Bot ML, Bangma CH, Steyerberg EW. Men's preferences for prostate cancer screening: a discrete choice experiment. Br J Cancer 2013;108(3):533-41.

33 Oliver K, Innvar S, Lorenc T, Woodman J, Thomas J. A systematic review of barriers to and facilitators of the use of evidence by policymakers. BMC Health Serv Res 2014;14:2.

34 Joensuu JT, Huoponen S, Aaltonen KJ, Konttinen YT, Nordstrom D, Blom M. The cost-effectiveness of biologics for the treatment of rheumatoid arthritis: a systematic review. PLoS One 2015;10(3):e0119683.

35 Prosser LA, Koplan JP, Neumann PJ, Weinstein MC. Barriers to using cost-effectiveness analysis in managed care decision making. The American journal of managed care 2000;6(2):173-9.

36 Cleemput I, Neyt M, Thiry N, De Laet C, Leys M. Using threshold values for cost per quality-adjusted lifeyear gained in healthcare decisions. International journal of technology assessment in health care 2011;27(1):71-6.

37 Kalkan A, Roback K, Hallert E, Carlsson P. Factors influencing rheumatologists' prescription of biological treatment in rheumatoid arthritis: an interview study. Implement Sci 2014;9:153. 


\section{Supplementary tables}

Table S6.1 The patient profile (as presented in the questionnaire)

\begin{tabular}{ll}
\hline The patient profile & \\
\hline Gender: & Female \\
Age: & 42 years \\
Work participation: & Secretary, mother of 2 children \\
Duration of disease: & 6 months, 3 months of treatment \\
Current disease activity: & Moderate disease activity (DAS28=4.6) with persistent synovitis \\
& Number of swollen joints (SJC): 5 \\
& Number of tender joints (TJC): 5 \\
& Erythrocyte Sedimentation Rate (ESR, mm/hr): 18 \\
& Patient Global Assessment (PGA, 0-100 mm VAS): 49 \\
& \\
Current treatments & MTX 25mg/week and Hydroxychloroquine 400mg/day \\
& Primary failure to the combination and no side effects \\
Prognostic factors: & No erosion \\
Comorbidities: & Anti-CCP positive \\
Risk factors: & No comorbidities \\
\hline
\end{tabular}

Table S6.2 Results from the Random Parameters Logit Model (overall and per country)

All 12 countries combined

\begin{tabular}{|c|c|c|}
\hline Attributes and Levels & $\begin{array}{l}\text { Estimate } \\
\text { (95\% confidence interval) }\end{array}$ & Standard Deviation \\
\hline \multicolumn{3}{|l|}{ Efficacy } \\
\hline Moderate response & Reference level & \\
\hline Good response & $2.299 * * *(2.126$ to 2.472$)$ & $0.306 * * *$ \\
\hline Remission & $3.910 * * *(3.647$ to 4.173$)$ & $0.890 * * *$ \\
\hline \multicolumn{3}{|l|}{ Safety } \\
\hline Very rare & Reference level & \\
\hline Rare & $-0.414^{* * *}(-0.533$ to -0.295$)$ & 0.011 \\
\hline Uncommon & $-1.038^{* * *}(-1.190$ to 0.887$)$ & $0.851^{* * *}$ \\
\hline \multicolumn{3}{|l|}{ Patient's preference } \\
\hline Patient favours treatment & $0.401^{* * *}(0.296$ to 0.505$)$ & 0.188 \\
\hline Patient is neutral & Reference level & \\
\hline Patient disfavours treatment & $-1.031^{* * *}(-1.197$ to -0.865$)$ & $0.977^{* * *}$ \\
\hline $\begin{array}{l}\text { Cost-effectiveness } \\
(10,000 \text { EUR/QALY) }\end{array}$ & $-0.154 * * *(-0.182$ to -0.127$)$ & $0.184 * * *$ \\
\hline $\begin{array}{l}\text { Overall medication costs }(1,000 \\
\text { EUR/year) }\end{array}$ & $-0.121^{* * *}(-0.132$ to -0.109$)$ & $0.658^{* * *}$ \\
\hline Constant & $-0.151 * * *(-0.229$ to 0.074$)$ & \\
\hline
\end{tabular}

*** significant at 1\%, 559 respondents, McFadden Pseudo R-squared =0.39, log-likelihood = -3278 


\begin{tabular}{lll} 
Belgium & & \\
\hline Attributes and Levels & $\begin{array}{l}\text { Estimate } \\
\text { (95\% confidence interval) }\end{array}$ & Standard Deviation \\
Efficacy & Reference level & \\
Moderate response & $2.083^{* * *}(1.462$ to 2.704$)$ & 0.111 \\
Good response & $3.551^{* * *}(2.526$ to 4.576$)$ & $1.236^{* * *}$ \\
Remission & Reference level & \\
Safety & $-0.372(-0.832$ to 0.088$)$ & 0.003 \\
Very rare & $-0.971^{* * *}(-1.559$ to -0.383$)$ & $0.926^{* * *}$ \\
Rare & $0.172(-0.263$ to 0.607$)$ & 0.439 \\
Uncommon & Reference level & \\
Patient's preference & $-0.842^{* * *}(-1.419$ to -0.265$)$ & 0.115 \\
Patient favours treatment & $-0.147^{* * *}(-0.247$ to -0.046$)$ & $0.128^{*}$ \\
Patient is neutral & & \\
Patient disfavours treatment & $-0.117^{* * *}(-0.159$ to -0.073$)$ & 0.030 \\
Cost-effectiveness & -0.143 & \\
(10,000 $€ / Q A L Y)$ & & \\
Overall medication costs & & \\
(1,000 $€ /$ year) & & \\
Constant & &
\end{tabular}

*** significant at $1 \%,{ }^{* *}$ significant at $5 \%,{ }^{*}$ significant at $10 \%$, McFadden Pseudo R-squared $=0.61, \log$ likelihood $=-191$

\begin{tabular}{|c|c|c|}
\hline Attributes and Levels & $\begin{array}{l}\text { Estimate } \\
\text { (95\% confidence interval) }\end{array}$ & Standard Deviation \\
\hline \multicolumn{3}{|l|}{ Efficacy } \\
\hline Moderate response & Reference level & \\
\hline Good response & $2.494^{* * *}(1.811$ to 3.177$)$ & $0.129 * *$ \\
\hline Remission & $3.897 * * *(2.874$ to 4.919$)$ & $1.022 * * *$ \\
\hline \multicolumn{3}{|l|}{ Safety } \\
\hline Very rare & Reference level & \\
\hline Rare & $-0.607 * * * \quad(-1.023$ to -0.191$)$ & 0.777 \\
\hline Uncommon & $-1.777 * * *(-2.440$ to -1.113$)$ & $1.082 * * *$ \\
\hline \multicolumn{3}{|l|}{ Patient's preference } \\
\hline Patient favours treatment & $0.533 * *(-0.114$ to 0.953$)$ & 0.064 \\
\hline Patient is neutral & Reference level & \\
\hline Patient disfavours treatment & $-1.396 * * *(-2.109$ to -0.683$)$ & $1.219 * * *$ \\
\hline $\begin{array}{l}\text { Cost-effectiveness } \\
(10,000 € / Q A L Y)\end{array}$ & $-0.045(-0.128$ to -0.038$)$ & 0.073 \\
\hline $\begin{array}{l}\text { Overall medication costs } \\
(1,000 € / \text { year })\end{array}$ & $-0.090 * * *(-0.133$ to -0.047$)$ & $0.079 * * *$ \\
\hline Constant & -0.161 & \\
\hline
\end{tabular}

$* * *$ significant at $1 \%, * *$ significant at $5 \%,{ }^{*}$ significant at $10 \%$, McFadden Pseudo R-squared $=0.58, \log$ likelihood $=-252$ 


\begin{tabular}{|c|c|c|}
\hline Attributes and Levels & $\begin{array}{l}\text { Estimate } \\
\text { (95\% confidence interval) }\end{array}$ & Standard Deviation \\
\hline \multicolumn{3}{|l|}{ Efficacy } \\
\hline Moderate response & Reference level & \\
\hline Good response & $2.928 * * *(1.940$ to 3.916$)$ & $0.840 * *$ \\
\hline Remission & $5.440 * * *$ (3.678 to 7.203$)$ & $1.297 * * *$ \\
\hline \multicolumn{3}{|l|}{ Safety } \\
\hline Very rare & Reference level & \\
\hline Rare & $-0.645 * * \quad(-1.210$ to -0.081$)$ & 0.078 \\
\hline Uncommon & $-1.210 * * *(-1.942$ to -0.477$)$ & $1.276^{* * *}$ \\
\hline \multicolumn{3}{|l|}{ Patient's preference } \\
\hline Patient favours treatment & $0.574 * *(-0.084$ to 1.063$)$ & 0.354 \\
\hline Patient is neutral & Reference level & \\
\hline Patient disfavours treatment & $-1.281 * * *(-2.094$ to -0.467$)$ & $1.907^{* * *}$ \\
\hline $\begin{array}{l}\text { Cost-effectiveness } \\
(10,000 € / Q A L Y)\end{array}$ & $-0.308 * * *(-0.467$ to -0.148$)$ & $0.182^{* *}$ \\
\hline $\begin{array}{l}\text { Overall medication costs } \\
(1,000 € / \text { year })\end{array}$ & $-0.188^{* * *}(-0.256$ to -0.121$)$ & $0.097^{* *}$ \\
\hline Constant & $-0.401^{* *}$ & \\
\hline
\end{tabular}

$* * *$ significant at $1 \%,{ }^{* *}$ significant at $5 \%,{ }^{*}$ significant at $10 \%$, McFadden Pseudo R-squared $=0.66, \log$ likelihood $=-225$

\begin{tabular}{|c|c|c|}
\hline Attributes and Levels & $\begin{array}{l}\text { Estimate } \\
\text { (95\% confidence interval) }\end{array}$ & Standard Deviation \\
\hline \multicolumn{3}{|l|}{ Efficacy } \\
\hline Moderate response & Reference level & \\
\hline Good response & $2.313^{* * *}(1.774$ to 2.852$)$ & 0.462 \\
\hline Remission & $4.344 * * *(3.463$ to 5.225$)$ & $1.205^{* * *}$ \\
\hline \multicolumn{3}{|l|}{ Safety } \\
\hline Very rare & Reference level & \\
\hline Rare & $-0.413^{* *}(-0.770$ to -0.055$)$ & 0.274 \\
\hline Uncommon & $-1.133^{* * *}(-1.561$ to -0.705$)$ & $0.674 * * *$ \\
\hline \multicolumn{3}{|l|}{ Patient's preference } \\
\hline Patient favours treatment & $0.623 * * * \quad(0.316$ to 0.929$)$ & 0.109 \\
\hline Patient is neutral & Reference level & \\
\hline Patient disfavours treatment & $-0.871^{* * *}(-1.310$ to -0.431$)$ & $0.691^{* * *}$ \\
\hline $\begin{array}{l}\text { Cost-effectiveness } \\
(10,000 € / Q A L Y)\end{array}$ & $-0.224 * * *(-0.326$ to -0.123$)$ & $0.279 * * *$ \\
\hline $\begin{array}{l}\text { Overall medication costs } \\
(1,000 € / \text { year })\end{array}$ & $-0.089 * * *(-0.123$ to -0.056$)$ & $0.062^{* *}$ \\
\hline Constant & -0.149 & \\
\hline
\end{tabular}

$* * *$ significant at $1 \%,{ }^{* *}$ significant at $5 \%,{ }^{*}$ significant at $10 \%$, McFadden Pseudo R-squared $=0.63, \log$ likelihood $=-404$ 


\begin{tabular}{|c|c|c|}
\hline Attributes and Levels & $\begin{array}{l}\text { Estimate } \\
\text { (95\% confidence interval) }\end{array}$ & Standard Deviation \\
\hline \multicolumn{3}{|l|}{ Efficacy } \\
\hline Moderate response & Reference level & \\
\hline Good response & $2.412^{* * *}(1.811$ to 3.013$)$ & 0.149 \\
\hline Remission & $4.664^{* * *}(3.660$ to 5.666$)$ & $0.787 * *$ \\
\hline \multicolumn{3}{|l|}{ Safety } \\
\hline Very rare & Reference level & \\
\hline Rare & $-0.886^{* * *}(-1.319$ to -0.453$)$ & 0.022 \\
\hline Uncommon & $-1.754 * * *(-2.340$ to -1.169$)$ & $1.029 * * *$ \\
\hline \multicolumn{3}{|l|}{ Patient's preference } \\
\hline Patient favours treatment & $0.489 * * *(0.137$ to 0.841$)$ & 0.194 \\
\hline Patient is neutral & Reference level & \\
\hline Patient disfavours treatment & $-0.968 * * *(-1.575$ to -0.361$)$ & $1.374 * * *$ \\
\hline $\begin{array}{l}\text { Cost-effectiveness } \\
(10,000 € / Q A L Y)\end{array}$ & $-0.144 * * * \quad(-0.235$ to -0.053$)$ & $0.169 * * *$ \\
\hline $\begin{array}{l}\text { Overall medication costs } \\
(1,000 € / \text { year })\end{array}$ & $-0.116^{* * *}(-0.158$ to -0.075$)$ & $0.072 * * *$ \\
\hline Constant & $-0.313 * *$ & \\
\hline \multicolumn{3}{|c|}{$\begin{array}{l}* * * \text { significant at } 1 \%, * * \text { significant at } 5 \%, * \text { significant at } 10 \%, \text { McFadden Pseudo R-squared }=0.64, \log \\
\text { likelihood }=-315\end{array}$} \\
\hline \multicolumn{3}{|l|}{ The Netherlands } \\
\hline Attributes and Levels & $\begin{array}{l}\text { Estimate } \\
\text { (95\% confidence interval) }\end{array}$ & Standard Deviation \\
\hline \multicolumn{3}{|l|}{ Efficacy } \\
\hline Moderate response & Reference level & \\
\hline Good response & $2.395^{* * *}(1.809$ to 2.981$)$ & $0.493^{*}$ \\
\hline Remission & $4.400 * * *(3.431$ to 5.369$)$ & $0.990 * * *$ \\
\hline \multicolumn{3}{|l|}{ Safety } \\
\hline Very rare & Reference level & \\
\hline Rare & $0.141(-0.227$ to 0.509$)$ & 0.044 \\
\hline Uncommon & $0.051(-0.423$ to 0.527$)$ & $1.008^{* * *}$ \\
\hline \multicolumn{3}{|l|}{ Patient's preference } \\
\hline Patient favours treatment & $0.290 *(-0.046$ to 0.626$)$ & 0.016 \\
\hline Patient is neutral & Reference level & \\
\hline Patient disfavours treatment & $-1.453 * * *(-2.009$ to -0.897$)$ & $0.838 * * *$ \\
\hline $\begin{array}{l}\text { Cost-effectiveness } \\
(10,000 € / Q A L Y)\end{array}$ & $-0.228 * * *(-0.326$ to -0.130$)$ & $0.205^{* * *}$ \\
\hline $\begin{array}{l}\text { Overall medication costs } \\
(1,000 € / \text { year })\end{array}$ & $-0.177 * * *(-0.227$ to -0.126$)$ & $0.087^{* * *}$ \\
\hline Constant & $-0.262 * *(-0.517$ to 0.007$)$ & \\
\hline
\end{tabular}

$* * *$ significant at $1 \%, * *$ significant at $5 \%, *$ significant at $10 \%$, McFadden Pseudo R-squared $=0.46$, loglikelihood $=-328$ 


\begin{tabular}{|c|c|c|}
\hline Attributes and Levels & $\begin{array}{l}\text { Estimate } \\
\text { (95\% confidence interval) }\end{array}$ & Standard Deviation \\
\hline \multicolumn{3}{|l|}{ Efficacy } \\
\hline Moderate response & Reference level & \\
\hline Good response & $2.929 * * *(2.044$ to 3.812$)$ & 0.129 \\
\hline Remission & $4.320 * * *(3.098$ to 5.542$)$ & $1.022 * * *$ \\
\hline \multicolumn{3}{|l|}{ Safety } \\
\hline Very rare & Reference level & \\
\hline Rare & $-0.302(-0.789$ to -0.185$)$ & 0.040 \\
\hline Uncommon & $-1.043^{* * *}(-1.738$ to -0.342$)$ & $1.245^{* * *}$ \\
\hline \multicolumn{3}{|l|}{ Patient's preference } \\
\hline Patient favours treatment & $0.237(-0.222$ to 0.696$)$ & $0.542^{*}$ \\
\hline Patient is neutral & Reference level & \\
\hline Patient disfavours treatment & $-1.273^{* * *}(-1.996$ to -0.551$)$ & $0.947^{* * *}$ \\
\hline $\begin{array}{l}\text { Cost-effectiveness } \\
(10,000 € / Q A L Y)\end{array}$ & $-0.211^{* *^{*}}(-0.348$ to -0.074$)$ & $0.311^{* * *}$ \\
\hline $\begin{array}{l}\text { Overall medication costs } \\
(1,000 € / \text { year })\end{array}$ & $-0.193 * * *(-0.251$ to -0.014$)$ & 0.018 \\
\hline Constant & -0.150 & \\
\hline
\end{tabular}

$* * *$ significant at $1 \%, * *$ significant at $5 \%, *$ significant at $10 \%$, McFadden Pseudo R-squared $=0.65$, loglikelihood $=-219$

\begin{tabular}{|c|c|c|}
\hline Attributes and Levels & $\begin{array}{l}\text { Estimate } \\
\text { (95\% confidence interval) }\end{array}$ & Standard Deviation \\
\hline \multicolumn{3}{|l|}{ Efficacy } \\
\hline Moderate response & Reference level & \\
\hline Good response & $3.399 * * *(2.194$ to 4.604$)$ & 0.518 \\
\hline Remission & $5.066 * * *(3.417$ to 6.715$)$ & $0.704^{*}$ \\
\hline \multicolumn{3}{|l|}{ Safety } \\
\hline Very rare & Reference level & \\
\hline Rare & $-1.140 * * * \quad(-1.747$ to -0.533$)$ & 0.109 \\
\hline Uncommon & $-2.487 * * *(-3.495$ to -1.480$)$ & $1.315^{* * *}$ \\
\hline \multicolumn{3}{|l|}{ Patient's preference } \\
\hline Patient favours treatment & $0.003(-0.506$ to 0.501$)$ & 0.176 \\
\hline Patient is neutral & Reference level & \\
\hline Patient disfavours treatment & $-1.690 * * *(-2.568$ to -0.811$)$ & $1.038^{* * *}$ \\
\hline $\begin{array}{l}\text { Cost-effectiveness } \\
(10,000 € / Q A L Y)\end{array}$ & $-0.180 * *(-0.319$ to -0.040$)$ & $0.257 * * *$ \\
\hline $\begin{array}{l}\text { Overall medication costs } \\
(1,000 € / \text { year })\end{array}$ & $-0.194 * * *(-0.262$ to -0.126$)$ & $0.082 * * *$ \\
\hline Constant & -0.236 & \\
\hline
\end{tabular}

$* * *$ significant at $1 \%,{ }^{* *}$ significant at $5 \%,{ }^{*}$ significant at $10 \%$, McFadden Pseudo R-squared $=0.64, \log$ likelihood $=-212$ 


\begin{tabular}{|c|c|c|}
\hline Attributes and Levels & $\begin{array}{l}\text { Estimate } \\
\text { (95\% confidence interval) }\end{array}$ & Standard Deviation \\
\hline \multicolumn{3}{|l|}{ Efficacy } \\
\hline Moderate response & Reference level & \\
\hline Good response & $4.963^{* * *}(1.716$ to 8.209$)$ & $2.445 * *$ \\
\hline Remission & $8.859 * * *(3.660$ to 14.057$)$ & $4.651^{* * *}$ \\
\hline \multicolumn{3}{|l|}{ Safety } \\
\hline Very rare & Reference level & \\
\hline Rare & $-1.145^{* *}(-2.204$ to -0.087$)$ & 0.101 \\
\hline Uncommon & $-3.311^{* * *}(-5.353$ to -1.268$)$ & $2.885^{* * *}$ \\
\hline \multicolumn{3}{|l|}{ Patient's preference } \\
\hline Patient favours treatment & $0.043(-0.825$ to 0.738$)$ & $1.050 * *$ \\
\hline Patient is neutral & Reference level & \\
\hline Patient disfavours treatment & $-1.116 * *(-2.139$ to -0.093$)$ & $1.232 * * *$ \\
\hline $\begin{array}{l}\text { Cost-effectiveness } \\
(10,000 € / Q A L Y)\end{array}$ & $-0.113 \quad(-0.297$ to -0.070$)$ & $0.286 * * *$ \\
\hline $\begin{array}{l}\text { Overall medication costs } \\
(1,000 € / \text { year })\end{array}$ & $-0.226 * * *(-0.397$ to -0.545$)$ & $0.209 * * *$ \\
\hline Constant & -0.572 & \\
\hline
\end{tabular}

$* * *$ significant at $1 \%, * *$ significant at $5 \%, *$ significant at $10 \%$, McFadden Pseudo R-squared= 0.63 , loglikelihood $=-236$

\begin{tabular}{|c|c|c|}
\hline Attributes and Levels & $\begin{array}{l}\text { Estimate } \\
(95 \% \text { confidence interval) }\end{array}$ & Standard Deviation \\
\hline \multicolumn{3}{|l|}{ Efficacy } \\
\hline Moderate response & Reference level & \\
\hline Good response & $3.330 * * *(2.473$ to 4.187$)$ & $0.630 * *$ \\
\hline Remission & $5.348^{* * *}(4.035$ to 6.662$)$ & $1.044^{* * *}$ \\
\hline \multicolumn{3}{|l|}{ Safety } \\
\hline Very rare & Reference level & \\
\hline Rare & $-0.165 \quad(-0.581$ to -0.251$)$ & 0.058 \\
\hline Uncommon & $-1.132 * * *(-1.731$ to -0.533$)$ & $1.360 * * *$ \\
\hline \multicolumn{3}{|l|}{ Patient's preference } \\
\hline Patient favours treatment & $0.711^{* * *}(0.285$ to 1.138$)$ & 0.546 \\
\hline Patient is neutral & Reference level & \\
\hline Patient disfavours treatment & $-1.444 * * *(-2.165$ to -0.723$)$ & $1.558 * * *$ \\
\hline $\begin{array}{l}\text { Cost-effectiveness } \\
(10,000 € / \text { QALY })\end{array}$ & $-0.209 * * *(-0.329$ to -0.089$)$ & $0.343^{* * *}$ \\
\hline $\begin{array}{l}\text { Overall medication costs } \\
(1,000 € / \text { year })\end{array}$ & $-0.156 * * *(-0.204$ to -0.106$)$ & $0.087 * * *$ \\
\hline Constant & -0.018 & \\
\hline
\end{tabular}




\begin{tabular}{|c|c|c|}
\hline Attributes and Levels & $\begin{array}{l}\text { Estimate } \\
\text { (95\% confidence interval) }\end{array}$ & Standard Deviation \\
\hline \multicolumn{3}{|l|}{ Efficacy } \\
\hline Moderate response & Reference level & \\
\hline Good response & $2.809 * * *(1.799$ to 3.820$)$ & 0.285 \\
\hline Remission & $5.049 * * *(3.247$ to 6.852$)$ & $1.213^{* * *}$ \\
\hline \multicolumn{3}{|l|}{ Safety } \\
\hline Very rare & Reference level & \\
\hline Rare & $-0.815^{* *} \quad(-1.489$ to -0.141$)$ & 0.163 \\
\hline Uncommon & $-1.276 * * *(-2.061$ to -0.492$)$ & 0.482 \\
\hline \multicolumn{3}{|l|}{ Patient's preference } \\
\hline Patient favours treatment & $0.471(-0.167$ to 1.108$)$ & 0.654 \\
\hline Patient is neutral & Reference level & \\
\hline Patient disfavours treatment & $-1.753 * * *(-2.822$ to -0.684$)$ & $1.354^{* * *}$ \\
\hline $\begin{array}{l}\text { Cost-effectiveness } \\
(10,000 € / \text { QALY })\end{array}$ & $-0.189 * * *(-0.207$ to -0.084$)$ & 0.136 \\
\hline $\begin{array}{l}\text { Overall medication costs } \\
(1,000 € / \text { year })\end{array}$ & $-0.146^{* * *}(-0.251$ to -0.014$)$ & 0.030 \\
\hline Constant & -0.300 & \\
\hline
\end{tabular}

$* * *$ significant at $1 \%,{ }^{* *}$ significant at $5 \%,{ }^{*}$ significant at $10 \%$, McFadden Pseudo R-squared $=0.67, \log$ likelihood $=-118$

\begin{tabular}{|c|c|c|}
\hline Attributes and Levels & $\begin{array}{l}\text { Estimate } \\
\text { (95\% confidence interval) }\end{array}$ & Standard Deviation \\
\hline \multicolumn{3}{|l|}{ Efficacy } \\
\hline Moderate response & Reference level & \\
\hline Good response & $1.922 * * *(1.299$ to 2.544$)$ & 0.416 \\
\hline Remission & $3.465 * * *(2.538$ to 4.392$)$ & $0.881^{* *}$ \\
\hline \multicolumn{3}{|l|}{ Safety } \\
\hline Very rare & Reference level & \\
\hline Rare & $0.003 \quad(-0.472$ to 0.478$)$ & 0.001 \\
\hline Uncommon & $-0.194 \quad(-0.680$ to 0.291$)$ & 0.048 \\
\hline \multicolumn{3}{|l|}{ Patient's preference } \\
\hline Patient favours treatment & $0.441 * * \quad(0.075$ to 0.808$)$ & 0.242 \\
\hline Patient is neutral & Reference level & \\
\hline Patient disfavours treatment & $-1.220 * * *(-1.943$ to -0.497$)$ & $1.604^{* * *}$ \\
\hline $\begin{array}{l}\text { Cost-effectiveness } \\
(10,000 € / Q A L Y)\end{array}$ & $-0.309 * * *(-0.441$ to -0.176$)$ & $0.205^{* * *}$ \\
\hline $\begin{array}{l}\text { Overall medication costs } \\
(1,000 € / \text { year })\end{array}$ & $-0.135^{* * *}(-0.178$ to -0.092$)$ & 0.044 \\
\hline Constant & $-0.322 * *$ & \\
\hline
\end{tabular}

$* * *$ significant at $1 \%,{ }^{* *}$ significant at $5 \%,{ }^{*}$ significant at $10 \%$, McFadden Pseudo R-squared $=0.46, \log$ likelihood $=-228$ 


\section{Chapter}

\section{Influence of disease activity on RA treatment choices in countries with restricted access to expensive, innovative drugs: a discrete choice experiment among rheumatologists}

M. Hifinger, M. Hiligsmann, S. Ramiro, V. Watson, F. Berghea, M. Péntek, A. Keat, J.L. Severens, B. Fautrel, A. Boonen RMD open, 2017; doi: 10.1136/rmdopen-2017-000453. [Epub ahead of print] 


\section{Abstract}

\section{Objective}

To assess the influence of disease activity of RA patients on treatment choices of rheumatologists in countries with restricted access to expensive, innovative drugs.

\section{Methods}

Rheumatologists from Hungary, Romania and United Kingdom were invited to complete two consecutive discrete choice experiments (DCE) with hypothetical drug treatments for two different patient profiles - high and moderate disease activity. Rheumatologists were asked to choose repeatedly between two unlabelled treatment options that differed in five attributes: efficacy (expected improvement and achieved disease activity state), safety (probability of serious adverse events), patients' preference (level of agreement), total medication costs and cost-effectiveness. A heteroscedastic discrete choice model using interaction terms between attribute levels and patient profiles (binary variable) was used to assess the preferences of rheumatologists towards each attribute and the influence of the patient profile.

\section{Results}

Overall, 148 rheumatologists completed the survey (46\% females, mean age 49 years, $49 \%$ academic). For both patient profiles, efficacy dominated the treatment choice over patients' preference, safety and economic aspects. However, for patients with high compared to moderate disease activity, the importance of drug efficacy significantly increased (from $48 \%$ for moderate to $57 \%$ for high disease activity), whereas the importance of patients' preferences significantly decreased (from 15\% to $11 \%$ ). No significant differences were observed for economic- and safety considerations.

\section{Conclusion}

Rheumatologists were willing to give up some efficacy to account for patients' preference when choosing treatments for patients with moderate compared to high disease activity. Disease activity however did not influence importance of economic aspects in treatment choices. 


\section{Introduction}

Latest treatment recommendations for patients with rheumatoid arthritis (RA) suggest that treatment of RA patients should not only aim to lower disease activity but should target remission in every patient. Initial treatment should include conventional synthetic disease modifying anti-rheumatic drugs (csDMARDs). When the treatment target cannot be achieved and disease remains at least moderately active despite csDMARDs (with or without steroids), addition of a biologic DMARD (bDMARD) should be considered. ${ }^{1}$

It has been widely acknowledged that the complexity of clinical decision making increased enormously. While exploding healthcare costs call for cost-effective treatment choices, the philosophy of patient centeredness and shared decision making has been widely advocated as approach that improves health outcomes. ${ }^{2-4}$ However, cost constraints may frequently come at the expense of patients' preference and even may compromise freedom of choice towards more efficacious drugs, thus posing a great challenge to doctors.

The drivers of rheumatologists' treatment decisions are intriguing but still little is known about this topic and insight is needed into how rheumatologists value different aspects such as costs, cost-effectiveness (CE) or patients' preferences when making treatment decisions. Recent studies revealed that across countries and independent of sociodemographic background, rheumatologists balance different characteristics of a drug treatment ${ }^{7,8}$ when choosing treatments for their RA patients. Drug efficacy clearly dominated the treatment choices, while clinicians were increasingly willing to consider economic implications as well as patients' preferences (in particular when patients expressed their dislike). However, it is not known to what extent the level of disease activity influences preferences in the treatment choice.

Reimbursement and budget restrictions experienced in daily clinical care may contribute to treatment benefits and costs. Especially in countries where access to expensive drugs is more restricted, rheumatologists might more consciously trade-off different drug treatment characteristics.

The present study therefore aimed to investigate, how the patient's disease status influenced the personal attitude of rheumatologists towards the different drug characteristics and how the importance of these characteristics changed when facing a different patient's disease profile. 


\section{Methods}

A discrete choice experiment (DCE) among rheumatologists was designed to assess the relative importance of different drug characteristics when selecting a drug treatment for a patient with RA. A DCE is based on the assumption that interventions can be described by characteristics (attributes) and corresponding attribute levels. In our study, rheumatologists from three countries with access to innovative, expensive antirheumatic drugs restricted to patients with high disease activity, were asked to select the preferred drug treatment in a series of choices that contained two hypothetical treatment options ( $A$ and $B$ ). Each treatment was described by a set of attributes and levels. ${ }^{9}$ To understand how the patient's disease characteristics would influence treatment choice, the DCE was repeated for two patient-profiles, differing in the level of disease activity (Figure 7.1).

\begin{tabular}{|c|c|c|}
\hline \multicolumn{3}{|l|}{ The patient profile } \\
\hline $\begin{array}{l}\text { Gender: } \\
\text { Age: } \\
\text { Work participation: } \\
\text { Duration of disease: } \\
\text { Current treatments } \\
\text { Prognostic factors: } \\
\text { Comorbidities: } \\
\text { Risk factors: }\end{array}$ & $\begin{array}{l}\text { Female } \\
42 \text { years } \\
\text { Secretary, mother of } 2 \\
6 \text { months, } 3 \text { months of } t \\
\text { Methotrexate } 25 \mathrm{mg} / \text { we } \\
\text { Primary failure to the co } \\
\text { No erosion } \\
\text { aCCP positive } \\
\text { No comorbidities } \\
\text { Smoking }\end{array}$ & $\begin{array}{l}\text { ildren } \\
\text { atment } \\
\text { and Hydroxychloroquine } 400 \mathrm{mg} / \text { day } \\
\text { bination and no side effects }\end{array}$ \\
\hline \multicolumn{3}{|r|}{$\mathbf{r}$} \\
\hline \multicolumn{2}{|c|}{ High disease activity at baseline } & Moderate disease activity at baseline \\
\hline $\begin{array}{l}\text { High disease activit } \\
\text { with persistent synov } \\
\text { - Number of swollen jo } \\
\text { - Number of tender join } \\
\text { - Erythrocyte Sediment } \\
\text { - Patient Global Asses }\end{array}$ & $\begin{array}{l}\text { S28=5.2) } \\
\text { JC): } 8 \\
\text { C): } 6 \\
\text { Rate }(E S R, \mathrm{~mm} / \mathrm{hr}): 26 \\
\left(P G A, 0-100 \mathrm{~mm} \vee A S^{\star}\right): 56\end{array}$ & $\begin{array}{l}\text { Moderate disease activity (DAS28=4.6) } \\
\text { with persistent synovitis } \\
\text { - Number of swollen joints }(\mathrm{SJC}): 5 \\
\text { - Number of tender joints }(\mathrm{TJC}): 5 \\
\text { - Erythrocyte Sedimentation Rate }(\mathrm{ESR}, \mathrm{mm} / \mathrm{hr}): 18 \\
\text { - Patient Global Assessment }(P G A, 0-100 \mathrm{~mm} \text { VAS }): 49\end{array}$ \\
\hline
\end{tabular}

Figure 7.1 The patient profiles presented to rheumatologists in the discrete choice experiment (DCE). aCCP=anti-cyclic citrullinated peptide; DAS28=28-joint Disease Activity Score, VAS=visual analogue scale 


\section{Data collection}

Rheumatologists have been recruited from three countries that restrict access to expensive drug treatments to patients with high disease activity (28-joint Disease Activity Score (DAS28) >5.1) and participated in the international study ${ }^{8}$ - (Hungary (HU), Romania (RO) and United Kingdom (UK).

From October 2014 until May 2015, certified and clinically active rheumatologists were invited to participate in this study. An anonymous online survey was distributed by email through a national principle investigator (PI) per country. Pls were requested to invite at least 150 rheumatologists per country, applying different approaches (convenience sampling, systematic involvement of societies, snowball sampling techniques).

\section{The patient profiles}

Both profiles were developed together with clinical rheumatologists $(n=8)$. The smoking female RA patient was diagnosed 6 months ago, and was anti-cyclic citrullinated peptide (aCCP) positive but non erosive. She continued to have active disease despite two CSDMARDs. In the first profile, the patient had moderate disease activity defined as a DAS28 of 4.6, while in the second profile, the patient had high disease activity with a DAS28 of 5.2. Both profiles indicated a need for treatment change when following international treatment recommendations.

\section{Design of discrete choice task and experiment}

In a DCE, careful selection of attributes and their levels is essential to obtain valid results. ${ }^{10}$ In this study, a step-wise approach was followed that emphasized that patient's preferences and the economic attributes of treatment had to be included to meet the study objectives. First, potentially important attributes, attribute definitions and levels related to choosing RA treatments were identified from the literature. Second, a consensus meeting with an expert group ( $n=6)$ consisting of rheumatologists and methodologists in the field of economic evaluations, DCE and decision making was performed to agree on an initial list of attributes. Third, the proposed candidate attributes, attribute definitions and levels were further discussed with rheumatologists $(n=8)$ that were not involved in previous steps to ensure they reflected clinical realities. In summary, treatment options were characterized by five characteristics, each specified by three levels; expected treatment efficacy (level of improvement and achieved state of disease activity), safety (probability of a serious adverse event, (AE)), patients' preference (level of agreement with proposed treatment), total medication costs and CE (incremental cost-effectiveness ratio (ICER)). An overview of final attributes, levels and level descriptions can be found in Table 7.1. 
Table 7.1 Attributes and levels describing drug treatment options in the discrete choice experiment

\begin{tabular}{|c|c|c|}
\hline $\begin{array}{l}\text { ATTRIBUTES AND ATTRIBUTE } \\
\text { DEFINITIONS }\end{array}$ & ATTRIBUTE LEVELS & LEVEL DESCRIPTIONS \\
\hline \multirow{3}{*}{$\begin{array}{l}\text { Efficacy } \\
\text { *Expected improvement } \\
\text { and status of disease activity } \\
\text { based on DAS } 28\end{array}$} & $\begin{array}{l}\text { 1. Good DAS28 response - } \\
\text { remission achieved }\end{array}$ & $\begin{array}{l}\text { DAS28 improvement by } 3.0 \text { points } \\
\text { Achievement of } \text { remission } \\
(\text { DAS } 28<2.6)\end{array}$ \\
\hline & $\begin{array}{l}\text { 2. Good DAS } 28 \text { response - } \\
\text { low disease activity } \\
\text { achieved }\end{array}$ & $\begin{array}{l}\text { DAS } 28 \text { improvement by } 2.0 \text { points } \\
\text { Achievement of low disease activity } \\
(2.6<\text { DAS } 28 \leq 3.2)\end{array}$ \\
\hline & Moderate DAS28 response & $\begin{array}{l}\text { DAS28 improvement by } 1.0 \text { point } \\
\text { Low disease activity or remission } \\
\text { cannot be achieved (DAS } 28 \text { remains } \\
>3.2 \text { ) }\end{array}$ \\
\hline $\begin{array}{l}\text { Safety } \\
\text { Probability of a serious adverse } \\
\text { event }\end{array}$ & $\begin{array}{l}\text { 1. Very rare } \\
\text { 2. Rare } \\
\text { 3. Uncommon }\end{array}$ & $\begin{array}{l}5 \text { out of } 100,000 \text { patients } \\
5 \text { out of } 10,000 \text { patients } \\
5 \text { out of } 1,000 \text { patients }\end{array}$ \\
\hline $\begin{array}{l}\text { Patient's Preference } \\
\text { Patient expressed level of } \\
\text { agreement with treatment choice }\end{array}$ & $\begin{array}{l}\text { 1. } \quad \text { Treatment favoured } \\
\text { 2. Neutral } \\
\text { 3. } \\
\text { Treatment disfavoured }\end{array}$ & \\
\hline $\begin{array}{l}\text { Cost-effectiveness } \\
{ }^{* *} I C E R \text {, in costs per QALY gained }\end{array}$ & $\begin{array}{l}\text { 1. Favourable } \\
\text { 2. Moderate } \\
\text { 3. Unfavourable }\end{array}$ & $\begin{array}{l}15,000 € / \text { QLLY } \\
30,000 € / \text { QLLY } \\
75,000 € / \text { QALY }\end{array}$ \\
\hline $\begin{array}{l}\text { Overall medication costs } \\
\text { Per year*** }\end{array}$ & $\begin{array}{l}\text { 1. Low } \\
\text { 2. Medium } \\
\text { 3. High }\end{array}$ & $\begin{array}{r}800 € / \text { year } \\
8,000 € / \text { year } \\
14,000 € / \text { year }\end{array}$ \\
\hline
\end{tabular}

DAS28=28-joint Disease Activity Score; ICER =incremental cost effectiveness ratio, QALY=quality-adjusted life year, EUR= Euro. * In the choice sets, also changes of the individual DAS28 components (tender joint count (TJC), swollen joint count (SJC), erythrocyte sedimentation rate (ESR), patient global assessment of disease activity (PGA)) were presented; ** ICER in costs (Euro, $€$ ) per QALY gained for the selected treatment compared to usual care; ${ }^{* * *}$ Economic attributes and levels were presented in local currencies ${ }^{11}$

To increase the response rate and/or improve response reliability, ${ }^{12}$ the number of choice sets in the DCE had to be limited. ${ }^{13}$ A Bayesian efficient experimental design was applied, resulting in 14 choice sets per patient profile (Ngene software ${ }^{14}$ ). A Bayesian design maximizes precision of estimated parameters for a given number of choice questions, ${ }^{9}$ by incorporating a priori information about the sign and value of parameters. A pilot DCE experiment with 10 rheumatologists was performed to generate the a priori information. Further, to avoid presenting respondents with implausible treatment options, the experimental design was restricted to realistic combinations between efficacy, costs and CE (e.g. within a choice option, a treatment with highest efficacy levels and lowest cost levels could not be allocated to the worst CE level). A dominance test (a choice set with one treatment option clearly dominating the other to ensure that treatment options were carefully reviewed by respondents) and two re-test choice sets 
(repetition of a choice set to assess test-retest reliability) were integrated in the final design. An example of a choice set is shown in Figure 7.2.

\begin{tabular}{|c|c|c|}
\hline EXAMPLE CHOICE SET & TREATMENT A & TREATMENT B \\
\hline $\begin{array}{l}\text { Improvement of DAS28 disease } \\
\text { activity* }\end{array}$ & $\begin{array}{l}\text { Good response - } \\
\text { Low disease activity achieved } \\
\text { DAS28 improved from } 5.2 \text { to } 3.2 \\
\text { SC Jimproved from } 8 \text { to } 3 \\
\text { TJC improved from } 6 \text { to } 3 \\
\text { ESR improved from } 26 \text { to } 7 \\
\text { PGA improved from } 56 \text { to } 30\end{array}$ & $\begin{array}{l}\text { Good response - } \\
\text { remission achieved } \\
\text { DAS28 improved from } 5.2 \text { to } 2.2 \\
\text { SCJ Improved from } 8 \text { to } 1 \\
: \quad \text { TJC improved from } 6 \text { to } 2 \\
\text { ESR improved from } 26 \text { to } 3 \\
\text { PGA improved from } 56 \text { to } 23\end{array}$ \\
\hline Risk of serious adverse events & $\begin{array}{l}\text { Rare - } \\
5 \text { patients out of } 10,000 \text { patients }\end{array}$ & $\begin{array}{l}\text { Uncommon - } \\
5 \text { patients out of } 1,000 \text { patients }\end{array}$ \\
\hline Patient's preference & The patient disfavours treatment & The patient favours treatment \\
\hline Cost-effectiveness $^{\star *}$ & $\begin{array}{l}\text { Unfavourable - } \\
75,000 \text { EUR/QALY }\end{array}$ & $\begin{array}{l}\text { Moderate - } \\
\text { 30,000 EUR/QALY }\end{array}$ \\
\hline Medication costs & $\begin{array}{l}\text { High - } \\
14,000 \text { EUR/year }\end{array}$ & $\begin{array}{l}\text { High - } \\
14,000 \text { EUR/year }\end{array}$ \\
\hline $\begin{array}{l}\text { Which treatment would you choose } \\
\text { for the patient? }\end{array}$ & Treatment A & $\begin{array}{c}\text { Treatment B } \\
X\end{array}$ \\
\hline
\end{tabular}

In the example choice set the respondent preferred treatment B over treatment $A$ when choosing a drug treatment for a patient with high disease activity

Figure 7.2 Example choice set. DAS28=28-joint Disease Activity Score, QALY=quality-adjusted life year, EUR= Euro. ${ }^{*}$ In the choice sets, also changes of the individual DAS28 components (tender joint count (TJC), swollen joint count (SJC), erythrocyte sedimentation rate (ESR), patient global assessment of disease activity (PGA)) were presented; ** Cost-effectiveness in costs (Euro) per QALY gained for the selected treatment compared to usual care

\section{The questionnaire}

The questionnaire had four parts, with the first part providing a description of the DCE task, followed by an explanation of attributes and levels and a description of the patient profiles (Figure 7.1). The second and third part contained both DCE experiments (for two different patient profiles, respectively). The last part of the survey collected sociodemographic background information of respondents to support interpretation of results. A pilot study of the survey was conducted among rheumatologists $(n=14)$ before dissemination of the final questionnaire. The online questionnaire was distributed using Qualtrics. $^{15}$

\section{Statistical analysis}

Responses were considered for data analysis when both DCE tasks were completed and participants successfully passed the dominance test (a choice set in which one option clearly outweighs the other option). 
A (utility) model was constructed with the observable relative rheumatologists' treatment preference (utility $U$ ) of rheumatologist (i) for a treatment choice (j) defined as a sum of preference scores for characteristics' levels.

$\mathrm{U}_{\mathrm{ij}}=\beta_{0}+\beta_{1}$ Good response $+\beta_{2}$ Remission $+\beta_{3}$ Rare $A E+\beta_{4}$ Uncommon $A E+\beta_{5}$ Favoured by patient $+\beta_{6}$ Disfavoured by patient $+\beta_{7}$ Cost-effectiveness $+\beta_{8}$ Costs

$\beta_{0}$ is the constant, $\beta_{1-8}$ are the mean attribute utility weights (rheumatologists' preferences) for the respective attribute. A positive significant coefficient, $\beta$, means that the respective attribute levels significantly increase overall treatment preference (utility). This is e.g. expected for treatment efficacy (both levels) or patient's agreement with a drug treatment option. A negative significant coefficient, $\beta$ in contrast means that the respective attribute level decreases the treatment preference, which is e.g. for safety (both levels), a patient's disagreement with a drug as well as increased costs. A possible non-linear relationship between attributes has been ruled out using interaction studies. The findings are in line with what was assumed in other DCEs that investigate economic considerations and/or patients' preferences in treatment choices. ${ }^{16,17}$ Of note, cost and CE were presented as discrete levels in the experiments, they were coded as continuous variables in the model with a linear specification providing a better model fit. $^{18,19}$

To investigate differences in treatment preferences between patient profiles, a heteroscedastic extreme value (HEV) model was selected (Nlogit, version $5^{20}$ ). The HEV model took into account scale heterogeneity between countries, while assuming the errors were identical across alternatives (profiles) and individuals (rheumatologists). A heteroscedastic discrete choice model using interaction terms between attribute levels and patient profiles (binary variable) was used to assess the attitude of rheumatologists towards each attribute and the influence of the patient profile. In the heteroscedastic model, a significant interaction reveals a significant differences in rheumatologists' treatment preferences for a certain characteristics across the two patient profiles. $^{21}$

Finally, the relative importance of the characteristics for each profile was estimated. The relative importance weights were calculated using the method described by Malhotra and Birks, ${ }^{22}$ by dividing the range of the level coefficients for one attribute by the sum of ranges of all attributes. Of note, for categorical variables the range is derived between the lowest and the highest level value.

\section{Results}

Overall 148 rheumatologists from three countries - HU ( $n=71), R O(n=42)$, UK $(n=35)$ completed the DCE and were included in the analysis. None of the respondents that completed both DCE tasks failed the dominance test. Mean age of participants was 
49 (SD 11) years, $46 \%$ being female. $49 \%$ of respondents worked in an academic setting. Further details can be found in Table 7.2.

Table 7.2 Rheumatologists' characteristics

\begin{tabular}{|c|c|c|c|c|}
\hline Country/N & Allcountries & $\mathrm{HU}$ & RO & UK \\
\hline characteristics & $N=148$ & $N=71$ & $\mathrm{~N}=42$ & $N=35$ \\
\hline Mean age (years \pm SD) & $49 \pm 11$ & $51 \pm 11$ & $43 \pm 9$ & $54 \pm 8$ \\
\hline Gender (\% female) & $46 \%$ & $69 \%$ & $58 \%$ & $23 \%$ \\
\hline Work environment (\% academic) & $49 \%$ & $49 \%$ & $47 \%$ & $55 \%$ \\
\hline
\end{tabular}

$\mathrm{HU}=$ Hungary, $\mathrm{RO}=$ Romania, $\mathrm{UK}=$ United Kingdom, $\mathrm{N}=$ number of responses per country and overall,

\section{Rheumatologist's preferences for a treatment choice for a patient with moderate and high disease activity}

Interactions between patient profile and efficacy (both levels) as well as between profile and patients' disagreement with treatment were significant $(p<0.05)$. Table 7.3 presents the analyses for both patient profiles.

Efficacy had the strongest contribution to the treatment choice independent of the patient profile. However, the relevance of efficacy somewhat decreased in the treatment choice when changing the profile from high $\left(\beta_{\text {Good response }}=1.97, \beta_{\text {Remission }}=3.25\right.$ ) to moderate disease activity ( $\beta_{\text {Good response }}=1.57, \beta_{\text {Remission }} 2.77$ ). The relative importance of efficacy decreased accordingly from $57 \%$ for patients with high disease activity to $48 \%$ for patients with moderate disease activity. The decrease in rheumatologists' treatment preference was seen for both efficacy levels. In contrast, the relative importance of patients' preference increased from 11\% when choosing a treatment for a patient with high disease activity to $15 \%$ for patients with moderate disease activity. Specifically, the interaction revealed that rheumatologists consider a patient's dislike significantly more in treatment decisions for patients with moderate disease activity (compared to patients with high disease activity).

Economic- and safety considerations played a relevant role with higher economic burden and increasing safety risks decreasing treatment preferences (Table 7.3) However, no significant interactions were found between profiles for the economic attributes absolute costs and relative CE - as well as safety (both levels), indicating that differences between profiles were not significant. 


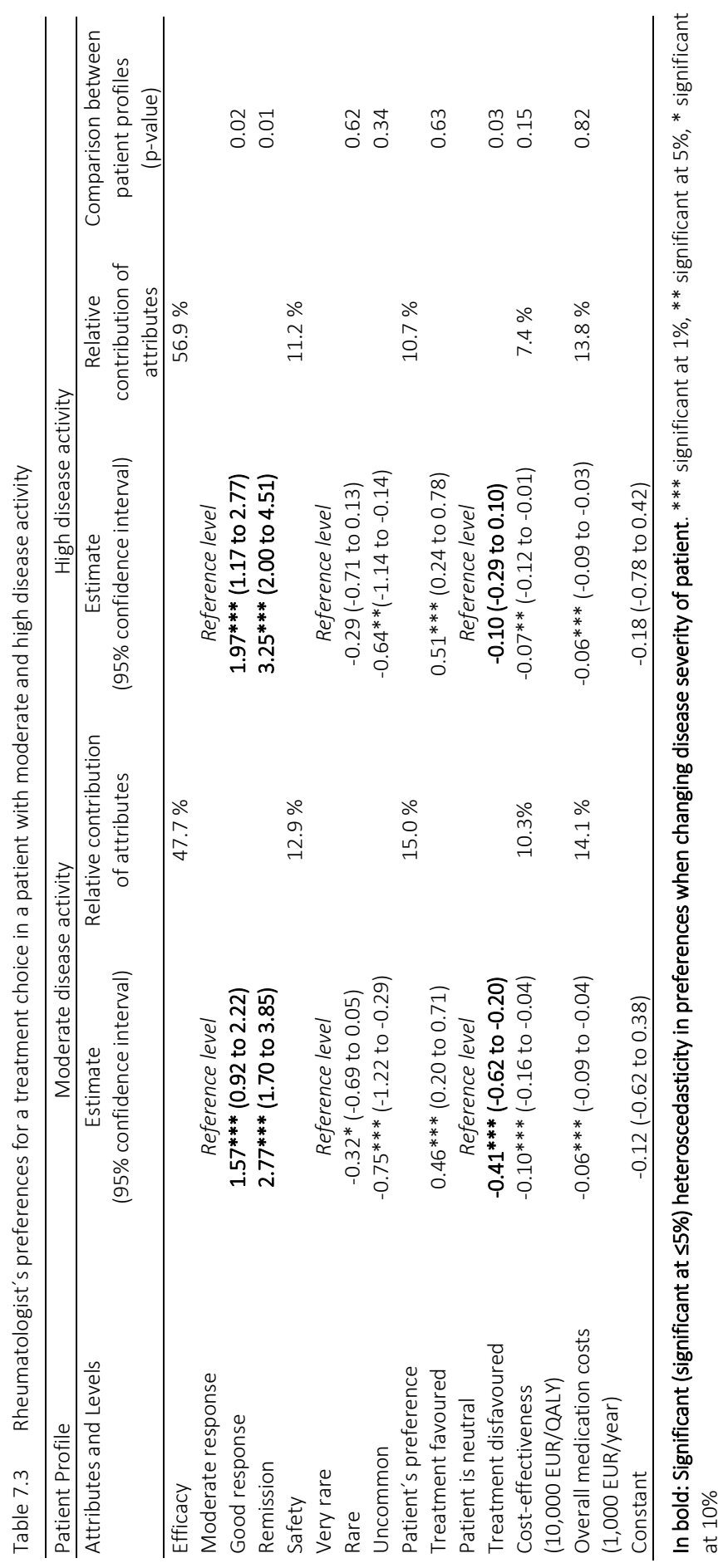




\section{Discussion}

Independent of the patient's disease severity, expected drug efficacy clearly dominated treatment choice when rheumatologists were faced with a treatment adjustment. However, for patients with moderate disease activity, efficacy became somewhat less important, when compared to drug choices for patients with high disease activity. This probably emphasizes the urgency recognized by rheumatologists in efficaciously suppressing inflammation, particularly in the presence of high disease activity. On the other hand, patients' preferences became more influential when the disease activity was less severe. Rheumatologists however remained equally conscious of cost and CE of drug treatments, irrespective of the patient's disease activity.

The dominating role of efficacy in treatment choices confirmed the findings of earlier studies. ${ }^{7,8}$ Interestingly, the attitude towards economic attributes did not change significantly when changing the patient's disease status. Rheumatologists included in the DCE experience stringent clinical criteria for costly drug treatment choices in clinical practice $^{5}$. In their countries, access to expensive innovative drugs is mostly limited to patients with high disease activity (i.e. only one of the presented patient profiles). The DCE however presented hypothetical scenarios and asked clinicians to make personal, scientific trade-offs irrespective of limitations in clinical practice. The findings indicate that rheumatologists remain conscious of costs but feel higher treatment costs are justified for patients with high and moderate disease activity to help patients reach low disease activity or remission as proposed in scientific guidelines. In other words, rheumatologists target remission in RA, with its known benefits, rather than focus on cost issues and be satisfied with a moderate disease activity level. Of note, although CE provides more valuable information on the efficient use of healthcare resources, rheumatologists are still strongly focused on absolute costs when making economic trade-offs.

We have chosen to perform the experiment in European countries with restricted access to expensive innovative drugs that do not allow prescription of these drugs to patients with moderate disease activity, as recommended in the European League against Rheumatism (EULAR) recommendations. ${ }^{1,23}$ It was considered these rheumatologists make more conscious choices among all the attributes, and were therefore of special interest for this experiment although this selection might limit generalisability. However, when comparing rheumatologists' attitudes towards economic implications, no systematic differences could be observed between countries with high and low access to expensive drugs. ${ }^{8}$

The role of patients' preference in treatment decisions of clinicians was summarized in recent reviews on shared decision making. ${ }^{24,25}$ It was found that clinicians primarily 
support the concept of shared decision making in situations where multiple comparable treatment options exist, although they tend to propose a treatment rather than share decisions in situations where one option clearly outweighs the alternatives or in cases of acute treatment needs. On this line, our findings may indicate that the extent to which patients' preferences are considered in treatment choices depends on the perceived urgency. Persisting high disease activity and previous treatment failures may imply such an urgent need to change treatment, especially when available alternatives are limited. Of note, an increasing number of DCEs investigated treatment preferences among physicians. A number of these DCEs were discussed in a recent review by Clark et al. ${ }^{26}$ Although the majority of DCEs systematically selected characteristics and levels, only a few clearly specified the selection of the patient profile. With the present study we could show that seemingly small adjustments in the patient profile can have an influence on the DCE results. Ideally, a clear definition of the patient profile for whom the clinician is making treatment decisions should become a routine part in the development of a DCE. The study has some limitations. First, although the respondents represented the entire spectrum of age, work-environment from each included country and experience we cannot exclude selection bias and generalizability of results. Second, the DCE has some inherent limitations, including the number of characteristics used to describe the treatment options is limited and may not fully reflect the complexity of a treatment decision in reality (e.g. multiple factors can influence the assessment of a drug's benefits, risks and the personal patient preference). Third, presenting two economic attributes - costs and CE - in the DCE has its limitations, as also absolute costs together with efficacy and safety provide insights into CE of a drug. However, it is important to understand that DAS28 response, rate of rare but severe side effects, and direct drug costs are not equivalent to cost-utility and therefore cost-utility as well as overall costs were included. Also, caution was taken in the generation of the choice tasks and implausible combinations between attributes efficacy, safety and costs were removed from the choice sets to ensure respondents were not confronted with unrealistic treatment options. Only including both economic attributes (drug costs and CE) allowed to raise awareness on the fact that clinicians are still predominantly focused on absolute costs despite relative CE being more informative to assess the value of a treatment. Fourth, by repeating the DCE with two different patient profile it cannot be completely ruled out that an increase in fatigue possibly influenced preferences (in particular the latter profile - high disease activity). However, present literature indicates that important systematic differences are unlikely. ${ }^{27}$ Finally we asked rheumatologists to state preferences to a hypothetical scenario. This showed that they trade-off various aspects; however, it remains unknown whether they reach decisions in the same way in clinical practice. ${ }^{28}$ 
Our study revealed that in countries with substantial economic restrictions for prescription of costly RA treatments, rheumatologists were willing to give up some efficacy to account for patients' preference when choosing treatments for RA patients with moderate compared to high disease activity. Disease activity however did not influence the importance of economic aspects in treatment choices, indicating that in line with present treatment recommendations, rheumatologists consider higher treatment costs equally justified for patients with high and moderate disease activity. 


\section{References}

1. Smolen JS, Landewe R, Breedveld FC, et al. EULAR recommendations for the management of rheumatoid arthritis with synthetic and biological disease-modifying antirheumatic drugs: 2013 update. Ann Rheum Dis 2014;73:492-509.

2. Voshaar MJ, Nota I, van de Laar MA, et al. Patient-centred care in established rheumatoid arthritis. Best Pract Res Clin Rheumatol 2015;29:643-63.

3. Barry MJ, Edgman-Levitan S. Shared decision making--pinnacle of patient-centered care. N Engl J Med 2012;366:780-1.

4. Oshima Lee E, Emanuel EJ. Shared decision making to improve care and reduce costs. N Engl J Med 2013;368:6-8.

5. Putrik P, Ramiro S, Kvien TK, et al. Inequities in access to biologic and synthetic DMARDs across 46 European countries. Ann Rheum Dis 2014;73:198-206.

6. Putrik P, Ramiro S, Kvien TK, et al. Variations in criteria regulating treatment with reimbursed biologic DMARDs across European countries. Are differences related to country's wealth? Ann Rheum Dis 2014;73:2010-21.

7. Hifinger M, Hiligsmann M, Ramiro S, et al. Patients' preferences and economic considerations play an important role in treatment decisions: a discrete choice experiment among rheumatologists. Rheumatology (Oxford) 2017;56:68-76.

8. Hifinger $M$, Hiligsmann $M$, Ramiro $S$, et al. Economic considerations and patients' preferences affect treatment selection for patients with rheumatoid arthritis: a discrete choice experiment among European rheumatologists. Ann Rheum Dis 2017;76:126-32.

9. Reed Johnson F, Lancsar E, Marshall D, et al. Constructing experimental designs for discrete-choice experiments: report of the ISPOR Conjoint Analysis Experimental Design Good Research Practices Task Force. Value Health 2013;16:3-13.

10. Coast J, Al-Janabi H, Sutton EJ, et al. Using qualitative methods for attribute development for discrete choice experiments: issues and recommendations. Health Econ 2012;21:730-41.

11. Currency converter. http://wwwxecom/currencyconverter/

12. Hall J, Fiebig DG, King MT, et al. What influences participation in genetic carrier testing? Results from a discrete choice experiment. J Health Econ 2006;25:520-37.

13. de Bekker-Grob EW, Ryan M, Gerard K. Discrete choice experiments in health economics: a review of the literature. Health Econ 2012;21:145-72.

14. Ngene. [http://www.choice-metrics.com/].

15. van Tuyl LH, Sadlonova M, Davis B, et al. Remission in Rheumatoid Arthritis: Working Toward Incorporation of the Patient Perspective at OMERACT 12. J Rheumatol 2016;43:203-7.

16. Torbica A, Fattore G. Understanding the impact of economic evidence on clinical decision making: a discrete choice experiment in cardiology. Soc Sci Med 2010;70:1536-43.

17. Carlsen B, Hole AR, Kolstad JR, et al. When you can't have the cake and eat it too: a study of medical doctors' priorities in complex choice situations. Soc Sci Med 2012;75:1964-73.

18. Bridges JF, Hauber AB, Marshall D, et al. Conjoint analysis applications in health--a checklist: a report of the ISPOR Good Research Practices for Conjoint Analysis Task Force. Value Health 2011;14:403-13.

19. Hauber AB, Gonzalez JM, Groothuis-Oudshoorn CG, et al. Statistical Methods for the Analysis of Discrete Choice Experiments: A Report of the ISPOR Conjoint Analysis Good Research Practices Task Force. Value Health 2016;19:300-15.

20. Nlogit. [http://www.limdep.com/products/nlogit/].

21. Train K. Discrete choice methods with simulation. New York: Cambridge University Press; 2003.

22. NK Malhotra DB. Marketing research: An applied approach. Pearson Education 2007;

23. Smolen JS, Landewe R, Breedveld FC, et al. EULAR recommendations for the management of rheumatoid arthritis with synthetic and biological disease-modifying antirheumatic drugs. Ann Rheum Dis 2010;69:964-75.

24. Pollard S, Bansback N, Bryan S. Physician attitudes toward shared decision making: A systematic review. Patient Educ Couns 2015;98:1046-57. 
25. de Haes $\mathrm{H}$. Dilemmas in patient centeredness and shared decision making: a case for vulnerability. Patient Educ Couns 2006;62:291-8.

26. Clark MD, Determann D, Petrou S, et al. Discrete choice experiments in health economics: a review of the literature. Pharmacoeconomics 2014;32:883-902.

27. Bech $M$, Kjaer $T$, Lauridsen J. Does the number of choice sets matter? Results from a web survey applying a discrete choice experiment. Health Econ 2011;20:273-86.

28. Mulley AG, Trimble C, Elwyn G. Stop the silent misdiagnosis: patients' preferences matter. BMJ 2012;345:e6572. 



\title{
Chapter 8
}

\author{
The eumusc.net standards of care for rheumatoid \\ arthritis: importance and current implementation
} according to patients and healthcare providers in

the Netherlands

M. Hifinger, S. Ramiro, P. Putrik, Y. van Eijk-Hustings, A. Woolf, J. Smolen, M. StofferMarx, T. Uhlig, R.H. Moe, M. Saritas, M. Janson, A. van der Helm-van Mil, M. van de Laar, H.Vonkeman, M. de Wit, A. Boonen Accepted in Clin Exp Rheumatol 


\section{Abstract}

\section{Objective}

The eumusc.net standards of care (SOCs) for rheumatoid arthritis (RA) aimed to improve quality of care across Europe. This study investigated importance and implementation of each standard according to patients and healthcare professionals (HCPs) in the Netherlands and identified barriers towards implementation.

\section{Methods}

Dutch patients, rheumatologists and rheumatology nurses rated importance and implementation (0-10 numeric rating scale (NRS); 10=most important/best implemented) for each of the 20 SOCs. A care gap, adjusted for importance, was calculated: (100=highest gap). Statistical differences between a) patients and HCPs and b) subgroups of patients (demographics, health) were tested. Additionally, patients indicated agreement (0-10) with 6 implementation barriers.

\section{Results}

386 patients and 91 HCPs were included. Both ranked adequate disease modifying antirheumatic drug treatment (9.3 (SD 1.2), 9.2 (SD 0.8)), access to care in emergencies (9.2 (SD 1.2), 9.2 (SD 1.0)) and regular re-appraisal when treatment fails (9.2 (SD 1.3), 9.0(SD1.0)) the most important SOCs, and these were among the best implemented (NRS $\geq 8.5$ ) SOCs. After accounting for applicability, patients and HCP identified care gaps for early diagnosis (25.5 (SD 32.0), 22.3 (SD 16.3)), availability of a treatment plan (25.1 (SD 22.7), 25.7 (SD 18.5)) and patients also for a regular schedule of assessment of disease (28.6 (SD 25.5)). Patients with poorer health or higher education scored systematically lower on care received while sharing similar priorities. Patients and HCPS considered limited reimbursement of specific health services a main barrier for implementation, patients identified additionally limited time of physicians.

\section{Conclusions}

Dutch patients and HCPs overall agreed on priorities in care and found relevant SOCs well implemented. Still suggestions for improvement were raised especially by patients with poorer health and/or higher education. 


\section{Introduction}

To raise quality of care and improve equity in health for all patients with rheumatic diseases across Europe, the European Musculoskeletal Conditions Surveillance and Information Network (eumusc.net) was initiated as a project co-founded by the European League against Rheumatism (EULAR) and the European Union (EU). ${ }^{1}$ As part of this initiative, eumusc.net developed the standards of care (SOCS) for the management of rheumatoid arthritis (RA). ${ }^{2}$ These were based on existing management recommendations and further selected and refined by an expert panel of health care professionals (HCPs) and patients. In addition to a version for professionals, a lay version has been developed to help patients understand whether they receive adequate care, and strengthen their voice in the management of their disease. ${ }^{2}$ This is particularly important as, despite the recognized relevance of patients' needs in healthcare, concerns and preferences of patients still receive little attention. ${ }^{3,4} \mathrm{~A}$ recent study revealed that needs and priorities are not the same for all patients, nor for patients and their care providers. Systematic differences were identified e.g. for RA patients with different disease severity. ${ }^{5}$ Other studies found that RA patients share different care priorities compared to HCPs, ${ }^{6,7}$ e.g. when choosing treatments, patients rather focused on the consequences of disease activity, whereas HCPs primarily focus on disease activity. ${ }^{8}$ Lack of alignment of care with patients' needs could be an important barrier for implementation of SOCs. Such insight is relevant for initiatives aiming to improve quality of care.

However, for successful implementation of SOCs in practice, insight into priorities and current level of implementation is not sufficient. It is equally essential to understand the broad range of barriers. In addition to discordance in priorities between patients and professionals, barriers may also include restrictions in the healthcare environment (e.g. health services not covered by the insurance systems or patients without adequate access to specialists) or within the stakeholders attitudes (e.g. clinicians do not see the need for certain health services).

Finally, to facilitate implementation, the SOCs were also meant to educate patients about optimal care and were proposed as a self-care tool to monitor the quality of care. Various previous studies investigated the benefit of different patient education formats and showed that patient education can contribute to improved outcomes in RA. ${ }^{9-13}$ Other studies suggest that RA patients are able to monitor their disease activity with beneficial effects on outcome, although not all patients were eager to do so. ${ }^{14-19}$ Hence, when proposing the lay version of the SOCs as a tool for implementation, it is also relevant to identify formats and approaches preferred by patients. 
Therefore, the objectives of this study were 1) to investigate the current level of implementation and importance of each SOC reflected in the eumusc.net SOCs from the perspective of the patients and healthcare professionals, 2) to identify potential barriers towards implementation of optimal care, and 3) to understand the attitude of patients and physicians towards using SOCs as a tool to monitor personal care.

\section{Materials and methods}

A cross-sectional study was conducted in the Netherlands (NL) in 2015 and 2016 among patients with RA and their HCPs, including rheumatology nurses and certified rheumatologists. The study protocol and patient survey were approved by the local Ethics Committee of all participating centres.

\section{Recruitment}

Patients diagnosed with RA by a rheumatologist and under care in one of four rheumatology practices (2 non-university and 2 university hospitals) from different regions in NL were invited to participate by letter or email. Further, all rheumatologists of the Dutch Society of Rheumatology and all rheumatology nurses from the rheumatology unit of the Dutch Nurses Association were invited by email.

\section{The questionnaires}

Based on the lay version of the eumusc.net SOCs, addressing 16 areas of care through 20 individual items (questions), two questionnaires (for patients and HCPs) were developed. The final patient questionnaire was then translated into Dutch to ensure patients fully understand each question. The available formal Dutch translation of eumusc.net SOCs has been used as basis for the translation of the questionnaire.

In Part 1 of the questionnaire, participants were asked to rate each of the 20 SOC items on a numeric rating scale (NRS) across two dimensions: (1) the level of care received personally (for patients) or the level of care received by average patient (for HCP) to assess implementation ( $0=$ not received at all; $10=$ fully received) and ( 2 ) the level of importance to assess priorities in care ( $0=$ not important at all, $10=$ very important). In the patients' questionnaire, respondents could alternatively select 'not applicable' or 'I do not understand' when asked for care received or 'no opinion' when asked for importance. All respondents had the opportunity to add personal comments for individual SOCs (patients) or the SOCs overall (patients and HCP). In addition, patients were asked to rate on a NRS (0-10; 10=fully agree) the level of agreement with six 
statements describing potential barriers for delivery of care according to agreed standards addressing (1) limited applicability of standards to patients' individual needs (2) restricted access to proposed care (access, availability, cost coverage) and (3) poor physician - patient interplay, resulting from (3a) differences in expectations and attitude and $(3 \mathrm{~b})$ physician's time dedicated to patients in clinical practice. To reduce the questionnaire burden, the questionnaire for HCPs only contained one open question on potential barriers for implementation. In Part 2, the opinion of patients and physicians on patient self-care and usefulness of a patient tool based on SOCs was assessed. Respondents were asked to rate on a NRS scales (0-10; I fully agree) their level of agreement with 11 statements covering 3 domains: (1) expected role of patients in the management of the disease, (2) possible applications of the self-care tool in clinical practice, and (3) possible sources to access such a tool.

Finally, data on patients' age, gender, disease duration (in years) and educational background (primary -, secondary - or university education) were collected. Patients' overall health status was assessed using the patient global assessment of disease (PatGA). They were asked to mark on a 0-10 NRS ( $0=$ very poor) how they are currently doing, considering all the ways in which illness affects them. HCPs provided information on age, gender and work-environment (academic hospital, non-academic hospital, private practice or other).

Questionnaires were piloted among 20 patients and 27 HCPs. The patient survey could be completed online or on paper, the HCPs questionnaire was administered online. ${ }^{20}$

\section{Statistical analysis}

First, for each SOC a third dimension, the 'care gap' between optimal care and current implementation was calculated as the difference between the current care received (actual score) and the optimal care (maximal-score: 10) multiplied by the reported importance [(10 - NRS $\left.\left.S_{\text {care received }}\right) * N R S_{\text {importance }}\right]$. Resulting scores could range from 0 to 100 (higher scores indicate a higher care gap). When respondents had selected an alternative response options ('not applicable', 'not understandable', 'no opinion'), no care gap could be calculated. Next, scores from patients and HCPs on each dimension of the SOC, on potential barriers, and on preferred mode of application (patients only) were presented using descriptive statistics.

Differences between patients and HCPs in assessment for 1) importance or 2) level of care received were tested for each SOC using independent t-tests (samples normally distributed) or the Mann-Whitney (samples not normally distributed), as appropriate. Same approach was followed to assess differences between sub-groups of patients based on gender, age (>65 (retired) versus $\leq 65$ (working age)), educational level (primary versus secondary or university education), disease duration ( $\leq 2$ years versus $>2$ years) 
and disease status (PatGA $\geq 7$ versus $<7$ (median)). Differences were considered statistically significant for $p<0.05$. To visualize the differences for the 20 SOCs between dimensions (for same group) or between (sub)-groups (for same dimension), spider graphs were created. In a scenario analysis, SOCs were also classified into broader domains representing information related SOCS and process/structure related SOCS to explore whether specific response patterns could be found across these traditional domains of quality of care (supplementary material, appendix A). Written comments of respondents to any of the survey questions were analysed qualitatively by identifying common constructs.

\section{Results}

In total, 386 patients and 91 HCPs (52 rheumatologists and 39 nurses) were included. Among HCPs, 64 (74\%) were female, mean age was 49 (SD 9). Among patients, 247 (66\%) were female, mean age was 61 (SD 11) (Table 8.1).

Table 8.1 Characteristics of patients and healthcare professionals

\begin{tabular}{|c|c|c|c|c|}
\hline & \multirow[t]{2}{*}{ Patients } & \multicolumn{3}{|c|}{ Healthcare Professionals } \\
\hline & & $\begin{array}{c}\text { Total (Rheumatologists } \\
\text { and Rheumatology } \\
\text { Nurses) }\end{array}$ & Rheumatologists & $\begin{array}{c}\text { Rheumatology } \\
\text { Nurses }\end{array}$ \\
\hline Number of participants & 386 & 91 & 52 & 39 \\
\hline $\begin{array}{l}\text { Age in years } \\
{[\text { Mean }(S D)]}\end{array}$ & $61.2(10.9)$ & $48.6(9.3)$ & $47.4(9.4)$ & $50.4(8.6)$ \\
\hline Gender [N (\%) female] & $247(66.2)$ & $64(73.6)$ & $28(54.9)$ & $39(100.0)$ \\
\hline $\begin{array}{l}\text { Education } \\
\text { [N (\%) university education] }\end{array}$ & $118(31.2)$ & n.a. & n.a. & n.a. \\
\hline $\begin{array}{l}\text { Disease Duration in years } \\
\text { [Mean (SD, median, range, } \\
\text { interquartile range)] }\end{array}$ & $15.0(12.5,55,17)$ & n.a. & n.a. & n.a. \\
\hline $\begin{array}{l}\text { Patient Global* } \\
\text { [Mean (SD)] }\end{array}$ & $6.4(2.0)$ & n.a. & n.a. & n.a. \\
\hline $\begin{array}{l}\text { Work setting } \\
\text { [N (\%) university setting] }\end{array}$ & n.a. & $26(29.9)$ & $14(26.9)$ & $12(34.3)$ \\
\hline
\end{tabular}

* Patient global assessment of disease activity (0-10 numeric rating scale, $0=$ poor health, 10=good health), n.a. = not applicable 


\section{Implementation and importance for each item of Standards of Care}

\section{a) The patients' perspective}

Table 8.2 shows for each SOC the mean score per dimension and Figure 8.1a visualizes patterns in scores in a spider graph. Scores for importance were $\geq 8.0$ for all but two SOCs, confirming their relevance. However, scores for implementation were systematically lower than for importance and this was significant in 19 of 20 SOCs. Highest scores for importance were found for adequate DMARD (disease modifying antirheumatic drug) treatment, regular re-appraisal of treatment targets in case of treatment failure and access to emergency contacts. These SOCs were well implemented. The highest care gaps were identified for information about alternative therapies (SOC 16, 38.1 (SD 29.1)), and information about options of surgery (SOC 10, 29.7 (SD 30.8)) but these were not applicable for 33 and $29 \%$ of patients, respectively (supplementary material, appendix B). Moreover, importance was low for SOC 16 (information about alternative therapies). When accounting for applicability, the top three care gaps were found for receiving a schedule of regular assessment of disease (SOC 5, 28.6 (SD 25.5)), early diagnosis within 6 months of symptom onset (SOC 1, 25.5 (32.0)) and availability of a treatment plan (SOC 3, 25.1 (SD 22.7)).

Patients with higher education or poorer health scored significantly lower on care received but similar on importance (Figure 8.2). Age, gender and disease duration did not reveal important differences with only few items showing significant differences between sub-groups (supplementary material, appendix C). When grouping SOCs according to information related SOCS and process/structure related SOCS, no specific patterns could be identified (supplementary material, appendix A)).

Patients proposed to add information on (a) how to manage impairments beyond disease activity/pain such as fatigue and limitations in physical function or activities of daily life, and (b) how to deal with the consequences of RA on social roles like work and family obligations. In addition, some patients suggested to better explain and/or simplify the language used to describe some SOCs. Of note, 30\% of patients responded 'I do not understand' for information about options of surgery (SOC 10). Across SOCs, patients with primary education tended to score 'I do not understand' more frequently than patients with secondary or university education (Supplementary material, appendix C). 


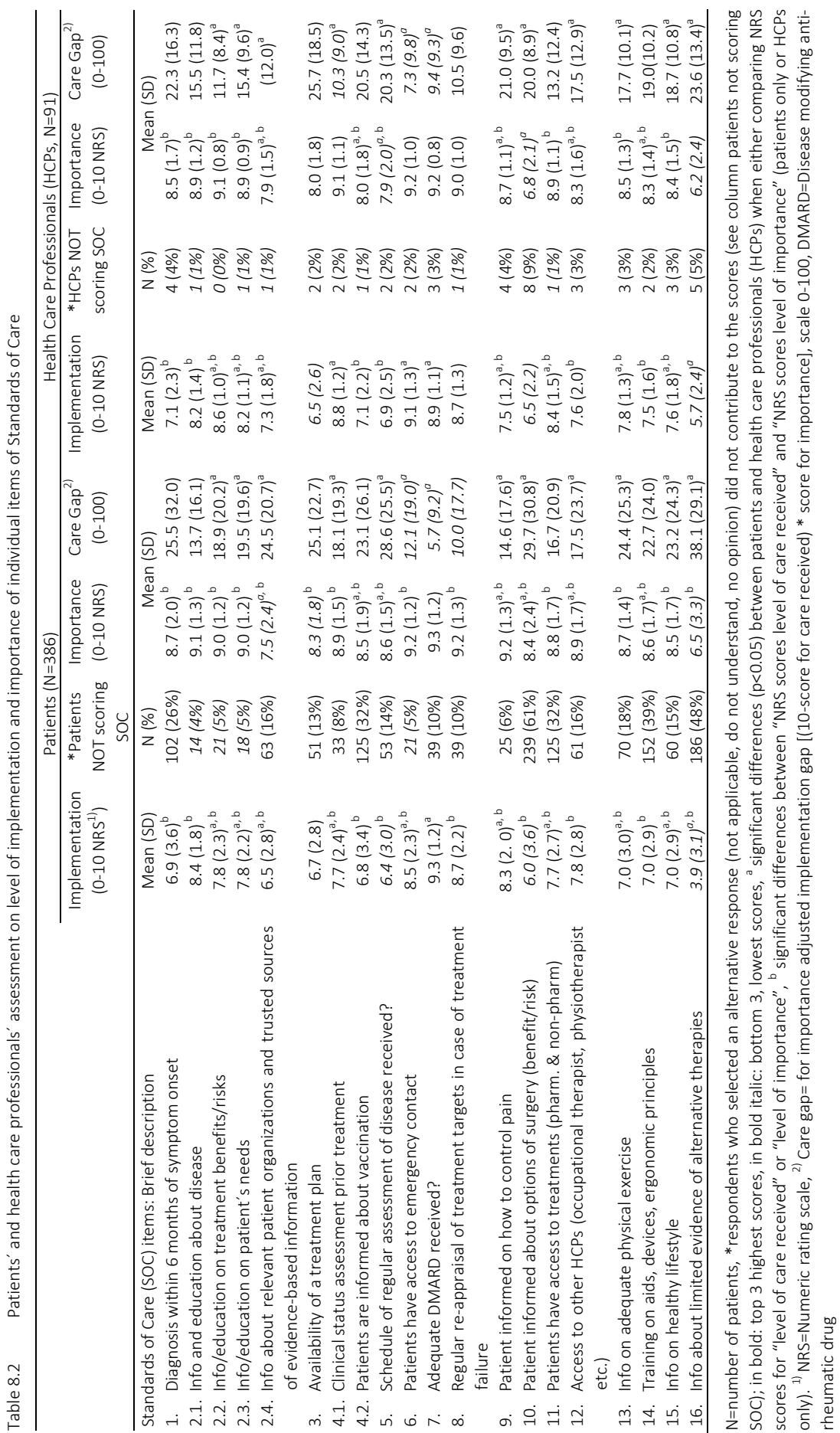


a. Difference between importance and care received/provided

The patients' perspective

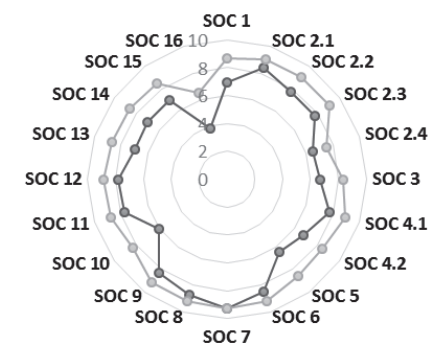

The health care professionals'perspective

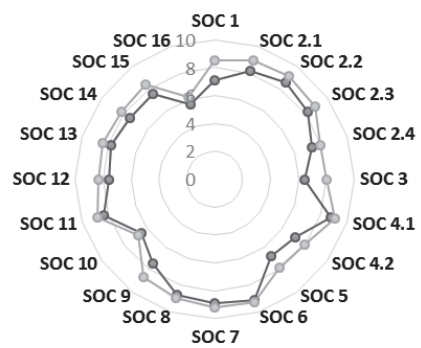

$\multimap-$ Level of care received $\longrightarrow$ Level of importance

b. Difference in perceptions between patients and healthcare professionals

Level of care provided/received

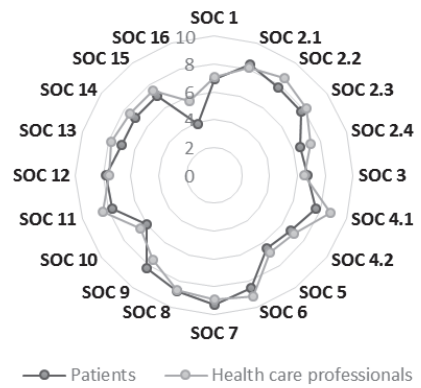

Level of importance

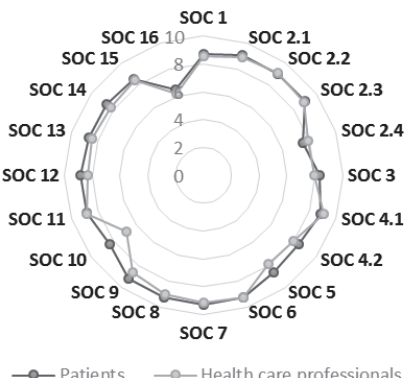

$\longrightarrow$ Patients $\longrightarrow$ - Health care professionals

SOC $=$ Standards of care; ${ }^{*}$ SOC items are significantly different between sub-groups $(p<0.05)$

Figure 8.1 Differences and synergies in the assessment of rheumatoid arthritis care in the Netherlands

\section{b) Comparison of patients' and healthcare professionals' perspective}

Overall, the differences in absolute scores for importance and implementation between patients and HCPs were small. However, for implementation patients more frequently scored significantly lower than HCPs. (Table 8.2 and Figure 8.1b). HCPs shared patients' priorities (importance) in care (SOC 6 to 8 ) and considered these to be well implemented but also gave priority to educating patients about treatment benefits and risks (SOC 2.2) and clinical status assessment prior treatment (SOC 4.1). For the care gaps, several SOCs $(n=12)$ turned out to be significantly different when comparing patients and HCPs, with patients often rating higher care gaps $(n=11)$. When accounting for the applicability of SOCs, the highest care gaps were similar for patients and HCP (SOC 1, 3 and 16). 
Additionally, HCPs identified room for improvement when informing patients on comorbidities, and educate them on the importance of family support.

When grouping SOCs as process/structure/information related SOCs, no systematic trend for higher or lower scores of either patients or HCPs could be observed (supplementary material, appendix A).

a. Patients' assessment according to global health status (median of global health)
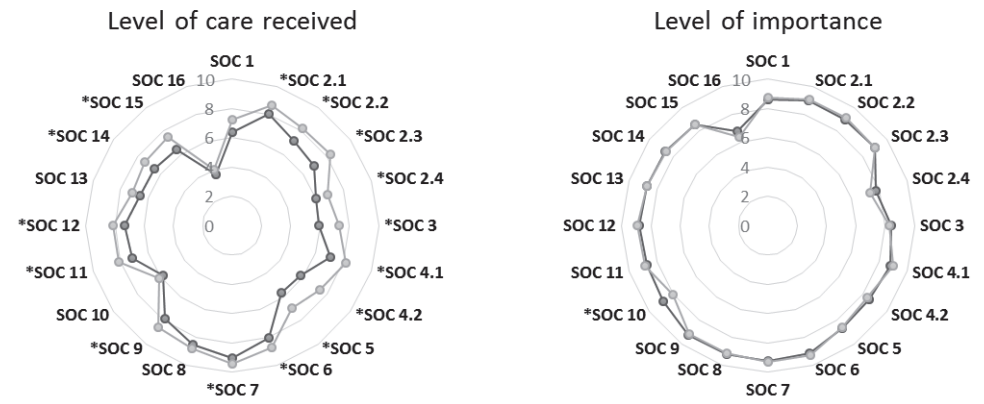

$\multimap$ - poor health $($ PatGA $<7) \quad \longrightarrow$ good health $($ PatGA $\geq 7)$

$\multimap$ - poor health $($ PatGA $<7) \quad \longrightarrow$ good health $($ PatGA $\geq 7)$

SOC= Standards of care; SOC items are significantly different between sub-groups $(p<0.05)$, PatGA=Patient Global Assessment

b. Patients' assessment according to education (primary vs secondary or high)
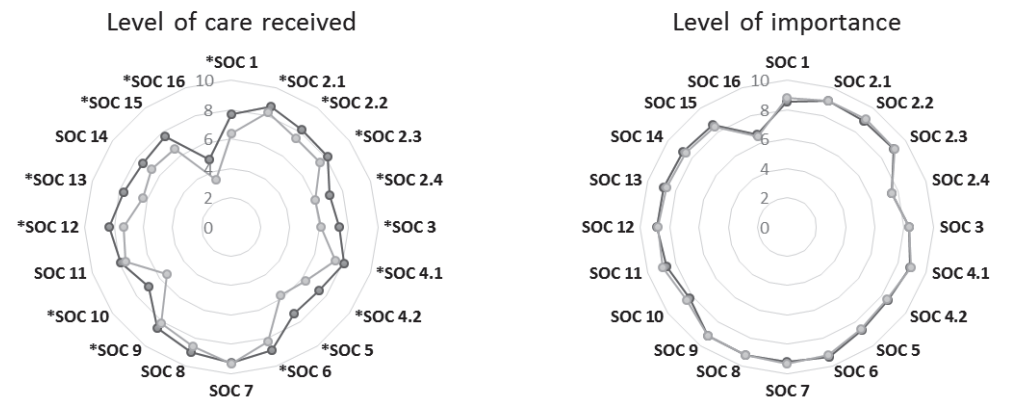

$\multimap$ primary education $\multimap$ secondary or high education

- $\ldots$ primary education $\quad \ldots$ secondary or high education

* SOC $=$ Standards of care; SOC items are significantly different between sub-groups $(p<0.05)$

Figure 8.2 Ratings of importance and implementation for each of the Standards of Care (SOC) according to patients' characteristics 


\section{Barriers for implementation of Standards of care}

Overall, patients indicated low agreement with pre-defined potential barriers for implementation. The highest limitation was reimbursement of services by the health insurance (4.9 (SD 3.6)). Furthermore, patients saw limitations in the applicability of standards due to differences in individual needs (3.6 (SD 3.0)). Although patients recognized that HCPs partly dedicate too little time to consultations (4.2 (SD 3.5)), patients overall acknowledge that clinicians see the need for patient education (2.6 (SD 3.0)) and implementation of SOCs (2.5 (SD 2.8)). On the same line, Dutch patients saw minor limitations in access to specialists (1.8 (SD 2.5)) (Figure 8.3). Physicians mainly agreed with patients that reimbursement of services proposed in SOC was the main barrier.

1. Recommended SOCs are not applicable or useful to my particular situation

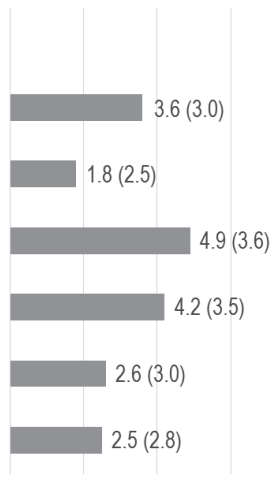

The access to specialists and other healthcare providers is extremely limited in my area making implementation of some recommendations difficult

3. Several recommendations of the Standards of Care are not (or not fully) covered by the national health service or my health insurance

4. In clinical practice, the time healthcare professionals have for patients seems increasingly limited

5. I have the impression that doctors think patients do not need to be educated about all aspects of care they receive

6. I have the impression that doctors do not see the need to implement the recommendations in clinical practice

0-10 numeric rating scale ( $0=\mid$ do not agree (no barrier), 10 | fully agree (barrier)), SD=standard deviation results presented as mean (SD)

Figure 8.3 Patients' agreement with potential barriers when implementing Standards of Care (SOCs)

\section{Use of lay version of standards of care as a patient self-care tool in clinical practice}

Both, physicians and patients, agreed on the importance of each other's role in care and both supported active involvement of patients in the management of their disease. However, physicians systematically indicated lower levels of agreement on the use of SOCs as a patient self-care tool. In terms of modes of access, patients indicated that SOCs should be accompanied with explanations (brochure or e-learning) and expected that HCPs ensured access to the SOCs (Table 8.3). 
Table 8.3 The use of a patient version of the Standards of Care in RA care

\begin{tabular}{|c|c|c|}
\hline Statement & $\begin{array}{l}\text { Patients }^{11} \\
\mathrm{~N}=356\end{array}$ & $\begin{array}{l}\text { Rheumatologists }{ }^{1)} \\
\qquad \mathrm{N}=31\end{array}$ \\
\hline & \multicolumn{2}{|c|}{ Mean (SD) } \\
\hline \multicolumn{3}{|l|}{ The roles and responsibilities of rheumatologists and patients in RA care } \\
\hline $\begin{array}{l}\text { It is the responsibility of my doctor to define and monitor the } \\
\text { treatment strategy for me }\end{array}$ & $8.6(1.8)$ & $9.3(0.9)$ \\
\hline $\begin{array}{l}\text { It is also my responsibility as patient to get actively involved in the } \\
\text { management of the disease and state preferences }\end{array}$ & $8.1(2.0)$ & $8.8(1.2)$ \\
\hline $\begin{array}{l}\text { Active participation of the patient in the treatment can influence } \\
\text { the treatment outcomes/ symptoms }\end{array}$ & $8.9(1.3)$ & $8.7(1.3)$ \\
\hline \multicolumn{3}{|l|}{ A lay (patient) version of the Standards of Care as patient tool } \\
\hline $\begin{array}{l}\text { All rheumatoid arthritis patients should know the Standards of } \\
\text { Care (i.e. optimal care for their disease) }\end{array}$ & $8.4(1.7)^{*}$ & $7.7(2.1)^{*}$ \\
\hline $\begin{array}{l}\text { The Standards of Care could be used by patients to get an } \\
\text { overview of the most relevant aspects of RA care they should } \\
\text { receive }\end{array}$ & $8.5(1.6)^{*}$ & $7.6(2.5)^{*}$ \\
\hline $\begin{array}{l}\text { The Standards of Care help patients to evaluate the quality of care } \\
\text { they receive }\end{array}$ & $8.6(1.5)^{*}$ & $7.7(2.2)^{*}$ \\
\hline $\begin{array}{l}\text { Knowing the Standards of Care helps patients to request from } \\
\text { their doctor additional information, service or care they } \\
\text { want/should receive }\end{array}$ & $8.7(1.4)^{*}$ & $8.0(2.0)^{*}$ \\
\hline \multicolumn{3}{|l|}{ Access to a lay (patient) version of Standards of Care } \\
\hline $\begin{array}{l}\text { A brochure/leaflet or e-health program with explanatory } \\
\text { information could help to fully understand the content and } \\
\text { purpose of the Standards of Care }\end{array}$ & $8.0(1.4)$ & $8.1(1.9)$ \\
\hline $\begin{array}{l}\text { The Standards of Care should be available as a print copy (e.g. } \\
\text { flyer, leaflet) that patients can receive from their doctor }\end{array}$ & $7.9(1.6)$ & $7.8(1.3)$ \\
\hline The standards of care should be easy to find on the internet & $7.5(2.2)$ & $7.7(1.8)$ \\
\hline $\begin{array}{l}\text { The Standards of Care should be available as an "App" for } \\
\text { smartphones and tablets. I want to have fast and simple access to } \\
\text { it and receive updates automatically }\end{array}$ & $6.1(2.7)$ & $7.9(1.1)$ \\
\hline
\end{tabular}

\section{Discussion}

Patients and HCPs agreed that adequate DMARD treatment, access to care in emergencies and regular re-appraisal of treatment targets in case of treatment failure are among the most important aspects of RA care, and that these were well implemented. Still, some relevant care gaps were identified including diagnosis within 6 months of symptom onset, availability of a treatment plan and in addition for patients receiving a schedule of regular assessment of disease. Patients and HCPs agreed that limited coverage of some recommended health services was a barrier for implementation; patients additionally pointed to the limited time of physicians during 
consultations. Patients with overall poor health and/or higher education rated level of care received as lower while still sharing similar priorities. Interestingly, patients and physicians equally shared a positive attitude towards active patient participation in care, but the concept of using SOCs as a patient self-care tool was less supported by physicians. In addition, some linguistic and content related improvements were suggested to optimize usability of the tool for patients.

The substantial agreement on the importance of different aspects of care was partly surprising as earlier international studies found clear discrepancies between patients' and HCPs' views. ${ }^{5,8,21,22}$ It should be noted that the development of the SOCs was a joint effort of experts and patients that likely contributed to the overall higher level of agreement. Notwithstanding, the present study confirmed that patients (compared to HCPs) rated priority of pain management significantly higher. ${ }^{5,8,23}$ Professionals still underestimate the impact of pain. Also, patient responses revealed that several aspects including management of limitations in physical function, fatigue, and the consequences of RA on work participation or family role ${ }^{8,24,25}$ were poorly reflected in the SOCs. While these points were included in the more detailed elaboration of the original SOCs for HCPs, they were clearly insufficiently emphasized in the lay version.

Room for improvement in care was also identified by all participants. Early diagnosis remained a care gap despite being frequently emphasized as highly relevant for long term treatment outcomes. ${ }^{26,27}$ Interestingly, in addition availability of a treatment plan and receiving a schedule of assessments was identified as an area that requires more attention in clinical care. The findings support an earlier study that emphasizes the need of such documents to support patients in the management of the disease. ${ }^{28}$

Some structural barriers for implementation of care included increasingly limited financial coverage of recommended health services in NL and the time pressure among physicians in clinical practice that may hinder adequate communication between patient and physician and thus potentially lead to poor outcomes. ${ }^{29}$ For the rheumatology management team, it will therefore remain challenging to address all the SOCs in a time constraint clinical practice situation. To some extent, e-health programs for patients might offer solutions but likely time of HCPs spent in educating patients should also receive better rewards. Also electronic health records, such as METEOR, may help centres and clinicians to optimize quality of care or improve patient education. ${ }^{30}$ However, electronic systems cannot fully replace personal interactions between patients and clinicians and should therefore be used with care. ${ }^{31}$

Patients with better overall health status found SOCs better implemented, a finding that is in line with an earlier study that found a positive association between better health status and patient satisfaction. ${ }^{32}$ However, the study also documented positive relationships between high satisfaction and older age or male gender whereas in the 
present study age and gender did not play an important role in the patients' assessment of care received. Likely, differences in the construct 'satisfaction' and 'level of care received' are not fully comparable, and contributed to the differences in findings between studies.

In line with earlier studies, patients with lower education rated to receive better care than patients with higher education. ${ }^{33,34}$ Possibly, patients with lower education had lower expectations towards information and education on care. Keeping in mind that several studies show that lower educated patients receive less optimal care for the same level of disease activity, results of the current study suggest that these patients might be too easily satisfied and not sufficiently critical. On that line, the impact of helping patients to understand what they can expect form the healthcare system, as part of their health literacy education, should receive more attention. ${ }^{33-35}$

Patients and HCPs overall agreed on the active role of patients in care. Earlier studies already advocated for patient centeredness and highlighted the positive impact of patients' participation in care. ${ }^{3,36}$ However, in line with earlier findings, HCPs were somewhat less supportive about a patient tool (based on SOCs) to allow patients to monitor quality of care. Possibly, HCPs are partly concerned about the limited additional benefit in patient outcomes. ${ }^{37,38}$

When developing SOCs towards a patient tool, patients further suggested more detailed explanations on individual SOCs to fully understand the purpose of each. Of note, in the present study 'I do not understand' was predominantly selected by patients with primary education and rated frequently for SOCs related to information/patient education (SOC 10, 16).

Also, patients frequently considered some of the SOCs as not applicable. In other words, timing of needs in the patients' disease journey should receive attention when developing self-monitoring tools for patients. E.g. in contrast to HCPs, patients perceive a high care gap when asked about SOC 10 - information on options of surgery, however given the success of newer therapies, the need for surgeries significantly decreased in recent years ${ }^{39}$ and consequently HCP may not inform patients about therapies not immediately relevant for them.

Some limitations should be considered when interpreting results. First, although the study included $91 \mathrm{HCPs}$ and more than 386 patients with diverse characteristics, response bias cannot be fully excluded. Second, when translating the original SOCs for HCPs into a lay version, simplification was needed but some oversimplification might have occurred. E.g. important aspects like how to deal with the consequences of RA on daily living have not been specifically addressed although importance for patients may be high. Third, when comparing patients' and HCPs' scores for implementation, HCPs overall tended to score higher. In this context, it may be relevant to recognize that 
patients primarily assessed the performance of others, while HCPs primarily assessed their own performances and thus likely tended to be less critical. A gold standard to assess 'care received' is difficult, but discrepancies in opinions can be informative. Last, the study has been conducted in NL, therefore extrapolation of results may partly be limited and we recommend to repeat this study in other countries with different healthcare environment. Still the present study provides valuable and generalizable insights into the needs of patients and could contribute to improvement of care in a number of European countries, especially when healthcare settings are largely comparable to NL.

\section{Conclusion}

With overall high ratings for levels of implementation, patients and HCPs recognized the comparatively high Dutch standards in relation to many other countries. Dutch patients and HCPs overall agreed on priorities in care for patients with RA and considered the most relevant SOCs were also the best implemented ones. Still, some room for improvement in RA care could be found, especially by patients with poorer health or higher education. Improvements should primarily target early diagnosis within 6 months of symptom onset, availability of a treatment plan and in addition address the patients' need to have a schedule of regular assessment of disease.

Supplementary tables are published online on http://www.clinexprheumatol.org/ 


\section{References}

1. Woolf AD. Driving musculoskeletal health for Europe: EUMUSC.NET. Reumatismo 2011;63:1-4.

2. Stoffer MA, Smolen JS, Woolf A, et al. Development of patient-centred standards of care for rheumatoid arthritis in Europe: the eumusc.net project. Ann Rheum Dis 2014;73:902-5.

3. Voshaar MJ, Nota I, van de Laar MA, et al. Patient-centred care in established rheumatoid arthritis. Best Pract Res Clin Rheumatol 2015;29:643-63.

4. Mulley AG, Trimble C, Elwyn G. Stop the silent misdiagnosis: patients' preferences matter. BMJ 2012;345:e6572.

5. Sanderson $T$, Morris $M$, Calnan $M$, et al. Patient perspective of measuring treatment efficacy: the rheumatoid arthritis patient priorities for pharmacologic interventions outcomes. Arthritis Care Res (Hoboken) 2010;62:647-56.

6. Singh JA, Saag KG, Bridges SL, Jr., et al. 2015 American College of Rheumatology Guideline for the Treatment of Rheumatoid Arthritis. Arthritis Care Res (Hoboken) 2016;68:1-25.

7. Smolen JS, Landewe R, Breedveld FC, et al. EULAR recommendations for the management of rheumatoid arthritis with synthetic and biological disease-modifying antirheumatic drugs: 2013 update. Ann Rheum Dis 2014;73:492-509.

8. Sanderson T, Morris M, Calnan M, et al. What outcomes from pharmacologic treatments are important to people with rheumatoid arthritis? Creating the basis of a patient core set. Arthritis Care Res (Hoboken) 2010;62:640-6.

9. Albano MG, Giraudet-Le Quintrec JS, Crozet C, et al. Characteristics and development of therapeutic patient education in rheumatoid arthritis: analysis of the 2003-2008 literature. Joint Bone Spine 2010;77:405-10.

10. Brus HL, Taal E, van de Laar MA, et al. Patient education and disease activity: a study among rheumatoid arthritis patients. Arthritis Care Res 1997;10:320-4.

11. Davis P, Busch AJ, Lowe JC, et al. Evaluation of a rheumatoid arthritis patient education program: impact on knowledge and self-efficacy. Patient Educ Couns 1994;24:55-61.

12. Fall $\mathrm{E}$, Chakroun N, Dalle N, et al. Is patient education helpful in providing care for patients with rheumatoid arthritis? A qualitative study involving French nurses. Nurs Health Sci 2013;15:346-52.

13. Lorig KR, Mazonson PD, Holman HR. Evidence suggesting that health education for self-management in patients with chronic arthritis has sustained health benefits while reducing health care costs. Arthritis Rheum 1993;36:439-46.

14. Dougados $M$, Soubrier $M$, Perrodeau $E$, et al. Impact of a nurse-led programme on comorbidity management and impact of a patient self-assessment of disease activity on the management of rheumatoid arthritis: results of a prospective, multicentre, randomised, controlled trial (COMEDRA). Ann Rheum Dis 2015;74:1725-33.

15. McBain H, Shipley M, Olaleye A, et al. A patient-initiated DMARD self-monitoring service for people with rheumatoid or psoriatic arthritis on methotrexate: a randomised controlled trial. Ann Rheum Dis 2016;75:1343-9.

16. Richter JG, Becker A, Koch T, et al. Self-assessments of patients via Tablet PC in routine patient care: comparison with standardised paper questionnaires. Ann Rheum Dis 2008;67:1739-41.

17. Koevoets R, de Glas NA, le Bourlout C, et al. Autonomous online health assessment questionnaire registry in daily clinical practice. Rheumatology (Oxford) 2013;52:883-7.

18. El Miedany Y, El Gaafary M, Palmer D. Assessment of the utility of visual feedback in the treatment of early rheumatoid arthritis patients: a pilot study. Rheumatol Int 2012;32:3061-8.

19. Newman ED, Lerch $V$, Billet J, et al. Improving the quality of care of patients with rheumatic disease using patient-centric electronic redesign software. Arthritis Care Res (Hoboken) 2015;67:546-5.3

20. van Tuyl LH, Sadlonova M, Davis B, et al. Remission in Rheumatoid Arthritis: Working Toward Incorporation of the Patient Perspective at OMERACT 12. J Rheumatol 2016;43:203-7.

21. Hewlett SA. Patients and clinicians have different perspectives on outcomes in arthritis. J Rheumatol 2003;30:877-9.

22. McPherson KM, Brander P, Taylor WJ, et al. Living with arthritis--what is important? Disabil Rehabil 2001;23:706-21. 
23. Carr A, Hewlett S, Hughes R, et al. Rheumatology outcomes: the patient's perspective. J Rheumatol 2003;30:880-3

24. Ahlmen M, Nor.denskiold U, Archenholtz B, et al. Rheumatology outcomes: the patient's perspective. A multicentre focus group interview study of Swedish rheumatoid arthritis patients. Rheumatology (Oxford) 2005;44:105-10.

25. Barton JL. Patient preferences and satisfaction in the treatment of rheumatoid arthritis with biologic therapy. Patient Prefer Adherence 2009;3:335-44.

26. Nell VP, Machold KP, Eberl G, et al. Benefit of very early referral and very early therapy with diseasemodifying anti-rheumatic drugs in patients with early rheumatoid arthritis. Rheumatology (Oxford) 2004;43:906-14.

27. Villeneuve E, Nam JL, Bell MJ, et al. A systematic literature review of strategies promoting early referral and reducing delays in the diagnosis and management of inflammatory arthritis. Postgrad Med J 2013;89:231-40.

28. Earle CC. Failing to plan is planning to fail: improving the quality of care with survivorship care plans. J Clin Oncol 2006;24:5112-6.

29. Stewart MA. Effective physician-patient communication and health outcomes: a review. CMAJ 1995;152:1423-33.

30. Bergstra SA, Machado PM, van den Berg R, et al. Ten years of METEOR (an international rheumatoid arthritis registry): development, research opportunities and future perspectives. Clin Exp Rheumatol 2016;34:S87-S90.

31. Pincus T. Electronic eRAPID3 (Routine Assessment of Patient Index Data): opportunities and complexities. Clin Exp Rheumatol 2016;34:S49-S53.

32. Bidaut-Russell M, Gabriel SE, Scott CG, et al. Determinants of patient satisfaction in chronic illness. Arthritis Rheum 2002;47:494-500.

33. Verkissen MN, Ezendam NP, Fransen MP, et al. The role of health literacy in perceived information provision and satisfaction among women with ovarian tumors: a study from the population-based PROFILES registry. Patient education and counseling 2014;95:421-8.

34. Putrik P, Ramiro S, Lie E, et al. Less educated and older patients have reduced access to biologic DMARDs even in a country with highly developed social welfare (Norway): results from Norwegian cohort study NOR-DMARD. Rheumatology (Oxford) 2016;55:1217-24.

35. Seurer AC, Vogt HB. Low health literacy: a barrier to effective patient care. S D Med 2013;66:51, 3-7.

36. Barry MJ, Edgman-Levitan S. Shared decision making--pinnacle of patient-centered care. N Engl J Med 2012;366:780-1.

37. de Haes H. Dilemmas in patient centeredness and shared decision making: a case for vulnerability. Patient Educ Couns 2006;62:291-8.

38. Lohr KN, Zebrack BJ. Using patient-reported outcomes in clinical practice: challenges and opportunities. Qual Life Res 2009;18:99-107.

39. Nystad TW, Fenstad AM, Furnes O, et al. Reduction in orthopaedic surgery in patients with rheumatoid arthritis: a Norwegian register-based study. Scand J Rheumatol 2015:1-7. 



\section{Chapter 9}

Summary and general discussion 

In this final part of the thesis, first the main results are summarized. Next, we discuss methodological challenges in the conduct of our studies. Finally, we address possible clinical implications of the results and suggest areas for future research.

\section{Summary (of the main findings)}

The important role of context in the outcome of chronic diseases is widely acknowledged. It is estimated that up to $80 \%$ of the avoidable burden of illness can be found in the context of persons or populations. ${ }^{1}$ This thesis addressed the role of two contextual factors that so far have received limited attention in rheumatoid arthritis (RA) care, namely the role of country of residence on outcomes in RA and the role of the healthcare professionals' (HCPS) preferences in the management of RA. The main findings are summarized in Figure 9.1. 
I. Country of residence as contextual factor in outcome measurement in rheumatoid arthritis

a. Country of residence has an important influence on variations in outcomes including fatigue, disease activity and physical function

b. When exploring the influence of specific country characteristics on fatigue, a stronger effect was found for the country's economic and development status compared to the country's level of income inequalities, climate and language

c. A paradox was observed for the relation between the country's wealth and outcomes: While patients from wealthier and more developed countries had lower objectively assessed disease activity, they perceived a higher impact of the disease (especially fatigue and well-being)

II. The healthcare professionals' preferences as contextual factor in the management of rheumatoid arthritis

a. When choosing drug treatments for patients with rheumatoid arthritis, efficacy clearly dominates rheumatologists' choices across countries

b. In addition to efficacy, rheumatologists overall account for patients' preferences and economic aspects when choosing drug treatments

c. Interestingly, patients' preferences are in particular influential on rheumatologists' drug choices when patients express their dislike with a proposed treatment

d. When considering economic aspects in a drug choice, rheumatologists primarily consider absolute costs. It is estimated that more than half of European rheumatologists even disregard the cost-effectiveness of a drug

e. Significant heterogeneity in preferences for a drug treatment choice exists among individual rheumatologists: While there is some influence of country of residence, the role of the rheumatologists' socio-demographic background seems minor

f. Overall, healthcare professionals agree with patients on priorities in rheumatoid arthritis care as well as key areas of care that need to be improved

Figure 9.1 Summary of key findings 
Further, on the following pages, the main findings of the individual studies of the thesis will be summarized in more detail.

\section{Part I: The role of country and socio-cultural context in outcome measurement in rheumatoid arthritis}

In chapter 2, we analysed the possible role of country of residence on fatigue, an important outcome for patients with RA. ${ }^{2}$ Fatigue is often assessed using a single global measure, the 0-10 visual analogue scale (VAS). In a study among 3920 RA patients from 17 countries from different world regions, we revealed that objective measures of disease activity, namely tender- and swollen joint counts (TJC, SJC) and erythrocyte sedimentation rate (ESR) had only limited contribution to the variation in the level of fatigue or in the likelihood to be severely fatigued (0-10 VAS $\geq 5)$, while more subjective outcomes (such as self-assessed physical function and overall health) moderately contributed to the observed variations. Of interest, fatigue varied importantly across countries, even after adjustment for individual and disease characteristics. In the Netherlands (NL), the country with the highest level of fatigue, average fatigue was 5.0, which was 3.5 points higher than in the country with the lowest level of fatigue, and the odds to be severely fatigued were 31-fold higher in NL, the country with the highest proportion of severely fatigued patients compared to the one with the lowest proportion (Venezuela). When trying to understand factors that could explain the 'country effect' on fatigue, we found that higher economic welfare, measured by gross domestic product per capita adjusted for purchasing power parity (GDP-PPP), and higher development status, measured by human development index (HDI), contributed to higher levels of fatigue and to a larger proportion of patients being severely fatigued, while effects of latitude (a possible surrogate for climate or sunshine), language and income inequality within the country (Gini-index) were negligible.

In Chapter 3, we then investigated whether the role of country of residence is similar across different outcome domains. The same dataset as in chapter 2 was used. Specifically, this study explored patterns in the role of country of residence when comparing more objective measures that assess disease activity (TJC, SJC, and an adjusted Disease Activity Score 28 (DAS28), consisting of both joint counts and ESR, but without patient global assessment of the disease (PatGA)) or physician global assessment of the disease (PhyGA)) with three more subjective patient-reported outcome (PRO) measures (fatigue, physical function, PatGA). Important country differences were present across all outcomes and persisted after adjusting for individual confounders. When grouping countries by their level of economic wealth (GDP-PPP), we observed opposite results for objective measures (DAS28, PhyGA) and PROs (fatigue, 
PatGA and less strongly also physical function). Patients in wealthier (higher GDP) countries had on average 1.0 point better DAS28 compared to poorer countries (lower GPD), but paradoxically worse PROs (e.g. on average, subjective self-reported fatigue was 1 point higher on a 0-10 VAS). Of note, independent of country of residence, patients with poorer education had worse objective- and patient-reported outcomes (PROS).

Chapter 4 introduced a methodological approach to investigate the influence of contextual factors on patient- and physician-reported outcome measures. Specifically, we investigated differential item functioning (DIF) within the item response theory (IRT) framework when measuring the construct 'physical function' captured using the different versions of the Health Assessment Questionnaire (HAQ) in RA. The IRT framework is a widely used approach to explore the psychometric properties of a measurement scale consisting of multiple items. IRT implies that both, the 'person's ability' and the 'item difficulty' are placed along the same single latent dimension, in this study 'physical function'. By exploring DIF, we could show that socio-demographic factors including age, gender, employment status and education cause bias across a substantial but varying number of items of the various HAQ versions. This means these individual items perform differently - assessed through standardized odds ratio in one subgroup compared to another (e.g. lower opposed to higher educated persons, or females opposed to males) at the same level of physical function - and these differences reach $10 \%$ or more. However, the effect on the composite HAQ scores after adjusting for DIF was minimal (mean composite scores increased by $<0.1$ ) indicating the overall accuracy of composite HAQs across socio-demographic groups. Further, regressions analyses of the HAQ before and after adjusting for DIF revealed that the association between socio-demographic factors and HAQ remains largely similar confirming the difference in $\mathrm{HAQ}$ scores between socio-demographic groups is not simply caused by item bias.

\section{Part II: The healthcare professionals' preferences as contextual factor in the management of rheumatoid arthritis}

In chapters 5 to 7 we studied how rheumatologists trade-off different characteristics of drug treatments. We aimed specifically to understand to what extent patients' preferences and economic implications of treatments play a role in rheumatologists' treatment choices, in addition to classical aspects such as efficacy and safety. Further, we were interested in understanding whether a) socio-demographic factors (Chapter 5), b) country of residence (Chapter 6) and c) the patient profile (Chapter 7) influence the treatment choice of rheumatologists. To answer this question, a discrete choice 
experiment (DCE), a frequently used method to elicit preferences in healthcare, ${ }^{3}$ was designed. Rheumatologists were asked to repeatedly choose their preferred drug treatment for the clinical context of a specific patient with clearly defined personal (female, 42 years old, smoking) and disease characteristics (moderate active RA despite two conventional synthetic disease modifying anti-rheumatic drugs (csDMARDs)). In a series of choice tasks, two alternative (hypothetical) treatment options were presented to rheumatologists, differing according to five attributes relevant to our study objective, i.e. efficacy, safety, patients' preferences, absolute costs and cost-effectiveness.

Chapter 5 shed light into the preferences of 63 Dutch rheumatologists towards drug treatment characteristics. Efficacy had the strongest relative contribution to the drug choice $(44 \%)$ followed by medication costs (24\%), patients' preferences (17\%) and costeffectiveness (14\%). Patients' preferences were most relevant when patients disliked a proposed treatment. Interestingly, when making economic trade-offs, absolute costs were more important than the weighted cost-effectiveness considerations. The study further showed an important heterogeneity in rheumatologists' preferences, although not explained by differences in age, gender or work-environment of rheumatologists.

Next, Chapter 6 revealed the role of country of residence on preferences towards drug treatments. Data from 559 rheumatologists from 12 countries were retrieved using the same DCE. The countries represented different European geographic regions with varying economic and healthcare environment comprising (Belgium (BE), Germany (GE), Hungary (HU), Netherlands (NL), Norway (NO), Sweden (SE), Spain (SP), United Kingdom (UK), France (FR), Italy (IT), Portugal (PT) and Romania (RO). The study confirmed the Dutch findings with a high importance of efficacy, but additional relevance of patients' preferences and economic aspects in drug treatment choices. The relative contribution of absolute costs was higher than of cost-effectiveness, and this happened across all countries, with the exception of the UK and HU, in which cost-effectiveness was more valued. Cluster analyses of the countries' mean relative importance weights for the five attributes revealed two clusters of countries. When further exploring the heterogeneity in individual preference profiles of rheumatologists using latent class models, four classes of rheumatologists were identified despite substantial inter-individual variations among clinicians. The majority of rheumatologists (43\%) belonged to the first identified class, and accounted for both economic attributes (absolute costs and costeffectiveness) but largely disregarded safety while rheumatologists belonging to the remaining classes $(22.6 \%, 31.1 \%$ and $11.1 \%$ respectively) largely disregarded costeffectiveness. Rheumatologists from FR, IT, PT, RO were significantly more likely to be located in the latter classes, and thus overall disregard cost-effectiveness. Of note, 
absolute costs remained a relevant criterion in treatment choices for $77 \%$ of individual clinicians.

Finally, the role of the patient's disease profile in rheumatologists' drug choice was described in Chapter 7. Rheumatologists from countries with more restricted healthcare settings and thus higher sensitivity to also economic implications of a drug choice, were asked to complete the above described DCE not only for a patient with moderate active RA, but also for a patient with high disease activity. In line with the previous studies, drug efficacy was the driver for treatment choices, irrespective of disease status. Interestingly, the importance of economic considerations was largely independent of disease severity, indicating that individual rheumatologists valued the beneficial effects of medication to lower disease activity and achieve remission similarly in patients with moderate and high disease activity. This findings confirm an indisputable support for a treat-to-target approach in every RA patient. ${ }^{4}$ Rheumatologists were however willing to give up some efficacy to account for patients' preferences when choosing treatments for patients with moderate compared to high disease activity.

As the management of chronic diseases including RA became more holistic in recent years, with evolution towards patient centred care in which patients have a voice in the care they want to receive, ${ }^{5-7}$ we dedicated the last chapter (Chapter 8 ) to the comparison of the patients' and HCPs' perspective on RA care. The study aimed to better understand concordance and discordance when it comes to priorities in daily care and areas that require improvement. For this study, we used the lay version of the 20 European Standards of Care (SOCS) and investigated the level of agreement for two dimensions: a) level of implementation of the SOCs and b) priorities in RA care among 386 patients and $91 \mathrm{HCPs}$ from NL. We found that patients and HCPs agreed that adequate DMARD treatment, access to care in case of emergency and regular reappraisal of treatment targets in case of treatment failure are among the most important aspects of RA care. Fortunately, these standards were considered as appropriately implemented by both patients and HCPs. However, some relevant care gaps were identified by patients and HCPs, including diagnosis within 6 months of symptom onset and availability of a treatment plan. Patients, to a larger extent than HCPs, suggested in addition improvements in receiving a schedule of regular assessment of disease. While patients and HCPs agreed that limited financial coverage of some recommended health services was a barrier for implementation, patients additionally pointed to the limited time of physicians during consultations. 


\section{Methodological considerations}

Specific methodological strengths and limitations of the individual studies in this thesis have already been addressed in the discussion sections of the respective chapters. Below, we expand on some overarching issues pertaining to the thesis.

\section{Country of residence in outcome research in rheumatoid arthritis}

While we highlighted the role of country of residence as a contextual factor in outcome of RA, the mechanisms through which 'country' actually exerts its influence on outcome remain difficult to understand. Possible explanations include underlying factors that characterize country of residence, linguistic issues of the outcome measure, and the design and analyses of multinational data.

\subsection{Availability of factors characterizing country of residence in outcome research}

Only a limited number of studies available in the literature investigated the influence of 'country' on variations in health outcomes beyond potential biological (often genetic) factors shared within populations. Such studies commonly interpret 'country' as a surrogate for healthcare standards i.e. the quality of a healthcare system and patients' access to care. ${ }^{8-13}$ In general, higher healthcare standards and better access to care are considered to result in better outcomes. However, only few studies formally tested this assumption. This is not surprising, as variables that allow measurement of 'quality of healthcare' including 'access to healthcare' on the country level are very limited. Even basic factors such as the number of HCPs relative to the population size or availability of reimbursed technologies and treatments for specific diseases and interventions at the population level are difficult to retrieve across countries. In RA, one study was able to show that variation in disease activity between countries was partly explained by difference in gross domestic product per capita (GDP), and further revealed the relation between GPD and disease activity was partly mediated by uptake of biologicals. ${ }^{14}$ However, access to high quality healthcare does not explain all country related variations in health outcomes. Our studies suggest that the influence of country is indeed more complex: first, multiple country characteristics contributed to variations in outcomes across countries, and secondly the magnitude and direction of influence can differ across outcome domains.

When searching for the availability of indices to operationalize possible candidate country characteristics in our study on variation in fatigue across countries, we faced a number of challenges. Several available country characteristics were associated with patients' reported fatigue, with strong (negative) influence of the country's economic 
and development status (GDP and HDI) and smaller influences of prevailing income inequalities (Gini-index), climate or language. However, when exploring whether more sunshine results in less fatigue, we used latitude of the country's capital, recognizing that latitude rather reflects hours of daylight than sunshine, and further ignores variation between regions in large countries. Also, although GDP can be a helpful proxy to describe the country's overall wealth, important differences may be present in economic prosperity within the country (e.g. urban vs rural regions). Further, available indices were not always calculated similarly across countries and were often not available for comparable periods in time. As an example, availability of the Gini-index, which we explored as a possible surrogate for inequality in access to healthcare, spanned 15 years, a period in which income inequalities may have substantially changed in selected countries. Finally, there is large overlap between some country-indices (e.g. HDI and GDP are strongly correlated) making it difficult to draw clear conclusions on their individual contribution.

\subsection{Country of residence as possible surrogate for the socio-cultural environment}

Importantly, a large part of the influence of country of residence on outcome remained unexplained and raised the question what this 'unexplained' variation actually represents. Much insight was obtained from the observed paradox with patients from wealthier countries overall scoring worse on PROs despite lower disease activity, reflected by lower TJC, SJC and ESR. PROs primarily assess how patients feel (e.g. fatigue, PatGA), and thus reflect the patients' appraisal of disease in the context of their personal believes and living environment. The reverse relationship between GPD and disease activity measures as opposed to fatigue, strengthened the idea that also intangible factors such as the socio-cultural environment play a role in the patients' individual disease experience. When interpreting the finding of higher fatigue and worse wellbeing in wealthy countries, we speculated that hectic and stressful lifestyle in higher income countries may play an important role. Possibly, in richer countries the society demands more from patients, eventually because it offers them better healthcare. In return, patients may be expected to keep up with the fast-paced lifestyle and high work productivity, an expectation patients may not always manage to cope with. In this context, it would have been interesting to also understand how the general population scores on the same scales (e.g. fatigue or general health) and compare the data with patients' responses across countries.

Understanding and measuring the construct of 'socio-cultural values' or 'socio-cultural environment' however is a challenge. The term 'culture' is a quite intangible notion that lacks clear definition. In the literature, multiple definitions for culture exist. Culture can be considered as a set of guidelines (explicit and implicit) that individuals inherit as 
members of a society and that tells them how to view the world, how to experience it emotionally and how to behave in it in relation to other people, supernatural forces (e.g. God) and to their natural environment. ${ }^{15}$ In a shorter definition, culture can be described in its broadest sense as a 'cultivated behavior'; that is the totality of what a person has learnt, accumulated experience which is socially transmitted, or more briefly, behavior through social learning. Both definitions reveal the multidimensional nature of culture and indicate the difficulty to transform it into a single, unambiguous, variable for research.

\subsection{Linguistic aspects, scale interpretation and item bias of outcome measures}

Multi-national studies on diseases outcome assume that measurement instruments are culture-proof, i.e. assess the same construct across countries. Over the last decades, much attention has been paid to correct linguistic and cultural validation when translating PROs into other languages. ${ }^{16}$ Notwithstanding, it cannot be excluded that some questions or even whole questionnaires had different meanings in different countries. Specific for our study on fatigue, the distinction in meaning between the words 'tiredness', 'fatigue' and 'exhaustion' does not exist in all languages. ${ }^{17}$ This suggests that linguistic aspects require continuous attention and add complexity to cross-country comparisons.

The linguistic and cultural validity of PROs further expands to clinimetric properties such as minimal important difference or cut-offs to categorize severity of symptoms. As part of our analyses, we explored the risk for patients to be severely fatigued across countries and used a score equal or above 5 on the numeric rating sale/ VAS as threshold for severe fatigue. This threshold was proposed in a study conducted in UK, Western Europe. ${ }^{18}$ However, it can be questioned whether this threshold is equally applicable across countries and cultures. Persons from different cultural background might have different perception on the level of fatigue that actually constitutes 'severe fatigue'.

An interesting approach to further understand whether a country effect in a multi-item outcome measure is true or results from an instrument bias, is the exploration of DIF in the context of IRT. In the present work, we investigated DIF for all the items contained in different $\mathrm{HAQ}$ versions across several socio-demographic patient characteristics. We showed that socio-demographic factors caused bias in the majority of the individual HAQ items, but the effect on the composite HAQ scores was minimal. Importantly, even after adjustment of HAQ scores for DIF, the socio-demographic factors contributed to variance in $\mathrm{HAQ}$, indicating differences in $\mathrm{HAQ}$ between these subgroups cannot be attributed to item bias only. Investigation of DIF on country level involved technical complexities, and therefore these analyses were not yet part of the present thesis. Preliminary data revealed that composite HAQs overall have good psychometric 
properties across countries, the use of M-HAQ may however be favoured when comparing physical function across countries. Important DIF on country level was in particular found for Serbia, Egypt, Russia, Morocco. ${ }^{19}$ For that reason, these countries were also removed from our study investigating DIF across socio-demographic variables (chapter 4). It should be reminded that IRT models are only applicable to multi-item questionnaires. Moreover, while DIF can reveal whether a contextual factor causes item bias, it cannot identify the underlying reason. Finally, when DIF for some items across countries is detected, the key question is actually whether these items should be deleted to ensure clinimetric comparability in outcome measures, or whether these items have high face validity. In the latter situation, different instruments across countries should be used, limiting direct comparability of scores.

\subsection{Datasets, study design and analyses of multinational observational studies}

When investigating the influence of country on outcomes and management of RA, we faced several challenges related to availability of multinational data, the study design and analysis of the data.

Setting up new studies/cohorts is complex, expensive and particularly involves a long period of time, therefore we used existing studies to the extent possible. To our knowledge COMORA and QUEST-RA are the two largest international observational studies in RA. In order to explore the complex relationship between individual and country-level determinants, it is essential that such databases are rich in individual level factors related to the disease, personal characteristics and personal environment. Unfortunately, none of the available datasets included variables such as personal/household income or level of health insurance (as proxy for uptake of care), coping style or level of self-efficacy. These person-level determinants can vary importantly between countries and thus would help to interpret independent differences between countries. On the other hand, collecting more background information increases length and complexity of questionnaires and increases risk of nonparticipation and selection bias.

Efforts to collect new data in the setting of multinational research should not be underestimated. The preference studies among rheumatologists (chapter 5 to 7 ) and the audit-study of European SOCs in RA as an international study (chapter 8 describes only the Dutch results) posed clear challenges. First, translation and adaptation of questionnaires to the varying local realities was a work intensive step that often restrained local principal investigators to support study conduct. Second, different regulations had to be followed with regard to ethical approval of clinical studies among patients and even professionals. Even on the level of participating centers within a country, important differences in the need, procedures and costs for study approvals 
existed. Last, when collecting new data in an international setting, ensuring generalizability of data remains a challenge as some approaches for recruitment might not be possible or feasible in all countries (e.g. differences in availability and accessibility of registries). Also, the preparedness of patients or professionals to participate in a study might differ between countries. Studies that aim to explore country of residence (or country level determinants of health) should give additional attention to sampling strategies and ensure proper phenotyping for country-relevant factors.

Of note, the data used in the present work include cross sectional data only. Notwithstanding, longitudinal data have additional value as they can, opposed to crosssectional studies, shed light into causal relationships and are further informative when studying changes over time (e.g. innovations in (costs of) technologies, regulations of healthcare systems, etc.).

In the present work we were naturally interested in true effects and not in spurious relationships. Therefore, we performed linear and logistic regression analyses to investigate the effect of a given country (compared to a reference country) on the outcomes. Following the Outcome Measures in Rheumatology (OMERACT) definition that effect modification would add to the importance of a factor as a real contextual factor, also interactions between individual and country socio-economic characteristics were tested. However, not all analytical methodological challenges could be solved following the selected approach. When a model is not corrected for the appropriate confounders, spurious relationships might be detected. In the case of the analysis of PROs (e.g. fatigue or PatGA), some additional factors could be relevant like level of illness beliefs or coping mechanisms or even genetic effects, relevant individual level confounders, that may cluster in countries and thus explain some of the observed impact of country of residence. Furthermore, by adding country or country characteristics as a factor variable to the models, we ignored the dependency in observations, as patients are nested within countries. This could have been taken into account by using a multilevel model. However, this is turn, is also limited in terms of power, as the power to detect country level predictors is driven largely by the number of countries. The number of countries included in multinational studies, though impressive in what concerns the logistic challenges they represent, is usually relatively small in statistical terms when analysing country-level variables. Nevertheless, this represent more elegant solutions to analyse multinational studies. Last but not the least, our analyses on country effects have been limited to observational studies. Also, an interesting question would be whether interventions have different effects across countries, in other words, whether effect sizes are country dependent. ${ }^{20}$ 


\section{Assessing preferences of healthcare professionals}

Few studies in health research addressed believes or behaviours of HCPs and their influence on management decisions and/or disease outcomes. ${ }^{21-24}$ Several well established methodological approaches are available. The selection primarily depends on the specific study question, and both qualitative as well as quantitative methods can be useful. For our research question, a DCE seemed an appropriate study design, as we were especially interested in how rheumatologists trade-off specific treatment characteristics when choosing a drug. Also, the DCE setting allows the use of a single and clearly defined 'paper patient profile' that eliminates heterogeneity in preferences related to variations in patient characteristics, likely a major source of heterogeneity in physicians' behavior in a real life clinical setting. Of interest, our study comparing clinicians' preferences for two different patient profiles confirmed an influence of the patient's disease severity on preference patterns of rheumatologists, suggesting the need for a clear definition of a patient profile in preference research.

When interpreting the findings of our preference studies, the principles of a DCE should be acknowledged. In a DCE, the number of attributes and levels that can be tested is limited, i.e. individuals can only account for a limited number of choice characteristics, (generally a maximum of about eight), that describe a choice option. On that line, we carefully selected the attributes and levels while keeping in mind the main study question. Further, it is essential to understand that a DCE can only provide insights into stated preferences while revealed preferences may differ in several aspects and thus partly limit conclusions for clinical practice. While in some situations the choices in real life are equally or even more important, stated preferences can also be important to understand what respondent would wish to choose in hypothetical situation. When such hypothetical choices do not exist, DCE might indicate how reality would preferably be adjusted.

With regard to the results, the high heterogeneity in preferences among individual rheumatologists was striking. Interestingly, available factors characterizing physicians (e.g. age, gender or work environment) could not explain the observed high interindividual heterogeneity, leaving the question 'how/why' physicians make their choices partly unanswered. It may have been additionally insightful to study the influence of factors such as affiliation with research or believe in authority. However, no data were collected in the present study that would allow for such analyses.

From the outset of the study, it was our intention to compare preferences of rheumatologists across countries. This posed additional methodological challenges. First, we computed the relative importance weights of the attributes for each country separately. However, results did not allow for statistical conclusion on differences between countries. As a second step in the approach to assess the potential effect of 
country on preferences, we aimed to include country as a covariate in the latent class model to assess if the probability to belong to a class differs between countries. However, given the limited sample size, it was not possible to add all individual countries as covariates. When trying to group countries into smaller, but theoretically meaningful groups, such as geographic regions, clinical criteria for drug reimbursement, type of insurance system or the country's wealth and development status, no clear patterns could be found. We therefore explored the data statistically and applied cluster analyses that grouped countries based on similarity in mean relative importance weights across the five attributes resulting in two clusters. To understand whether country and individual characteristics could further explain heterogeneity, we continued our analyses with a latent class model. This analysis revealed four different response patterns that could be primarily described by the rheumatologists' attitude towards economic treatment characteristics and safety while attitude towards efficacy and patients' preferences did not determine affiliation with a class. Last we included the cluster as a covariate in the latent class model. We observed that countries from one cluster (FR, IT, PT, RO) have a higher probability to disregard cost-effectiveness considerations.

\section{Clinical implications \& future research}

\section{Influence of country on outcomes in rheumatoid arthritis}

Although evidence on the influence of 'country' on outcomes might not have immediate impact on daily clinical care, we feel our findings are useful when supporting patients to self-manage the disease, and also to get further insight into outcome determinants.

It is important that patients understand that outcomes experienced by patients (such as fatigue) are complex and multifactorial. Patients' experiences of impairments and limitations are not only related to the biology of the disease and its treatments, but are also influenced by context including personal appraisal. Specifically for fatigue, patients can be informed that, although (severe) fatigue is a common symptom among patients with RA, no clear relationship has been shown between disease activity and fatigue. ${ }^{2}$ In addition, it might be informative to share the results of our paradox and thus stimulate patients' self-reflection on internal and external stressors in their life, including personal expectations, pressure at work or pressure to fulfil multiple social roles. Of interest, recent studies exploring fatigue over time suggest that despite significant advances in RA care during the past decade as reflected in lower SIC and lower ESR, patients express more fatigue and worse pain. ${ }^{25,26}$ This further strengthened our hypothesis that 'context', likely internal and external stressors, contribute importantly to a patient's individual disease experience. 
With regard to future research on fatigue, it could be interesting to apply multidimensional fatigue questionnaires in multinational studies. Multidimensional questionnaires aim to explore several types of fatigue and often distinguish physical, emotional, mental and cognitive fatigue. ${ }^{27}$ Such studies might be helpful to understand whether also types of fatigue indeed differ across countries. We hypothesize a more dominant role of emotional and cognitive fatigue in Western high income countries. As part of such a study, exploring DIF related to country might help to understand whether some items related to subdomains of fatigue have indeed a different position in the latent scale 'fatigue' in some countries. Moreover, future research projects may explore the role of stress on PROs (and specifically on fatigue) in RA. Extensive literature can be found on measures to assess levels of (perceived) stress ${ }^{28-30}$ that can be helpful to address the role of stressors such as self-expectations, social or economic pressure on the individual disease experience. It may be further interesting to investigate not only whether stress relates to fatigue, but also to explore how this relates to other individual personal contextual factors such as coping strategies or self-efficacy, and whether such relationships are different across countries. Currently, there is limited evidence on the role of these personal factors in relation to e.g. fatigue. ${ }^{31}$ Moreover, insight into country level differences in perceived stress and its impact on the patient's disease experience can fuel discussions on Western lifestyle and start initiatives on the public health level to adopt a lifestyle that is less prone to stress, anxiety and pressure.

The paradox in our study also raises the question whether priorities in patient goals would be different across countries. Existing studies on patients' needs and priorities commonly provide information from highly developed countries in Europe or North America. ${ }^{32-35}$ It may therefore be interesting to understand how patients from different world regions prioritize the core outcome domains as identified by international initiatives such as the International Classification of Functioning, Disability and Health $(\mathrm{ICF})^{36}$ and OMERACT. ${ }^{37}$ Of interest, our study investigating treatment priorities and gaps related to the European SOCs, collects data from rheumatologists and patients in more than 40 European countries to understand differences in priorities in care across countries and regions. However, data collection is still ongoing in some countries, therefore data are not part of the present work.

This thesis made clear that a sound methodological framework is needed when further investigating the role of country of residence in relation to outcomes. In addition to the theoretical framework and classification of personal and environmental contextual factors, the approach to select patient-level and country level factors for studies should be clarified, valid and reliable instruments to measure such factors should be developed and appropriate statistical approaches to understand relationships should be applied. As indicated in the paragraph on methodological challenges, to really understand whether 
country of residence plays a role independent of possible individual level factors, there is a need to better understand how the personal factors interact with system level factors. Structural equation modeling and multilevel analyses will become the rule and not the exception in such study questions.

Last but not least, we have to acknowledge that our studies addressed observational and cross-sectional data. Even more relevant to understand whether the effect of interventions would be different across countries and/or across different outcomes. ${ }^{20}$

\section{The role of healthcare professionals' preferences in management (and outcome) of rheumatoid arthritis}

In clinical care, patient outcomes are much dependent on the choices, attitudes and behaviours of HCPs. Within the limitation that data from our DCE are retrieved from a hypothetical experiment and not from observation in real life, the findings show that all over Europe most rheumatologists consider patients' preferences and make economic trade-offs when choosing treatments for their patients.

The prominent role of patients' preferences and economic implications in addition to dug efficacy, can be seen as a paradigm shift in clinical decision making. Awareness of the values and believes of patients and the need to spend money wisely, seem to affect today's treatment choices.

While these evolutions are necessary in the context of our dynamic society, we revealed important variations in the clinical decision making among individual rheumatologists. Of note, a recent DCE investigating treatment decisions on de-escalation of DMARDs confirms heterogeneity in decisions around drug treatment. ${ }^{38}$ The high heterogeneity is of some concern as it jeopardizes equality in care, a common principle that can be found in all European healthcare systems. ${ }^{39}$ In simple words, it should not be the lucky incidence of a patient to be treated by a doctor who is more open to patients' preferences, or who is less cost-sensitive when proposing a treatment. Certainly, some variations in attitudes between clinicians are acceptable but our data suggest that the variations are significant and concerning. Medical doctors are often expected to fulfil two contradicting roles, as gatekeepers for increasing healthcare costs on the one hand and provider of best available healthcare accounting for the patients believes and values on the other hand. Resolving this decisional conflict that likely contributes to observed heterogeneities is not straightforward as the personality of the clinician as well as environmental factors may influence the clinical decision making process.

A first step towards reducing heterogeneity likely includes raising awareness on an existing problem and open discussions among rheumatologists about their views on benefits and pitfalls of shared decision making and economic trade-offs in daily life. Existing studies already identified potential difficulties clinicians face in an increasingly 
complex decisional process. ${ }^{40,41}$ However little is known about how these challenges actually impact treatment choices. To feed such discussions, more qualitative research on physicians' behavior might certainly be additionally supportive. In particular, it would be helpful to understand why negative preferences of patients receive more attention compared to positive preferences and how clinicians balance relative cost-effectiveness considerations and absolute budget impact.

However, neither stated preferences analyses nor additional qualitative research reveals what rheumatologists actually do in varying contexts. On this line, it is additionally important to collect data on individual level and system level factors that actually influence treatment decisions in real life. In line with one of the study objectives of this thesis, comparison across countries and regions with varying healthcare setting will be further insightful.

While increased insight into heterogeneity is a first step, it will not solve the question which heterogeneity is acceptable and justified. This requires a discussion among rheumatologists on their actual view on 'value based healthcare' in the consultation room. Although access to technologies is to a large extent regulated though reimbursement criteria, HCPs of many countries still have large autonomy when choosing among diagnostic procedures and treatments. The high heterogeneity indicates that making trade-offs in clinical care is not straightforward. Value based healthcare, a term that can increasingly be found in this context, has the potential to resolve parts of the decisional conflict between value and costs. Perhaps this movement will empower rheumatologists to emphasize 'added value' compared to the widely established budget driven approach. On this line it is essential that physicians agree on 'which value', thus 'what health' they want to improve. Are we willing to e.g. pay for satisfaction of patients or do we want keep a more limited view on health? Importantly, cost reduction without considering the outcomes is dangerous and self-defeating, leading to false savings and potentially limiting effective care. But expenditure without any benefit in patient outcomes are an absolutely unacceptable waste. It is clear that these complex questions on preferences in relation to costs and budget are difficult. Respect for different opinions is needed but also transparency as this will feed discussions. Healthcare providers need to take their position in public debates on how they view 'value based healthcare' for individual patients and emphasize the continuing conflict that can exist between group level evidence of decision and the decisions for the individual. In this era, shared decision making, trade-offs between health effects and costs could be made more explicit in each important clinical decision. 


\section{Conclusion}

The studies presented in this thesis explored the role of country of residence and physicians' preferences in outcome and/or management of RA. We provide evidence that in the $21^{\text {st }}$ century, choices of rheumatologists are not only driven by drug efficacy, but also by patients' preferences and by economic considerations. We also revealed that (country-) wealth is important for 'objective' health but not necessarily for patient's experienced disease impact. Caring for patients is more than only providing the best possible treatment. 


\section{References}

1 McQueen DV. Contextual Factors in Health and Illness. Global Handbook on Noncommunicable Diseases and Health Promotion: New York, NY : Springer New York : Springer; 2013:83-93.

2 Nikolaus S, Bode C, Taal E, van de Laar MA. Fatigue and factors related to fatigue in rheumatoid arthritis: a systematic review. Arthritis Care Res (Hoboken) 2013;65(7):1128-46.

3 Clark MD, Determann D, Petrou S, Moro D, de Bekker-Grob EW. Discrete choice experiments in health economics: a review of the literature. Pharmacoeconomics 2014;32(9):883-902.

4 Smolen JS, Landewe R, Bijlsma J, et al. EULAR recommendations for the management of rheumatoid arthritis with synthetic and biological disease-modifying antirheumatic drugs: 2016 update. Ann Rheum Dis 2017;76(6):960-77.

5 Voshaar MJ, Nota I, van de Laar MA, van den Bemt BJ. Patient-centred care in established rheumatoid arthritis. Best practice \& research. Clin Rheumatol 2015;29(4-5):643-63.

6 Bansback N, Shojania K, Lacaille D. Improving patient-centred care for rheumatoid arthritis. CMAJ 2016;188(14):999-1000.

7 Stoffer MA, Smolen JS, Woolf A, et al. Development of patient-centred standards of care for rheumatoid arthritis in Europe: the eumusc.net project. Ann Rheum Dis 2014;73(5):902-5.

8 Rubin RR, Peyrot M, Siminerio LM. Health care and patient-reported outcomes: results of the crossnational Diabetes Attitudes, Wishes and Needs (DAWN) study. Diabetes Care 2006;29(6):1249-55.

9 Allemani C, Rachet B, Weir HK, et al. Colorectal cancer survival in the USA and Europe: a CONCORD highresolution study. BMJ Open 2013;3(9):e003055.

10 Allemani C, Sant M, Weir HK, et al. Breast cancer survival in the US and Europe: a CONCORD highresolution study. Int J Cancer 2013;132(5):1170-81.

11 Matz M, Coleman MP, Carreira H, et al. Worldwide comparison of ovarian cancer survival: Histological group and stage at diagnosis (CONCORD-2). Gynecol Oncol 2017;144(2):396-404.

12 Matz M, Coleman MP, Sant M, et al. The histology of ovarian cancer: worldwide distribution and implications for international survival comparisons (CONCORD-2). Gynecol Oncol 2017;144(2):405-13.

13 Spika D, Bannon F, Bonaventure A, et al. Life tables for global surveillance of cancer survival (the CONCORD programme): data sources and methods. BMC Cancer 2017;17(1):159.

14 Putrik $\mathrm{P}$, Ramiro S, Kvien TK, et al. Variations in criteria regulating treatment with reimbursed biologic DMARDs across European countries. Are differences related to country's wealth? Ann Rheum Dis 2014;73(11):2010-21.

15 Helman C. Culture, health, and illness. 5th ed. ed. London :New York, NY :: Hodder Arnold ; Distributed in the United States of America by Oxford University Press; 2007.

16 Beaton DE, Bombardier C, Guillemin F, Ferraz MB. Guidelines for the process of cross-cultural adaptation of self-report measures. Spine (Phila Pa 1976) 2000;25(24):3186-91.

17 Radbruch L, Strasser F, Elsner F, et al. Fatigue in palliative care patients -- an EAPC approach. Palliat Med 2008;22(1):13-32.

18 Pollard LC, Choy EH, Gonzalez J, Khoshaba B, Scott DL. Fatigue in rheumatoid arthritis reflects pain, not disease activity. Rheumatology (Oxford) 2006;45(7):885-9.

19 Norton S, Hifinger M, Ramiro S, Putrik P, Sokka-Isler T, Boonen A. Comparability of the health assessment questionnaire between countries: Psychometric examination of cross-national measurement equivalence Ann Rheum Dis 2016;75(2):165.

20 Yusuf S, Wittes J. Interpreting Geographic Variations in Results of Randomized, Controlled Trials. N Engl J Med 2016;375(23):2263-71.

21 de Bekker-Grob EW, Bliemer MC, Donkers B, et al. Patients' and urologists' preferences for prostate cancer treatment: a discrete choice experiment. Br J Cancer 2013;109(3):633-40.

22 Gregorian RS, Jr., Gasik A, Kwong WJ, Voeller S, Kavanagh S. Importance of side effects in opioid treatment: a trade-off analysis with patients and physicians. J Pain 2010;11(11):1095-108. 
23 Caldon LJ, Walters SJ, Ratcliffe J, Reed MW. What influences clinicians' operative preferences for women with breast cancer? An application of the discrete choice experiment. Eur J Cancer 2007;43(11):1662-9.

24 Torbica A, Fattore G. Understanding the impact of economic evidence on clinical decision making: a discrete choice experiment in cardiology. Soc Sci Med 2010;70(10):1536-43.

25 Nieuwenhuis WP, de Wit MP, Boonen A, van der Helm-van Mil AH. Changes in the clinical presentation of patients with rheumatoid arthritis from the early 1990s to the years 2010: earlier identification but more severe patient reported outcomes. Ann Rheum Dis 2016;75(11):2054-6.

26 van Steenbergen HW, Tsonaka R, Huizinga TW, Boonen A, van der Helm-van Mil AH. Fatigue in rheumatoid arthritis; a persistent problem: a large longitudinal study. RMD Open 2015;1(1):e000041.

27 Hewlett S, Dures E, Almeida C. Measures of fatigue: Bristol Rheumatoid Arthritis Fatigue MultiDimensional Questionnaire (BRAF MDQ), Bristol Rheumatoid Arthritis Fatigue Numerical Rating Scales (BRAF NRS) for severity, effect, and coping, Chalder Fatigue Questionnaire (CFQ), Checklist Individual Strength (CIS2OR and CIS8R), Fatigue Severity Scale (FSS), Functional Assessment Chronic Illness Therapy (Fatigue) (FACIT-F), Multi-Dimensional Assessment of Fatigue (MAF), Multi-Dimensional Fatigue Inventory (MFI), Pediatric Quality Of Life (PedsQL) Multi-Dimensional Fatigue Scale, Profile of Fatigue (ProF), Short Form 36 Vitality Subscale (SF-36 VT), and Visual Analog Scales (VAS). Arthritis Care Res (Hoboken) 2011;63 Suppl 11:S263-86.

28 Brant H, Wetherell MA, Lightman S, Crown A, Vedhara K. An exploration into physiological and selfreport measures of stress in pre-registration doctors at the beginning and end of a clinical rotation. Stress 2010;13(2):155-62.

29 Kopp MS, Thege BK, Balog P, et al. Measures of stress in epidemiological research. J Psychosom Res 2010;69(2):211-25.

30 Rehkopf DH, Kuper H, Marmot MG. Discrepancy between objective and subjective measures of job stress and sickness absence. Scand J Work Environ Health 2010;36(6):449-57.

31 Matcham F, Ali S, Hotopf M, Chalder T. Psychological correlates of fatigue in rheumatoid arthritis: a systematic review. Clin Psychol Rev 2015;39:16-29.

32 Carr A, Hewlett S, Hughes R, et al. Rheumatology outcomes: the patient's perspective. J Rheumatol 2003;30(4):880-3.

33 Hewlett S, Cockshott Z, Byron M, et al. Patients' perceptions of fatigue in rheumatoid arthritis: overwhelming, uncontrollable, ignored. Arthritis Rheum 2005;53(5):697-702.

34 Campbell RC, Batley M, Hammond A, Ibrahim F, Kingsley G, Scott DL. The impact of disease activity, pain, disability and treatments on fatigue in established rheumatoid arthritis. Clin Rheumatol 2012;31(4): 717-22.

35 Sanderson T, Morris M, Calnan M, Richards $\mathrm{P}$, Hewlett S. Patient perspective of measuring treatment efficacy: the rheumatoid arthritis patient priorities for pharmacologic interventions outcomes. Arthritis Care Res (Hoboken) 2010;62(5):647-56.

36 Verstappen SM. Outcomes of early rheumatoid arthritis--the WHO ICF framework. Best practice \& research. Clin Rheumatol 2013;27(4):555-70.

37 Boers M, Kirwan JR, Wells G, et al. Developing core outcome measurement sets for clinical trials: OMERACT filter 2.0. J Clin Epidemiol 2014;67(7):745-53.

38 Kuijper TM, Folmer R, Stolk EA, Hazes JMW, Luime JJ. Doctors' preferences in de-escalating DMARDs in rheumatoid arthritis: a discrete choice experiment. Arthritis Res Ther 2017;19(1):78.

39 Jönssona B. RS, Wilking N. Cost effectiveness in practice and its effect on clinical outcomes. J Cancer Policy 2014;2(1):10.

40 Carlsen B, Hole AR, Kolstad JR, Norheim OF. When you can't have the cake and eat it too: a study of medical doctors' priorities in complex choice situations. Soc Sci Med 2012;75(11):1964-73.

41 de Haes H. Dilemmas in patient centeredness and shared decision making: a case for vulnerability. Patient Educ Couns 2006;62(3):291-8. 

Valorization 



\section{Valorization}

In this section of the thesis, the societal relevance of the work will be described.

It is estimated that rheumatoid arthritis (RA) affects about $1.0 \%$ of the adult population worldwide, thus RA remains a major public health problem associated with considerable costs to the healthcare system and the society as a whole. ${ }^{1}$ Despite advancements in the understanding of the disease and availability of pharmacological treatments in recent decades, RA still cannot be prevented or cured, and remains a lifelong burden to patients. Pain, functional impairment, fatigue and depression are common symptoms of RA and interfere with patients' participation in social activities and with overall quality of life. $^{2-4}$ To enhance equal care for all patients across countries, recommendations for pharmacological management as well as standards of care have been formulated at an international level (e.g. European League Against Rheumatic Diseases, American College of Rheumatology). ${ }^{5-8}$ However, these recommendations mostly rely on evidence from studies conducted in a limited number of countries from Western Europe or North America. While such international recommendations and standards have the potential to improve health outcomes of patients worldwide, we should realize that they are in fact aspirational, as implementation in the different countries heavily depends on cultural and economic background. Patients with diverse socio-cultural backgrounds may differ in how they perceive the disease burden and consequently result in different treatment needs and priorities. Societies that differ in financial potential or ideology could have different needs and priorities and could choose for different solutions. In 2014, the Lancet Commission on Culture and Health argued that the systematic neglect of culture in health and health care is the single biggest barrier to the advancement of the highest standard of health worldwide. ${ }^{9}$

In the present work, we investigated the role of country of residence as surrogate for a certain socio-cultural environment from the perspective of the patient but also the health care professional. On this line, our findings contribute to the understanding of the role of culture to health and healthcare at the individual and country level.

In part I of the thesis, we revealed that country has an important impact on outcomes in RA. The countries' wealth, exemplified by the Gross Domestic Product per capita, explained only part of this observed variation. We moreover revealed a paradox, namely, patients from highly developed countries with overall good access to high quality healthcare services, have a lower (objective) disease activity but experience more fatigue and lower well-being. Although further research will be needed to fully understand (1) the role of country and (2) the paradox relationship between a country's wealth and perception of health, the findings suggest that the country's socio-cultural environment may contribute to the patients' disease experience in RA. Specifically for 
outcomes in RA, the present data suggest that internal and external stressors (e.g. a patient's self-expectation or a demanding fast paced work environment, multiple social roles) play a key role in the experience of health of individuals (and populations). These insights may be of added value to patients and care givers. The thesis may contribute to the understanding of socio-cultural context in RA and support a shift in mind-set from a predominantly biomedical treatment approach, that overall applies to all patients irrespective of country or cultural context towards a broader view on care that also involves the patient's individual socio-cultural context. Healthcare professionals may bring forward the possible influence of stressors on health perception by informing patients in the consultation room. Patients may be invited to self-reflect on possible stressors in their life as reduction of such stressors may improve health beyond what can be achieved with medical treatments.

As the term socio-cultural context affects multiple areas of life and all health care players, awareness on the important relationship between culture and health cannot be limited to patients and their healthcare professionals alone but needs to be extended to health policy makers and society. For example, the World Health Organization (WHO) has initiated a number of initiatives to specifically involve European policy makers in the discussion on culture and health. ${ }^{10-12}$ Our findings may contribute to the understanding on how the wider socio-cultural environment of RA patients may influence their wellbeing and fuel discussions on how policy makers and society can create a more supportive socio-cultural environment for RA patients.

In Part II of the thesis, we additionally looked into the role of (culturally derived) attitudes and beliefs from the perspective of the healthcare professionals. As key players in most healthcare systems, their treatment decisions contribute enormously to health outcomes. Among rheumatologists, important variations could be found in how they value different treatment characteristics, i.e. economic aspects and patients' preferences in addition to efficacy and safety, when choosing drug treatments for their RA patients. Interestingly, country of residence as well as socio-demographic background could not sufficiently explain the observed variations. However, such high variability in care decisions for a single patient already calls for attention and indicates possible inequities in care. Although patterns are not fully understood, raising awareness of the unexplained heterogeneity in care decisions and its possible impact on health of patients may already fuel discussions on possible improvements in the decision making process.

Without any doubt, complexity of treatment decisions in RA care increased substantially in recent decades. To secure patient's access to especially the new generation of expensive RA therapeutics, economic trade-offs became unavoidable, even to the wealthiest societies. While formal economic evaluations are essential for policy makers to decide at the regional/national level on availability of treatments to specific groups of patients, our data clearly show that individual physicians also make economic trade-offs 
in the clinical encounter. Our study revealed that clinicians overall consider absolute costs more important than relative cost-effectiveness data, although cost-effectiveness data are more informative to assess the economic value of a treatment. In this context, it is however relevant to understand that most health care systems support economic trade-offs based on absolute budgets, especially on the micro-level (hospitals or individual clinicians). Although this approach for management of healthcare costs partly explains physicians' preferences, it is to some extent worrisome as cost-effectiveness of a drug should be the more relevant driver of treatment decisions compared to absolute costs. In an era of increased availability of 'high cost, high impact drugs' in many disease areas, health policy makers may need to reconsider their cost-management approaches. The use of a more expensive treatment regimen may be justified when (long-term) effects such as reduced (long term) sick leaves or avoided work disability are taken into account. Breaking-up health related budget silos may further support such a shift in cost management.

Finally, it is important to emphasize that making economic trade-offs in the clinical encounter usually implies a decisional conflict. With introduction of very expensive treatment options in RA and other disease areas, clinicians increasingly face a situation in which they have to choose a treatment strategy with a possibly lower (chance of) treatment success for an individual patient to secure availability of resources for patients with higher treatment needs. Based on evidence and arguments brought forward by different disciplines and form varying stakeholders, physicians should also strive for a more shared viewpoint regarding value for money spent in healthcare. On this line, the debate can be opened whether and to what extent patients should be involved in the economic considerations when choosing treatments. Patient societies could play a key role and lead such discussion in the future. 


\section{References}

1 Cross M, Smith E, Hoy D, et al. The global burden of rheumatoid arthritis: estimates from the global burden of disease 2010 study. Ann Rheum Dis 2014;73(7):1316-22.

2 Boonen A, Severens JL. The burden of illness of rheumatoid arthritis. Clin Rheumatol 2011;30 Suppl 1: S3-8.

3 Uhlig T, Moe RH, Kvien TK. The burden of disease in rheumatoid arthritis. Pharmacoeconomics 2014;32(9):841-51.

4 Cutolo M, Kitas GD, van Riel PL. Burden of disease in treated rheumatoid arthritis patients: going beyond the joint. Semin Arthritis Rheum 2014;43(4):479-88.

5 Singh JA, Furst DE, Bharat A, et al. 2012 update of the 2008 American College of Rheumatology recommendations for the use of disease-modifying antirheumatic drugs and biologic agents in the treatment of rheumatoid arthritis. Arthritis Care Res (Hoboken) 2012;64(5):625-39.

6 Smolen JS, Landewe R, Bijlsma J, et al. EULAR recommendations for the management of rheumatoid arthritis with synthetic and biological disease-modifying antirheumatic drugs: 2016 update. Ann Rheum Dis 2017;76(6):960-77.

7 Smolen JS, Landewe R, Breedveld FC, et al. EULAR recommendations for the management of rheumatoid arthritis with synthetic and biological disease-modifying antirheumatic drugs: 2013 update. Ann Rheum Dis 2014;73(3):492-509.

8 Stoffer MA, Smolen JS, Woolf A, et al. Development of patient-centred standards of care for rheumatoid arthritis in Europe: the eumusc.net project. Ann Rheum Dis 2014;73(5):902-5.

9 Napier AD, Ancarno C, Butler B, et al. Culture and health. Lancet 2014;384(9954):1607-39.

10 World Health Organization (WHO). Health 2020. A European policy framework and strategy for the 21st century [Online]. Available from: http://www.euro.who.int/en/health-topics/health-policy. 2013.

11 World Health Organization (WHO). Culture matters: using a cultural contexts of health approach to enhance policy-making [Online]. Available from: http://www.euro.who.int/en/health-topics/healthpolicy. 2017.

12 World Health Organization (WHO). Beyond bias: exploring the cultural contexts of health and well-being measurement [Online]. Available from: http://www.euro.who.int/en/health-topics/health-policy. 2015. 
Acknowledgements 



\section{Acknowledgements}

After four intensive and inspiring years, the journey of my PhD in Maastricht has come to a conclusion and it is time to give my heartfelt thanks to those who helped to make this a truly unique and enjoyable experience. Within those four years, we also welcomed our two wonderful little boys, Philipp and Leo, into the family, making this PhD trajectory both intense in work and rich in events. Without the support of the people around me during this time, this achievement would not have been possible.

First of all, I would like to thank all patients and healthcare professionals involved in my studies. Your contributions were essential to all scientific findings included in this book, and I cannot repeat often enough that my, as any, research would not be possible without your support.

My dear promotor, dear Prof. Boonen, dear Annelies, there are no adequate words to express my gratitude for all you did for me during the past four years. Thank you for your never-ending support from sunrise to far beyond sunset that enabled me to complete this $\mathrm{PhD}$ thesis alongside raising two little children. Your immeasurable knowledge, your dedication and passion for research combined with your understanding and supportive mentorship during the calmer and more turbulent stretches of the journey made you the perfect supervisor for my PhD. From the very first moment you made me feel part of your team, despite the geographical distance between our work desks, and I am truly thankful for the immense trust you placed in me by agreeing that I could work mostly from my home town, 800km from Maastricht. My PhD would not have been possible without your dedication, trust and true mentorship, and I would like to give you my heartfelt thanks.

Dear co-promotor, dear Dr. Hiligsmann, dear Mickaël, I would like to express my deepest gratitude for everything you taught me during the past four years. Thank you for patiently navigating me through the world of statistics, for all your creative ideas, your critical input and your constant availability. You always made time to respond to my questions and queries, and I am extremely thankful that you joined my PhD journey as a dedicated, supportive and knowledgeable co-supervisor whom I could always rely.

My co-promotor, Dr. Ramiro, dear Sofia. I still remember when I first shared my plans with you to pursue a PhD program during maternity leave. You inspired me with your true believe that everything can be done if you really want it; the sky being the only limit. It was after this conversation that I decided to start this PhD journey, a decision I never regretted. Thank you for accompanying me, first as a colleague and later as a co- 
supervisor. I am grateful for all your critical input, your ideas and your exceptional personal support during these years. Thank you!

Many more colleagues have played an important role for this dissertation. In total, there are more than 30 people co-authors to the articles of this book. And clearly, none of the articles would have been published without you. I am truly thankful for your dedication and scientific expertise shared with me during the past four years.

Naming everyone who professionally or personally contributed to my PhD theses would go far beyond the limits of this passage, however, I would like to mention a few of them who played a prominent role.

Dear Prof. Márta Péntek, Prof. Loreto Carmona, Prof. Bruno Fautrel, Prof. Till Uhlig, Prof. Ronald van Vollenhoven, Prof. Peggy Jacques, Dr. Jacqueline Detert, Dr. José Cannas da Silva, Dr. Carlo Scirè, Dr. Florian Berghea, Dr. Andrew Keat, Prof. Hans Severens, thank you for supporting the preference studies as principle investigators and critical scientific advisors. This challenging European project could not have been conducted without your dedication, immense scientific knowledge and experience. Working with you and learning from you was truly rewarding and I would like to sincerely thank you for all the support I received during this project.

Dear Dr. Maarten de Wit, Prof. Josef Smolen, Dr. Michaela Stoffer-Marx, Prof. Anthony Woolf, Prof. Annette van der Helm-van Mil, Prof. Mart van de Laar and Dr. Harald Vonkeman, thank you for your continuous support in our implementation project for standards of care.

Dear Prof. Maxime Dougados, dear Prof. Tuulikki Sokka-Isler, I truly appreciate having been given the opportunity to work on two exceptional international datasets COMORA and QUEST-RA - which helped me to learn a lot about patients with rheumatic diseases all over the world. Thank you for making this possible.

Dear Dr. Verity Watson, dear Dr. Sam Norton, dear Dr. Andras Keszei, thank you for your continuous statistical help and creative ideas, which were key to several studies in this book. In particular, I would like to say thank you for your patience as you explained to me the complex statistical concepts you proposed for analysis of our data. I learnt an incredibly amount from you.

Dear Dr. Yvonne van Eijk-Hustings, thank you for your endless support during the development of the patient questionnaire for our European study on standards of care. Your experience as rheumatology nurse was irreplaceable.

I am also extremely grateful to my colleagues at the department of Rheumatology in Maastricht. Thank you for supporting a number of my studies with your scientific and clinical expertise. And even more important: Thank you for making me feel part of your team whenever I joined you in Maastricht. 
Dear Marian and Yvonne, thank you for your all help in organizing my study visits to Maastricht, and for keeping me closely connected to the department while working remote.

Thanks are also due for my closest colleagues at Sandoz. Finding support for pursuing a PhD during maternity leave was not a given. In particular, I would like to thank Anastassia for connecting me to my supervisor Prof. Annelies Boonen. Further, I would like to thank Claudia, Stefan, Ines, Sabine and Sandra for encouraging and supporting me during the set-up of this ambitious project.

Dear Polina, you were among the first PhD students I met when I came to Maastricht. After endless days, including some very late hours, working with you on a variety of projects, you turned from colleague Polina into a friend. Meeting you was one of the best experiences while working on the thesis. Thank you for always being available any time I looked for support. Thank you for sharing your scientific knowledge with me, and thank you for being one of the most valuable advisors throughout my PhD trajectory. We have gone through the same rough sea. We were blessed with wonderful children during our PhD journey but faced the universal challenges of parenting while pursuing a professional track. Embarking on this journey together was inspiring and encouraging. At the end of my thesis you will join me as paranymph. Thank you for helping me to make this day a memorable one.

Dear Anna-Maria and Eva, my closest friends since we went to school together as little girls. It is a gift to maintain friendships throughout several decades and partly across continents. Although you may think that you had little contribution to this work, you play an essential role in my life with endless unique moments shared together.

Dear Kristina, thank you so much for your support especially during the last year of my thesis. I will never forget our endless walks through the forest to re-charge batteries that were drained by a difficult start with our little ones. You were there any time I needed someone to talk to. Thank you!

Dear Susanne and Adam, my parents-in-law. Thank you for your indispensable support during these years. You were there for our boys any time I needed you, sometimes on shortest notice. But even more important, you encouraged me to continue this professional journey during the more difficult stretches. Thank you for making me part of your family. 
Dear Thea and my dear dad, thank you for your support with the children during the past four years. At the outset, we spent several weeks at your home. You even set up an office for me so to work in Regensburg while you took care of the children. Thank you for all of your support during this time.

I feel privileged to end with words of love and gratitude to my own family.

Dear Jakob, my beloved husband, even though you haven't written a single word of the thesis, your endless support is in every letter of it. Your continuous love and trust in me was of the greatest importance and carried me safely through easier and more difficult stretches of this journey. Words cannot describe how much I value this. Thank you for being an exceptional partner and loving father, whom I can unconditionally rely upon in any situation.

Dear Philipp, dear Leo, even though you cannot read these lines today, I want to share my gratitude with you. You bring joy and happiness to my life with every smile you share (and you share a lot of them). Being a mum is a never-ending adventure and your unconditional love, curiosity and love for life inspired me and kept me going over the last four years, and beyond.

Thanks to the three of you for being part of my life every day. 
Curriculum vitae 



\section{About the author}

Monika Hifinger was born on September $28^{\text {th }}, 1978$, in Regensburg, Germany. After completing secondary education in 1997, she studied Pharmaceutical Sciences at the Friedrich-Alexander University in Erlangen (Germany), for which she obtained a Master degree in 2002. As part of the educational program for German pharmacists she then worked in a public pharmacy in Munich and as research scientist at the University of Helsinki, Finland. In 2003, she graduated as certified pharmacist in Germany. In 2004, she started her career in the pharmaceutical industry as regulatory affairs manager and project manager at ratiopharm, in Ulm (Germany) and Goa (India). In 2007, she moved to Hexal/Sandoz in Munich (Germany) and worked in different roles at Sandoz Biopharmaceutical Development including as program leader for biosimilars. In 2013, she returned to research and joined the department of Rheumatology at the Maastricht University Medical Centre and the Care and Public Health Research Institute (CAPHRI), Maastricht University. This research work resulted in the present PhD thesis. 



\section{List of publications}

1. Hifinger M, Putrik P, Ramiro S, Keszei AP, Hmamouchi I, Dougados M, Gossec L, Boonen A. In rheumatoid arthritis, country of residence has an important influence on fatigue: results from the multinational COMORA study. Rheumatology (Oxford). 2016 Apr; 55(4):735-744.

2. Putrik P, Ramiro S, Hifinger M, Keszei AP, Hmamouchi I, Dougados M, Gossec L, Boonen A. In wealthier countries, patients perceive worse impact of the disease although they have lower objectively assessed disease activity: results from the cross-sectional COMORA study. Ann Rheum Dis. 2016 Apr; 75(4):715-720.

3. Hifinger M, Hiligsmann M, Ramiro S, Severens JL, Fautrel B, Watson V, Boonen A. Patients' preferences and economic considerations play an important role in treatment decisions: a discrete choice experiment among rheumatologists. Rheumatology (Oxford). 2017 Jan; 56(1):68-76.

4. Hifinger M, Hiligsmann M, Ramiro S, Watson V, Severens JL, Fautrel B, Uhlig T, van Vollenhoven R, Jacques P, Detert J, Canas da Silva J, Scirè, CA, Berghea F, Carmona L, Péntek M, Keat, A, Boonen A. Economic considerations and patients' preferences affect treatment selection for patients with rheumatoid arthritis: a discrete choice experiment among European rheumatologists. Ann Rheum Dis. 2017 Jan; 76(1):126132.

5. Hifinger M, Norton S, Ramiro S, Putrik P, Sokka-Isler T, Boonen A. Equivalence in the Health Assessment Questionnaire (HAQ) across socio-demographic determinants: Analyses within QUEST-RA. Semin Arthritis Rheum. 2017 Aug; doi: 10.1016/j.semarthrit.2017.08.003. [Epub ahead of print]

6. Hifinger $M$, Hiligsmann $M$, Ramiro $S$, Watson $V$, Berghea $F$, Péntek $M$, Keat $A$, Severens JL, Fautrel B, Boonen A. Influence of disease activity on RA treatment choices in countries with restricted access to expensive, innovative drugs: a discrete choice experiment among rheumatologists. RMD Open. 2017 Sep; doi: 10.1136/rmdopen-2017-000453. [Epub ahead of print]

7. Hifinger $M$, Ramiro S, Putrik P, Eijk-Hustings $Y$, Woolf A, Smolen J, Stoffer-Marx $M$, Uhlig T, Moe RH, Saritas $M$, Janson $M$, van der Helm-van Mil A, van de Laar $M$, Vonkeman $\mathrm{H}$, de Wit $\mathrm{M}$, Boonen $\mathrm{A}$. The eumusc.net standards of care for rheumatoid arthritis: importance and current implementation according to patients and healthcare providers in the Netherlands. Clin Exp Rheumatol. (accepted for publication) 
